
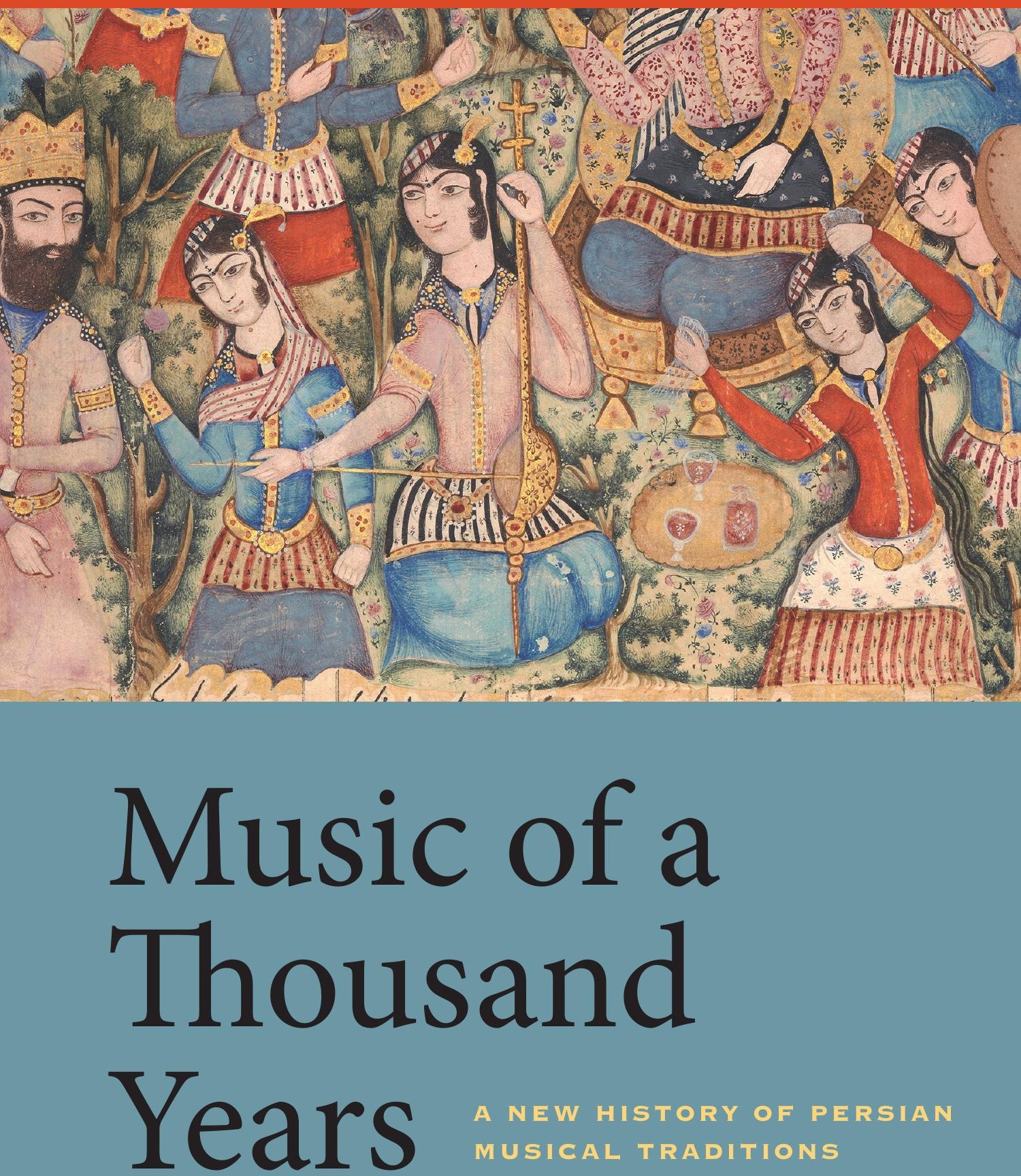

ANN E. LUCAS 
Luminos is the Open Access monograph publishing program from UC Press. Luminos provides a framework for preserving and reinvigorating monograph publishing for the future and increases the reach and visibility of important scholarly work. Titles published in the UC Press Luminos model are published with the same high standards for selection, peer review, production, and marketing as those in our traditional program. www.luminosoa.org 



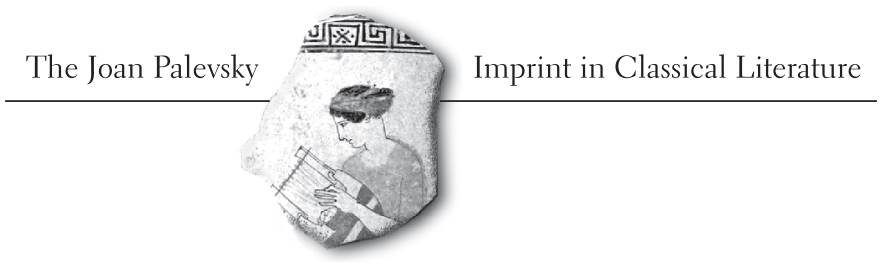

In honor of beloved Virgil-

"O degli altri poeti onore e lume ..."

-Dante, Inferno 
The publisher and the University of California Press Foundation gratefully acknowledge the generous support of the Joan Palevsky Imprint in Classical Literature. 
Music of a Thousand Years 



\title{
Music of a Thousand Years
}

A New History of Persian Musical Traditions

\author{
Ann E. Lucas
}

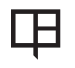

UNIVERSITY OF CALIFORNIA PRESS 
University of California Press, one of the most distinguished university presses in the United States, enriches lives around the world by advancing scholarship in the humanities, social sciences, and natural sciences. Its activities are supported by the UC Press Foundation and by philanthropic contributions from individuals and institutions. For more information, visit www.ucpress.edu.

University of California Press

Oakland, California

(C) 2019 by Ann E. Lucas

This work is licensed under a Creative Commons CC BY-NC license. To view a copy of the license, visit http://creativecommons.org/licenses.

Suggested citation: Lucas, A. E. Music of a Thousand Years A New History of Persian Musical Traditions. Oakland: University of California Press, 2019. DOI: https://doi.org/10.1525/luminos.78

Library of Congress Cataloging-in-Publication Data

Names: Lucas, Ann E., 1978- author.

Title: Music of a thousand years : a new history of Persian musical traditions / Ann E. Lucas.

Description: Oakland, California : University of California Press, [2019] | Includes bibliographical references and index. | This work is licensed under a Creative Commons CC BY-NC license. To view a copy of the license, visit http://creativecommons.org/licenses. |

Identifiers: LCCN 2018051868 (print) | LCCN 2018054350 (ebook) | ISBN 9780520972032 (ebook) | ISBN 9780520300804 (pbk. : alk. paper) Subjects: LCSH: Music-Iran-History and criticism. | Maqam. | Dastgah. Classification: LCC ML344 (ebook) | LCC ML344 L83 2019 (print) | DDC 780.955-dc23

LC record available at https://lccn.loc.gov/2018051868

$\begin{array}{llllllllll}28 & 27 & 26 & 25 & 24 & 23 & 22 & 21 & 20 & 19\end{array}$

$\begin{array}{llllllllll}10 & 9 & 8 & 7 & 6 & 5 & 4 & 3 & 2 & 1\end{array}$ 
For Sue 



\section{CONTENTS}

List of Illustrations $\quad x i$

List of Maps xiii

List of Tables xiv

Acknowledgments $x v$

A Note about Transliteration xvii

1. Ancient Music, Modern Myth 1

Part One: Culture of Maqam 23

2. Musical Empires 25

3. Musical Structure: Cosmology and the Universal Order, c. 1100-1800 48

4. Music and Morality: Listening to Dangers Inherent in the Cosmos 65

5. The Politics of Song: Music for Kings, Music for Empire, c. 1400-1722 81

Part Two: The Culture of Dastgah 103

6. Musical Structure, Musical Nation, c. 1800-1950 105

7. The Nation's Music: Discovering and Recovering the Dastgah 130

8. Music and Morality: The Recovery of a Nation, c. 1880-1940 168

9. Singing the Nation: Words of the People, Music for Iran 185

10. History, Agency, and the Power of Music 209 
Notes

221

Discography 230

Reference List 231

Index 


\section{ILLUSTRATIONS}

1 Common format for representing the twelve-maqam system as a closed, interconnected system 30

2 Depiction of the twelve-maqam system with usul from the Bahjat al-Rūh 31

3 The Khafif Saqil rhythmic cycle 32

4 Two versions of the Ramal rhythmic cycle 33

5 High Wall in the "Music Room" of the 'Ali Qapu Palace 82

6 Mural of Shah Tahmasp I with Humayun 82

7 Mural of Shah 'Abbas I with Vali Muhammad Khan 83

8 Modal interpretation of the dastgah by Jean During 107

9 Modal interpretation of the dastgah by Lloyd Miller 108

10 Examples of gusheh that exhibit modal independence 109

11 Legend for figures 13,15 , and $16 \quad 136$

12 The dastgah Shur 137

13 Interpretation of the dastgah Shur's representation 138

14 The dastgah Nava and Mahur 139

15 Interpretation of the dastgah Nava's representation 140

16 Interpretation of the dastgah Mahur's representation 140

17 Nodal lines in On The Sensations of Tone 145

18 Nodal lines in the Majma' Al-Advār 145

19 Helmholtz resonator in On The Sensations of Tone 146 
20 Helmholtz Resonator in the Majma' Al-Advār 146

21 Tuning fork experiment in On The Sensations of Tone 146

22 Tuning fork experiment in the Majma 'Al-Advār 146

23 Hedayat's hypothetical scales of the seven dastgah 152

24 Legend for figure $23 \quad 152$

25 Legend for figure $26 \quad 159$

26 Vaziri's changing representation of the dastgah scales 159

27 Vaziri's analysis of the gusheh Bīdād 161 
M A P S

1 The Ghaznavid Empire at its largest 37

2 The Ilkhanate at its largest 39

3 Division of the former Ilkhanate, c. 134539

4 The Timurid Empire at its largest 41

5 The empire of the Qara Qoyunlu Turkomans 41

6 The Safavid Empire at its largest under Shah 'Abbas I (r. c. 1599-1629) 43

7 The Afsharids Empire at its largest and after its fall 46

8 Iran, Qajar Dynasty Territorial Legacy 118-119 
TA B L ES

1 Summary of Hedayat's Description of Dastgah Shur in practice 148

2 Summary of Hedayat's Description of Dastgah Mahur in Practice 149

3 Summary of Hedayat's Description of Dastgah Nava in Practice 150

4 Division of Poetry in Chahargah According to Davami,

First Version 191

5 Division of Poetry in Chahargah According to Davami, Second Version 193 
I owe so much gratitude to so many people who both directly and indirectly facilitated my research and the production of this book. I must first thank Amir Hosein Pourjavady, Mohsen Mohammadi, Ali Jihad Racy, Anthony Seeger, and James L. Gelvin, all of whom directly educated me and guided the development of this book and made its publication possible. I am so grateful for all of the insight and critique you all provided over months and years. I also owe a great debit of thanks to Hamid Reza Maleki, who was so instrumental in facilitating my first trip to Iran. Thank you Hamid Reza for all of your help, and thank you to your wonderful family, who were all so welcoming to me during my time there. I would also like to thank Sassan Tabatabai, who read and critiqued many of my song text translations. I was hoping to avoid translating Persian poetry, as any translation of it feels highly unsatisfactory compared to the original. Thank you for helping me confront such challenges of poetry translation throughout the writing of my book.

There are many great music scholars in Iran and my ability to conduct research on the subject of Persian music relied directly on high-quality scholarship produced by Iranian scholars over the past several decades. Of these scholars I am greatly indebted to Hooman Asadi, Taqi Binesh, Hormoz Farhat, Sasan Fatemi, Mojtaba Khoshzamir, Ali Reza Mir Ali Naqi, Faramarz Payvor, Mansourah Sabetzadeh, and Sasan Sepanta. I am further indebted to the great legacy of ethnomusicological research in Iran, which includes scholars such as Stephen Blum, Margaret Caton, Jean During, Lloyd Clifton Miller, Owen Wright, and Ella Zonis. I would especially like to thank Bruno Nettl, whose own hypothesizing about the history of Iranian music and theoretical explorations of music history first got me interested how we narrate Iranian music history. 
I truly stand on the shoulders of so many giants, whose work made my research possible in so many different ways. Please accept my heartfelt gratitude for all you have taught me over the years. I could not have researched this book without active assistance from other researchers, nor could I have done my work without the research of so many scholars that went before me. 
This book references indigenous terminology extensively. For the most part, indigenous terms that recur throughout the book are only fully transliterated once parenthetically when the term is first used. When referencing proper titles and terminology of specific texts, terms are transliterated for Persian if the original text was in Persian, and for Arabic if the original text was in Arabic. Foreign terms may be fully transliterated more than once for clarification of usage in specific contexts, or when cited directly from both Arabic and Persian language texts.

\begin{tabular}{|c|c|c|c|}
\hline 1 & $\overline{\mathrm{a}}^{*}$ & 1 & $\overline{\mathrm{a}}^{*}$ \\
\hline i & $\overline{\mathrm{A}}$ & $i$ & $\overline{\mathrm{A}}$ \\
\hline ب & $\mathrm{b} / \mathrm{B}$ & ب & $\mathrm{b} / \mathrm{B}$ \\
\hline 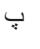 & $\mathrm{p} / \mathrm{P}$ & - & $\mathrm{p} / \mathrm{P}$ \\
\hline ت & $\mathrm{t} / \mathrm{T}$ & $ت$ & $t / T$ \\
\hline$ث$ & $\underline{\mathrm{s}} / \underline{\mathrm{S}}$ & $ث$ & $\mathrm{th} / \mathrm{Th}$ \\
\hline ج & $j / J$ & ج & $j / J$ \\
\hline ङ & $\mathrm{ch} / \mathrm{Ch}$ & - & - \\
\hline$\tau$ & h/H & $\tau$ & h/ب̣ \\
\hline$\dot{\tau}$ & $\mathrm{kh} / \mathrm{Kh}$ & $\dot{\tau}$ & $\mathrm{kh} / \mathrm{Kh}$ \\
\hline د & $\mathrm{d} / \mathrm{D}$ & 2 & $\mathrm{~d} / \mathrm{D}$ \\
\hline$\dot{~}$ & $\underline{\mathrm{Z}} / \underline{\mathrm{Z}}$ & $\dot{j}$ & $\mathrm{dh} / \mathrm{Dh}$ \\
\hline J & $\mathrm{r} / \mathrm{R}$ & J & $r / R$ \\
\hline j & $z / Z$ & j & $\mathrm{z} / \mathrm{Z}$ \\
\hline$j$ & $\mathrm{zh} / \mathrm{Zh}$ & - & - \\
\hline
\end{tabular}




\begin{tabular}{|c|c|c|c|}
\hline \multicolumn{4}{|c|}{ Transliteration Chart } \\
\hline Persian & Transliteration & Arabic & Transliteration \\
\hline س س & $\mathrm{s} / \mathrm{S}$ & س س & $\mathrm{s} / \mathrm{S}$ \\
\hline ش & $\mathrm{sh} / \mathrm{Sh}$ & ش & $\mathrm{sh} / \mathrm{Sh}$ \\
\hline 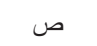 & ș/S & ص ص ص إ & ș/S \\
\hline 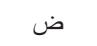 & $\dot{\mathrm{Z}} / \mathrm{Z}$ & 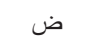 & $\mathrm{d} / \mathrm{D}$ \\
\hline$b$ & $\mathrm{t} / \mathrm{T}$ & $b$ & $\mathrm{t} / \mathrm{T}$ \\
\hline ظ & $\mathrm{z} / \mathrm{Z}$ & ظ & $\mathrm{z} / \mathrm{Z}$ \\
\hline$\varepsilon$ & • & $\varepsilon$ & • \\
\hline$\dot{\varepsilon}$ & $\mathrm{gh} / \mathrm{Gh}$ & $\dot{\varepsilon}$ & $\mathrm{gh} / \mathrm{Gh}$ \\
\hline ف & $\mathrm{f} / \mathrm{F}$ & ف & $\mathrm{f} / \mathrm{F}$ \\
\hline 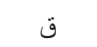 & $\mathrm{q} / \mathrm{Q}$ & 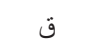 & $q / Q$ \\
\hline s & $\mathrm{k} / \mathrm{K}$ & $s$ & $\mathrm{k} / \mathrm{K}$ \\
\hline s & $\mathrm{g} / \mathrm{G}$ & 3 & $g / G$ \\
\hline J & $1 / \mathrm{L}$ & J & $1 / \mathrm{L}$ \\
\hline s & $\mathrm{m} / \mathrm{M}$ & s & $\mathrm{m} / \mathrm{M}$ \\
\hline ن & $\mathrm{m} / \mathrm{N}$ & ن & $\mathrm{m} / \mathrm{N}$ \\
\hline g & $\overline{\mathrm{u}} / \overline{\mathrm{U}} / \mathrm{aw}$ & g & $\overline{\mathrm{u}} / \overline{\mathrm{U}} /-\mathrm{w} / \mathrm{W}$ \\
\hline 。 & $\mathrm{h} / \mathrm{H} / \mathrm{eh}$ & : & $\mathrm{ah} / \mathrm{at}$ \\
\hline$ى$ & $\overline{\mathbf{1}} / \overline{\mathrm{I}} / \mathrm{y}$ & ى & $\overline{\mathbf{1}} / \overline{\mathrm{I}} / \mathrm{y}$ \\
\hline 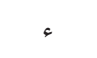 & , & 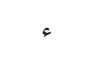 & , \\
\hline or & $\mathrm{a} / \mathrm{A}$ & or & $\mathrm{a} / \mathrm{A}$ \\
\hline or! & $\mathrm{e} / \mathrm{E}^{* *}$ & or! & $\mathrm{i} / \mathrm{I}$ \\
\hline or $\hat{\imath}$ & $\mathrm{o} / \mathrm{O}$ & ori & $\mathrm{u} / \mathrm{U}$ \\
\hline 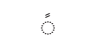 & an & 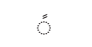 & An \\
\hline
\end{tabular}

* diacritical omitted for initial 1

** also transliterated as -i for the Persian ezafeh grammatical particle 


\section{Ancient Music, Modern Myth}

The past is a foreign country; they do things differently there.

-L. P. HARTLEY, THE GO-BETWEEN

The past is another planet.

- NEIL DEgRASSE TYSON, COSMOS

In the fall of 2000, I was sitting in one of my classes at UCLA, eagerly awaiting an announced guest speaker. He was coming to teach us about traditional Persian music, one of Iran's great music traditions. I was excited because I already had some knowledge of Arabic and Turkish music, but at the time I knew much less about Persian music. Arabic and Turkish music had many similarities as well as a shared history, so it seemed that Persian music would relate to these other cultures of the Middle East in some way. But the concept of Persian music clearly referenced something different in my imagination. It was an image of great antiquity. Great Persian empires stood in Central and West Asia long before the Arab expansion or Turkic migrations overtook these empires, so surely Persian music could be older than music from these other large regional cultures. In my mind, the idea of Persian music certainly carried a unique sense of history and cultural prestige in comparison with these other large language groups of the region.

The guest lecturer arrived and proceeded to give us a history of Persian music that met with my expectations. He first established that Persia and Iran were one in the same. When people spoke of Persian music, they were in fact talking about Iranian music associated with the Persian language. He then acknowledged that scholars knew very little about music of ancient Persia, but some vague evidence of Persian music-making was still observable in bas reliefs and other artifacts found among the ruins of the Achaemenid Empire (700-330 BCE) and the Sassanian Empire (224-650 CE). He began teaching about the known history of Persian music from the same era of history when narrations of Arabic music history often begin: after the rise of Islam, starting around the ninth century CE. My assumptions were correct: the history he told did indeed portray Iranians as active partici- 
pants in a cosmopolitan music culture, first in the company of the Arabs and later in the company of Turkic and even Mongol peoples. There had basically been one general set of extensively documented musical principles that Iranians had shared with other language groups of the Middle East for many centuries, within a shared culture that paired Islam with a dynastic system of kingship. As the guest lecturer narrated this history, he highlighted key historical writings and sources on music in the Persian language, focusing on the very important role of Iranians in this extensive, sophisticated music culture.

Once he arrived at the sixteenth century, about halfway through the class, our guest stopped narrating this history and informed the class that Persian music went into decline for several centuries and afterward traditional Persian music became something completely different than anything he had just discussed. He then began to explain what traditional Persian music was now, speaking of a new system of music that emerged in the nineteenth century, distinct from the historical music principles he had just described. According to our guest's own knowledge of Persian music history, the music described in the first part of class was a wholly different phenomenon from traditional Persian music since the nineteenth century. It was a phenomenon of the modern era, while historic Persian music was something altogether different.

While the first part of his presentation had fit with my expectations of Persian music, the second part completely contradicted my assumptions about the historicity of Persian music. He was telling us that traditional Persian music did not come out of the mists of ancient Persian antiquity, nor did it come from a glorious renaissance of culture that came with the rise of medieval Islamic empire. Traditional Persian music came from the modern nation of Iran beginning in the nineteenth century, which marked a time and place of difficult turmoil. The images of a medieval ruler in his court, feasting surrounded by the sophisticated entertainment of his musicians evaporated. This was the music of a very complicated, modern place that had experienced two revolutions, authoritarian rule, and most recently an anti-imperial Shi'a Islamic regime. The historical narrative of ancient Persian music was clearly important to understanding Iranian music, but it did not explain key aspects of Iran's indigenous music in the modern era, which had a different structure as well as a different context.

I saw something very profound in this narrative and this change. The nineteenth century marked a pivotal moment in Europe's growing global influence and global interventions. The United States would eventually take over various aspects of Europe's global interventions, and much of Iran's modern history can be narrated according to which Western power asserted control over its national sovereignty, and how various constituencies within Iran attempted to reassert indigenous control against these different foreign interventions. In this context, it is not surprising that Iranians never wholly stopped playing music with indigenous roots. Though Western music had been (and, in many ways, still is) ubiquitous in 
Iran, they nevertheless maintain a unique tradition of Persian music that shows no obvious signs of Westernization.

This more recent music system functions within an indigenous framework that follows some basic tenets of all music in the Middle East. It has multiple melodic modes that use various pitches both within and beyond those used in Western scales. Playing music often involves various amounts of improvisation upon basic melodic phrases. There are rhythms played by drums that may accompany the melody. Performances consist of both unmetered improvisations by solo instruments and metered sections that are often composed. Metered compositions may be played by a soloist or a larger ensemble of instruments, and when the latter performs as a group, the metered melodies become heterophonic, with different instruments elaborating on the same melody in a slightly different way. The instruments common in the tradition include long-necked lutes, zithers, spiked fiddle, and endblowned flute, which all bear relation to musical instruments in other parts of the Middle East, Central Asia, and even South Asia. While a singer is not required to perform this music, it is desirable. When a singer is present, the instruments focus on accompanying the singer, but the basic process of working through unmetered improvisation and metered composition continues to prevail.

Traditional Persian music since the nineteenth century continues to share these types of musical features with other indigenous musics of its surrounding region. This is true if one compares traditional Persian music with historical practices, but it is also true if one compares it with contemporary indigenous music traditions across the cultures of the Middle East, Central Asia, and North Africa. In this sense, the modern manifestation of traditional Persian music is not an imported, alien musical phenomenon in its geographic and historical context. But the performance practice itself-how musicians decided to go about organizing their music to determine how they would actually learn it and play it-is both surprisingly specific and unlike the historic music taken as its ancient Persian antecedent.

In leaving the class and beginning my research, these specifics of organization and structure were central to my questions. At the heart of traditional Persian music's modern existence today is a melodic repertoire referred to as the radif (radif), organized into separate ordered sets of melodies referred to as dastgah (dastgāh). Both musicians and scholars remark on the unique nature of the radif, which has formed the basis of traditional Persian music's pedagogy and performance practice in the twentieth century. In historical documentation, it seems to have been formed around a distinct performance practice of the late nineteenth century, and the furthest back any family of musicians associated with that practice can be documented is the nineteenth century. The oldest any music scholar could responsibly declare it based on the historical evidence would be the late eighteenth century, and even this requires much speculation about what might have been. ${ }^{1}$ If one assumes that there really has been a continuous, multimillennia existence of Persian culture, 150 to 170 years of history barely registers as a signifi- 
cant space of time to practice a particular music tradition. But even in relation to the history of Persian-speaking people since the rise of Islam, the history of this particular music represents a very short legacy.

The melodic material of the radif ranges from short motifs to multisectional pieces, and it can be used as the basis of an instrumental or vocal improvisation or for composition. Though there were originally only seven dastgah within which this melodic material was ordered, sections of the original seven dastgah were subdivided in the twentieth century to create a total of eleven or twelve melodic complexes. Seven of the dastgah are still the largest of these melodic complexes, while four to five additional smaller complexes may be referred to as dastgah or avaz (avāz). In theory, each of these melodic complexes has a set of melodies that operate within a fairly distinct set of unique pitches. For this reason, both musicians and scholars tend to treat them as scales or modes. Yet it is the melodies of the radif themselves that define the traditional progression of unmetered improvisation and metered composition in performance. The melodies, referred to individually as gusheh ( $g \bar{u} s h e h$ ), determine which pitches will be used in the performance of a dastgah, and in what order specific sets of pitches can be used.

Historically, a performance of this radif-dastgah tradition consisted of musicians choosing a dastgah-or perhaps an avaz-dastgah-and creating a performance around the particular melodic material chosen. Musicians would improvise upon the gusheh of a dastgah in a fairly organized way, with some melodies being more improvised upon than others, even as most were unmetered. Additional metered compositions that are often not part of the radif appear at set times in the performance of a dastgah to supplement the mostly unmetered improvisation. These compositions are defined by how their rhythms are counted and their association with a given dastgah relates to how their pitch usage mirrors that of the gusheh in the dastgah.

While conducting my research, I wanted to know how and why this particular performance practice associated alternately with radif and dastgah developed as music particular to Iran in the modern era, and why a different approach to music-making was so important within educated courtly society in Persianspeaking lands for the six centuries previous. The older principles of music-making that held the narrative position of the radif-dastgah tradition's antecedent in the history of Iran's Persian music were quite different from radif or dastgah in significant ways. I came to refer to these older principles as the twelve-maqam system because they generally centered on twelve melodic modes, referred to alternately as maqam (maqām), shadd (shadd), or pardeh (pardeh). The twelve maqam were melodic modes that alternately broke down or combined in various ways to create additional modes. This distinct commitment to systematic, internal derivation and extraction of melodic modes was central to the twelve-maqam systems' conception. Within this closed system of melodic modes, any given modal entity needed to be matched with rhythmic cycles called usul ( $\bar{u} s \underline{u} l)$ to create an 
actual, functional melody. These melodies further related to an ever-changing set of compositional forms. Some forms were songs in Persian, Arabic, or Turkish, while others were instrumental pieces, but all had various configurations of primary and secondary melodies, recapitulations, and codas. In order to make music in the twelve-maqam system, musicians had to combine the use of a maqam or related melodic mode with an usul in the execution of these forms, which were structurally distinct from any of the gusheh or compositional forms of the radifdastgah tradition.

Both the radif-dastgah tradition and the twelve-maqam system arise somewhat suddenly in the historic record, and in each case this sudden rise correlates with a historical event. The radif-dastgah tradition emerged at the height of European colonization and intervention in the region, but also in a moment of monumental global transmutation in the history of humanity: the Middle East's full integration into the global economic system and the global system of nation-states. Yet the twelve-maqam system began to dominate educated musical discourse of the region in the midst of the Mongol invasion: the moment Genghis Khan's massive push for dominance over all of Asia overtook key parts of the Islamic world. These two different historical moments introduced different contingencies that changed the trajectory of history in West and Central Asia, even as the changes they affected caught people unawares. While modern Iranian musicians saw great continuity in the history of their national Persian music, I saw a historical record of great political and social disruption, often fostered by unforeseen circumstances. History writ large for the region could be told as an ongoing series of invasions, migrations, and other exogenous changes, involving various language groups over millennia. If such changes and disruptions were large enough, they could be key moments of cultural transformation that related to musical transformation.

\section{ANCIENT MUSIC, MODERN MYTH: RESEARCHING IDEOLOGIES IN THE MUSIC OF IRAN}

In the case of the radif-dastgah tradition, it was ethnographic researchers who were the first to address the extent to which it breaks with the norms established and maintained in the Persian-speaking world historically. Jean During suggested the radif-dastgah system did not directly descend from the twelve-maqam system, but rather seemed Azeri in origin. Indeed, the Qajar Dynasty-whose nineteenthcentury court in Tehran patronized the radif-dastgah tradition-was Turkic from Azeri territory. In addition to patronizing the radif-dastgah tradition at their seat of power in Tehran, they also patronized a similar music tradition sung in Azeri Turkish in their court in Tabriz. This court music of Tabriz became the basis for the music of Azeri mugham. ${ }^{2}$ Bruno Nettl further suggested that, though it was not Westernized per se, the radif-dastgah tradition still could represent changes that occurred in relation to the rise of Western musical hegemony in Iran dur- 
ing the late nineteenth and early twentieth centuries. He thought that the radif specifically could have been created out of a modern sense of Iranian nationalism. ${ }^{3}$ These contrasting hypotheses notwithstanding, both During and Nettl observed how different the radif-dastgah tradition was in relation to Persian music history and sought ways to explain why the modern phenomenon of traditional Persian music was so different from historical norms documented in Persian-language sources.

Nettl and During were just two of several foreign scholars studying music in Iran as it was in the late twentieth century and the primary focus on the ethnographic present at that time limited what researchers could conclude about musical change both during and before modern era. It did not, however, limit researchers' interest in expounding on the idea of an ancient Persian music history, nor did it prevent speculation about how the radif-dastgah tradition evolved out of the ancient ether of Persian music history. Though During's and Nettl's attempts to explain the conundrum of the radif-dastgah tradition's modern emergence are telling, they are also relatively unique within all ethnographic attempts to historicize the modern tradition. Ethnographic researchers have confidently dated the ultimate origins of Persian music to eras both before and after the rise of the twelve-maqam system. Thus, the ultimate origins of Persian music might be in pre-Islamic times (c. 550 BCE-650 CE), or the height of the 'Abbasid Caliphate (c. 750-950), or somewhat after the final fall of the 'Abbasid Caliphate in the thirteenth century, when Persian reemerged as a broadly-used lingua franca, and writings began outlining the basic tenants of the twelve-maqam system. ${ }^{4}$

When I first arrived in Iran to do research in 2003, I encountered Iranian musicologists arguing about the question of where the radif came from on fairly specific historical terms. Two scholars, Hooman Asadi and Mohsen Mohammadi, had begun a debate about the influence of the West that Nettl proposed, and the specific terms of musical change in the modern era. Iranian musicology more broadly was turning more attention to music from the sixteenth to the eighteenth century, an era that had been largely ignored in research conducted prior to the $1990 .^{5}$ Iranian musicologists took a period of history that had been considered a period of musical decline and demonstrated how it encompassed an extensive amount of musical activity. Their new discoveries have highlighted how there was continuous Persian music-making from the era of the twelve-maqam system into the modern era of dastgah and radif, and this has put more attention on the idea that the twelve-maqam could have gradually evolved into new approaches to musicmaking in the nineteenth century, which provided the basis for the radif-dastgah tradition as it came to exist in the twentieth century. As a result, the historical question of how Iranians evolved away from using the system of maqam into the system of dastgah and eventually radif has taken on a significance it did not have in the late twentieth century, and it is a question of paramount importance to Iranian scholars specifically. 
In reading, speaking with, and observing Iranian musicologists, I realized that my interests in Persian music history were quite distinct from theirs. They were seeking to write the one, true history of Persian music. This required one definitive explanation for how the twelve-maqam system turned into the modern system of traditional Persian music. For them, the gap between maqam and dastgah was a missing piece in a single culture's historic music puzzle. By contrast, I saw different cultures that dominated in different points in time, and distinct methods of musicmaking that related to these temporally distinct cultural spaces. I was researching at least two distinct cultural puzzles and looking for alignments between cultural change and changing conceptions of music.

My perspective was not one that could make much sense to my Iranian musicology counterparts. The music culture of radif I encountered in the twenty-first century was steeped in pre-radif music history, and previous ethnographers' testaments to the ancient nature of Persian music came directly from the conceptions of music history narrated by the Iranian musicians they worked with. A number of musicians in the radif tradition were musicologists, studying and editing editions of Persian music treatises written between the twelfth and nineteenth centuries, while also studying the Arabic treatises they believed to have been written by Iranians before the twelfth century. But one did not have to be so educated in specific historical information about music to make ancient historical perspective the basis of musical understanding. Some musicians I met knew far less about the specifics of these historical writings, but nevertheless referenced tropes of this premodern history in discussions, lessons, and lectures. One of the most common ways to do this was to reference commonalities in language and music jargon. On one hand, the general shared usage of Persian language was evidence of an ongoing, shared music culture. Yet both musicians and musicologists could also point to overlap in nomenclature: terms used to describe structures in the twelve-maqam system that also appear in the terminology of the radif-dastgah tradition.

This dependency on language analysis to create cultural commonality in music history fascinated me. To achieve a narrative of one specific shared cultural legacy of ancient Persian music, interpreting language over and above music was essential. The language provided opportunities for interpretation that music did not, yet the interpretation had to be very selective. Throughout the Middle East, there are overlapping pools of terminology that many types of music traditions from multiple language groups pull from in their application of music jargon. Persian terminology specifically is very common even in the music terminology of nonPersian speakers. The types of terms that get repurposed are often quite abstract and sometimes they do not have any demonstrable musical meaning in any particular tradition. When they do, the musical meaning could have multiple possible interpretations. When it is possible to compare actual music to its terminology, the fungible nature of language is apparent, even when everyone speaks Persian. For instance, in the radif-dastgah tradition, the term avaz has several different mean- 
ings. It is sometimes used to refer to the smaller dastgah, but it also refers to the vocal-based improvisatory section of a performance. It can also generally mean melody or song. In general modern Persian usage, it can mean any kind of sound, musical or not.

This case of music having a shaky relationship with language is not unique. Charles Seeger was the first to observe the general reality that language could not properly represent music, or be analyzed in place of analyzing music. ${ }^{6}$ But language remains a modern tool anyone can use to construct identities for music, identities that the music itself may or may not be able to validate. Focusing on general shared linguistic features of certain types of music in specific contexts has allowed ethnolinguistic identity to remain the central theme of Iranian music history. Musicians can talk about what have become the great names of Iranian music history, mixing premodern treatises by writers like al-Farabi (d.c. 950) and 'abd al-Qader al-Maraghi (d.c. 1435) with names of the earliest known practitioners of radif, such as Mirza 'Abdullah (c. 1843-1918) and Husayn Qoli (d. c. 1915). They understand that the music system used by Mirza 'Abdullah and Husayn Qoli was not discussed by premodern treatise writers. But they did share some music terminology and they probably also shared some semblance of a mother tongue. This overlap in language provides a rhetorical bridge to narrate Iran's singular Persian music history, even when that narrative relies on cultural commonality between diverse historical realities and their divergent concepts of music. Major differences in music's conception, structure, and value at different points in time could not represent any significant change in the cultural order, as long as the ethnolinguistic bond of the language could be found in either general or specific terms. In this context, no one has been waiting to understand the specific way the maqam could have evolved into the dastgah before declaring Iran's claim to a long history of Persian music valid. No one needs to know how the transformation occurred exactly to know that these two systems have to be connected and defined by a single shared culture.

My idea of different music existing at different points in time because of distinctions in culture over time was not simply foreign in the realm of Persian music research because it was somehow foreign to Iranian sensibilities. In the case of Persian music, the narrative of a single, ethnolinguistic, national music history has been underpinned by Western scholarship, specifically some of the earliest research done on music of the Middle East in Europe under the nineteenthcentury rubric of Oriental studies. By the 1930s, some practitioners of the radifdastgah tradition had received education in Europe and knew that Europeans had researched ancient music of the Arabic- and Persian-speaking world, and that this research had revealed a distinct, noteworthy history that Europeans saw as being Persian in nature. Information on the work of Oriental musicologists such as Raphael Georg Kiesewetter (1773-1850), and Jan Pieter Nicolaas Land (1834-1897) appears in some of the early writings about the radif-dastgah system. The earliest 
attempts of radif-dastgah musicians to trace a single Persian music history focused on making a connection between the ancient twelve-maqam system, which Orientalists praised, and their own radif-dastgah tradition. ${ }^{7}$

Though Orientalist scholars had a big impact on how the history of Persian music would ultimately be told, Iranians were always providing their own interpretations of how Persian culture related to Iran's history of music. In 1942 the Iranian Journal Rūzgar-i Naw published two articles attributed to the prolific Orientalist musicologist Henry George Farmer (1888-1966). One was titled “The Great Sciences of Iran in the Art of Music" ("Ulamā'-i bozorg-i İān dar fann-i mūsīqī”) and the other "The Impact and Influence of Iran on the Construction of Instruments" (“Ta’tīr va nufūz -i İrān dar țab'īyat-i alāt-i mūsīqî̀). ${ }^{8}$ These articles were indigenous explanations of information from Farmer's chapter in Arthur Upham Pope's multivolume magnum opus A Survey of Persian Art from Prehistoric Times to the Present, published in 1938. Ironically, Farmer depended heavily on Arabic sources and French translations of Persian texts to write this chapter and mostly spoke of cross influences between Persians and Arabs. Conversely, the Persian interpretations of his work said less about the Arabs, and much more about Iran, taking Farmer's article as validation of Iran's historic musical legacy. Yet publishing the reinterpretation of Farmer's work in Persian under his name validated the veracity and importance of the information, even more than published research under a Persian name.

This borrowing and reinterpreting of Orientalist musicology research on music of the Middle East were thus ongoing and pervasive before ethnographic research began on the radif-dastgah tradition later in the twentieth century. Europeans were telling Iranians they had a great history of Persian music worth preserving. This may not have been the dominant message coming from Europe, but it was a message indigenous peoples of the Middle East heard from Europe and it did not fall on deaf ears. Henry George Farmer was at the 1932 Congress of Arab Music of in Egypt, where he was one of several European voices making this argument to Arabs in support of their unique music heritage against the pervasive growing influence of Western music. The comparative musicologists from Europe further asserted this perspective on the broader basis that Arabs had different music from Europe because of their distinct racial traits. Many Arab voices at this conference favored adapting to a more Western music aesthetic, but key Europeans voices were there to argue in favor of the indigenous music. ${ }^{9}$ Farmer echoes these sentiments in his chapter on Persian music from 1938. He begins with the statement "In spite of the many alien influences traceable in Persian culture over a period of several millennia, Babylonian, Assyrian, Greek, Aramaean, Indian, and Arabian, there is perhaps something sui generis in Persian music." ${ }^{\circ} \mathrm{He}$ ends the chapter by complaining that the import of Western-style military music to Tehran was "Occidentalizing the Persian musical ear, to the detriment of the native art." ${ }_{11}$ 
While Orientalist research and comparative musicology have proved to be underpinned by problematic assumptions and issues of racial bias, not all music scholars or musicians of "the East" want to remove themselves from their joint legacy. In Iran, the musicians and the musicologists often value Orientalism's focus on the great "otherness" of Eastern music history, which they understand to be mostly Iranian music history. From the perspective of Iranian musical intellectuals I met, it was clear that Orientalists found Iran's long-lost music of ancient times and demonstrated how Iran's Eastern music had a great musical sophistication and great history that are both distinct yet comparable to Europe. Iran having its own distinguished music culture and distinct music history vis-à-vis the West is part of larger nativist discourses against the domination of Western culture in Iran, of which there are many.

The priorities of Orientalist musicology and comparative musicologists also involved many nineteenth-century ideas that still hold sway in American higher education. Orientalist musicology focused on history and the historic writings in Arabic and Persian that referenced ancient Greek philosophy, a central aspect of academic learning in the West even today. Medieval writing on music first appeared in Arabic between the ninth and thirteenth centuries CE, and then continued in Persian starting sometime around the thirteenth century. Orientalist musicology initially took an interest in historic Arab and Persian music because of its ties to ancient Greek music, which tied Oriental music history to Occidental music history. Yet the distinct contributions of Arabs and Persians based on their unique histories and racial distinctions eventually became important, even as such racial distinctions were also the basis for the analysis of music in comparative musicology. ${ }^{12}$

In focusing on the individual writings of a handful of authors, Orientalists also established a certain degree of Great Man Theory in their musicology, with each medieval author representing a musical genius, from which unique aspects of genius among the races of the Middle East could be observed. Europe had Bach, Brahms, Beethoven, within an endless list of composers and theorists, while the ancient Middle East mostly had great music theorists like al-Kindi (c. 801-866), al-Farabi, Ibn Sina (980-1037), Safi al-Din Urmawi (d. 1294), Qutb al-Din Shirazi (c. 1300), and 'abd al-Qader al-Maraghi. On this basis, Kiesewetter famously proclaimed Safi al-Din Urmawi to be the "Zarlino of the Orient," with one genius of the East mirroring another genius in the West. ${ }^{13}$ Among the Arabs and the Persians, each genius revealed some aspect of the race's musical and cultural truth. Orientalist musicological writings sought to understand a single, verifiable, correct truth of music history among the races of the region via the study of individual geniuses.

The lingering legacy of Oriental studies in scholarship on music of the Middle East tends to present some functionalist limitations on what music and musical change could possibly mean. If Iran's Persian identity is sui generis, then tra- 
ditional Persian music will always be a mere reflection of Iran's Persian culture no matter how much music and society change. In moments of massive social upheaval, music can only serve to maintain the complex whole of Persian culture. While other music traditions of the world demonstrate the agency of music to engage in social protest and the inversion of social norms, or even to foster unique subcultures of their own, traditional Persian music largely continues to simply represent the continuity of a predetermined cultural order.

It is within this functionalist/positivist framework of understanding-and Iran's knowledge of it - that most of the modern historiography of Persian music currently resides. Yet this is not purely a conundrum of Persian music or Iran. In many of the nations around Iran, musicians and researchers often want to know what music of the past was really like, and how much historic indigenous traditions have in common with contemporary traditions. These avenues of inquiry often occur via set ethnolinguistic categories. Thus cultural categories like Persian, Arab, Turkish (or Azeri, or Kurdish, or Uzbek, or Afghan) can stand as a priori, while researchers focus on analyzing the music itself and inserting it into a predetermined cultural category of historical development. In this context, musical analysis proceeds largely from the presumption that modern ethnolinguistic identities have a perennial existence in the known history of music in the Middle East, no matter how awkward or incomplete the resulting historical narrative might be.

The focus on reconstructing individual ethnolinguistic music histories has allowed scholars to focus their analysis on what music of the past might have looked like, sometimes in great detail. Conversely the meaning of it all remains open to interpretation and standing disagreements on music's meaning seem unending. Today, Iranians, Arabs, Turks, Afghans, Uzbeks, and Tajiks could argue ad infinitum about which group gets to claim the historic legacy of great music thinkers like al-Farabi, Safi al-Din Urmawi, and Maraghi. These arguments stem from the ambiguity of these figures' historical context in relation to current ethnolinguistic realities. ${ }^{14}$ They physically and intellectually moved between language groups, with no comment about where they were born or what language they spoke from birth. Instead, they focused their lives on the urban spaces where patrons of their work could be found, and they wrote in whatever the lingua franca was in their time and place. Thus, while the twelve-maqam system had a general region of practice, it was not defined by any one language group, race, or nation.

By contrast, the modern tradition of Persian music is very defined by a national ethnolinguistic identity. The radif-dastgah tradition belongs to Iran and only Iran, referred to by musicians and scholars using such labels as traditional Iranian

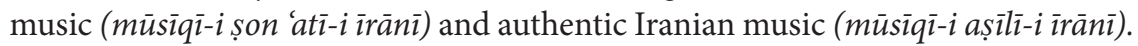
Practitioners of the radif-dastgah tradition might leave Iran and live almost anywhere on Earth, but this music tradition would still be Iranian. Before this tradition existed, historical documentation discussing music did not use Iran as a geo- 
graphic concept that delineated where on the map music practices would start or stop. Whether it was purely theoretical music ( $m \bar{u} s \bar{i} q \bar{\imath})$, sophisticated urban music practices (ghinna'), or basic melody and rhythm (lahn and $\bar{q} q \bar{a}$ ), the adjective Iranian (ìrānī) did not relate to music. People of the past were not blind to differences in different peoples, languages, and locations. Indeed, musicians tended to occupy predominantly cosmopolitan spaces where music-making must account for such differences. It was not enough to make music for Persian-speaking people ('ajam). Music had to speak across languages.

In continuing to read music treatises about the twelve-maqam system written in Persian and Arabic as far back as the thirteenth century, the differences I saw between the radif-dastgah tradition and the twelve-maqam system became more striking. The twelve-maqam system clearly shares features with music traditions of the Middle East and Central Asia cross-culturally, as does the radif-dastgah tradition. ${ }^{15}$ Yet the rise of a traditional Persian music based on the organizational principles of dastgah and radif in the nineteenth century pivoted away from the twelve-maqam system's organizational principles in significant ways. In his expansive analysis of modal concepts in the Middle East and South Asia musicologist Harold Powers analyzed Turkish and Arabic modal concepts together, but had to analyze modal concepts in the radif-dastgah tradition separately. ${ }^{16}$ The historic twelve-maqam system had more in common with the latter than the former, in terms of both structure and execution.

Even beyond basic structural features, however, the twelve-maqam system was epistemologically different from the radif-dastgah tradition. Structural features and music-making processes were different, and these differing structural features had different meanings and goals even as they necessitated different music-making processes in very different contexts. These two music systems were from very different places in time and thus related to different cultural orders. Both modern musicians of the Middle East and their scholars anticipate changes in music to indicate changes in culture when music is different between geographies and language groups. Yet changes in cultural order also occur across time. Accounting for temporally distinct cultures with specificity across history can answer questions about music history that music alone cannot.

Given the central place of the twelve-maqam system in multiple music histories of the region, it could not have simply evolved into the radif-dastgah tradition within a single, Persian cultural trajectory. Nor could it inevitably evolve into any other modern maqam/makam tradition in relation to a single Turkic or Arabic cultural trajectory. The centrality of cultural stability to modern understandings of music history in the Middle East, whether indigenous or foreign, belies the important implications of musical change and what it reveals about cultural differences between the past and the present. In considering the potential for significant change in music to indicate the existence of different cultural orders in distinct temporal space, the twelve-maqam system is something much more than a mere 
progenitor of the radif-dastgah tradition. The radif-dastgah tradition is also something much more than a mere regurgitation of a perennial culture.

\section{WRITING AND REWRITING PERSIAN MUSIC HISTORY}

In recent years, more critical readings of music history and musicians' historical narratives in areas surrounding Iran have provided a basis to distinguish between past and present musical epistemologies. For instance, Jonathan Shannon distinguishes the contemporary nostalgia of Middle Eastern musicians for medieval alAndalus as a cultural imaginary that lives in contemporary musicians' rhetoric, far away from the realities of medieval Muslim Spain. ${ }^{17}$ In South Asia, research by Katherine Butler and Bonnie Wade has demonstrated that modern agency and cultural synergies created the indigenous tradition of Hindustani music leading up to the nineteenth century. ${ }^{18}$ Beyond these localized deconstructions of historical discourse, the entire discipline of anthropology has also experienced very broad critiques of its culture paradigm via reflexive analysis of the discipline in relation to its subject of culture and indigenous peoples. ${ }^{19}$ Anthropology's internal critique has stemmed in part from the realization that many indigenous traditions that researchers initially identified as quite old were in fact quite new.

In the midst of these changing conceptions of music, history, culture, and tradition, Iran has been largely absent. This is partially due to purely logistical challenges of ethnographic research and music performance. The revolution in 1978-1979 and ensuing upheaval, followed by international sanction, prohibitive travel policies, and heavy government intervention into music regulation, have all provided difficult hurdles for both Iranian musical performance and research. Social and cultural historians have faired somewhat better under the current Iranian government. Research since 1978 on early-twentieth-century Iran has been able to reveal the modern agency involved in the rise of the modern Iranian nation, referencing indigenous interpretations of European intellectual trends such as Orientalism, nationalism, and political activism. ${ }^{20}$

But the Iranian government throughout the twentieth and twenty-first centuries has also done a high degree of enforcement of its own nationalist narratives of Iranian history, making these kinds of alternative interpretations of Persian history for music more difficult. By the 1960s many indigenous musicians and researchers depended on the Pahlavi Ministry of Culture and Ministry of Information for their work, even as the Pahlavi state had been invested in notions of modern Iran as the heir to the great ancient Persian empires for several decades. ${ }^{21}$ In this environment, researchers had the impetus to write within a narrative of Iranian music history that related to the Pahlavi preference to connect Iran to the most ancient interpretation of Persian culture available. ${ }^{22}$ When the revolution in the late twentieth century brought Shi'a Islamic identity to the fore, this placed emphasis on the origins of Iranian identity in the sixteenth century, when Shi'a Islam came to dominate the 
Iranian plateau. Pre-Islamic and even early Islamic history no longer provided the primary framework of Iran's political identity, and thus more historical research of music in Iran now focuses on music from the period from the sixteenth century to the present. The Islamic Republic's influence on music has primarily been directly filtered through its regulation of music performance, which has altered the nature of current music practices in novel ways, even as it claims to maintain some type of native purity. ${ }^{23}$ Yet government ideas about what Iran is, where it come from, and what its ideal cultural essence is change the framework for understandings of music far beyond performance.

More recently, government officials have tried to mix and match various aspects of pre-Islamic and Islamic identity with their specific political interests in modern Middle Eastern affairs. The most visual example of this more recent trend was the ceremonial induction of the ancient Persian ruler Cyrus the Great (600-529 BCE) into the Shi'a government's Basij militia in 2010. ${ }^{24}$ This required the government to get an actor to play the part of the ancient Zoroastrian ruler, upon whom the president placed a kuffiya, the iconic scarf of the mostly Sunni Arab Levant, which the Basij wear both in support of Sunni Palestine and in keeping with the Shi'a organization Hezbollah in Lebanon.

While performing a formal ceremony to symbolically induct a prehistoric Persian king into a modern government militia seems unusual and ostentatious, it demonstrates that the pre-Islamic nationalist narrative that dominated Iranian politics for most of the twentieth century still has power and relevancy. Finding ways to explain or otherwise connect the pre-Islamic nationalist narrative with the more recent history and nationalist discourses of the Islamic Republic is a useful initiative in current Iranian politics. It also demonstrates the futility of taking the modern discourse on Iranian national identity as the historical truth of identity in the Persian-speaking world for all time. Grand spectacles such as this display highly visual juggling of contradictory imagery, highlighting the large amount of agency involved in creating and re-creating a modern national identity. The continuity emphasized in historical discourses surrounding Iran's Persian musicwhether from a musician or a scholar, an Iranian or a foreigner-contradicts the ephemeral construction of unity for a single Iranian culture and history. Modern Iranians write and rewrite their own history, even as the peoples in surrounding nation-states write and rewrite their histories, creating overlap and conflict in historical discourse. Music provides evidence upon which to build multiple subjective interpretations of past realities to explain the ever-changing present moment and prospects for the future. ${ }^{25}$

Ensuring that Iran has a place on the modern political map of the world requires this ongoing negotiation of Iranian identity and objective enforcement of its subjective nature. Despite the perceived historic symmetry between Iran and the Persian language, only about 50 percent of Iranians speak Persian as their first 
language. Iran encompasses a lot of both musical and cultural diversity. Even Persians have music traditions that are unique to one particular region or even one particular city. ${ }^{26}$ Some of its larger language minorities have agitated for national independence over the past century, including Azeris, Baluchis, and Kurds, who all have their own contiguous language regions that defy Iran's borders as well as those of surrounding nations. Within Iran itself, there are multiple possibilities for national divisions that modern Iran has had to confront.

The fall of the Soviet Union in the 1990s and the subsequent independence of Persian- and Turkic-speaking peoples of Central Asia have created even more challenges to Iran's historic Persian façade. While Iran clung to the European label of Persia for most of the twentieth century, the term Persianate emerged as a common term to describe societies that fell outside of Iran's national history as awareness grew of Persian-speaking people in Central and South Asia. When Central Asia emerged as an accessible area for research in the shadow of Iran's Islamic revolution in the 1990s, the use of adjective Persianate soared. Central Asia and South Asia have become prime areas for research on Persianate music while Iran has remained isolated.

All of this demonstrates that Iran is a modern nation-state that must actively work to create and maintain itself as a distinct cultural entity that has political standing in the modern world. Like all nation-states, this requires Iran to engage in ever-changing narratives that justify its historical existence in the midst of changing circumstances and other national possibilities. Iran's national identity is negotiated, renegotiated, and enforced in relation to other nations, who are also negotiating and renegotiating their national identities.

Music has a role to play in such negotiations. Thus, one old song in the radif tradition highlights the negotiation of Iran vis-à-vis Azerbaijan in the early twentieth century, describing Azerbaijan as “Iran's key, Iran's hope, Iran's martyr” while singing against Azerbaijan's Turkic identity by telling it to "avoid the Turks and the Turkish." ${ }^{27}$ More recently, Iran formally turned to the West for musical affirmation of its cultural strength. In 2009, UNESCO approved Iran's application to have the radif inscribed on its "Representative List of the Intangible Cultural Heritage of Humanity." Here the international community officially recognized the radif as a key aspect of Iranian music that "reflects the cultural and national identity of the Iranian people." ${ }^{28}$ These are musical actions taken in an ongoing negotiation of national culture. Iran made its application for the radif to be added to this list a year after UNESCO started it. In its first year, UNESCO added multiple music traditions from Iran's neighbors, including the Azeri Mugham, Uzbek and Tadjik Shahmaqom, and Uyghur Maqam. With nations all around it receiving cultural validation from UNESCO through music, Iran could not afford to be left out. Indeed, Iran is very concerned about its standing in its surrounding region. It is currently very focused on the countries around it and what they can do to com- 
promise Iran's position, including their ability to present affronts to its political interests and cultural identity.

\section{PERSIAN MUSIC IN CULTURAL HISTORY:}

\section{A NEW APPROACH}

While people studying musical practices in areas of the world with little physical documentation of music history may be able to embrace the idea of history as a pure exercise in mythology for the present, it creates a teleological quandary for areas like the Middle East where historical documentation of musical ideas and practice goes back centuries. In meeting Iranian musicians in the twenty-first century and directly experiencing their music and their understanding of their culture, I wanted my research to honor their perspectives, including their interpretations of music history. The feeling of obligation to the present I experienced was immediate and visceral.

This presents a predicament for considering the meaning of the musical past. I can read about the musical past, but I cannot directly observe or hear a reality from centuries in the past. I can ponder how those musicians existed in the past playing different music under very different circumstances, but their reality cannot live with me the way current Iranian music culture can. For this reason, direct experiences with a present musical reality weigh heavily on attempts to understand documentation of the musical past, no matter how many centuries or millennia removed music history is. It is possible to do complex analysis to reveal highly distinct music systems of the past in detail, and yet there is a tendency to construct the significance of music culture past in relation to a designated music culture present, no matter how musically and culturally distinct the past maybe. In considering a new approach to Persian music's historiography, moving away from such telescopic interpretations of the past provides an opportunity to locate the more specific meanings of music at different points in time. This greater specificity of meaning can reveal a more active and arguably more significant role for music and musicians in the societies of the Persian-speaking world, past and present.

In considering how to write historiography that more equally accounts for the possibility of distinctions in musical and cultural order marking differing epochs, I kept reading the historical writings in Persian considered by both musicians and scholars to be the physical and intellectual evidence of Iran's great music history, seeking points of analysis that could provide insight into the musical past on its own terms, with no predetermined narrative direction for culture or identity beyond what documentation could support. I focused my research on the catalog of Persian music treatises compiled by the Iranian musicologist Mohammad Taghi Massoudieh in the late twentieth century, Manuscrits persans concernant la musique. ${ }^{29}$ Besides being an extensive catalog of Persian musical writings in print, I found that this catalog had a certain symbolic significance, acting as a metaphori- 
cal bible of Persian music that documented its historic tales and origins over centuries. Massoudieh was a very influential scholar in late-twentieth-century Iranian musicology and his cataloging of Persian manuscripts validated modern belief in Persian music's unity and antiquity and modern Iran's ownership over this Persian musical legacy. I was also able to analyze writings Massoudieh did not document, but his cataloging of manuscripts remained the center of my research. The types of manuscripts he documented had been used to tell a specific story about Iran's history. I wanted to reanalyze this documentation without the assumptions of Iranian national history.

I quickly discovered that Oriental musicology's influence over indigenous musical thought and the diffuse history of Persian-speaking peoples in Asia reflected the geography of the historical documentation in this catalog and the general trajectory of historical studies of Iranian music history overall. The documentation of Iran's music history cataloged by Massoudieh was all over the Eurasian continent, which held much of it in archives and libraries all over Europe, South Asia, and Central Asia. Researching the catalog required me to travel to Iran, and the United Kingdom, Germany, and France, while requesting documents from archives in the Netherlands, Uzbekistan, Russia, Pakistan, and India. Sometimes I could get Persian music treatises from institutions I could not visit through normal requests to the constituent institutions. Sometimes I shared documents I had access to with Iranian musicologists who needed them, and in turn they shared documentation they had obtained. All this movement belied notions of armchair scholarship. Not even Iranian musicians themselves had full access to Persian music history. They would have to travel far and wide to see it.

I started my research reading texts that other scholars had written about, but also texts no one had written about, and large sections of text that scholars omitted from analysis due to their inability to illuminate practice or their redundancy of discourse. Redundancy of discourse, even purely theoretical concepts, struck me as too important of a phenomenon to ignore. Modern studies of historical music texts from the Middle East have tended to follow medieval European classification of discourse between the purely speculative (musica speculativa or 'ilm) and the practical (musica practica or 'amal), leaving the latter to either admire or ignore and the former to explain what really happened. ${ }^{30}$ But reading all statements and locating consistent patterns of musical discourse across such categorization can reveal and map music's relationship with the cultural order: stable constructs of human belief and meaning and what music contributed to those constructs within a particular space and temporality, in relation to both praxis and possibilities of praxis.

Within this general framework, I saw the need to reread much of what had already been read and I deal with the documentation already recognized as central to Iran's Persian music history. Restricting the analysis of music within the set labels such as "Persian history" or "Iranian culture" put significant limits on 
the types of information that could be valued in these writings and narrowed the possibilities for how they could be analyzed. But in taking music as a key indicator that could define cultural and temporal space, new readings of these texts are possible.

Analyzing musical thought's relationship to the stability and change of the cultural order creates a cultural history of music in the true sense of cultural history: the study of how specific musical knowledge and practice can be aligned with nonmusical knowledge and practice in the broader context of cultural production. The goal of such a cultural history is to identify the specific realities that made different parameters for music-making possible at different points in time. In this approach to historiography, parameters of music culture relate to the successive temporal alignments between discourses within a field (in this case, music) and the discourses of other fields that make up its surrounding context. Within this framework, music is part of an active realm of cultural production that can reveal significant changes in cultural dynamics. More significantly, music analyzed as cultural production in this framework can reveal the dynamics of changing local histories, as well as connections between local history and the broader dynamics of world history.

On its face, this kind of study borrows much from Foucauldian archeology. ${ }^{31}$ In such a study, the purpose of discourse analysis would be to locate a broad conceptual basis for a set of musical possibilities within the cultural order, looking for moments of one discourse's extinction in relation to another, in order to locate successive change in music and culture, rather than a single, evolving cumulative change..$^{32}$ Yet some of the strongest epistemological breaks in the history of Persian-speaking people are not accompanied by wholesale cultural or musical extinction, highlighting points made about the relationship between historical events and the contrasting stability of cultural order in historical anthropology. Thus, Marshall Sahlins insists that the past does not have to be victimized by the present in the sense that it can be analyzed to locate its own unique cultural order. He further suggests, beyond Foucault, that the goal of modern historiography is "understanding people's cultural constructions of events, not of determining 'facts' in the physicalist sense of objective happenings." ${ }_{33}$

In the analysis of historical documentation from this perspective, radical transformations of culture occur in relation to exogenous events and world history, yet the standing cultural order will have input into the process of adaptation and reinterpretation in the establishment of a new order. Indigenous peoples of the Middle East do not simply lose their cultural orders in the midst of invasions, migrations, and colonizations, nor do they maintain the cultural order and render historical events and the causations of world history meaningless to local cultural perspective. Rather, the cultural order becomes a key aspect of how societies adapt to events and establish new cultural order via idiosyncratic responses to the event, not just contact with external forces. In this context, the idea of musical 
tradition is less one of an enduring monument to a single cultural existence and more akin to Marshall Sahlins's definition of tradition as a culturally specific form of change. ${ }^{34}$ Humanity's local musical abilities and knowledge come into play as adaptive responses to changing life circumstances tied to an ever-changing world.

In writing a cultural history of Persian music in this way, Nettl's suggestion of the radif-dastgah tradition emerging from the dual historical events of rising Western cultural hegemony and rising sentiments of nationalism takes on a very different meaning that warrants investigation, with deeper consideration of the relationship between music, cultural order, and historical events. On one hand, social scientists no longer take nationalism for granted as a purely organic pride in a naturally perennial culture of a nation. It is almost a truism to say that nationstates are actively constructed in the modern era, with grand historical narratives built upon purloined historical data. This is the source of modern Iran's ability to give different and even contradictory conceptions of national identity, without ever questioning the legitimacy of Iran's perennial nature. This metaphorical stealing of history is part of the adaptation process: an aspect of older, localized cultural order being actively repurposed in adaptation to modernity, in support of the modern nation.

The specific circumstances encompassing the historical event of modernity's transmutation facilitate a heterogeneous synergy between various aspects of indigenous cultural order, external forces, and the localized contingencies of the event itself. In this context, the modern radif-dastgah tradition is not required to be either a replica or an abandonment of indigenous music culture, nor does it have to be a compromise position between Persian and Western culture. It can be a culturally moded change in music's practice and conception that addresses unique cultural adaptation to the modern world in a particular place. It is not limited to being a static symbol of Iran's national culture: it can be an active producer of Iranian culture that makes the nation of Iran possible, in part by voicing a narrative for modern Iran using new interpretations of indigenous musical expression.

The radif-dastgah tradition's unique historical moment highlights its distinction from the twelve-maqam system. No one writing about, thinking about, or performing within the twelve-maqam system in the fifteenth century had a crystal ball to tell them of the historical events from which the radif-dastgah tradition emerged four centuries later. Though the modern music culture of the radif-dastgah tradition requires the history of the twelve-maqam system to adapt to Iran's modern cultural order, the twelve-maqam system related to a different cultural order, which emerged in the adaptation to very different historical events in the Persian-speaking world: the rise of Islam via Arabic-speaking peoples from the West, and the Mongol Invasion accompanied by Turkic migrations from the East. It is here, in the midst of cosmopolitan, polyglot Islamic empires across Central and West Asia, that the twelve-maqam system became a highly valued model of music's conception and performance practice. 
To consider historical documentation of music in the Persian-speaking world in relation to these contrasting historical events, I identified three categories of musical discourse found across Persian writings about music, from the thirteenth century into the 1940s, which demonstrate the contrasts between the cultural order of the twelve-maqam system and the radif-dastgah tradition. Discourse on the meaning of technical aspects of music's structure and execution directly addresses what made each music system possible and valuable within its constituent historical context. Discourse on the moral parameters of musical practices further extrapolates contrasting moral dilemmas in the execution and conception of musical expression for each constituent music system. Finally, song texts allow musical expression to fully enunciate contrasting priorities of each system's cultural context.

On the basis of these three categories of discourse in relation to two distinct music systems, I have organized my analysis into two parts: part 1 for the twelvemaqam system from the thirteenth to the eighteenth century, and part 2 for the radif-dastgah tradition from the nineteenth century to the 1940s. Chapter 2 is an introduction to part 1, providing a more detailed background and history of the twelve-maqam system and its intellectual practitioners within the Persianate Islamic empires established by Mongol and Turkic rulers. Chapter 3 examines technical discourse on the twelve-maqam system, along with its metaphysical and cosmological underpinnings. Chapter 4 examines the discourses of morality surrounding the practice of listening for divine connection in the context of Islamic mysticism. These discourses run concurrent with the twelve-maqam system, sometimes in the same texts, reflecting on the benefits and perils of mystical practices that used listening to musical expression as a method of direct connection with God. Chapter 5 completes part 1 with an analysis of song text collections from the Timurid courts (1370-1501 CE) and the Safavid courts (1501-1722 CE). These texts highlight the centrality of imperial principles in musical expression, while also demonstrating musical adaptation to the changing politics of empire over time.

Chapter 6 is an introduction to part 2 that provides a more detailed background and history on the radif-dastgah tradition and the historical context of its intellectual practitioners within the fall of the cosmopolitan model of empire and the rise of the nation of Iran. Chapter 7 examines technical discourse on the radifdastgah tradition, focusing on how its structure related to developing national discourses in the descriptions and theoretical models of the tradition described by Forsat al-Dowleh Shirazi (1855-1920), Mehdi Qoli Hedayat (1864-1955), and Ali Naqi Vaziri (1887-1980). Chapter 8 examines the changing morality of music in this newly nationalized culture, considering the moral issues of national music discussed from different perspectives by Vaziri and the singer-poet Aref Qazvini (1882-1934). Chapter 9 examines the nationalist choices that create much of the original structure for radif-dastgah performance, as well as the modern nationalist 
discourses of tasnif (tașnif) — the metered song compositions commonly inserted into radif-dastgah performances.

In chapter 10, I conclude by reflecting on the significant contingencies that put Iran's musical modernity on a unique path, which was further shaped and reshaped by different readings of what the nation of Iran needed from its music in order to survive and thrive. I consider the larger picture of the contrasts between the radif-dastgah tradition and the twelve-maqam system, and return to the question of methodology in music historiography and how placing cultural production at the center of music history sheds light on music's larger role in both local and world history. 

PART ONE

Culture of Maqam 



\section{Musical Empires}

The longest-standing basic principles of music's structure in the documented history of the Persian-speaking world emerged and thrived within the context of dynastic rule that succeeded the waning Islamic Caliphate. With Islam underpinning the rise of Mongol and Turkic kingdoms in the thirteenth century, different versions of the same basic concept of the twelve-maqam system appeared on opposite sides of the Caliphate's domain in West and Central Asia. It then moved from court to court as musicians and their music adapted to the changing fortunes of dynastic patrons and the rise and fall of empires. In this context, documentation surrounding this approach to music comes from the various cities where dynastic rulers and their aristocracies resided at any given time, cities as far east as Bukhara and as far west as Baghdad. Documentation of the twelve-maqam system eventually also appeared in South Asia and Anatolia as rulers who patronized the system moved to occupy more territory.

The twelve-maqam system thus embodied a basic concept of music-making for a polyglot cosmopolitan dynastic context over a wide geographic and linguistic area. Yet it also mostly occupied a narrowly defined cultural context: specific urban centers that stood as islands of dynastic rule. The association of the twelvemaqam system with a system of patronage emanating from dynastic courts placed it in a political space that typically stood separate from the larger geographies dynasts sought to control. This relationship between the twelve-maqam system and empire lasted throughout an era of dynastic governance, where an Arabized form of Persian functioned as the lingua franca of cosmopolitan empires where Islam continued to be the dominant religion that also sanctioned dynastic rule.

In current narratives of Iranian music history, the existence of the twelvemaqam system begins at the end of the 'Abbasid Caliphate's fall, between the twelfth and thirteenth centuries. It thrived through a perceived golden age of Ira- 
nian culture overseen by Mongol and Turkic rulers, peaked in the Timurid Empire in the fifteenth century, and entered a period of musical decline in the Safavid Empire of the sixteenth and seventeenth centuries. Both dynastic governance and the twelve-maqam system disappeared for good with the rise of the nation-state under Qajar rule in the nineteenth century.

The complex of ideas about music's structure and execution associated with the rubric of the twelve-maqam system stood for at least six centuries as a central embodiment of music's ideal organization and performance. At the core of this ideal was the idea of melodic organization being center in twelve primary pitch modalities. These pitch modalities - their relationships with additional derivative modalities and their application vis-à-vis rhythm in the course of composition-formed the basic conception of music's construction and creation. The details of modal derivation and compositional forms would change, and different rhythms would also appear at different times in this period, yet the structural logic expressed in the twelve-maqam system itself and the conception of its application in practice remained in place in various guises for six hundred years.

Documentation of the twelve-maqam system began in Arabic from the 'Abbasid capital Baghdad and in Persian from the Ghaznavid kingdom, one of the first Turkic Persianate kingdoms to overtake the Caliphate farther east in Central Asia. Writing for the 'Abbasid Caliph al-Musta'sim (r. 1242-1258), Safi al-Din Urmawi (d. 1294) initially produced the most widely cited Arabic texts that described a fundamental premise for pitch structures concordant with a basic model of the twelve-maqam system. His description came in the context of extrapolations on ideas about music found in the Greek-based tradition of Islamic philosophy that had previously developed within the Caliphate. While Safi al-Din's ideas would be remembered and quoted for centuries after his death, a man named Muhammad bin Muhammad bin Muhammad Nishaburi who served in the Turkic Ghaznavid court of Bahram Shah (r. 1118-1152) had written about a similar if simpler conception of twelve pitch modalities somewhat earlier. ${ }^{1}$ Nishaburi did not appear to know about the Graeco-Arabic writing tradition farther west, yet his structural conception of twelve primary pitch modalities mirrored Safi al-Din's discussions of twelve pitch modalities in significant ways.

Persian writings about music did eventually take on the influence of the Graeco-Arabic writing tradition, and many Persian writings that describe the twelve-maqam system in more consistent detail beginning in the fourteenth century reflect the influence of the broader philosophical discussions that had grown out of the prior Graeco-Arabic discourses on music. Some Persian writings comment directly on the writings of Safi al-Din, including writings about music from the mystical philosopher Qutb al-Din Shirazi (d. 1311), and the prolific court musician 'abd al-Qader al-Maraghi (d. 1434). Safi al-Din, Qutb al-Din, and Maraghi form the core of what Henry George Farmer called "the Systematic School" because of their ability to synthetize many of the priorities of earlier Graeco-Ara- 
bic writings in relation to practice. ${ }^{2}$ Yet all three also described some version of the twelve-maqam system, with Shirazi and Maraghi discussing it both as Safi al-Din described it and as an aspect of musical practice in their different lifetimes and locations. The relevance of themes derived directly from earlier Graeco-Arabic writings continued in the sixteenth century, as information from this earlier tradition transferred directly into subsequent Persian writings. Maraghi’s Persian writings were some of the most directly cited authorities on music in the fifteenth and sixteenth centuries, and writings like his kept the Graeco-Arabic framing of the twelve-maqam system represented by Safi al-Din. The longer that Persian remained the lingua franca, however, the more direct knowledge of the GraecoArabic tradition waned. By the seventeenth century, writings about the twelvemaqam system focused more completely on the twelve-maqam system, and had fewer philosophical trappings of earlier musical discourses. Basic themes initiated in Graeco-Arabic writing centuries earlier remained part of the musical discourse, but direct knowledge of the origins of these discourses dissipated.

\section{THE TWELVE-MAQAM SYSTEM: \\ CONSONANCE AND DERIVATION}

At its core, the twelve-maqam system was based on twelve abstract modalities that related to a larger concern with creating and organizing consonant sets of pitches that could be used for the purposes of music-making, once combined with separate concepts of meter and musical form. The few sources that actually outline parameters for these modalities represent them as octave scales. Thus Safi al-Din Urmawi referenced twelve modalities he called shadd and he presented each shadd as an eight-note scale with the first note representing the scale's last note a register lower. Safi al-Din placed these shadd into a theoretical schema for scale creation that Safi al-Din referred to as adwar (adwār). In this theoretical adwar, Safi alDin defined seven possible consonant tetrachords and twelve possible consonant pentachords that could combine to create different scale possibilities. The shadd represented twelve scales located at various placed in the adwar. The full adwar presented eighty-four possible distinct individual scales (dä'irah), and while each scale had a set numbered position in the totality of the scales ( $a d w \bar{a} r)$ the twelve shadd were each labeled with a distinct proper name: Oshshaq ('oshshāq), Nawa (nawā), Busalik (būsalīk), Husayni (hūsaynī), Hijaz (hijāz), Rahavi (rāhawī), Iraq ('irāq), Rast (rāst), Zangulah (zankūlah), Zir-Afkand (zīrāfkand), Bozork (bozork), and Isfahan (isfahān). Safi al-Din further provided charts showing the possible transpositions of these specific scales, independent of the logic of his adwar. ${ }^{3}$

Beyond these twelve shadd, Safi al-Din further designated six other named scales as avaz (awāzah): Gardaniya (kardāniya), Gawasht (kawāsht), Nawruz (nawrūz), Maya (māyah), Shahnaz (shahnāz), and Salmak (salmak). The musicologist Owen Wright has noted that while the shadd had a consistent octave 
organization that fit well within Safi al-Din's adwar, the avaz represented a mixture of modal possibilities, some that were structurally similar to the tetrachord/pentachord structure represented in the shadd and others that represented smaller sets of pitches. ${ }^{4}$ What distinguished both the shadd and the avaz from the rest of the scales in the adwar, however, was their apparent relation to practice. While Safi al-Din forwarded a seminal theory of scale creation that united concerns of theory with the realities of practice, the shadd and avaz were established aspects of practice, for which his theory of adwar could only partially account.

The unique phenomenon of the adwar notwithstanding, Safi al-Din wrote about two core features that would ultimately define the parameters of the twelvemaqam system over centuries. First was the notion of two distinct categories of twelve primary and six secondary pitch modalities that maintained meaningful associations with each other. Second was the notion that functional pitch modalities should derive from previously established consonant organizations of pitch. While Safi al-Din's specific use of pentachords and tetrachords would only ring true in certain places for a short period of time, the centrality of systematic modal derivation from previously established modal material within closed parameters lasted for the duration of the system's relevancy and defined its premise for legitimate consonant mode creation.

These two phenomena manifested in a different presentation in the writings of Nishaburi, who described twelve primary pitch modalities he called pardeh and six secondary modalities he called sho'beh (sho'beh). The terminology in his scheme was different than Safi al-Din's, and his description was less technical. He also wrote in generalities without outlining any specific scales. Yet Nishaburi highlighted the systematic derivation concept by emphasizing that the six secondary modalities derived from specific pairings of the twelve primary pitch modalities: each pardeh could be paired with another specific pardeh, and between the two a new modality was created, one of six sho ${ }^{\circ}$ beh total. ${ }^{5}$

The writings of Nishaburi and Safi al-Din read very differently and suggest various ways of thinking about how one type of modal entity would be derived from another. Orientalists and musicologists came to regard Safi al-Din's full adwar as a seminal creation in the history of music in the Middle East, because it combined the best features of the previously discussed theory of consonant scale creation with practical considerations of intervals on stringed instruments. Safi al-Din was one of the first writers on music in the Middle East to describe a system of scales that could be both systematic and used in practice. Graeco-Arabic writings produced by Islamic philosophers such as al-Farabi (d. c. 951) and Ibn Sina (d. 1037) were concerned about systemization of consonant pitch organization but did not attempt to integrate the Greek-based premise of their reasoning regarding pitch with practices of their time and place. Safi al-Din's adwar appeared to overcome this separation between philosophical principle and practice. He described two distinct categories of twelve- and six-pitch modalities in the context of many pos- 
sibilities for scales, which balanced concerns about systematic consonance with what would be functional in practice. ${ }^{6}$

Nishaburi, by contrast, did not write in conversation with previously established norms of the Caliphate's Graeco-Arabic writing tradition for music. Yet he still described two distinct sets of twelve and six pitch modalities, and located a systematic pattern of derivation, this time between the two categories of modalities. As writing about two distinct categories of pitch modalities continued past the final years of the Caliphate, a more consistent and specific conception of the twelve-maqam system emerged that in many ways reflected influence from both the concept outlined by Nishaburi and that of Safi al-Din.

It was in the fourteenth and fifteenth centuries that the term maqam became more consistently synonymous with the twelve primary modalities of the system, even as avaz became the consistent term for the six modalities that derived from the maqam. The term sho'beh came to denote pitch sets from which the maqam were derived. In principle, the idea of sho'beh could reference the basic premise of the pentachords and tetrachords Safi al-Din had conceived. But these sho'beh all had proper names and distinct modal identities and it is not apparent how many pitches constituted a sho 'beh. They could serve as the basis for a maqam or independent modal structures unto themselves, just like a maqam or avaz. Texts typically named twenty-four specific sho'beh and often showed pairs of specific sho'beh as being the basis for each of the twelve maqam, which were further mapped out in pairs to create the six avaz.

Like the avaz, it is not clear what the structural relationship was between specific maqam and their pairs of sho'beh. The few descriptions of the pitches of different sho'beh give varying numbers, anywhere from four to eight. Yet their presence was consistently explained using the idea they had a structural relationship with the twelve maqam, which in turn had a structural relationship with the six avaz. Texts about the twelve-maqam system debated other possibilities for constructing the twelve maqam and extrapolating additional modalities from them, but it was the relationship between the twelve maqam, six avaz, and twenty-four sho ${ }^{\circ}$ beh that ultimately stood as the prevailing core structure of mode creation.

This notion of a closed system of combining different consonant sets of pitches to create different pitch modalities had a further extrapolation beginning in the seventeenth century. While the avaz, maqam, and sho'beh remained, the sho'beh were further deconstructed into even smaller set of pitches typically referred to as gusheh. The gusheh was the least-described aspect of the twelve-maqam system. Some descriptions followed the pairing principle of the initial system's conception, with two gusheh forming each of the sho'beh for a total of forty-eight gusheh, while others described larger or fewer numbers of gusheh without explaining how these very small sets of pitches created each of the sho'beh. Yet the gusheh were considered the source of the sho'beh and thus stood as an extension of the basic notion of closed derivative pitch organization present in the twelve-maqam system from its earliest descriptions. 


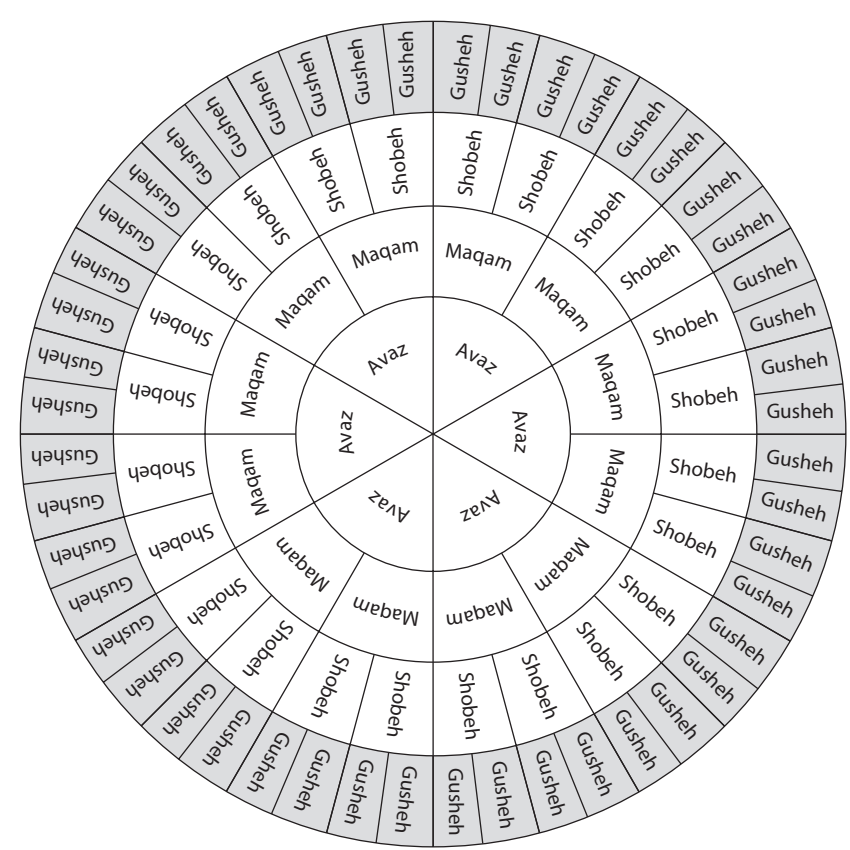

FIGURE 1. Common format for representing the twelve-maqam system as a closed, interconnected system

Owen Wright was the first modern musicologist to extrapolate notated scales for the twelve-maqam system, focusing on the handful of texts that actually name pitches associated with each maqam relatively early in the system's existence. Conversely, writings about the twelve-maqam system overall only occasionally dwelt on the specifics of pitch, focusing instead on the interrelationship of avaz, maqam, sho beh, and later the gusheh. In this context, the most common representation of the system was some kind of diagram that demonstrated the relationships between different aspects of the pitch organization. One of these representations was a circle, which mapped out the six avaz at the center, and twelve maqam around their parameter, naming which two maqam were used to derive each of the six avaz. A further rung mapped out which two sho ${ }^{\circ}$ beh formed each of the twelve maqam. Later depictions added gusheh around the sho'beh, naming each of the two gusheh that created each sho'beh (see figures 1 and 2).

By the fifteenth century, texts about music consistently emphasized the importance of interrelationship between aspects of the twelve-maqam system. The avaz could not exist without the maqam, and the maqam could not exist without the sho ${ }^{\circ}$ beh, and eventually the sho beh could not exist without the gusheh. The theoretical derivative interrelationships were central to the acceptance of the modalities as applicable in practice. Safi al-Din's full adwar of scale possibilities would never become relevant to ongoing music in practice: it was the interrelated modal- 


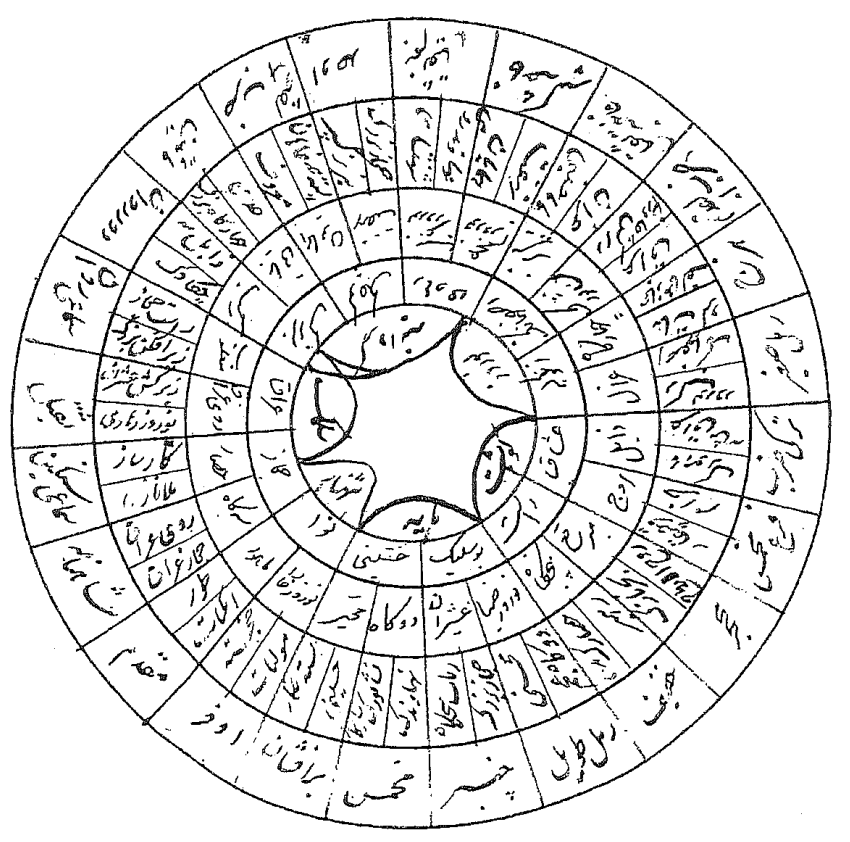

FIGURE 2. Charting of the twelve-maqam system in the Bahjat al-Rüh surrounded by the usul. Undated text held by the Bodleian Library Oxford University Ouseley 117, folio 23 recto

ities of the twelve-maqam system that would ultimately have a relationship with creating melody for the purpose of music-making in practice.

\section{MAKING MUSIC: THE TWELVE-MAQAM SYSTEM IN RHYTHM AND COMPOSITION}

In order to actually make music using the twelve-maqam system, a modal entity from the system had to be paired with rhythm and cast into a specific musical form in the course of composition. The twelve-maqam system had a parallel set of rhythmic patterns for percussion instruments, referred to as usul (usūl), typically discussed after descriptions of the twelve-maqam system. Descriptions of these rhythmic patterns changed over time, though they were often demonstrated using some imitation of the representation of 'aruz (' $\operatorname{aru} \dot{z}$ ): the system of poetic meters (buhūr) used as the basis of both Arabic and Persian poetry. While some writings substitute 'aruz for a distinct system of rhythmic conception, the two also appeared side by side with different specific representations of rhythm eventually replacing any reference to 'aruz altogether.

Like the maqam, avaz and sho'beh, and gusheh, the usul each had proper names to distinguish different usul from one another in language. The prolific musician and author 'abd al-Qader al-Maraghi writing in the fifteenth century 


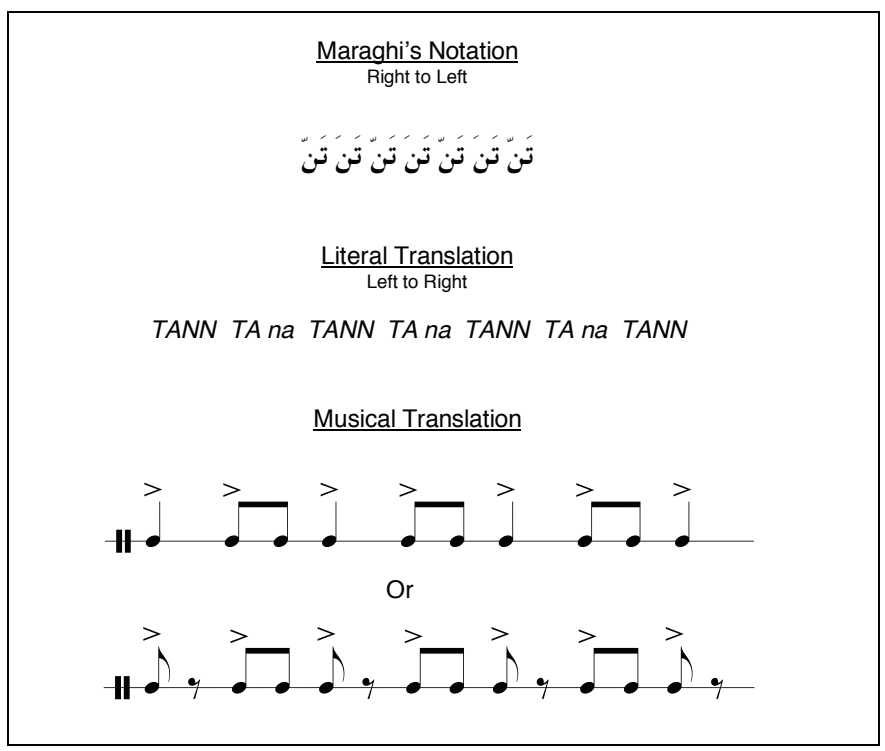

FIGURE 3. The Khafif Saqil rhythmic cycle according to Maraghi

thus described a series of rhythmic cycles (advār-i $\left.\bar{i} q \bar{a}^{e} \bar{a} t\right)$ common in his time using various distributions of vowels around the consonants te $ت$ and nun $ن$ provided varying amounts of description beyond this notation, which had been used in Graeco-Arabic writings centuries before. For example, he described a cycle named "light-heavy" (khafif $\underline{s}$ squil) as a cycle of fourteen beats while also indicating which beats where played and which were silent (see figure 3 ). ${ }^{7}$

The notion of usul embodied this concept of a metered pattern of rhythm serving as the organization of time underpinning melodies composed using maqam, avaz, or sho beh. While this basic premise was a consistent one for the actual creation of melody in the twelve-maqam system, the usul and description of usul varied over time. Thus, writing at the end of the seventeenth century in the Safavid court in Isfahan, the head of court musicians, Amir Khan Gorgi, notated some different usul, using syllables built around the consonants dal $د$ and kaf $ک$. Thus Amir Khan described an usul of his time named ramal as having two versions, one significantly longer than the other (see figure 4$){ }^{8}$

The place where both maqam and usul came together to make music was in composition. Indeed, while there was no tradition of notating compositions for preservation, the few written notations of music in the twelve-maqam tradition were theoretical demonstrations of composition, showing how to apply usul and maqam together to create a set melody within a set meter. ${ }^{9}$ Improvisation, by contrast, had no specifically formulated place in the system and there is no description of how one would improvise within the twelve-maqam system. Music-making was always the proper matching of elements of the twelve-maqam system with usul 


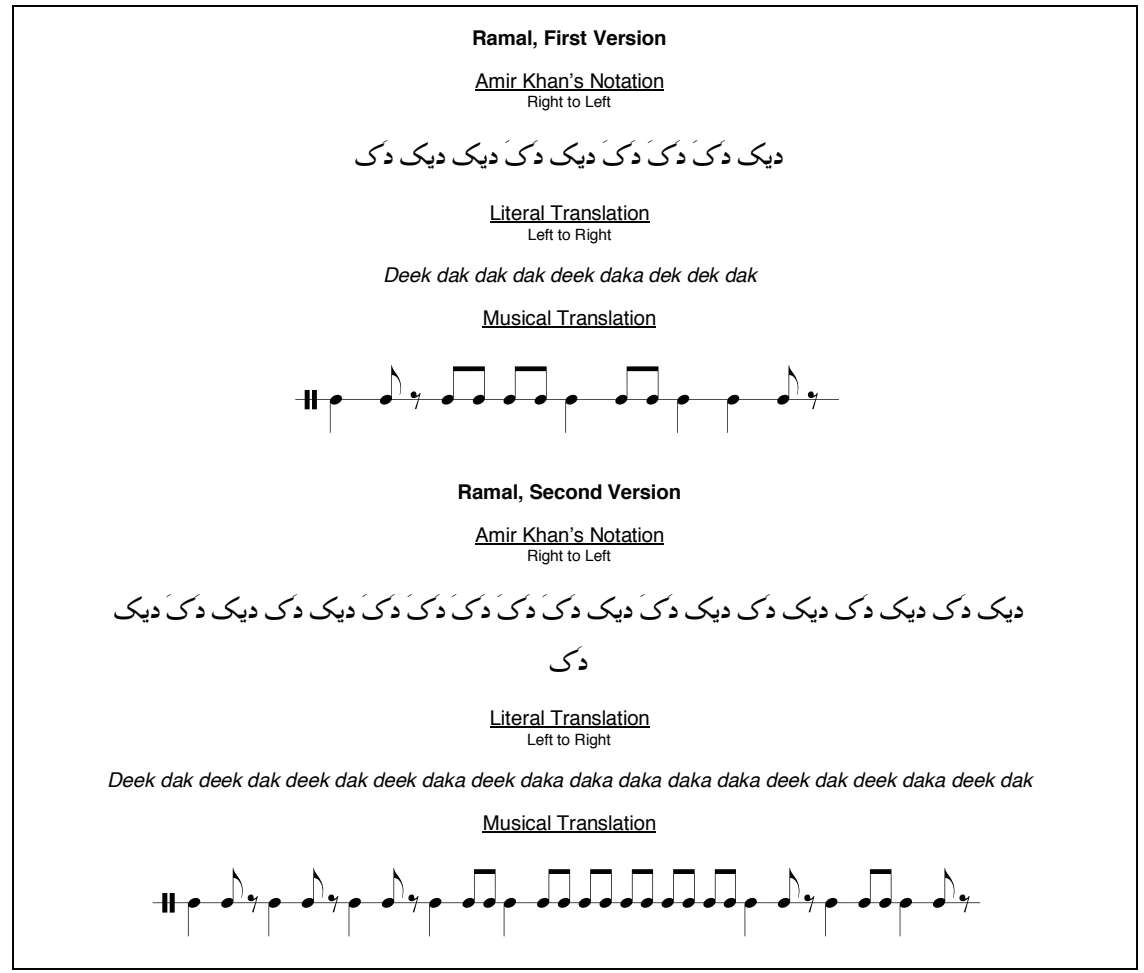

FIGURE 4. Two versions of the Ramal rhythmic cycle according to Amir Khan

within specific set compositional forms. These compositional forms were often the last aspect of music to be described in writings about the twelve-maqam system, even as the forms themselves changed over time.

Compositional forms could be defined by several factors, including their internal organization, whether they were instrumental or vocal, and which usul were typically used. The poetry genre and language being used also distinguished different song types from one another. Structures within compositions were typically stated without definition, though the terminology itself might offer insight into what defined different parts of a composition. The most commonly stated term for a distinct section of melodic development within a composition was khaneh (khäneh), which may or may not be further defined within the description of a particular form. In this way, Maraghi described the compositional form pishraw (pishraw) as an instrumental piece with anywhere from two to fifteen khaneh, or two to fifteen distinct melodic sections. He implied that different khaneh may have melodies built upon different maqam, avaz, and sho beh, while also stating that ramal was one of the typical usul used in the composition of a pishraw. Maraghi stated that if someone added poetry to a melody of a khaneh from a pishraw and performed that song with the original usul of the pishraw, this type of song would be called a hava'i (havāâ).10 
Conversely, he used the term qawl ( $q a w l$ ) to refer to any singing done in Arabic, whether set in musical meter without a specific poem in mind or sung with a known poem with reference to the poem's specific poetic meter. The preeminent suite organization described by Maraghi was the nawbat murattab, which was a suite of songs that began with a qawl, followed by a ghazal (ghazal): a song sung in Persian and organized according to the same rhythmic as the opening qawl. The ghazal would be followed by a taraneh, which was a song that could be sung in either Arabic or Persian, but it had to use poetry organized in quatrains (ruba'i) and use an usul that facilitated the phrasing of quatrains. The nawbat murattab ended with a song form called foru dasht (furu dasht), which Maraghi simply described as a song in Arabic. Unlike the more general term qawl, the foru dasht was a specific type of Arabic song that only appeared at the end of the nawbat murattab and served as a closing section of the entire suite.

Most compositional forms were songs that were partially defined by the language and poetry they used with implications for the rhythmic cycles they could accommodate. Even with rhythm being a primary consideration, they could still also have complex melodic organizations. Thus Maraghi described a song form sung in Persian called 'amal ('amal), which had its own specific progression of sections: first an introductory section he called motla' (motla'), then a middle section he referred to as sawt (sawt) or miyan khaneh (mīyān khāneh), and finally a concluding melodic section he referred to as both tashiyeh (tashīyeh) and baz gasht (bāz gasht). ${ }^{11}$

While there are variations in descriptions of compositional forms within the twelve-maqam system from the fifteenth and sixteenth centuries, their descriptions are relatively consistent until the seventeenth century. References to some compositional forms within the twelve-maqam system disappear in the seventeenth century, including the nawbat murattab. A generally defined pishraw instrumental form remained, while song forms were added and redefined. While Persian writings on the twelve-maqam before the seventeenth century alternated between Arabic and Persian terms for sections of compositions, treatises of the seventeenth-century Safavid Empire employed a fairly standardized Persian terminology. This included references to primary melodic sections (sar khāneh), the middle or secondary melodic section (mīyān khāneh), and final sections that could be alternately referred to as recapitulations or reprises (bar gasht), or codas (zayl). In addition to these defined melodic sections, Safavid song forms using the twelve-maqam system were also defined by whether or not they started with poetry (ash 'är) or "hits" (naqarāt). Sections of hits had no words, and the usul alone defined the music's rhythm without poetry. In sections of hits the voice sang on a system of vocables rather than poetry.12

The placement of sections of hits and sections of poetry in songs was key in defining Safavid compositional forms, even as sar khaneh, miyan khaneh, and bar gasht/zayl were also part of defining form. For instance, a previously general term for any musical composition, kar $(k \bar{a} r)$, became a Safavid term for a specific form that started with a section of hits, followed by poetry and then another section 
of hits. ${ }^{13}$ Yet a kar's actual form contained two sar khaneh, which were then followed by a miyan khaneh that had its own melodic development, which was then followed by a zayl or bar gasht. The term 'amal ('amal) came to denote the same structure of two sar khaneh, miyan khaneh and bar gasht, only it began starting with poetry rather than a section of hits. It appears that both sar khaneh usually began with either a section of hits or poetry in order to define a form as either kar or 'amal. What made the miyan khaneh section different was its completely different melodic development in comparison with the sar khaneh, and its ability to start with either a section of hits or poetry.

Safavid compositional forms presented somewhat different organizations and definitions from forms of the fifteenth century. It gave the form called 'amal a completely different conception, and the term qawl also came to denote a different form. By the seventeenth century, the qawl was no longer denoted an Arabic song, but rather a Persian song that followed the same structure as the kar and 'amal, but did not have the final bar gasht.

Indeed Arabic did not keep its standing as a common language for song after the sixteenth century. In the Safavid Empire, it was replaced by Turkish. Amir Khan described four distinct Turkish song genres, each defined by their use of different types of Turkish poetry. Indeed, though the Ottoman Empire is considered beyond the narrative of Iranian music history, Ottoman courts shared some features of compositional form with music in the Safavid Empire, including a mixture of Turkish and Persian songs, and the instrumental pishraw (peşrev). ${ }^{14}$

The diverse, changing usul and compositional forms that accompanied the twelve-maqam system demonstrate that it had a place in practice that was greatly concerned with both metered melody and set, replicable forms for music composition. Song forms were the most common types of compositional forms, with a variety of musical features defining the distinction between different types of songs. The use of poetry often determined the use of usul, but not always. Yet the dominance of song in the musical practices associated with the twelve-maqam system put much emphasis on the use of language. While Persian was the lingua franca of writing, it was not the sole language of music-making, or of life in the empire. The twelve-maqam system's polyglot song forms reflect the continuing polyglot nature of its primary context in and around various dynastic courts, where the religions, the rulers, and their administration used language other than Persian.

\section{MUSIC OF THE SHAH, SULTAN, AND SUFISM}

Though Safi al-Din wrote from the capital of the Abbasid Caliphate, the Abbasids had already lost much of their imperial dominance by the time he gained their patronage, a situation highlighted by Nishaburi's affiliation with the Ghaznavid court in former Caliphate lands farther east. Music's dependency on royal patronage (like poetry's and philosophy's) had a history that preceded any mention of twelve shadd, pardeh, or maqam. Court music had a basis in the practices of the 
Byzantine and Sasanian Empires, which various Caliphates often adopted as part of their own model of empire as they conquered Byzantine and Sasanian lands. At its height in the tenth century, the 'Abbasids and their constituent aristocracy in Baghdad patronized musicians from all over the growing Islamic world, with the Umayyad Caliphate based in Cordoba fostering a similarly polyglot culture of musical patronage under the umbrella of Islamic rule. Documentation indicates that Persian-speaking people from the former Sasanian Empire were well represented among the servants and entertainers at the Caliphal courts, and they continued to serve similar roles in the post-Caliphate dynastic administrations.

The gradual waning of the Caliphate initially put musicians in service to subsidiaries of the 'Abbasids, who in turn became primary dynastic authorities over smaller aspects of the Caliphate. For instance, al-Farabi had been patronized by the 'Abbasid Caliph al-Riadii (r. 934-940), to whom he dedicated his now famous work on music, Kitāb al-mūsìqā al-kabìr. Yet al-Riadi ultimately became bankrupt and powerless, and the philosopher and musical polymath moved on to a subsequently long tenure in Aleppo with the Hamdanian ruler Sayf al-Dawlah (r. 945-967). The rule of the Hamdan family had been appointed and overseen by the 'Abbasids, but the weakening of the 'Abbasids brought the Hamdanian rulers into their own independent ruling position over their administrative lands, which brought their own independent patronage of music.

The loosening of 'Abbasid control farther east allowed both 'Abbasid subsidiaries and other powers to come to the fore of dynastic rule. Ibn Sina lived most of his relatively short life in the eastern portion of former 'Abbasid territory under the patronage of three different small dynasties: the Samanids (819-999), the Buyids (934-1062), and the Ghaznavids (977-1186). Each of these kingdoms represented different factors influencing the end of 'Abbasid rule in Central Asia. As with the Hamdanian kingdom, the Samanids were a local family ruling as a subsidiary of the 'Abbasids. The Buyids were also indigenous to Central Asia, but 'Abbasid influence had become so weak they were able to overtake the Samanids despite having fewer ties to 'Abbasid rule. The Turkic Ghaznavids then invaded from farther east, one of the first Turkic dynasties to emerge out of invasions and more generalized migration from the east (see map 1). The dynastic landscape of ibn Sina's lifetime was a portrait of what it meant to live on the edge of empire. The empire's borders were porous and ever changing, even as direct dynastic control over large empires was limited.

The slow demise of the 'Abbasids and these specific developments on their easternmost borders formed the basis of a new phase for ruling Islamic dynasties, which would ultimately be dominated by dynastic rulers who were Mongol, Turkic, or some combination of both, with a geography of urban ruling centers in former Sasanian lands. This was the context of the twelve-maqam system's emergence. It came into full common parlance over a vast region where dynastic principalities were coming and going, even as centers of Islamic dynastic power in the region shifted east as Mongol and Turkic invaders moved West. 


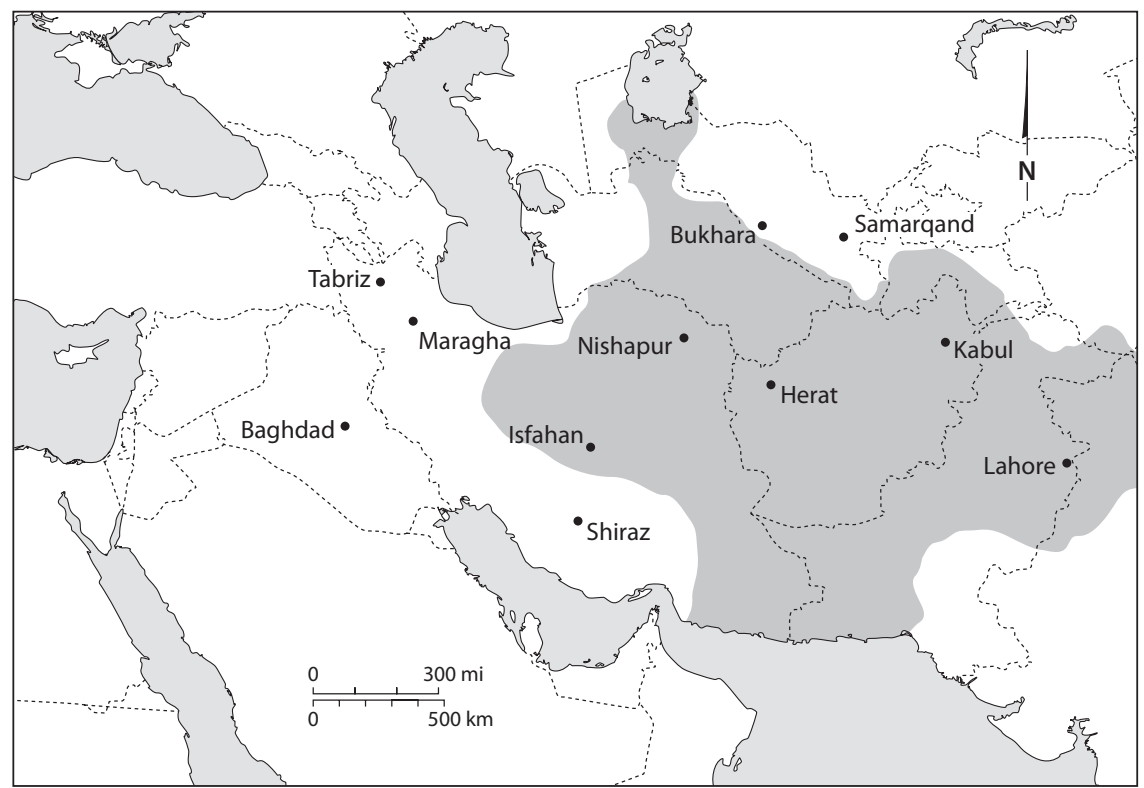

MAP 1. The Ghaznavid Empire at its largest

The new arrivals from East Asia built upon existing dynastic institutions, just as the 'Abbasids had. Yet the Mongol siege of Baghdad signaled a pivotal change. In a world where Islam came to define successful imperial expansion, the Mongol's full contravention of the Caliphate initially presented a seminal intervention in the cosmic order. Conversely, the nomadic invaders' ultimate adoption of Islam, and their appropriation of sedentary dynastic rule and indigenous signification of dynastic hierarchy, opened up a new cycle of cosmic history. With centers of dynastic power established on top of lands that had been part of both the Abbasid and the Sasanian cosmic order, Mongol-Turkic dynasts pulled from multiple indigenous dynastic legacies in order to establish and maintain their legitimacy. Their adoption of Persian as their lingua franca highlighted the layers of indigenous symbolism repurposed to support their rule. As an already established language of dynastic power from Sasanian times, the Persian language emerged in the wake of Mongol and Turkic rule as a lingua franca that had since transformed to embody both dynastic and Islamic power. Imbued with the sacred iconographs of Islam's written Arabic language and extensive Arabic vocabulary, Persian in the wake of the Caliphate embodied both a regional history of cosmic dynastic authority and the religious authority of Islam. For dynastic rulers with no attachment to the specific history of the Caliphate, this represented a strong balance of political and religious legitimization. Kingly epochs, whether about contemporary rulers or legends of rulers past, further legitimated their rule: all stories of kings, 
shahs, and sultans, whether pre-Islamic or contemporary, could legitimate the post-Caliphate dynastic order.

In this context, dynastic rule's relationship with Islam was parasitic. The Turkic and Mongol adoption of indigenous religion served to support their inherent right to rule, even as Islamic authorities could not keep their positions if not for the favor of the newly converted dynasts. Mysticism proved to be a valuable aspect of Islam for invading powers, as more non-Arabic speaking people converted and held political power over communities of Muslims who were not necessarily Arabs. Mysticism and syncretism made Islam more accessible to the converted, even as new dynasts provided support for intellectual Islamic thought. In current narratives of Iranian music history, the seemingly liberal approaches to Islam after the Mongol invasion foster a golden age of Persian culture, as music, literature, and art using the Persian language become expressions of aristocratic culture. Yet this context related to the power of Mongol and Turkic rulers, in addition to the indigenous value of the Persian language. Turkic rulers specifically would continue to dominate ruling West and Central Asia up until the twentieth century, and their ever-changing fortunes and political condition determined the continuity and geographic distribution of the twelve-maqam system.

Though Turkic rulers established some presence in Persian-speaking territory before the Mongols, Chingiz-Khan's extensive invasion of Central and West Asia brought Mongol rulers to the fore. From the twelfth to the sixteenth century, control over the region of the twelve-maqam system would move primarily between the control of Mongol and Turkic rulers. The initial Mongol rulers represented localized subsidiaries of Chingiz-Khan's larger empire, and thus carried the title of ilkhan. The first Ilkhanate moved into Khurasan in 1221, expanding toward Baghdad and into Anatolia (see map 2). While the original Ilkhanate ultimately ended around 1328, other smaller Mongol kingdoms that had emerged around and on top of the Ilkhanate ruled smaller areas from Khurasan to Antaolia until the cusp of the fifteenth century (see map 3).

After Safi al-Din and Nishaburi, some of the first Persian writings about the twelve-maqam system that address it in relation to the earlier Arabic writings of Safi al-Din occurred under Mongol patronage. Musicians themselves continued to move from court to court following court patronage as they had before, yet the growth of Islamic mysticism also opened up the possibility that people engaging in musical expression would travel to different regions following various Sufi sects and pilgrimage practices. In either case, music would still move with some frequency, with the underpinning of dynastic patronage serving as the primary support of the cosmopolitan music culture associated with the twelve-maqam system.

The writers that produced more technical descriptions of the twelve-maqam system after the Mongol invasion initially maintained Mongol court affiliations. Qutb al-Din Shirazi's (1236-1311) discussion of twelve pardeh in relation to Safi al-Din's adwar appeared in his larger encyclopedia of philosophy, Durrat al-tāj. 


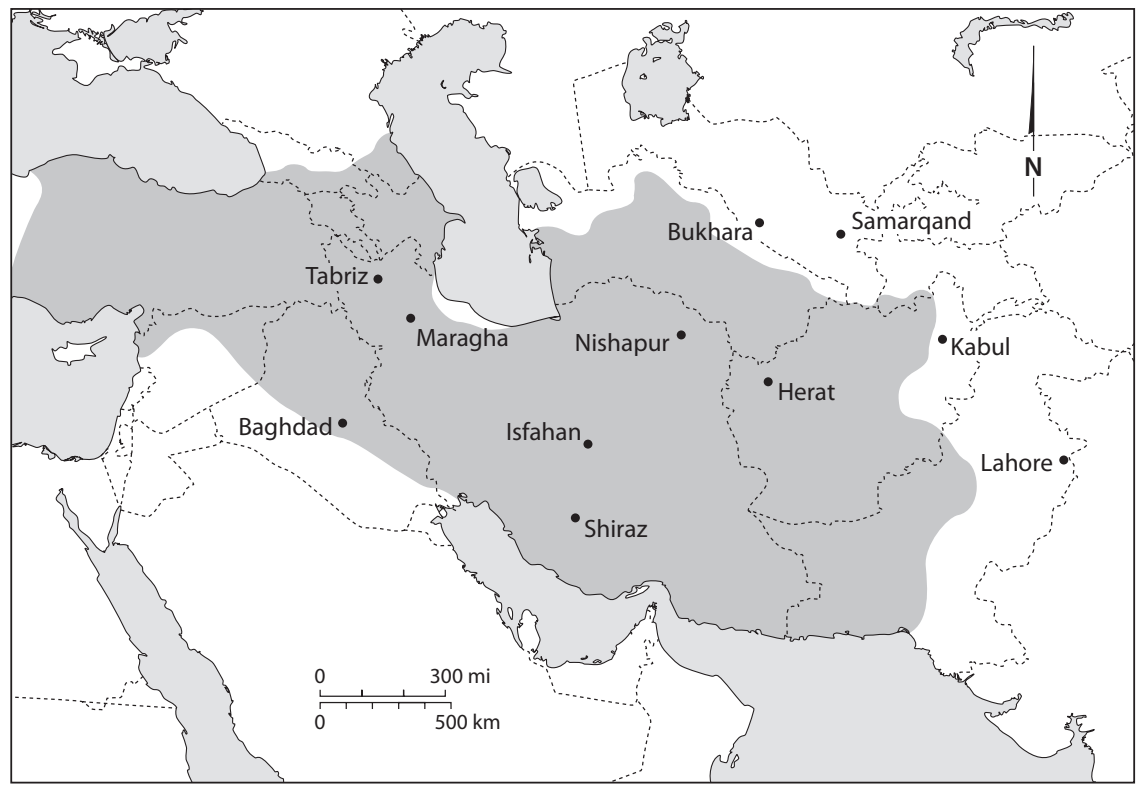

MAP 2. The Ilkhanate at its largest

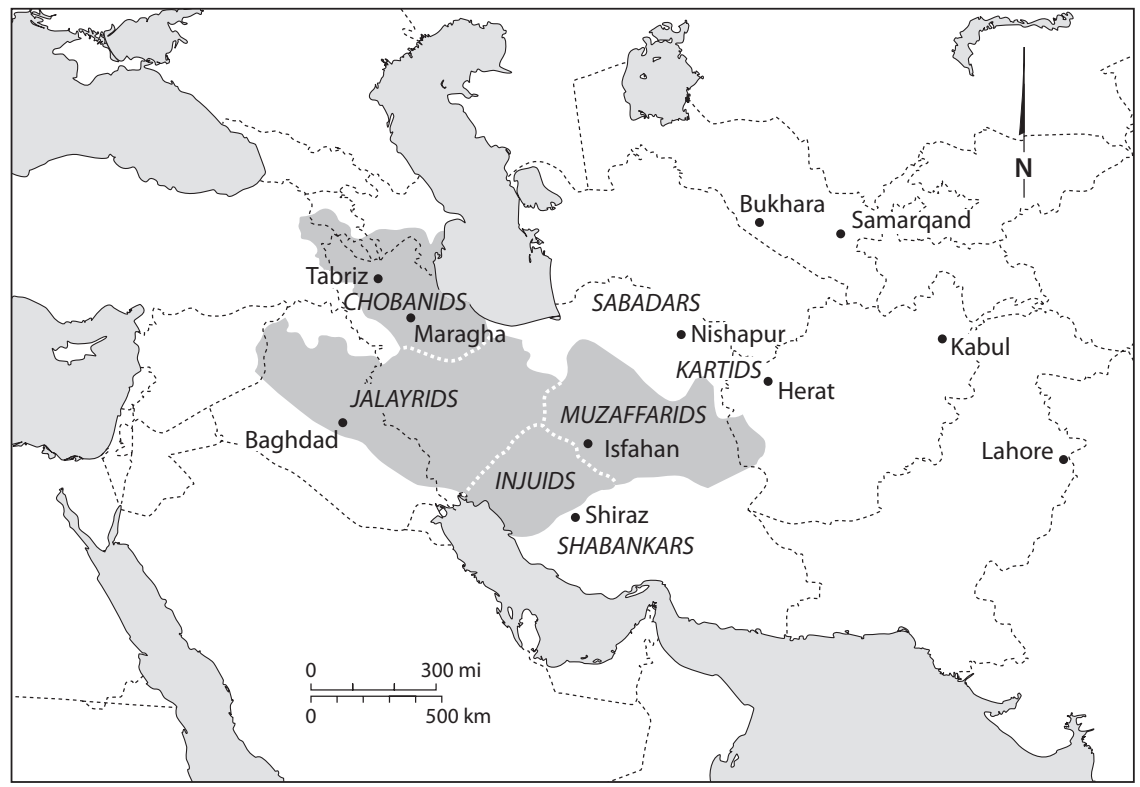

MAP 3. Division of the former Ilkhanate, c. 1345. Shaded areas show areas held by Mongol rulers: the Chobanids, Injuids, Jalayarids, and Muzaffarids 
As a doctor, philosopher, and mystic, this encyclopedia was just one of the major texts Qutb al-Din wrote while acting as a political liaison at various regional courts, most notably an official representative of the Ilkhan ruler Ahmad Nikudar (r. 1281-1284). A lesser-known philosopher, Shams al-Din Muhammad ibn Mahmud al-Amuli, also produced an encyclopedic work that included a section on music and twelve pardeh, the Nafä'is al-funün, under the patronage of another offshoot of the Ilkhanate, the Mongol Injuid Sultanate that controled land southwest of Isfahan (r. 1335-1357).

If the most educated of aristocratic society pondered music from the confines of the court, musical performers who primarily served as entertainers were subject to these confines as well. Perhaps the best-known prolific Persian court musician, 'abd al-Qader Maraghi, moved far and wide to serve both Mongol and Timurid courts. He was a servant under the first Ilkhanate, and then moved into the courts of the Mongol Jalayarid Dynasty when they overtook his initial patrons. Among the Jalayarids he was first patronized by Sultan Husayn I (r. 1374-1382) and then by Sultan Ahmad (r. 1383-1410). With the rise of Timur and the Timurid Empire, Maraghi moved to the Timurid courts to serve Timurid patrons and he died while in service to the Timurids around 1434. In his lifetime he lived and worked in disperate cities, including Baghdad, Shiraz, Samarqand, and Herat.

Maraghi's writings about the twelve-maqam system are dated from his time in Herat, though he would have worked on them much earlier. His most extensive music, titled Jami al-alhān, provided both commentary on Safi al-Din and Qutb al-Din and descriptions of practice from Maraghi's time. Unlike many of the writers before him, Maraghi did not appear to be a polymath or a philosopher. He specialized in music and was a highly valued court musician who who attained high standing in the courts he served. As an educated and literate musician, he read and wrote in both Arabic and Persian. His movement between many different cities and courts demonstrates the amount of movement a highly valued, educated musician could have in one lifetime, as different dynasts came to power and sought musicians for different courts and different seats of power in different capital cities.

The rise of the Timurid Empire initially supplanted many smaller Mongol kingdoms in West and Central Asia with one larger empire controlled by Timur himself and by members of his distinct Turko-Mongol clan. Timur spent the end of the fourteenth century taking control of smaller Mongol territories that had replaced the larger IlKhanate, adding these lands to others he had conquered farther east (see map 4). Under the guise of reestablishing the administrative divisions that had made up the single great empire of Chingiz Khan, Timur maintained Persian as lingua franca in the former Mongol Ilkhanate lands and kept many courtly customs of these Mongol predecessors. Despite his interest in reuniting the Mongol Empire, however, the Timurid Empire struggled to remain united after Timur's death in 1405. Turkmen specifically maintained active campaigns to take lands from Timurid rulers (see map 5). 


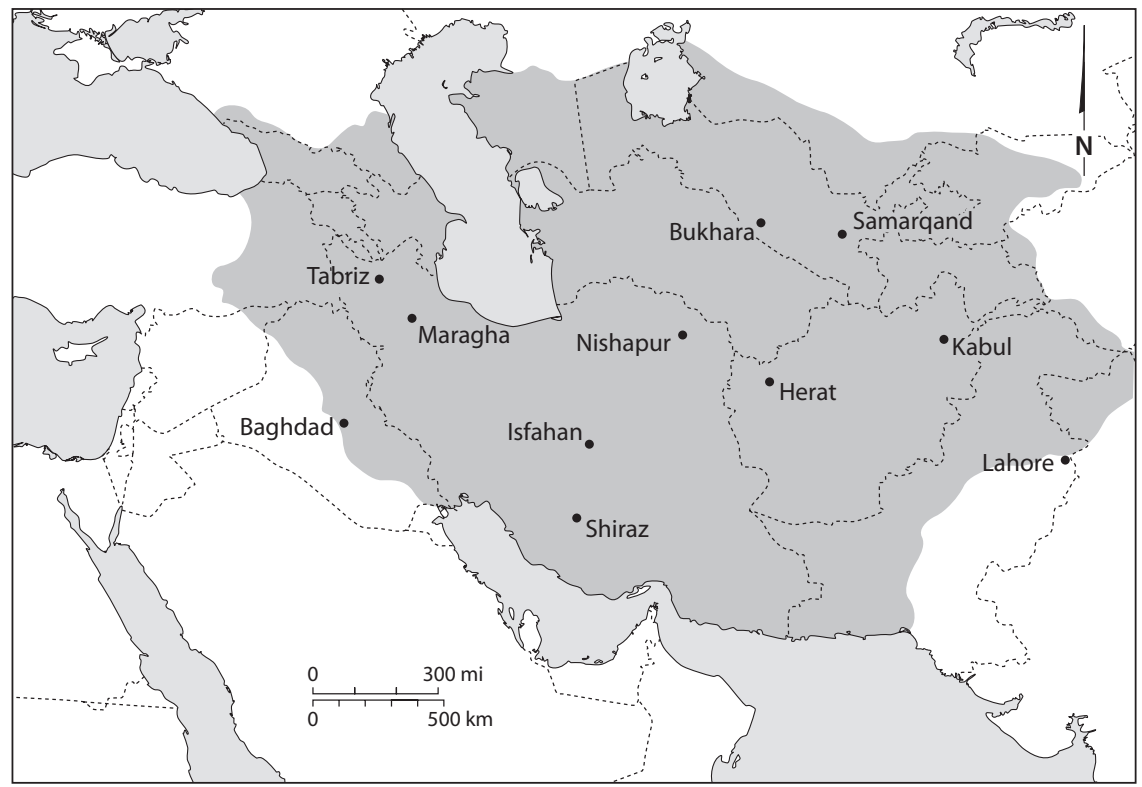

MAP 4 . The Timurid Empire at its largest



MAP 5. The empire of the Qara Qoyunlu Turkomans. Darker shading shows the core areas they held, while the lighter shading shows areas briefly held. 
Discussions of the twelve-maqam system written somewhat later than the lifetime of Maraghi highlight the ongoing movement of musicians between Timurid courts, the courts of their subsidiaries, and dynastic challengers, and some movement related to Sufi pilgramages. For instance, the poet Bana'i produced an extensive treatise on music and the twelve-maqam system in the vein of Maraghi dated 1482. In his lifetime, Bana'i served both in the courts of Timurid rulers and in courts of their subsidiaries, the White Sheep Turkmen (Aq Qoyūnlü). In his court service he moved between Herat, Baghdad, Tabriz, and Qandahar to serve different dynasts at different times. ${ }^{15}$ The poet and Sufi scholar Nur 'abd al-Rahman Jami (1414-1492) was also highly valued at court. In his poetry and mystical writings, there is a short treatise on music in line with Qutb al-Din and Maraghi. Jami studied in Samarqand and also served both Timurid court in Herat and the White Sheep court in Tabriz, while also traveling extensively for Sufi pilgramage. ${ }^{16}$

The rise of the twelve-maqam system in tandem with Mongol-Turkic Empires marked a significant musical change at the moment of significant political change, yet the political change mantained the tradition of music patronage among the dynastic aristocracy, which had previously been modeled under the Caliphate and empires that the Caliphate had displaced. Musicians, musical thought, and the twelve-maqam system itself moved according to the changing fortunes of different dynastic rulers. While these moves could take music and musician across long distances to very different geographical spaces, the cosmopolitian setting of the court provided a similar cultural context for the twelve-maqam system across both space and time.

\section{THE TWELVE-MAQAM SYSTEM IN THE AGE OF GUNPOWDER}

In current narratives of Iranian music, the Timurid era represents the pinnacle of Persian music's golden age, while the end of their rule and the rise of the Safavid Dynasty in the sixteenth century represent a period of musical decline in Persian music's evolutionary development. But the dynastic model of governance did not disappear with the Safavids, nor did the twelve-maqam system. The rise of the Safavids in the sixteenth century coincided with a new era of Muslim empire, where new technologies allowed for more centralized dynastic power throughout West, Central, and South Asia (see map 6). Dubbed the era of gunpowder empires, the Safavids, Ottomans, and Mughals all developed various means of more centralized administration around this time, even as they continued to battle one another in the continued imperial struggle for ever more land and resources. Islam remained the religion of all three empires, with the Safavids recasting themselves as divine figures within their own constructions of Shía Islam.

This new era of Mulsim empire still had court cultures built out of previously established norms of courtly life. Timurid musicians initially moved on 


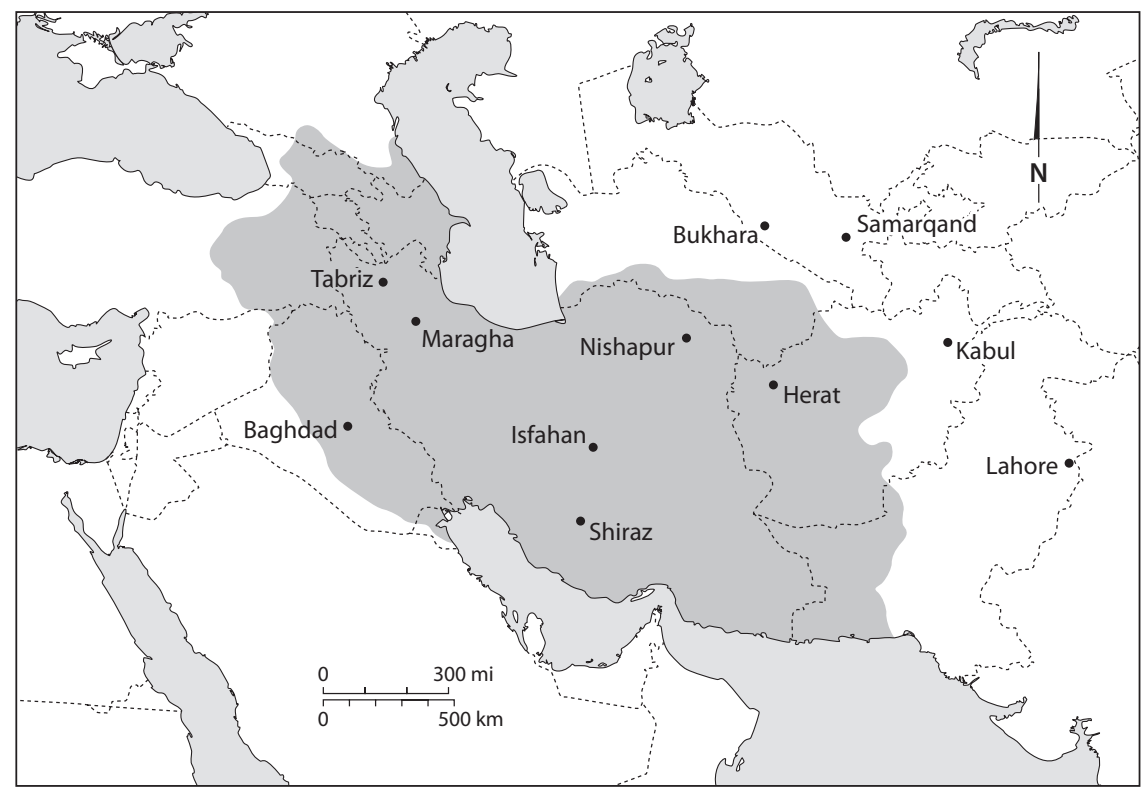

MAP 6. The Safavid Empire at its largest under Shah 'Abbas I (r. c. 1599-1629)

to serve the courts of all three of these dynasties and the twelve-maqam system went with them to all three empires. But the twelve-maqam system and its specific conceptual basis did not remain centrally dominant to music-making in all three empires. The music of Ottoman courts moved toward an open system of modes and the long-form musical structure fasil now synonymous with Ottoman music. ${ }^{17}$ In the Mughal courts writings about music acknowledged and explained the twelve-maqam system's structure as an alternative presentation of the indigienous modal system of South Asia. It was thus only in the Safavid Empire that the twelve-maqam system remained the most dominant concept of music's proper derivation and the relevanncy of the twelve-maqam system ultimately depended on Safavid patronage. This meant that the fall of the Safavids in the early eighteenth century and the subsequent chaos that followed seriously compromised the twelve-maqam system's standing. Ultimately the fall of the Safavids opened up space for additional conceptions of music's organization to gain relevance before consistent music patronage returned under the Qajar dynasty.

The Safavids had ambigous ethnic origins and initially premised their power on the idea they were descendents of the Prophet Muhammad. They came from a syncretic Islamic tradition that combined various aspects of Sufism and Shi'ism, and the first Safavid shah, Shah Isma'il, declared himself to be both the rightful ruling dynast and a unique manifestation of divinity on Earth. The Safavid Empire 
thus developed around a distinct conception of Shi'a Islam that cultivated a unique orthodoxy concerning the merging of divine authority with dynastic authority. This centralization of the two key nexuses of power in the premodern Islamic world had a corollary in the Ottoman Empire, which claimed authority to rule based in part on the idea they descended from the Caliphate.

The movement of Timurid musicians into the Ottoman court resulted in the son of 'abd al-Qader al-Maraghi serving the Ottomans in their first Anatolian capital, modern-day Bursa. He wrote a Persian treatise about the twelve-maqam system, dedicated to the Ottoman Sultan Mehmet II. ${ }^{18}$ Some previous writings about the twelve-maqam system were also reproduced in Ottoman territory, yet none of these specific writings about the system from the past was reproduced in Safavid territory. Beyond initial Timurid transplants, the Ottomans and Safavids directly exchanged musicians in military bargains, and the greater military success of the Ottomans suggests that musicians tended to move from the Safavid Empire to the Ottoman Empire when such exchanges took place. ${ }^{19}$

While the military rivalry between the Ottomans and Safavids created particular circumstances for musicians moving between these two empires, Timurid musicians also joined the Mughal courts, and later some musicians serving Safavid rulers also served patrons of the Mughal aristocracy. Like those of the Ottomans, Mughal writings about the twelve-maqam system include reproductions of some older writing about the twelve-maqam system, including writings of Qutb al-Din and a copy of Hassan Kashani's Persian text from the fourteenth century titled Kanz al-tuhaf, which also described the twelve-maqam system in the context of Safi al-Din's adwar. ${ }^{20}$

The more widespread documenation of musicians moving from Timurid to Mughal territory is the twelve-maqam system itself, which appears in Persian writings from Mughal lands beginning in the seventeenth century and continuing throughout the eighteenth century. Unlike the Ottomans, who eventually developed an Arabic script for Ottoman Turkish and made it their official court language while moving toward an open modal system, the Mughals kept Persian as their court language into the nineteenth century and kept writing about the twelve-maqam system.

Persian writings about music from Mughal territory were not always reproductions of older writings, and original writings describing the twelve-maqam system from South Asia often placed it alongside South Asia's own rag/ragini system. A description of the twelve-maqam system is thus included next to the rag/ ragini system in the encylopedic work Tuhfat al-hind, composed around 1674 by the Mughal nobleman Mirza Khan ibn Fahr al-Din, in the court of the Mughal ruler Aurangzeb Alamgir (r. 1658-1707), for the ruler's son, Muhammad A'zam (1653-1707). A writer named Mazhar Muzaffar also authored a text that described the twelve-maqam system side by side with the rag/ragini system dedicated to the Mughal ruler Shah 'Alam II (1720-1806). ${ }^{21}$ 
The description of the maqam in these texts and others included the gusheh as a fundamental aspect of the system, indicating a similar understanding of the system to that in Safavid lands. This was in part because musicians from other regions continued to move to Mughal courts after the fall of the Timurids, including musicians from Safavid courts. For instance, one author of a section of text about the twelve-maqam system that referenced the gusheh structure was named Nizam al-Din Ahmad Gilan. He can be connected to the Safavid courts of Shah 'Abbas (1577-1628) and Shah Safi (1629-1642), and then to the court of the Mughal ruler 'abd Allah Qutb Shah (1611-1672).

While the movement of musicians continued to be controlled by the fortunes of empire, changes in administration also affected who participated in music-making and the twelve-maqam system. The Safavids pulled their military and administrative support from different populations of polyglot peoples than their Timurid predecessors. Their military support came from their Turkic Qizilbash followers, and they also appointed peoples of the Caucases to positions in their court administration. Thus, one of the last heads of court musicians at the Safavid court, Amir Khan Gorji, wrote a Persian tract about the twelve-maqam system and composed songs in Persian, but his name indicates he was actually Georgian. Additionally, Safavid songs could be set in Persian or Turkish.

Thus it was in the Safavid Empire of the sixteenth and seventeenth centuries that the twelve-maqam system remained central to the conception of music, even as there were amendments to previously established notions of music's structure and changes in the political players and polyglot makeup of courtly life. The modern perception of music's decline under the Safavids relates to several factors, including the apparent loss of collective musical memory and sophistication. Safavid writings about music do not display interest in the detailed considerations of music so important to Farmer's Systematic School, nor do they appear to maintain or even remember anything specific about Safi al-Din's adwar or its extrapolations like those of Qutb al-Din and Maraghi. The most tangible aspects of music's essence, such as sound and consonant intervals, lose their significance in writings from Safavid lands.

Another factor is the extent to which the centralization of empire meant that the Safavids did directly administrate music in ways unthinkable before their rise to power. Different Safavid rulers intervened to regulate or otherwise control court music, military music, and performative practices with musical content, such as shahnameh recitation and particular Shía ceremonies. Though court musicians were always subject to the whims and preferences of their courtly patrons, the Safavids' greater tendency to exert direct control over music suggests that musicians had less agency in their empire.

Yet another factor was the greater ability of the Ottomans and Mughals to support more extensive music patronage, as their courts maintained more continuity of such patronage throughout the eighteenth and the nineteeth centuries. The 


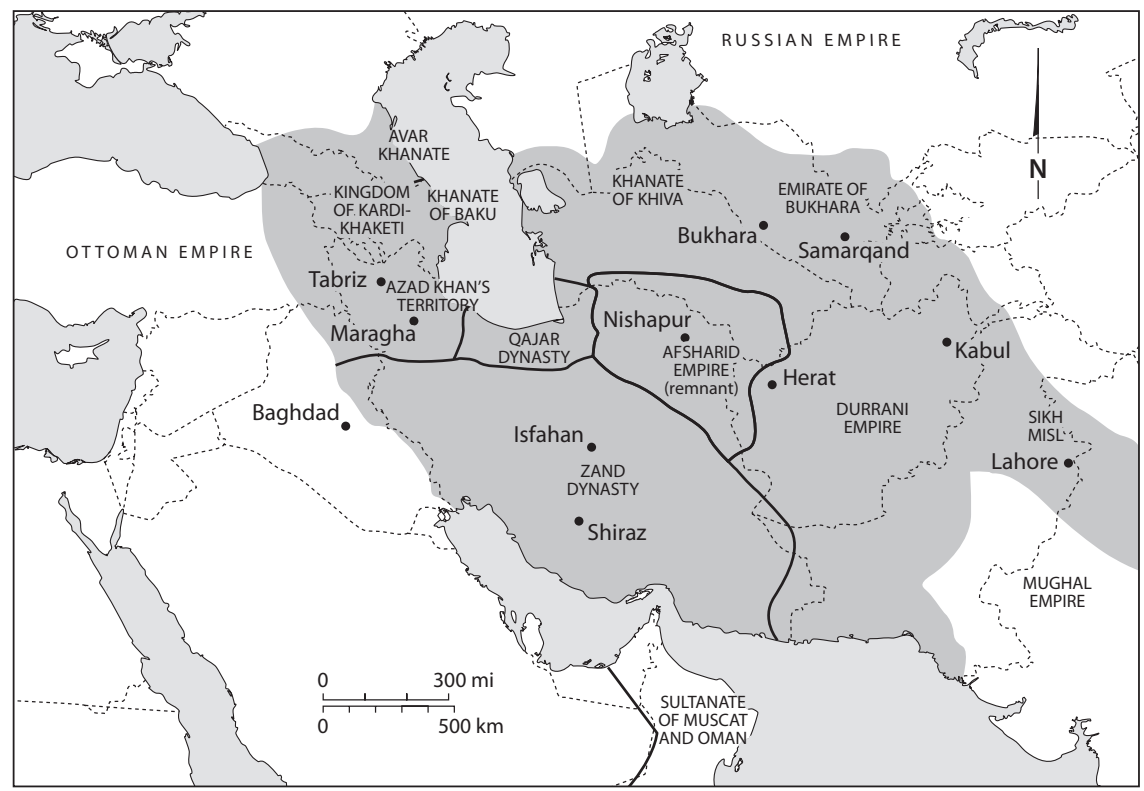

MAP 7. The Afsharids Empire at its largest and after its fall. The majority of lands initially accrued by the Afsharids (shaded) quickly became divided between various regional rulers, with the Zands controlling the largest portion of their former lands, and the Qajars maintaining a small seat of power from which they would eventually build their larger empire.

connection between Safavid music culture and that of its neighbors highlights the Safavid empire's smaller size, shorter tenure, and particularly devastating demise. While the Safavids were always trying to grow their empire and worked to expand as a matter of survival, they ultimately were not able to maintain control of most of the additional territory they gained. Some specific political and economic weaknesses of the Safavids as well as difficult confrontations with the Tsardom of Russia left Safavid rulers weak by the end of the seventeenth century. This allowed for a particularly brutal invasion by Afghan forces in 1722, which began a long period of political instability.

In this sense, the circumstances of Safavid's reign did create the beginning of the end of the twelve-maqam system. The political weakness of the Safavids and the particular circumstances of their fall changed the course of music history. While music patronage continued in Ottoman and Mughal territories straight through the eighteenth century, music patronage faltered in former Safavid lands along with dynastic rule as a whole. Brief apperances of large kingdoms like that of Nader Shah Afshar (r. 1736-1747) appear to have resulted in some music patronage, but the patronage was highly limited and short lived, as only Nader Shah and the Zands held on to significant amongs of land and resources, and then for rather short periods of time (see map 7 ). ${ }^{22}$ 
The history of the twelve-maqam system shows two distinct periods of its existence, followed by a rather sudden fading out of relevancy in the eighteenth century. In its era of dominance both the conception of pitch organization and the procedures for creating music were stable. The logic for establishing pitch modalities was conceved in terms of derivation, and music-making was largely an act of systematic composition in light of usul, language, and compositional forms. Changes and differences in aspects of this system's organization and performance demonstrate the active reality of music connected with dynastic courts. Musicians had to move and the twelve-maqam system had to adapt to changing dynastic contexts. Even during periods of relative stability in the twelve-maqam system's conception and practice, the lives of musicians could be quite unstable. Yet the basic parameters of the system prevailed from the cusp of the Mongol invasion in the thirteenth century until the ultimate decline of the dynastic model of governance beginning in the eighteenth century.

The abrupt fading out of the twelve-maqam system's relevance mirrored the abrupt fading out of dynastic models of governance that had supported it. While the fall of the Safavids fostered a uniquly chaotic situation for dynastic governance during the eighteenth century, the Ottomans and Mughals were also beginning to face new challenges to dynastic rule that would eventually render this model of governance mute. By the time dynastic governance obtained a stronger footing in former Safavid lands at the cusp of the nineteenth century, the entire model of dynastic governance was ending throughout the Middle East and South Asia: neither the twelve-maqam system nor the dynastic model of governance would survive the nineteenth century.

It was the circumstances of Islamic empire in the shadow of the Caliphate that formed the context of the twelve-maqam system, which stood as the optimum representation of all musical thought and practice until the eighteenth century, when both the twelve-maqam system and the dynastic model of governance quickly lost relevance. Throughout its tenure, the twelve-maqam system did not belong to one langauage group or an ethnolinguistic culture seperable from court life. Instead, it depended on the universal applicability of both dynastic heirarchy and Islam. It depended on sacred languages in polyglot contexts, and such cosmopolitian contexts were part of the structure of premodern empires in the Middle East and Central Asia. This cosmopolitan reality of dynastic life required distinct approaches to musical thought and expression and the twelve-maqam system represented both the specific requirements of this culture and the unique contingencies of its history. 


\section{Musical Structure}

\section{Cosmology and the Universal Order, c. 1100-1800}

By far the most significant idea that the twelve-maqam system carried from the time of the Caliphate to the cusp of the modern era was the idea that music's correct conception and execution had an absolute relationship with the natural order and human existence. In writings that discuss the twelve-maqam system, this initial conception of music was often expressed at the beginning, as it was in earlier musical writings of the Caliphate. To introduce a detailed explanation of the twelve-maqam system, authors generally asserted in one way or another that music was 'ilm ('ilm, 'ülum, pl.), riyazi (riyāzī), fann (fann), or sina'at (șinā'at). In the nineteenth century, modern Orientalists in Europe, and even modern scientists, took such assertions in premodern Arabic and Persian writings about music to be a validation of the modern distinction between art and science as part of the natural order. Many writings about the twelve-maqam system could be read as discussing protomodern conceptions of music by taking 'ilm and riyazi to denote science and math, and distinguishing these from art, expressed as fann, or sina'at. Even as ancient Greece came to stand as the inevitably antecedent to Europe's modern existence, Greek influence on premodern Middle Eastern conceptions of music held similar modern connotations beginning in the nineteenth century. Discussions of music in Persian or Arabic that applied term 'ilm stood as equivalent to Europe's medieval category of musica speculativa: purely speculative discussion of music in theory, not the reality of musical practice. ${ }^{1}$ Indeed, Farmer's analytical distinction between the Graeco-Arabic writings on music and his so-called Systematic School was the extent to which ancient Greek influence on musical thought resulted in either a purely aspirational "science-ing" about music, or a systematic conception of music that was executable in practice. Descriptions 
of the twelve-maqam system marked the beginning of music's full realization as a balance between science and art, theory and practice.

These bifurcated concepts, however, were not the basis of the terminology in use surrounding the twelve-maqam system. Like the Latin word scientia, 'ilm was

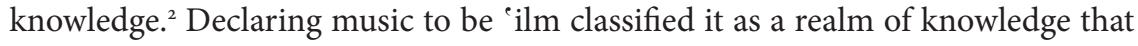
one could come to understand and use according to objective, predictable parameters. It did not, however, delineate music as purely theoretical or distinct from the practice of human musical expression. The reason for expounding on music as knowledge was to indicate its ideal parameters in human expression. Music as a realm of knowledge followed from the observation that sound itself had set parameters of expression. Sound could only be produced via the collision of two bodies in air. If sound had such rules of production in nature, so too did music. Such laws of nature were not a theoretical imposition: they were as inherent in the nature of music as they were to the nature of sound. Understandings of the twelvemaqam system thus proceeded from the idea that musical knowledge needed to be investigated and documented for the purposes discovering the natural parameters of music. These natural parameters determined the proper use of music within humanity as a whole.

The further application of the term riyazi to music related to the active nature of music as knowledge. The Persian word for math was taken from the Arabic term for math (riyāẹiyāt). The root of this word $(r-\bar{u}-\underline{d})$ related closely to systematic training both conceptual and physical: math but also exercise and sport. The Arabic equivalent to the Persian word riyazi could actually mean either a mathematician or an athlete. Qutb al-Din Shirazi presented an approach to analysis that demonstrates the complexity of how music as knowledge related to the realities of active music-making. Qutb al-Din acknowledged a difference between a knowledge-based method of establishing consonant pitches ( ${ }^{\mathrm{i}} \mathrm{ilm} \overline{\mathrm{i}}$ ) and a theorybased method (nazarī). In Qutb al-Din's schema, the approach based on knowledge "extracts the intervals from an instrument according to the confines of the strings and can be explained easily with an instrument in hand." By contrast, his theoretical approach consisted of working out intervals using pure mathematical calculation of intervals. ${ }^{3}$ In the music section of the Nafä'is al-fanūn, Amuli similarly associated the working out of musical intervals on stringed instruments with

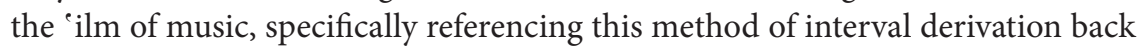
to Safi al-Din. ${ }^{4}$

In Qutb al-Din's conception, the knowledge-based approach to choosing consonant pitches was not a purely theoretical one: it was determined by the confines of a musical instrument and had its basis in what could actually be done in the course of practice. Nor was the act of computating consonant musical intervals as abstract ratios strictly defined as a question of 'ilm, specifically because the knowledge of music related to what could be physically done in practice. The distinction 
designated by Maraghi indicated a somewhat different concept of two dependent approaches to music. In addition to music as 'ilm, he described music as 'amal ('amal), which is typically translated as practice. While he describes musical knowledge as separate from musical practice, he nevertheless emphasized a dependent relationship between these two concepts. Maraghi did not write about only one or the other. He had to write about both together because proper musical practice derived from correct musical knowledge, and correct musical knowledge was expressed in musical practice. From this perspective one could not understand the twelve-maqam system or use it properly without first considering the parameters of musical knowledge, and then practicing music in light of that knowledge.

To this end, treating music as fann or sina at related to music's skillful practice. Writing about music some time between 1341 and 1363, Hassan Kashani described the sina at of music as

The most noble of the sina' at because most types of knowledge ('ulüm) are dependent on it, such as algebra and geometry and astronomy and the 'ilm of medicine and calculation .... and the sina at of music is based on the ratios and the calculation of intervals and cycles; hence it is the most noble of the sina at because the stuff of the [other] sina at and practices are from the objects of nature and their subjects are physical structures, except music, whose subject is spiritual essence; and it affects the souls (nüfuss) of the listeners [and] the emotion of the affect of the listener derives from its spiritual influence. ${ }^{5}$

Kashani's statement connected the notion of 'ilm to that of 'amal via the notion of sina at. Understanding knowledge of music meant being able to practice it in skillful ways that systematically engaged the human body and the cosmos. It did not require any visible existence, yet it still had set parameters in nature. By continuing to view music as a realm of knowledge, discussions of the twelve-maqam system described this particular music system as functional vis-à-vis the natural world and the cosmos. This meant that making music had correct universal methods that were both discoverable and desirable.

The writings of both Kashani and Qutb al-Din highlight a key goal of understanding musical knowledge and applying it correctly in practice: to affect the human soul (nafs) and emotions in specific ways. Rather than simply affecting emotion in an audience, musical performance under the twelve-maqam system continued the conception of music as a practice capable of physically altering audiences via music's systematic ability to create change in humanity's mentality. This formed the basis of a legend demonstrating al-Farabi's musical ability that stayed in circulation in texts about the twelve-maqam system. First he played a melody for his audience and made them spontaneously laugh, followed immediately by another melody that spontaneously made them cry, followed immediately followed by another melody that spontaneously put them to sleep so he could leave. This story expressed the one-to-one relationship between properly executed musical knowledge and the audience's emotional and physical response. 
The basic notion that music's fundamental structures had a direct relationship with human physicality, emotionality, and spirituality carried over from the Graeco-Arabic tradition into writings about the twelve-maqam system. An idea that twelve-maqam authors expressed repeatedly was the notion that certain maqam, avaz, and sho'beh should be played to invoke specific types of emotions in different types of people. Hence Safi al-Din states:

Know that every shadd has an affect in the soul (nafs), pleasing but different. Some have the affect of strength and bravery and expansion and those are 'Oshshaq ('oshshāq) and Busalik (bīsalīk), and Nava (navā); and that is why they are pleasing to the Turks and the Abyssinians (habasheh) and the Ethiopians (zanj) who reside in the mountains. However, Rast (rāst) and Nawruz (nawrūz) and 'Iraq ('irāq) and Isfahan (işfahān) have a cheering and pleasant affect, while Bozorg (bozorg) and Rahavi (rahāvī) and Zirafkand (zīrāfkand) and Zanguleh (zankūlah) and Husayni (hūsaynī) have the affect of a type of sorrow and angst. ${ }^{6}$

Though Safi al-Din stated that different aspects of the twelve-maqam system were likely to affect different language groups in different ways, he referenced the notion that these different groups had different inherent personality traits to which the music related. This conception had its basis in humeral theory. Thus in an eleventh-century text, Qābūs-nāmeh, the author ibn Qabus (1021-1099) provided the following advise for musicians:

When you are seated in a gathering, look about you. If the audience comprises men
with a ruddy and sanguine complexion, play mostly on the second string ( $(\bar{u} r \bar{u} d$ );
if they are yellow-faced and choleric, play mainly on the lower strings ( $z \bar{i} r)$; if they
are dark-skinned, lean, and melancholic, play on the third string (setār); if they are
pale-faced, obese with a clammy complexion, play mostly on the bass string (bam);
these strings (rüd) have been invented to suit the four different human tempera-
ments; and those knowledgeable of the 'ilm music made this sina at based on these
four temperaments.

Both of these sets of instructions tie the needs of musical performance to the tendencies of physical traits, which further related to emotional tendencies. Writings about the twelve-maqam system give many variations on this theme of music's ability to systematically manipulate the whole of humanity's physical, emotional, and spiritual experiences in systematic ways. For instance in the Jāmie al- $u l u \bar{m}$ by Fakhr al-Din Muhammad 'Umar Razi (1149-1210) the author explained that

The melody that is happy and ecstatic occurs when the low pitch goes to the high pitch so that the soul (nafs) goes from the descent of sadness to the assent of ecstasy (tarab) and joy. And the melodies that are appropriate for sadness and wailing are those where one hears low pitches after high pitches ... so that the soul goes from the height of happiness to the descent of sadness. ${ }^{8}$

In another variation, 'abd al-Rahman Sayf Ghaznavi attributed different healing powers to different maqam: 
He [Plato] says that the virtues of singing the maqam of Bozorg and its melodies are this: that it heals intestinal pain and it is beneficial for colic. Hearing it clarifies the mind. The maqam's affects are from the house of Leo with the sho'beh of Homayun (homāyun) and Nahoft (nahoft) ... and he says the maqam of Rahavi is beneficial in regard to the illness of convulsions and paralysis and trembling and back pain, its effects are from the house of Pisces and known with the sho'beh of Nawruz-i Arab (nawrūz-i ${ }^{\circ}$ arab) and the sho'beh of Nawruz-i 'Ajam (nawrüz-i ${ }^{\circ}$ ajam). ${ }^{\circ}$

The status of people in society also had a relationship with the natural order, which meant that the twelve-maqam system could also be systematically invoked to affect different classes of people:

For the great kings, they sing in the maqam of Hijaz (hijāz) and Segah (segāh), Nawruz-i Ajam and ... and Rahavi and Husayni and Dogah (dogāh) and Mohayyer (mohayyer) [and] they enjoy it; and for the solitude the ascetic it would be nice if they sing in the maqam of Rahavi; and in front of the students if they sing in the maqam of 'Iraq and Nishaburak (nìshābūrak) and Maghlub (maghlūb) they gain much zeal and enthusiasm. ${ }^{10}$

In all of these ways, the twelve-maqam system could manipulate the nature of the human condition to invoke certain physical and emotional responses in a perfunctory manner. The fixed nature of both music and the human condition allowed anyone to infer how a modality would affect any given person based on the known emotional affects of modalities and the known attributes manifest in a person's characteristics. This was the universal power of musical knowledge in the context of practice.

Safi al-Din's statement about mountain-dwellers indicates that physical differences between peoples indicated larger differences in personality, yet both physical and emotional differences between people could be related back to the different physical environments in which they resided. The original humeral theory associated the different humors of the body with different elements of the Earth, and such associations could be extended to music. Different maqam could be matched to different humors and elements, or different strings on a stringed instrument could have these associations. The association between different maqam, avaz, and sho'beh and different climates more broadly came from the systematic relationship between music and the movement of celestial bodies, which had implications for climate on Earth:

In the season of fall when the sun is in the house of Libra, Scorpio, and Sagittarius one must sing several melodies that are appropriate to their nature of dirt and cold and dryness: like 'Oshshaq and Chahargah (chahārgāh) and Busalik and Bozorg and Kuchak (küchak) and Nayriz (nayriz) and Homayun and 'Ozzal ('ozaāl) and Husayni. ${ }^{11}$

These types of discussions about how music should be performed in the context of the twelve-maqam system in order to be most impactful on an audience highlight the interconnectedness of musical knowledge with other types of knowl- 
edge. Writings about the twelve-maqam system address the question of how music would affect a listener in very specific, physical ways. Hence the twelve-maqam system's veracity and relevancy derived from its ability to systematically interact with known aspects of natural existence. Developing musical knowledge facilitated this systematic interaction, which stood as the ideal of musical performance in the twelve-maqam system.

\section{THE UNIVERSALITY OF THE \\ TWELVE-MAQAM SYSTEM}

The understanding of the twelve-maqam system as a core manifestation of correct musical knowledge made it a universally applicable music system for humanity and the known natural world. Demonstrations of its universality come in descriptions of the systematic ways it can affect humanity in practice, but also in its systematic relationship with peoples both within and beyond its known geographic range. Writings about the twelve-maqam system often associated different maqam, avaz, and sho'beh with both different types of people from different physical environs and different humanly organized geographies. Writing in 1666, the author 'Inayatallah bin Mir Haj al-Herawi described the following scenario:

In 'Arabistan sing in the maqam of Rahavi and Zanguleh and Chahargah and 'Ozzal; and in the kingdom of Khorasan sing in the maqam of Rast and Panjgah (panjgāh) and Hijaz and Segah; and in the kingdom of Transoxiana (mavarä' al-nahr) sing in the maqam of Husayni and Dogah (dogāh) and Mohayyer and Kuchak and Bayati (bayāti $)$, and they will like it and the residents of that region have happiness and enthusiasm; in the kingdom of 'Iraq sing in the maqam of Isfahan, Nayriz (nayriz), and Nishaburak and Mahur (māhür) and they will like it; and in the area of the Roman Empire (Rüm) sing in maqam Nava and 'Oshshaq and they will like it; and in the region of India (Hindūstān) sing in the maqam of Busalik and Bozorg and Saba $(s a b \bar{a})$ and Chahargah and 'Ozzal and they will like it and the residents of that area would be delighted. ${ }^{12}$

These types of different geographical associations for different aspects of the twelve-maqam were common in descriptions of its structure and significance, both within and somewhat beyond its known geographical distribution. One anonymous seventeenth-century stated that "The instrumentalist, the reciter (qawwäl), and the singer ... must be of many essences so that his singing is like a flower in Turkish and Persian and Arabic and Hindi and other languages like these." It also described music as "the twelve pardeh and six sho'beh; and every melody that exists from Arabic, Persian, Turkish, Roman, Armenian, Hindi, and others is not outside of these twelve pardeh."13 Another seventeenth-century perspective took this notion one step further, doling out different maqam to the entire world, using the seven regions of the globe associated with Ibn Khaldun's geography of the world. ${ }^{14}$ 
In the minds of those who knew of it, the twelve-maqam system was an applicable music system for all known humanity. The universal applicability of its musical knowledge was only further demonstrated by contact with different methods of music-making from beyond its realm. With the rise of the twelvemaqam system coming at the cusp of Mongol rule, musical instruments from East Asia initially had a place in the twelve-maqam system's performance practice. Two surviving texts from the Ilkhante, one titled "The Chinese Instrument of Bowls" ("Sāz-i qaț āt-i chīn̄̄") and the other titled "Instrument of Bars They Make from Metal" ("Sāz-i alvāh ke az pūlād sāzand”), described East Asian metalophones and their use in the context of both the twelve-maqam system and Safi al-Din's conception of consonant pitches. ${ }^{15}$ The text described the tuning of the instruments according to Safi al-Din's seventeen-note gamut and stated which aspects of the twelve-maqam system each instrument could produce. According to the author, the Chinese segmented instrument consisted of a series of gongs that were tuned to produce Hijaz, Nahoft, Husayni, and Mohayyer. The text about the instrument of metal bars stated that the first row of bars on the instrument was tuned to Rast and that the instrument could also produce Dogah, Mohayyer, and Gardanieh (gārdāniyeh).

In the Jāmie al-alhān, Maraghi described many instruments he observed used at court, and some were stringed instruments that, like the instruments of metal bowls and slats, were associated with the ruling class originating in northeast Asia. Despite their distant origins, Maraghi still described what aspects of the twelvemaqam system such instruments could produce. These included a stringed instrument called the shudraghī, which could play 'Oshshaq, Nava, and Busalik, and another called yātūghān, which could extract all of the maqam, avaz, and sho ${ }^{\circ}$ beh. ${ }^{16}$

The twelve-maqam systems' encounters with instruments coming from other cultural contexts did not weaken perceptions of the system's universal premise. Even encounters with wholly different concepts of musical structures did not necessarily call the universality of the twelve-maqam system into question. Encounters with other concepts of musical structure were most extensive in the Mughal Empire, where descriptions of the twelve-maqam system came alongside descriptions of the gendered rag/ragini system of South Asia. Mughal Persian writings about the twelve-maqam system typically indicated that the rag/ragini system was indigenous to South Asia (Hind). Conversely, they often identified the twelve-maqam system as coming from a different place, northwest of Hind variously referred to as Iran, Turan, and Fars. While these three locations were all somewhat different, such terminology accounted for the twelve-maqam system's geographic origins relative to the Mughal Empire, among the Timurid domains of the Mughal's dynastic antecedents. It further referenced the twelve-maqam system's association with dynastic legitimization, referencing three ancient kingdoms ruled by legendary dynasts whose legends continued to legitimate dynastic authority. 
Though they acknowledge musical difference associated with geographic difference, Mughal writings about the twelve-maqam system ultimately determine that the differences between the twelve-maqam system and the rag/ragini system are not that significant. These two systems are merely two different manifestations of music's shared universal principles. One reason to describe these two systems side by side was to demonstrate their structural similarities despite their different geographic origins. Mughal writings disagree on the specifics of these similarities. It is most common for these writings to consider the maqam equivalent to rag, and the sho ${ }^{\circ}$ beh or the gusheh equivalent to ragini. ${ }^{17}$ Most Mughal writings have specific sections dedicated to explaining the two systems' similarities and all ultimately engaged in the same discourses of music's basis in universal knowledge. Indeed, the one Mughal author that did not note any specific equivalencies, Baqiya Na'ini (c. 1594-1640), used the introduction to his text to expound on the unity of voice between these two musics as a reality of metaphysical truth, with no need for specific explanation of musical similarity. ${ }^{18}$

While the twelve-maqam system could be largely interpreted as a manifestation of universal knowledge on the edges of its central area of usage, it did experience some direct challenge to its authority in its primary regional context. In 1273 an astronomer, ibn al-Munajjim, challenged Safi al-Din's assertions about twelve shadd in his polymath work Ashjär va as mār. In discussing music, the author praised the work of Safi al-Din, but then went on to describe a different music system that encompassed only seven primary modes, each of which he associated with one derivative mode for a total of fourteen modes.

The author referred to all of the modes as pardeh and he used names like Rast, Isfahan, Busalk, 'Oshshaq, 'Iraq, and others associated with the twelve-maqam system to name his fourteen modes. The author did not elaborate on the system enough to know what implications its differences could have for creating music, yet the fundamental logic of its structure related closely to that which legitimated the twelve-maqam system. As an astronomer, the author focused on the number seven as a significant number in the cosmos, referencing the seven known heavenly bodies: the sun, the moon, Mercury, Venus, Mars, Jupiter, and Saturn. Indeed, ibn al-Munajjim associated each of his primary pardeh and its derivative with one of these planets. ${ }^{19}$ This logic indicates that ibn al-Munajjim operated within the same principles that legitimated the twelve-maqam system. Music still had a knowable set order based on the broader natural order. Ibn al-Munajjim presented an alternative model for what the order could be, based on different priorities of knowledge.

Ibn al-Munajjim's unique idea about music's structure mirrored the more common associations of the twelve-maqam system with various aspects of the natural order, including the seven planets. Other texts also designated only seven maqam as the original modes from which four others were derived, and the seven planets are occasionally cited as the source of these original seven maqam. ${ }^{20}$ Attributing 
specific maqam to the seven regions of the world was derived from the differing astral location of the seven planets over each region. Writings that address reasons for the final number of twelve maqam often tied it to the twelve houses of the zodiac and authors frequently associated each of the twelve maqam with a specific house of the zodiac. ${ }^{21}$

Such connections between the twelve maqam and heavenly bodies extended out into other aspects of the natural order. In keeping with the movement of heavenly bodies across the sky, music treatises routinely recommended that certain modalities of the twelve-maqam system be played at specific times of the day and night. They also associated different maqam, avaz, and sho ${ }^{\circ}$ beh with specific seasons of the year and days of the week. ${ }^{22}$ Starting in the sixteenth century, treatise authors extended these types of associations between the twelve maqam and the natural order and began to associate specific avaz, maqam, and sho beh with the vocalizations of various different wild animals. ${ }^{23}$

\section{THE KEEPERS OF MUSICAL KNOWLEDGE: WISDOM AND THE WRITTEN WORD}

The conception of music as a fundamental reality derived from the broader realities of the cosmos placed musical norms outside the realm of custom or reflexive preference. Writings about the twelve-maqam system were not about a localized, human musical creation. Instead, music resulted from a discovery of natural musical phenomena, at once external to but affective on the human condition. When music was manifest in its correct and natural form, it worked in tandem with the human condition and the universe at large, with the latter being an aspect of the former. For many centuries, the twelve-maqam system represented the most correct music system according to these considerations. It did not, however, have to be the only musical answer to these broader questions of how the cosmos worked. Beyond the alignments the twelve-maqam system embodied vis-à-vis the cosmos, it required additional legitimation within humanity's ongoing pursuit of knowledge.

This additional legitimation came from people categorized as keepers of wisdom. Texts about the twelve-maqam system consistently cite wise men of the past to legitimate both the twelve-maqam system itself and the musical concepts discussed in its wake. Sometimes these luminaries were cited collectively as the wise ones (hukamä), or the ancient ones (qudamä). Other times authors cited specific people from the past whom they considered wise and knowledgeable. This practice of looking to affirmed people of past wisdom for answers about music predated the twelve-maqam system. Initially, relied on the reputation of such names as Aristotle, Pythagoras, Plato, and Euclid to begin thinking about music as something that had a known natural order. The twelve-maqam system embodied a continuation of this cultivation of musical knowledge based on the previous work of wise men. 
Some wise men cited in Persian music treatises about the twelve-maqam system were still ancient Greek philosophers, while others were the authors of GraecoArabic writings about music that predated the twelve-maqam system. Safi al-Din and Maraghi were also added to the pantheon of the wise. Some of these ancients did not have specific texts associated with their names, and even when they had specific written ideas to be referenced, legend could dominate documented ideas regarding their contributions. In some cases, the wise have no specific connection to music: having standing in any area of knowledge could indicate the ability to contribute to proper understanding of music.

This wisdom of ancients could be spoken of in terms of specifics or generalities. The more ancient the wisdom, the vaguer assertions became about their contribution to music. The group of authors Farmer associated with his Systematic School, for instance, were mostly in a direct line of wise commentary. Safi al-Din's ideas about music were premised on ideas forwarded by al-Farabi and ibn Sina. Qutb al-Din Shirazi directly referenced ideas forwarded by Safi al-Din, while also referencing al-Farabi, ibn Sina, and Euclid. Maraghi directly referenced Safi al-Din, while also discussing ideas forwarded by al-Farabi and ibn Sina. Bana'i, writing somewhat later, in the early sixteenth century, directly cited the writings of Safi al-Din and Maraghi. In this scenario, engaging in direct and specific commentary on past wisdom legitimated each discussion of music. ${ }^{24}$

In addition to specifically citing texts written by past authorities, music treatise authors also cited stories and legends about various wise men's great musical works. Hence, while some authors cite al-Farabi as an authority based on his texts, others recount the tale of his performance at court that made people laugh, cry, and fall asleep, which does not appear in any of his known writings. Such legends were common, more so than commentary on previously established musical discourse. One of the most common explanations of the origins of the twelve-maqam system retold a legend about Pythagoras from ancient Greece, recasting it in relation to the twelve maqam:

One night a person appeared before Pythagoras in a dream and said, "Tomorrow go to the bazaar of the blacksmith in order to discover a secret from all the secrets of wisdom." He woke up; it was early morning. He arose and went in the direction [of the bazaar of the blacksmith] and he was in that bazaar thinking about discovering the secret, when he heard a sound from the collision of two heavy bodies that sounded an interval together that was appropriate and caused pleasure. He went to a corner and put a hair in his mouth and plucked it with his nail and a sound came out from there, but it was weak so he substituted silk for it and was thinking of how to create an instrument that had silk strings tied to it. One day, passing by a mountain, he came across a [dead] turtle. Its flesh was decayed; the skin was in the shell. Because the wind passed through its holes a sound came out from there. He took it up and built the lute (barbat ). ... Know that the original maqam were twelve ... [and] they have said that Pythagoras produced seven of them. ${ }^{25}$ 
The story of Pythagoras inventing music and musical instruments based on the consonant pounding of metal in a blacksmith shop entered discussions of the twelve-maqam system from the earlier Graeco-Arabic writings on music that directly referenced ancient Greek writings on music. ${ }^{26}$ Variations on this story were the most common creation stories for music found in texts that discuss the twelvemaqam system. Pythagoras's discovery of music itself and the twelve maqam are one and the same in this story: the wise man discovered the natural phenomena of music, which meant he discovered the basis of the twelve-maqam system. Beginning around the sixteenth century, descriptions of Hebrew prophets discovering music via the twelve maqam also became common. In another version of music's discovery, each of the twelve maqam was discovered by a different prophet as part of the story of their prophecy. ${ }^{27}$ A more common story specifically tied the discovery of music and the maqam to the life and prophecy of Moses, whose name $(M \bar{u} s \bar{a})$ bore some visual resemblance to the first two syllables of the word music $(m \bar{u} s \bar{i} q \bar{i}) .{ }^{28}$ The story added the twelve maqam into a story about Moses described twice in the Qur'an (Surat al-Baqarah 60, Surat al-A 'raaf, Aiya 160), where Moses was able to bring forth water from a rock. Thus, Dawreh Sofrachi in his Risāleh-i kermāniyeh (c. 1582) wrote that

Some have said that Moses, at the time of crossing the river Nile, when he arrived at the river, he saw a rock. His majesty Gabriel said, "Oh Moses! Pick up this rock so that you may come to use it." Moses picked it up and carried it until the time he arrived weary to the wilderness with his tribe and they remained [there] for forty days. Thirst became prevalent among them. Moses prayed. Gabriel arrived [and said,] "Oh Moses! Strike your cane to the rock." When he hit [it], springs of water came out and they occurred in twelve portions and from each portion a voice came so that from them [there were] exactly twelve. Gabriel came and said, "Oh Moses! Moses, take the twelve maqam." [And] from there he acquired [them]. ${ }^{29}$

In some cases, Sasanian kings who ruled between the initial prophets recognized by Islam and the coming of the Prophet Muhammad were also considered progenitors of music and maqam. The Sasanian king Khosrow Parviz (590-628) and his son Kavadh II (Shìrüyeh), who ruled for only a year after his father, were the most common kingly references. Hence, Dawreh Sofrachi recounted the story of Moses discovering music above, but also described how some said seven of the Hebrew prophets created the first seven maqam and the rest were added at the time of Khosrow Parviz and Kavadh II. Though the initiators of the system were consistently well-known people even by modern standards, secondary contributors cited as adding to the system later could be more obscure. Hence Haji Husayn Isfahani Zahiri, writing sometime in the seventeen century, described how the six avaz were created by six prophets and said that "these six were all that the people of music had until the time of the kingdom of Khosrow Parviz; and then Khalif Shams al-Din Mohaqeq Farsi and the master Sa ${ }^{\circ}$ di ${ }^{~}$ Iraq-who were rarities of the epoch-situated a maqam in the low end and high end of each avaz." ${ }^{\circ}$ 
Though the prophets and Khosrow Parviz were oft-discussed historical figures, Khalif Shams al-Din Mohaqeq Farsi and Sa di 'Iraq are more obscure references. Yet Zahiri's description of them as "rarities of the day" placed them in the category of the exceptionally wise people capable of discovering music, including music that the prophets themselves missed. Khosrow Parviz's appearance in narratives about sources of music and the twelve-maqam system related to the musicians of his court. The names above are more obscure references to these musicians.

A musician named Barbad was the most often mentioned musician of Khosrow Parviz's court written about in Arabic and Persian literature after the fall of the Sassanian Empire. Outside of writings about music, Barbad stood as one of Khosrow Parviz's most legendary musicians for his wit and cunning, but he rarely made an appearance in writings dedicated to the subject of music. An exception to this trend appeared in Nishaburi's treatise. Nishaburi wrote that Barbad created the first seven maqam in accordance with the seven planets, while Sa ${ }^{\circ}$ di, his student, made them into twelve maqam under the rule of Kavadh II. ${ }^{31}$ While the attribution of the first seven to Barbad is unique, the logic of the attribution is not. According to Nishaburi, Barbad was not the source of the first seven maqam because he was a witty musical performer. Rather he was the source because he-like Pythagorashad knowledge of music's relationship with the heavily bodies.

The wise progenitors of music were thus cast as a polyglot set of wise men, with knowledge and insight beyond that of most people. With this knowledge and insight they were able to discover the fundamental nature of music, which led them to discover aspects of the twelve-maqam system. The earliest wise men who discovered the twelve maqam were usually from before the rise of Islam. Later wise men writing in Arabic brought additional knowledge that further clarified the nature of the system.

Because the demonstration of their wisdom was the discovery of fundamental aspects of music, the wise men associated with the twelve-maqam system were typically ancient relative to the system itself. Indeed 'abd al-Qader al-Maraghi was the only wise man to emerge as a point of reference for musical knowledge after Safi al-Din. Beyond direct commentary, texts generally referencing the wisdom of Maraghi began appearing around the sixteenth century. He was the only person to write about the twelve-maqam system in Persian to achieve classification as one of its wise men.

Maraghi's later classification demonstrates the parameters of who could be considered a source of historical wisdom on music. Maraghi's writings about music and the twelve-maqam system persistently stressed his own wisdom. Initially, Maraghi produced multiple commentaries on the writings about music from past wise men. ${ }^{32}$ Even in his longest work, the Jämi al-alhān, he first addressed the themes of past authorities concerned with the "ilm of music before addressing music as practice ( ${ }^{\circ}$ amal) of his time. 
By dedicating an unusually large amount of space to commenting on past musical authorities and participating in discussions about their concerns, Maraghi emphasized his own alignment with established wisdom and knowledge concerning music. Maraghi's discussion of practice, however, was not merely a passive description of music in his time: it was a unique demonstration of Maraghi's own musical knowledge. Throughout his discussion of practice he described how he revived disused musical practices and instruments. ${ }^{33} \mathrm{He}$ also described his invention of new instruments. ${ }^{34}$ His inclusion of his own contributions was unique. Including a section describing musical instruments was a common feature in writings about the twelve-maqam system, yet other authors focused strictly on their breadth and classification, similar to Graeco-Arabic writings. ${ }^{35}$ They did not focus on the novelty of any newly invented instrument, whether by the author or any contemporary.

Maraghi thus described different aspects of practice in order to describe his unique contributions to practice via his great musical knowledge, which referenced back to previously established priorities of musical knowledge. Reviving disused instruments and practices demonstrated his valuation of ancient musical wisdom. Conversely new inventions also valued the ancient. While the legend of al-Farabi's amazing application of musical knowledge in practice did not come from al-Farabi himself, Maraghi tells his own amazing story of his exceptional musical knowledge. In his discussion of the multisectional suite the nawbat murattab (nawbat murattab), Maraghi described how he had invented a fifth piece to add to its typical four-song structure. He then further described his musical prowess by recounting how he composed a different nawbat murattab for each night of the month of Ramadan, far more than any person wise in the ways of music thought could be composed in such a short amount of time. ${ }^{36}$ This story mirrors the amazing stories about other wise men regarding their musical contributions, yet Maraghi was the only person to write about the twelve-maqam system and also tell such a story about himself.

With all of these unique engagements with the framework of musical knowledge surrounding the twelve-maqam system, Maraghi could achieve the status as a source of musical wisdom like that of more ancient sources. Hence, it was not uncommon for authors living after Maraghi to venerate him as a source of musical wisdom and to cite him as a source of musical knowledge. Many song texts of unknown origin are attributed to Maraghi beginning in the sixteenth century. The legitimacy of the twelve-maqam system's expansion to include the gusheh related specifically to the question of whether or not Maraghi endorsed it as a modal designation. Aqa Mo'men Mosannef, writing in the sixteenth century, stated that the gusheh was not mentioned by Maraghi and declared the gusheh illegitimate based on Maraghi's omission of it. ${ }^{37}$ Conversely, Sadr al-Din Muhammad Qazvini writing around the same time came to the opposite conclusion and legitimated the gusheh because he believed it was handed down from Maraghi. ${ }^{38}$ 
This kind of contradiction highlights how wisdom was constructed to create wise men, whose legends then influenced musical thought and practice. Writers used the various wise men to legitimate their positions on various details of the system's structure. Changing notions of who these wise men were and what these wise men did and said had the ability to affect how music was conceived and practiced. Writings about the twelve-maqam system asserted certain truths about the nature of music that were observable in the cosmos. They asserted other truths about the twelve-maqam system based on what wise men of the past had discovered. The twelve-maqam system stood as the ultimate manifestation of musical knowledge from these two legitimating forces.

Depending on correct knowledge, skill, and wisdom, the twelve-maqam system maintained a close relationship with the rarity of the written word and the use of language as a conspicuously esoteric act. This is most visible in sections of writings about the twelve-maqam system that discuss rhythm, where the usul were discussed as an extension of the rules of poetry, while composition was conceived of as a conceptual process of writing. While the twelve-maqam system itself could be classified as central to the knowledge of compiling melody ('ilm-i ta'alif), it was knowledge of rhythmic aspects of music ("ilm-i $\left.i q \bar{a}^{e}\right)$ that connected the twelvemaqam system to proper musical composition (tașniff). ${ }^{39}$

Unlike individual avaz, maqam, sho'beh, and gusheh, individual usul were consistently notated using various linguistic methods of structural representation. Sometimes authors actually notated usul using the notation specifically reserved for poetic meter either as a substitute for or as an addition to a specific system of notating the usul. Other times authors simply used terminology associated with poetic meter to describe usul. Words such as poetic foot (vatad), syllable (șabāb), and interval (fäsilah) are all applicable in discussions about poetic meter and also used in description of rhythm. This detailed knowledge of 'arūz and the ability to demonstrate the system of poetic meter on paper fell strictly within the realm of the literate and highly educated. Indeed several poets including Jami (1414-1492) and Omar Khayyam (1048-1131) actually wrote music treatises, and other treatises might also set descriptions of the twelve-maqam system as poetry. ${ }^{40}$

Descriptions of the twelve-maqam system were surrounded by such conspicuous applications of Arabic-derived poetic language structure. Yet the connection between composition and esoteric language usage could also be seen in the lesser-discussed subject of composition itself. The few authors who actual used a notation of melody to describe the twelve-maqam system used it only to demonstrate the basic premise of combining an aspect of the twelve-maqam system with usul in order to compose a melody. Beyond such generalized models, specific compositions were only represented if they were songs, because they were represented as words. The words of compositions-the poetic texts sung-were the most common representation of compositions using the twelve-maqam system. The word for a musical composition (tașnif) referred to a compilation of some- 
thing, often written documents, while the word for composer (mușannif) referred to a compiler of things in a general sense, rather than a specific creator of melody (mulahn). The lack of functional musical notation to record specific melodies did not separate the music of the twelve-maqam system from specialized systems of description. Written words were the specialized system of description.

The relationship between music and complex forms of written language demonstrates that the authors of music treatises were not merely dependent on wise men of the past to tell them which musical ideas were legitimate. In reality, the authors themselves were themselves wise men: members of a narrowly defined educated elite associated with the court. The very fact that treatise writers were able to write about music as a complex area of knowledge and practice attested to the fact that those who wrote about the twelve maqam were a selective group of people who could use the rarified lingua franca of empire and also the language of Islam. While the twelve-maqam system stood as an objective reality of universal musical truth, that truth was not meant to be accessible to everyone. It could only be understood by people who were well informed, infinitely wise, or divinely blessed.

\section{CONCLUSION}

The twelve-maqam system defined a culture where music needed to meet an objectively determined universal standard, which focused on achieving a universal relationship between the cosmos and humanity. It was a culture defined by rare amounts of education and literacy that most commonly emanated from the court and an insular aristocracy associated with dynastic structures of governance. This served as the twelve-maqam system's primary cultural context, defining its venues and its audience as polyglot and cosmopolitan, but also isolated. The twelve-maqam system held the distinction of being universally applicable to humanity, and it existed in a cosmopolitan setting where the universality of music was consistently tested for universal relevancy. Yet this cosmopolitan setting was also one of special privilege for certain elites who often existed apart from the broader population of dynastic subjects.

The ways in which music was defined and classified in writings about the twelve-maqam system reveal the continuing influence of Islamic philosophy's initial classifications of knowledge, and its initial derivation from ancient Greek philosophy. Yet they also reveal an ever-growing indigenization of Greek notions of knowledge over time, as Greek concepts of knowledge became intertwined with notions of wisdom more central to Islam.

For instance, in the Enumeration of Knowledge, al-Farabi listed six categories of knowledge and placed music in a category he called instructionary or preliminary knowledge ( ${ }^{~} \mathrm{ilm}$ al- $\mathrm{ta}^{\mathrm{e}} \mathrm{li} \mathrm{m}$ ), which also included the knowledge of math, geometry, optics, astronomy/astrology, weight measurements, and tool-making/mechanics. 
His category of preliminary knowledge owed much to the ancient Greek quadrivium, while not being strictly defined by its limited four subjects. Al-Farabi also recognized two types of knowledge within his six categories of knowledge: theoretical knowledge (al- ${ }^{\circ}$ ilm $i$-nnazarī) and practical knowledge (al- ${ }^{\circ}$ ilm al- ${ }^{-}$amalì).

The interest in discussing music as knowledge versus practice common in writings about the twelve-maqam system owed much to concepts of knowledge classification like those of al-Farabi, where both music as pure concept and music as a physically delimited activity had their distinct knowledge-based conceptions. On this basis, whether or not discussions of the twelve-maqam system treated music as only 'ilm or as 'ilm and 'amal, either classification related to conceptions of music as knowledge. In this sense, there was no practice of music related to the twelve-maqam system apart from knowledge of music. It defined music-making as an act of knowledge.

In his knowledge category of tool-making al-Farabi included the skill ( $\left.\sin \bar{a}^{e} a h\right)$ of making musical instruments, alongside instruments for use in astronomy and mathematics. Even as tools of astronomy revealed more knowledge of the cosmos, instruments of music revealed more knowledge about music. And the application of this knowledge in practice had implications for its ability to manipulate the human soul.

The philosopher Shahab Ahmed has noted a turn philosophy took in the Islamic world as ancient Greek ideas took on more Islamic influence. In bringing the concerns of Greek philosophy into a world defined by Islamic concepts of divinity, two themes became central: establishing theoretical rules of the cosmos, and further establishing practical rules to put humanity in consonance with cosmic law. Among these practical rules were those specifically for perfecting the soul. This transformation of priorities was matched by a change in terminology. By the fifteenth century philosophy as a concept (falasafah) was replaced by general notions of divine wisdom tied directly to the terminology of the Qur'an (hikmah). ${ }^{41}$

This indigenization of knowledge defined the twelve-maqam system's conception and importance in historical context. The importance of universal, cosmic law also meant that music needed to account for the whole of known humanity and the various differences among humanity that were nevertheless underpinned by a larger cosmic design. The notion that music could manipulate humanity in systematic ways was not new, but the growing concern with executing music within the parameters of some specific cosmic design became paramount. The twelvemaqam system's variations on musical structure all addressed practical rules for practicing music within a systematic, divinely established universal existence. This was the shared cultural basis of Farmer's Systematic School, but also of the conception of the twelve-maqam system beyond this limited range of discourse.

In fact, an emphasis on cosmic knowledge and divine truth had more possible sources of wisdom from which musical knowledge could come. The pantheon of wise people who could validate musical knowledge was relatively diverse, as divine 
knowledge was not delimited by specific parameters of education or literacy. The prophets of Islam and other cosmic actors were as likely a source of cosmic knowledge as Pythagoras, as was any musician who had demonstrated an ability to apply knowledge of music in practice to elevate humanity and the human soul. How someone applied music in practice derived heavily from ideas about how music could best influence humanity. While there was no one answer to the question of how music might be applied to achieve harmony with cosmic law, the twelvemaqam system stood as a long-term demonstration of a system that was in keeping with this cosmic law.

While Shahab Ahmed presented his analysis to demonstrate the active role of Islamic philosophy throughout premodern Islamic societies, this cultural frame for music's meaning, significance, and possibilities for practice was nevertheless limited. The twelve-maqam system did not represent common music, as cosmic knowledge was not common. It explicitly represented a higher dimension of human existence, seeking to remove music from regional variation and place it into a context of universal practice. It was tied to courtly aristocracy and its concomitant religious elite. In this context, the twelve-maqam system derived from discourses of universal truth, even as it embodied a rarified form of musical knowledge. 


\title{
Music and Morality
}

\author{
Listening to Dangers Inherent in the Cosmos
}

Modern scholarship on the history of music in the Middle East often places Islam in moral opposition to music. ${ }^{1}$ Yet Islam-in both its orthodox and its heterodox forms-was never something apart from the twelve-maqam system's conception, nor was it separable from the structures of empire in which the twelve-maqam system thrived. The institutions of Islam had been enmeshed with the structures of empire for several hundred years before the twelve-maqam system emerged. Thus, even as music became a subject of Graeco-Arabic writings, texts about a spiritual culture of "listening" (sama") also emerged. Listening practices in Islam developed as an aspect of Sufism, and the mystical conception of Islam fostered by Sufism maintained a strong degree of influence in the Mongol and Turkic courts, where the twelve-maqam system gained dominance. Mystical practices like spiritual listening provided mechanisms to know the truth of Islam without direct knowledge of Arabic or the Qur'an. This made Sufism a key force in Islam's spread beyond the Arabic-speaking world.

Indeed, Sufism would prove hard to separate from dynastic governance even when dynasts sought other avenues of Islamic spirituality. The Safavid Dynasty officially denounced Sufism in favor of Shi' ism when they came to power in the sixteenth century. The importing of Shi'a clergy to create their new Shi'a empire brought with it attacks on the Sufism patronized by past dynasts, and this included attacks on the musical practices the new Shi'a religious class associated with Sufism. While these attacks insisted on the immorality and debauchery of both Sufism and music, they were political arguments that served the elevate Shi'ism over Sufism in a political context. Sufism, however, never fully ceded its political power, nor did all Safavid rulers fully remove it from their own spiritual lives. Both 
mystical or juristic actors within Islamic institutions were seeking political agency within the structures of dynastic governance, and such political agency was an aspect of religious authority. ${ }^{2}$

The ability to perceive the divine directly via sound-be it the spoken word, metered chanting, or full musical expression-held a special place in conceptions of Islamic spiritual life before the rise of the twelve-maqam system. The culture of listening grew alongside the twelve-maqam system, similarly premised on a body of previously established wisdom from Arabic sources. Though writings on listening belong to a distinct literature on Sufism, the legitimation of both music and listening was rooted in a similar culture of previously established knowledge and wisdom. Conversely, the more formal ceremonial aspects of rituals for remembrance through chanting (zikr) or divine musical listening $\left(\right.$ sama $\left.^{\circ}\right)$ were closely related to the broader activities found in the ongoing culture of courtly gatherings organized for formal entertainment that often involved a great deal of music and poetry. Song texts associated with the twelve-maqam system and songs of majles at the court contain songs about the Sufi sama as well as songs that use Sufistic poetic metaphor.

The relationship between music-making and Sufism vis-à-vis the court culture of the twelve-maqam system can be established from the body of mystical writings that address the subject of sama', which appear concurrently with writings about the twelve-maqam system. During the dominance of the twelve-maqam system, many older Sufi texts from Arabic were translated and circulated in Persian, while new Persian writings also appeared. Some writers about the twelve-maqam system were also mystical poets. While texts about listening initially appeared in larger works about Sufism-adābìyät i-tașawwuf-later discussions of spiritual listening appeared next to descriptions of the twelve-maqam system when genres of Sufi writings became less common after the fifteenth century. ${ }^{3}$ The ideas and practices surrounding sama ${ }^{\circ}$ were not ultimately a countercultural phenomenon: concerns about how to do it properly mirrored concerns about how to make music properly as a matter of objective perspective. Both had implications for how humanity would or would not benefit from music, and the benefits and deterrents stemmed from the set order of the cosmos.

Writings about the practice of listening brought together two perspectives, one of Sufi practice and one of orthodox intellectual understanding. This dialog of perspectives highlighted the unique temporal challenges of music's morality in a cosmos ruled by divine laws that manifest in physical ways. The systematic affect of the twelve-maqam system on a listener extended from divine, cosmic realities. Sufistic writings about listening ultimately had to consider this situation and the problems of aural cosmic power vis-à-vis the imperfection of humanity. In this context, Islam as whole was not morally adverse to music. It did, however, need to consider the implications of music's power in the universe. There were legitimate reasons to be wary of music's cosmic power, when considering the fallibility of humanity rather than the perfection of systematic musical structure. 
Though many discussions about sama in Sufi texts did refer to specific Sufi gatherings dedicated to listening to music and poetry in order to attain unity with God, they did so in the course of discussing the broader implications of finding God through listening. While descriptions of music and the twelve-maqam system often started from defining the nature of sound, so too did discussions of sama ${ }^{e}$ begin from the question of simply hearing sound. In discussions of listening, there was no limit to how one might find unity with God through hearing a sound, be it through the Qur'an itself, music, poetry, idle speech, or abstract noises. In one of the Sufi texts written in Persian, Kashf al-mahjūb, the Sufi teacher 'Ali ibn 'Usman Hujviri (d. c. 1072) discussed the word sama first as the general term listening and classified it as one of the five senses, all of which may be used to perceive God and the greatness of God's creation. He stated that listening was the most important of all the senses because in order for God's message to be known it must be heard. ${ }^{4}$ Yet all kinds of sound could reach humanity through the sense of hearing. In one story authors commonly recounted in Sufi texts, Satan appeared to the mystic Junayd (830-910) in a dream and Junayd asked Satan if he ever had the opportunity to produce evil among his companions. Satan then told Junayd that he had the opportunity to affect Junayd's companions every time they were listening (sama ${ }^{e}$ ) or looking (nazar). ${ }^{5}$

While creating music of the twelve-maqam system was a specialized activity based on specific knowledge, most humans had access to hearing regardless of their moral or intellectual abilities. This was fraught with peril, as it opened up everyone to all kinds of influences regardless of their preparedness for such influence. Yet within the larger context of discussing how listening could bring one closer to God or perhaps lead one astray, writings about listening did often place music in a favorable category, at times for its accessibility. Most writings on listening mention music or melody (lahn), both in terms of specific Sufi practices and in more general terms. In both his Arabic and his Persian writings, the eminent scholar Ghazzali (1059-1111) named a variety of different types of spiritually beneficial musical listening in addition to the official Sufi ceremony. These additional categories valued accessibility, such as hearing songs that people sang on their pilgrimage to Mecca, songs for mourning, songs for holidays such as weddings, love songs between husbands and wives, parents and children, Muslims and God, as well as songs that promoted bravery. ${ }^{6}$

While discussions of the twelve-maqam system focused on achieving a perfect method for creating music based on rarified forms of knowledge, writing about listening confronted how humanity had universal access to all kinds of sound regardless of education or spiritual preparation. Texts about listening addressed the ease with which human ears can perceive any kind of sound either actively or passively, and weighed the benefits and pitfalls of music as an overt sound phenomenon created specifically to manipulate the human condition. These texts address the complex moral landscape created by music's accessibility 
to all people and attempt to balance multiple factors that determine the meaning of music in context.

\title{
THE BASIS FOR APPROVING AND DISAPPROVING OF MUSIC IN SAMA`TEXTS
}

The vast majority of Sufi texts about sama' as a systematic practice directly addressed whether or not it was lawful (haläl), generally allowable (mobāh), morally questionable (makrūh), or forbidden (harām) in Islam. The most important influences on how Sufi authors viewed the morality of sama ${ }^{e}$ in these terms, derived from a particular author's understanding of how various considerations related to sama' were viewed by the Prophet Muhammad and his companions as well as other great Muslims. Some of the stories that conveyed this information were about the private life of the Prophet Muhammad and remain part of Islam's hadith tradition tracing back to his wife 'Aisha. In addition to Muhammad, the actions of his close companions Abu Bakr (c. 573-634) and ' $\operatorname{Umar}$ (c. 584-644) as well as his cousin 'Ali (c. 599-661) figure prominently into these stories. One commonly referenced story refers to an event where 'Aisha was listening to a female slave sing:

\begin{abstract}
'Aisha said: one of the slaves was a singer and she sang something before me and the Prophet came. He was in such a state of ecstasy (hâl) and he sang too. Later 'Umar came. That slave fled. The Prophet smiled. 'Umar said, "Oh Prophet what has made you smile?" The Prophet told him of the ecstasy. "Umar said, "I will not leave this house until I have heard everything the Prophet heard." The Prophet of God ordered that slave to come and sing something and ' Umar heard [her].
\end{abstract}

Another similar story from 'Aisha shows Abu Bakr having a very different reaction to a similar situation:

It is known that the Prophet was in the house of 'Aisha. Two slave girls were there singing something and he did not stop them. . . . Abu Bakr said two times, "Instruments (mizmār) of Satan in the house of the Prophet!" The Prophet said, "Calm down Abu Bakr! Every group (qawm) has a holiday and our holiday is today. ${ }^{8}$

Both of these stories specifically described Muhammad listening to singing and poetry and approving of it even when performers and other listeners demonstrate a certain amount of shame in it. Another hadith commonly cited to demonstrate Muhammad's general approval of recreational viewing of performance included a narration from 'Aisha where she recounted watching several Ethiopians (zangīyān) engaging in either war games or singing, playing drums and stomping their feet near a mosque. In recounting this event, 'Aisha was quoted as saying that Muhammad specifically asked her if she would like to watch the Ethiopians, and when she told him that she did, they both watched until she has seen enough. ${ }^{9}$ 
Though these were some of the most common stories about Muhammad in reference to his approval of music, Sufi authors also cited other stories about the Prophet, many of which specifically associated Muhammad with the Sufi ritual of sama'. 'Abd al-Mafakhir Yahya Bakharzi (d. 1324) recounted the story of a cleric who prohibited sama ${ }^{\circ}$ but then saw Muhammad doing the Sufi ritual in a mosque:

The cleric said: one day I was in the mosque sitting in the corner. A group came and sat in the corner and they spoke and sang (qawl) and did sama'. I in my heart opposed it, that in the house of God they would say poems and sing. When the night came I saw the Prophet sit in the same area of the mosque and Abu Bakr sat in front of him and sang ( $q a w l$ ) and the Prophet put his celebrated hand on his chest in the same way as a person that is in spiritual ecstasy (wajd). I said to myself, "The Prophet is hearing sama'. This group, why did I oppose them? The Prophet came to my side and said, "This truth is from God" (hatha haq min haq). ${ }^{10}$

Other Sufi authors spoke of Muhammad appearing to people in dreams and stating that the sama ' ritual of the Sufis was permissible but that the Quran must

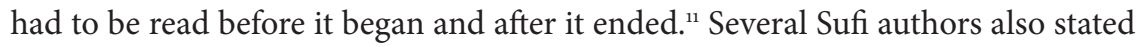
that Muhammad said there would be sama ${ }^{\circ}$ in heaven. ${ }^{12}$ Yet other Sufi authors legitimated the Sufi practice of sama' by recounting how Muhammad recited poetry out of joy after the angel Gabriel told him that the pious Muslims would enter heaven five hundred years before worldly people. ${ }^{13}$

Though Sufi authors were familiar with a wide variety of lore concerning the Prophet Muhammad's approval of musical expression with the voice and sama', some authors did cite examples of the Prophet and his companions speaking ill of formal musical practice, ghina $\bar{a}$. One Sufi author quoted Muhammad as saying "Music (ghina $\bar{a})$ cultivates disharmony as water cultivates seeds." ${ }^{14}$ Yet another stated, "Ali disavowed Mu'awyah because he had female slaves that sang. And he looked at the Ethiopian woman singing and he said she was associated with Satan and those like Satan; and also they said that this is the primary reason we hate music (ghinä)." ${ }^{15}$ In addition to these outright admonitions of music, several Sufi texts also noted an incident in the life of Muhammad where the Prophet put his fingers in his ears upon hearing some kind of music being played. Though the citation of this story suggests that it would be used to demonstrate the impermissibility of music, texts that recount this tale often did so in order to explain that it did not signal Muhammad's aversion to music, citing the lack of information about the intention of his action. ${ }^{16}$

Some Sufi authors looked to later Muslim leaders to consider the permissibility of sama . One common story recounted someone asking a later Muslim leader, usually ibn Jarir al-Tabari (839-923), whether or not sama ${ }^{\circ}$ would be in heaven or hell on the Day of Judgment. He replied that it would not go to heaven, but it would also not go to hell. ${ }^{17}$ 
Hence, the varying ideas any given author discussed about the actions and statements of Muhammad, his companions, and other early Muslim leaders formed a basis for the different perspectives on music and the moral validity of sama ${ }^{\circ}$. Music, however, was not the only practice under moral scrutiny in these discussions. Indeed, some Sufi authors dedicated most of their defense of sama ${ }^{e}$ to the defense of poetry, treating poetry as having the most misunderstood moral standing. Despite this defense, Sufi authors also designated certain types of poetry as immoral. ${ }^{18}$ Thus, Ghazzali declared sama' impermissible if it used poetry containing cursing and text that glorified drunkenness, despite his overall defense of poetry as moral. A more common issue related to poetry's permissibility discussed by Sufi authors was the immorality of verbal trickery, referred to as lahu al-hadith. Some of the criticism of music addressed by Sufi authors came from the classification of music as lahu al-hadìth. Yet Sufi authors pointed out that music was not in fact verbal trickery and that this classification is reserved for speech that is meant to deceive and lead one astray. Still, Ghazzali specifically designated the poetry of unbelievers as lahi al-hadith, as well as the Persian literary tradition of the Shähnāmeh, which included glorification pre-Islamic Persian kings who were unbelievers. ${ }^{19}$ One author writing during the reign of Shah Solomon Safavid (r. 1666-1692) spoke especially harshly of this genre, noting that "They read the poem of the Shähnammeh that is mostly stories about Fars and their explanation; and the verses of it are many and yet that which is mentioned in the Shähnammeh is mostly lies and exaggerations of the poetic tongue from the types of lies and exaggerations of the devil." ${ }^{20}$

With so much focus on the morality of specific texts, music as a general practice or concept was not often treated as morally questionable as an independent phenomenon, but rather as a question of context. Texts used in song were one factor, the nature of performance settings was another. While musical instruments in general were occasionally singled out as immoral, Ghazzali actually declared music played with certain specific musical instruments to be forbidden: the rebāb, chang, barbad, rū $d$, and nāy-i 'irāqì. Ghazzali conceded there was nothing wrong with the instruments themselves; however, because they were associated with wine drinkers they were forbidden. ${ }^{21}$ Muhammad Bin Jalal Razavi, writing later in the seventeenth century, confirmed a general association between musical instruments and drunkenness, noting that jurists said that musical instruments were forbidden, while also noting their association with wine drinkers. ${ }^{22}$

These statements related to earlier ideas expressed in Arabic writings not translated into Persian. Thus ibn Abi al-Dunya (823-894) specifically associated musical instruments with "singing girls" (qin̄att), immorality $\left(z i n \bar{a}^{-}\right)$, the drinking of wine (shurb al-khamr), and the wearing of silk (lubs al-harir). ${ }^{23}$ This combination of factors associated musical instruments not just with wine drinking, but with a specific lifestyle that was generally quite lavish. Sufi authors occasionally attributed immorality to the lavishness of the rich explicitly. In addition to Ghazzali's com- 
ments another statement found in other texts noted that while certain Sufi sects may or may not use musical instruments, Muhammad generally warned against the immorality of spending time with rich people and the king. ${ }^{24}$

The overall focus on satisfying physical desires and wants was a key aspect of the context in which music could be immoral. Ibn Mutahhar (1049-1141) described a type of forbidden sama ${ }^{e}$ he referred to as physical sama $\left(\right.$ sama $^{e}-i$ tab $\left.^{e} \bar{\imath}\right)$, in which "they play instruments (mizmār) and they sing songs and poems and the desire of enchantment (lahu-i tarab) comes around and that is a sin and it is forbidden (harām)." ${ }^{25}$ Yet the idea that music's immoral position was largely a question of its context rather than its actual nature is confirmed in the Kashf al-mahjūb, where Hujviri stated:

\begin{abstract}
Anyone who says that he does not like melody (lahnn) and voices ('așvāt) and musical instruments is lying, or making hypocrisy or he is not in his right mind or beyond the known classifications of man or animal. They prohibit [these things] in order to observe the law of God but the jurists agree that when musical instruments are not used to find debauchery in the heart through hearing they are allowed (mobāh). ${ }^{26}$
\end{abstract}

\title{
THE POWER OF MUSIC AND SOUND
}

The extensive consideration of the morality of deliberate listening extended from the considerable power of music and words over the human condition. The twelvemaqam system could be used to create music that appealed directly to the physical realities of the human condition, and skilled musicians could play in such a way as to manipulate listeners' bodies. Divine messages came via words. The Qur'an was the word of God, delivered to Muhammad via the voice of the angel Gabriel. These two realms of sound held enough power over the human condition that they required much thought in considering how to encounter such power via listening. Writings about sama ${ }^{\circ}$ discussed extensively how hearing things-be they music, or poetry, or something specifically spiritual such as the Qur'an-could be a powerful and dangerous occurrence. Hujviri described how the 'Abbasid musician Isaac Musli walked through a garden singing, which caused a bird to die and fall out of a tree. ${ }^{27}$ Bakharzi described how the prophet David "Sang on his breath and chanted psalms in a beautiful voice to such an extent that fairies, people and birds gathered to hear his singing and from his assemblies several hundred corpses were removed." ${ }^{28}$ Qushayri recounted a longer tale of death via sound, which he attributed to someone named Daraj:

We ... were walking by the shore of the Tigris between Basra and Oboleh. I saw a beautiful palace. There was a tower in that palace. There was a man in that tower and a female slave in front of him. She sang this verse:

The path to God is a love that is given from me to you

Everyday the color is changing however it is made more beautiful by you. 
I saw a young man standing below the tower and his hands were cupped in prayer. He tore his clothes as he listened and said, "Oh, slave, by the life of your master repeat [this line]: 'Every day you change your color, but this one is the most beautiful on you." That master said to her, "Sing that which he wants." The slave girl sang and the young man said, "Allah who is God is with me in this very same way so that every day it is a different color." He then let out a yell and died. The master of the palace said to the slave girl, "I set you free for God" and the residents of Basra came out and they buried him (the dead man). The master of the palace stood and said, "You do not know me and I do not know you. I called you to witness everything; so everything that is mine I give away for God's sake and I set every slave free." And he tied a piece of fine linen around his waste ( $i z \bar{a} r$ ), threw another one on his shoulder, and went away and they never saw or heard from him again. ${ }^{29}$

Descriptions of words and melody killing people who heard them-or otherwise harming them when they were heard-are a key theme in writings about sama ${ }^{e}$. There were tales of how verses of the Qur'an as well as prayers could have the same affect as music and poetry. Thus, Hujviri recounted a series of annihilations coming from such Islamic texts:

One of the main companions of the Prophet recited a verse of the Qur'an while he was presiding over public worship, let out a cry, and died. Abu Jafar Juhani, a distinguished follower, upon hearing a verse that Salih Murri read to him, let out a loud groan and left this world. Ibrahim Bakha'i states that while he was passing through a village in the neighborhood of Kufa he saw an old woman praying. As the signs of holiness were visible on her visage, he waited until she finished praying and then addressed her in hopes of obtaining a blessing. She said to him, "Do you know the Qur'an?" He said yes. She said a verse at which point she cried out and sent her soul forth to meet God. ${ }^{30}$

When writings described such dramatic deaths happening to Sufis, it was treated as an aspect of weakness on the part of the Sufi, or some other imperfection in their execution of sama'. In a commonly recounted story of a young inexperienced Sufi disciple (murìd), his inability to control his response to the Sufi incantation of prayers and remembrance of holy figures ( $\underline{z} i k r)$ cost him his life:

A young man was in companionship with Junayd and every time he heard something from the $z i k r$ he would yell. One day Junayd said, "If you do this again my companionship will become forbidden to you." So from that time when he heard something he would not move and a visible transformation came about in him and from the root of every hair ran drops of perspiration. One day he (Junayd) recited something, [and the young man] cried out and died. ${ }^{31}$

Not all of these types of stories ended in death, nor was inexperience always the cause of difficulty in sama'. Some stories recounted how mystics who showed no affect during sama ${ }^{c}$ at a younger age could have dangerous overreactions to it in old age..$^{32}$ Physical weakness and mental weakness were the shared features of 
those who were overcome in sama to the point of death. Absence such weakness, Sufis who properly conducted sama could experience superhuman abilities with no threat of death. Suhrawardi (c. 1145-1234) described various situations where people in sama ${ }^{\circ}$ did amazing things:

It has been stated by some of the sheikhs who say that "We saw groups walking on water, and they did sama" on the water in extreme stupefaction and wonder. And there was a group that did sama in the fire and did not know the heat of the fire." And a great man said, "I saw a person that in the time of sama" took the flames of a candle and put them in his eye. I went close to his eye; the fire and the light came out from his eye." 33

Such stories where people accomplished amazing physical feats were common demonstrations of the power of sama ${ }^{e}$ in the presence of someone who was strong enough to withstand the power of what was being heard. ${ }^{34}$ Ultimately, these types of stories highlight the volatility of organized sound and how people perceived it as a powerful cosmological medium. Regardless of whether or not the sound was music or poetry, or something more explicitly spiritual such as the Qur'an or a blessing, it had the real ability to drive a human being to the physical extreme of death or even beyond such extremes into the realm of capabilities beyond the human body's known capacity. Under these circumstances, music was something akin to dynamite: a very powerful substance that could come to great ends if used properly, or could easily result in death if used improperly.

Despite these concerns, authors made conflicting statements about the role of the listener in determining the impact of sama on a person's moral being. The condition of the listener was often considered a primary factor in whether or not sama ${ }^{e}$ would be beneficial or detrimental, either physically or spiritually. In the text titled Miṣbāh al-hidāyah wa miftāh al-kifāyah by 'Izz al-Din Kashani (c. 12501334), the author states that "The virtue of sama" is that it strengthens everything that reigns in the kingdom of humanity and makes it better. Hence, within the reality of a group that is doing [it] and belonging to their transmission of love and devotion of truth, sama ${ }^{e}$ promotes and assists in the search for perfection. And in the reality of some for whom their hearts are empty it is the cause of ruin and trouble." ${ }^{35}$ Hujviri further described sama" as "like the sun, which shines on all things but affects them differently according to their degree. It burns or illumines, dissolves or nurtures." He also stated that "Sama is calamitous and a source of evil to anyone whose whole heart is not absorbed in the thought of God."36

This notion that the value of sama ${ }^{e}$ was delimited by the nature of the person listening stood in conflict with the most significant spiritual by-product of sama ${ }^{e}$ : wajd (wajd). The purpose of doing sama ${ }^{\circledR}$ was to produce actual contact between an individual and God, resulting in an ecstatic euphoric state referred to as wajd. Texts described wajd as something that occurred spontaneously in the course of sama ${ }^{e}$, and while an individual doing sama ${ }^{e}$ could prepare for it to occur, indi- 
viduals could not actually make it occur. Indeed, it was possible for wajd to come upon a person who was neither seeking it nor prepared to experience it. This is the primary significance of the many stories authors tell about people being killed by hearing something: in an instant they had direct contact with the truth of God, were overwhelmed by it, and died.

For Sufis who specifically sought the presence of God through sound, wajd was described as causing an immense euphoria that often provoked movement in the body. Some authors referred to this movement as dance (raqs); others distinguished it as something quite different from dance. In all cases the movement was spontaneous and beyond the control of the person experiencing it. It could cause the person to tear their cloths apart, and for this reason Sufi discussions of sama ${ }^{e}$ sometimes included a discussion about the protocols surrounding the tearing apart of ones robes. Additionally, people experiencing wajd could be capable of doing things that were considered physically impossible, hence the descriptions of Sufis walking on water, standing in fire, and putting the candle's flame in their eyes without hurting themselves. Bakharzi cited a description of wajd stating, "The condition of a person experiencing wajd is as such that at the time of wajd ... they could drive a sword into his face and he would not experience the perfunctory pain of it." ${ }^{37} \mathrm{He}$ also remarked, "[For] the person who experiences the wajd of sama ${ }^{c}$ it is ... a substitute for food and from it they get the same nourishment that is from food. The dear ones break fast once in two or three days because their soul (nafs) gets the joy of food and its nourishment. If they hear sama they come into wajd. To them it is the equivalent of food." 38

There was some debate among Sufi authors about whether sama' could be a truly systematic practice done to achieve wajd via specified methods, or if wajd had to be a more spontaneous experience in the midst of listening. In one of the earliest Sufi texts written in Persian, Mustamli Bakharzi (d. 1042) asserted that sama should only involve sudden inspiration (hâl) and it was illegitimate to approach sama ${ }^{\circ}$ as a cognizant realm of knowledge with aims and goals that could be systematically achieved ( ${ }^{\mathrm{i}} \mathrm{lm}$ ). ${ }^{39}$ Bakharzi further asserted that sama ${ }^{e}$ was completely spontaneous and could not be done at a set time because one did not know when or how the inspiration for sama ${ }^{e}$ would come..$^{40}$ Despite this emphasis on spontaneity, many authors agreed that while sama' could strictly involve hal, it also had the potential to be an ${ }^{~} \mathrm{ilm}$ in which one could know how to predispose oneself to achieve wajd via sama ${ }^{\circ}$ and take systematic steps toward achieving wajd when listening. ${ }^{41}$ For this reason, many Sufi discussions of sama ${ }^{e}$ included a section on the decorum of sama ${ }^{c}$ that addressed the proper way to prepare oneself in order to achieve wajd and how to conduct oneself in the presence of those experiencing wajd.

This debate about $h \bar{a} l$ versus 'ilm extended into discussions about the content of what one hears during sama ${ }^{e}$. Many texts about sama ${ }^{e}$ asserted that there was a relationship between what a listener hears and their ability to achieve wajd by 
hearing it. Many texts on sama also attributed a special power to music in the production of wajd. Qushayri noted, "No one can disavow enjoying a nice melody and finding repose in it because children become calm from a nice melody and the camels haul difficult heavy loads in the desert over long and hot distances to the nice melody of the camel herder." ${ }^{42}$ Kashani stated, "Anyone who is not able to find pleasure in a nice melody shows that his heart is dead or the hearing of his interior self is ruined." ${ }^{43}$ Another anonymous text noted, "In all of the notes from the melodies of music is the secret of the divine secrets." ${ }^{44}$ Ghazzali took this assertion somewhat further, positioning music as the most significant inspirational force in sama'. Indeed, Ghazzali insisted that hearing music was actually more powerful than hearing the Quran. One of the reasons he gave for making this assertion was that some sections of the Qur'an were dedicated to specific questions of law and living. These sections were intended to simply convey specific information rather than to inspire a direct experience of God's presence. Another reason he gave for privileging music over the Qur'an in sama ${ }^{\circ}$ was that the Qur'an had to always be the same and it could not and should not be altered. By contrast music was free to explore all kinds of variety and to adjust to the mood and taste of the listener. ${ }^{45}$

Despite all of this attention to what kinds of sounds were appropriate for sama ${ }^{\circ}$ and the creation of wajd, authors of sama texts also asserted that it was possible for anything, even something nonsensical or perhaps even immoral, to be useful and good for sama ${ }^{e}$. Examples authors cited of the latter phenomenon included people finding inspiration in the squeaking of a water wheel, the ringing of a gong, and the yelling of merchants in the market. ${ }^{46}$ The infinite nature of God implied that divinity existed anywhere and everywhere. This meant that it was possible to perceive the presence of God in even the most mundane sounds of everyday life.

Additionally, Ghazzali noted that Sufis and other people focused on God could listen to immoral forbidden things and not be harmed by them. ${ }^{47}$ One story commonly recounted by Sufi authors described a great Sufi master entering a room where beginners learning how to do sama' were practicing. Fearing the imperfections of their practice could affect the great master, the students stopped. However, the great master informed them that they could continue, because he was in such a spiritually high place that no profane sounds could affect him..$^{8}$

\section{THE PROBLEMS OF FALLIBILITY AND IMPERFECTION WITHIN THE HUMAN CONDITION}

In describing the various things one should do in sama to find wajd and perhaps even complete communion with God via the removal of the self (fana'), several problems consistently arose. One issue related to faking wajd and generally pretending to participate fully in sama ${ }^{\circ}$ when in fact the listener was not fully engaged in the process. Authors of sama texts occasionally endorsed a "fake-it-until-you- 
make-it" approach to learning how to properly do sama'. Conversely, the act of faking sama ${ }^{c}$ and pretending to focus on God when in fact the listener was focused on something else was considered heresy and blasphemy. Sufi authors discussed this at length: to do sama ${ }^{e}$ without devotion was a sin that one could easily commit without intending to do so. Authors stressed that people doing sama should hold themselves back from the bodily movement wajd caused, only moving when they simply could not stop themselves from doing so. This would avoid the possibility of going through the motions before achieving wajd, which would result in pretending to have the experience and generally misrepresenting one's relationship with God. While it was possible to move truthfully in agreement with another person's wajd, it was equally possible to move falsely and sinfully in pure imitation, acting as if you had found connection with God rather than actually experiencing any true connection. ${ }^{49}$

This was an important issue in discussions of sama ${ }^{\circ}$. In a common example of how sinful it was to fake sama ${ }^{e}$, Bakharzi recounted how people reacted to a sheikh who was fond of doing sama ${ }^{e}$ :

[He] did sama often. They said to him, "You are being excessive with samae" He said, "In gatherings we are busy with sama'. It is better than those who sit and make gossip." His retort was heard by another sheikh. He said, "Alas ... one sin in sama" is worse than many years of gossiping." ${ }^{50}$

The point of this exchange was that committing a sin in sama ${ }^{e}$ necessarily meant committing a sin directly against God. If people pretended to do sama ${ }^{\text {e }}$ they were in affect lying to God and the chances of this occurring increased the more one did sama'. By contrast, gossiping was a lesser evil. Even though it was a $\sin$, it was a sin against humanity rather than against God.

This point was reinforced by another story involving a man in wajd admonishing another man who was faking wajd in his midst:

$\mathrm{Zu}$ al-Nun Mesri came to Baghdad with his singer (qawāl) and a group sought permission for him to sing something. The sheikh gave his permission and the singer started [to sing].... The heart of $\mathrm{Zu}$ al-Nun became happy and he rose and came into wajd and he fell and destroyed his forehead and blood poured from it and he fell to the ground. And from that group one rose as if he was in the sama ${ }^{\circ} . \mathrm{Zu}$ al-Nun looked at him ... and that person sat down and this sitting down was from the fact that the person knew that he did not have truth and good intentions and he must not be in wajd..$^{51}$

In this story the true believer was able to identify and scorn the pretense of someone faking wajd, even as his own true experience of wajd left him injured. Thus, even as wajd lifted one believer up, human behavior and bad intentions made another participant a hypocrite. This type of hypocrisy was of great concern, with much space in writings about sama ${ }^{e}$ dedicated to discussing the intentional faking of wajd. 
The bad intentions of a given individual were, however, not the only hindrance to achieving union with the divine through sama ${ }^{\circ}$. Another issue presented by the human condition was the worldly aspect of the soul. Some writings about sama described the soul as a single entity, referring to it as either nafs (nafs) or or ruh (rüh). Others confront the divided soul of Islamic thought, which had two parts: the soul's worldly aspect (nafs) and the soul's spiritual aspect (rüh). In this model of the soul, the ruh consistently functioned as a person's connection to God, while the nafs occupied a significantly more complicated position. Though it could function as an evil spiritual force driving people toward worldly things, it could also function as an entry point for worldly things to join with the spiritual world. It could also function as a subsidiary of the ruh that was necessarily involved in the worldly state of an individual but was nevertheless controlled by the ruh. In relation to sama', sound had an allure for both aspects of the soul, and music specifically had functions in the spiritual realm that directly involved the soul. Depending on the spiritual state of the person listening, music could have an affect on the ruh or the nafs with the former generally treated as a positive and spiritual experience and the latter generally treated as a worldly experience that could have negative implications. Qushayri stated that

The effect of wajd in sama' is due to the good melodies and the measured voices, and pleasure in those things is the providence of the ruh and only that. Or the bringing together of voices with the meaning of poetic verses and the relishing of that which is held in common between the ruh and the heart in the truth of those seeking God and between the ruh and the nafs (nufüs) in the truth of ruined people. ${ }^{52}$

Under this scenario, listening to music could be spiritually positive or spiritually negative, just depending on which aspect of the soul it touched. Hence, Bakharzi stated, "Every person that hears sama" in truth becomes a truthful person and every person that listens with the nafs becomes an atheist" and "[For] every person that hears sama ${ }^{\circ}$ from the greed of the nafs the hearing of it is forbidden (harām)." ${ }_{53}$ Ibn Mutahhar described three categories of sama': general ('ām), special (khāss), and most special (akhaș). While the special and most special sama ${ }^{c}$ involved lesser and greater degrees of spiritual listening, when ibn Mutahhar described general sama" he stated that it "is heard with the nafs and it brings [moral] bankruptcy." ${ }_{54}$ This ability for the nafs to respond to music and turn the hearing of music into something evil even led various authors to state that sama' could only be beneficial to individuals in which "the heart is alive and the nafs is dead." ${ }^{5}$ Even with this negative view of the nafs, there was not complete unanimity on the idea that the nafs would cause a negative reaction with music if present. Bakharzi noted, "when the ruh gets enjoyment from melodies (naghmāt) the nafs that is evil (havâ' $\bar{\imath})$ is weakened." ${ }^{6}$

In addition to the issues presented by the worldliness of the nafs, authors of texts about sama ${ }^{e}$ also described various other imperfections of the human con- 
dition as a major hurdle in attempting to use music and sound to find communion with God. While sama ${ }^{e}$ in theory could put one in direct contact with God, authors often described the Sufi practice of sama' as having become nothing more than a social gathering with all kinds of moral pitfalls. Thus Kashani states:

Most of the crowds that are present in this time base it (sama') on sensual desire and physical enjoyment, not on the rule of truth and devotion and the search for increasing hal that the position of this method was originally based on. And the cause of the presence of groups in the assembly of sama', the motive, is consuming food so that in the assembly it is expected; and [it is for] the group preferring dance and lust (lawu) and enchantment (tarab) and social delight ("asharat) and groups desiring to witness prohibited things and morally questionable (makrūh) things and groups that summon worldly aspects. ${ }^{57}$

Another common complaint about sama' in practice was the concern that common people ('avvām) would participate in it. This concern was based on the belief that the vulgar masses were spiritually lacking to such an extent that hearing music could only act on their nafs and thus be spiritually harmful. Qushayri stated, "I heard that sama ${ }^{\circ}$ is forbidden for the common people because they still have nafs." ${ }^{8} 8 \mathrm{He}$ also quoted the early Islamic jurist Shafi $(767-820)$ as saying that "[Sama $\left.{ }^{e}\right]$ is not forbidden, but for the common people it is morally questionable such that if a person makes it his profession his witness is rejected [at court]." 59 Ghazzali took a slightly different view noting that a common person who does sama "is allowed because enjoyment of any kind is allowed, except if he builds his custom and character [on it] and most of his time is made for the purpose of it. This is the same stupid person whose witness is refused." 60 There is a certain contradiction in how often guidelines for commoners must be discussed and how often they are barred from sama ${ }^{e}$. Bakharzi actually gave the protocols for what to do when the Sufis' sama' was with a singer who was a commoner. Yet he also suggested that sama' should always be done at night so that the common people did not know about it. ${ }^{61}$

Ultimately, what authors who discuss sama' were attempting to work out were the difficulties involved in bridging the divide between the imperfection of humanity and the perfection of God. The goal of sama ${ }^{e}$ was to bring one into contact with God, however the various imperfections and intricacies of the human condition inevitably entered the picture and hindered this goal. In embodying both human and divine elements, music necessarily became part of this ongoing negotiation between the worldly imperfection of humanity and the ultimate perfection of God. On one hand, music was a cosmic force that could be produced systematically by humanity and thus had the potential to provide a bridge into the spiritual realm. On the other hand, music in the hands of humanity's imperfection could not guarantee the right spiritual outcome. This situation necessarily precluded the possibility that music and sama could ever be consistently treated 
as a wholly moral practice for human beings, who were inherently fallible, even in their search for God.

\section{CONCLUSION}

Problems presented by musical forms of listening have four different sources. Initially, there was no clarity in the Islamic historical or religious record regarding how music and sama' should be regarded. Though sound could be organized in a way to affect humanity's spirituality, the Qur'an was silent on the issue, while the hadith and other stories about early Muslims contradicted one another. Yet musical forms of expression could possess extreme power over the human condition. Anything that could manipulate the human body and mind to the point of causing physically impossible feats and even sudden death could hardly be considered insignificant to humanity's well-being. Conversely, writings about sama confront the reality that musical expression was quite common. The sound of music was powerful but it was also everywhere, often beyond the control of the wise and powerful and in the hands of the ignorant. The source of music's power was also unknown: it derived from the cosmos but its ultimate source was obscured by the limits of human understanding.

Authors of texts both on sama ${ }^{e}$ and on the twelve-maqam system document a wide variety of contexts where music had a role to play. Music existed in the grandeur and legitimacy of the dynastic court, yet the court was not wholly responsible for maintaining spiritual mores, and courtly gatherings for entertainment had the potential to be debaucherous and counter to greater unity with God. People also used melody to make the camels go and to help children go to sleep. Musical expression happened in the house of the Prophet and in heaven. Both those seeking unity with God and those seeking to indulge their evil sense-pleasures performed and listened to music. Music could bring one closer to God, or it could make them forget about God altogether. It could speak to the nafs and destroy someone, or it could speak to the ruh and facilitate a connection to God. Music could move the body and bring one to God without the individual's intent or even consent. Likewise, an individual's intent could intervene and turn music and sama ${ }^{e}$ toward less desirable designs.

This diversity of moral contexts existed at the convergence of music's cosmic power and humanity's inherent imperfection. For all of the unity of the cosmos, the practice of sama e embodied the notion of humanity's separation from God and longing to find unity with a divine source apart from itself. The twelve-maqam system aligned with the logic of the cosmos, yet it existed in the hands of humanity. Music's dual reality as an expression inherent in God's creation and an expression of humanity made on human terms raised questions about the source and use of its power. A wholly cosmic expression could create inherently good empowerment for humanity in its pursuit of the divine. Human intervention in cosmic expres- 
sion, however, could introduce imperfections that turned the power of music toward something more sinister.

Discussions about musical instruments in writings about sama highlight the issue of music's cosmic/human predicament. The human voice could be used to sing without any deliberate modification: God created the human voice in such a way that it could sing. The ability to include words and melody together in song also gave specific moral clarity to musical content. By contrast, musical instruments took God's creation-trees, plants, and metals - and turned it into objects that were products that changed the creation of God into something much more explicitly human. While a reed flute could be simple enough to evoke its original form as a plant among the creations of God, the more complex and sophisticated stringed instruments relied on so much worldly input from human sources that the form of their original materials in nature was unrecognizable. Additionally, their voices lacked words as a tangible source of moral definition. In a real way, musical instruments were less godly than the human voice. For such completely human constructs to be able to manipulate people's mental, spiritual, and physical condition in such a profound and abstract way could easily suggest that something or someone other than God was doing the manipulation. When made using instruments, music's ability to affect humanity was profound but the source of its power was ambiguous even as its voice was undefined.

Writings about sama place the power of the twelve-maqam system within the perspective of humanity's ongoing challenges in achieving greater unity with God, even while inhabiting a deeply fallible human body, mind, and soul. Certain people could achieve great wisdom to overcome this fallibility, and writings about the twelve-maqam system emphasize wisdom and knowledge as a matter of establishing music's legitimacy, both within the broader cosmos and in relation to the human experience. Texts about the twelve-maqam system describe music as having power too strong to be a neutral phenomenon among humanity. Without any specific explanation for music's power in relation to God, music came with no specific information on which "other world" it served. The power had to be used wisely. Like the structures and application of the twelve-maqam system, listening to music required an adherence to objective standards of wisdom that related to the nature of the cosmos and humanity at large. 


\section{The Politics of Song}

Music for Kings, Music for Empire, c. 1400-1722

In the city of Isfahan, several palaces still stand from the Safavid Dynasty, which ruled over the Iranian Plateau around 1501 to 1722 . The Safavids invested much in the grand appearance of their persona, overseeing the building of great architecture and a renaissance in visual art that surpassed their Timurid, Mongolian, and Turkmen predecessors. In their 'Ali Qapu Palace one can still visit the Safavids' so-called music room: a very ornate room for courtly entertainments with a very effective acoustical design (see figure 5). Inside the Safavid Palace of Forty Columns (chehel sotūn), musicians appear in multiple murals. Depictions of different Safavid rulers engaging in the dynastic duties of fighting and feasting (razmo bazm) appear in the reception hall of this palace, where contingents of musicians and dancers appear in the murals of feasts. One commemorates the reception of the Mughal ruler Humayun in the Safavid court by Shah Tahmasp I (r. 1524-1576) (see figure 6). Another depicts Shah 'Abbas I (r. 1588-1629) hosting the ruler Vali Muhammad Khan from Bukhara (see figure 7). The Shah who built the palace, Shah 'Abbas II (r. 1642-1666), appears in a third mural welcoming another ruler from Central Asia, Nader Muhammad Khan.

Both the music room and the murals are part of a larger representation of Safavid power that was meant to be seen. Shah 'Abbas I initiated the building of 'Ali Qapu palace as a grand entrance to the Safavid domain, right on the main square of the Safavid capital. In the reception room at the Palace of Forty Columns, the murals of Tahmasp I, 'Abbas I, and 'Abbas II are on display in a room dedicated to receiving visitors. The murals of feasts all feature large amounts of wine, food, and musical entertainment laid out in front of the royal entourage, which is organized in a V-shaped formation pointing toward and the prominently positioned shah. 


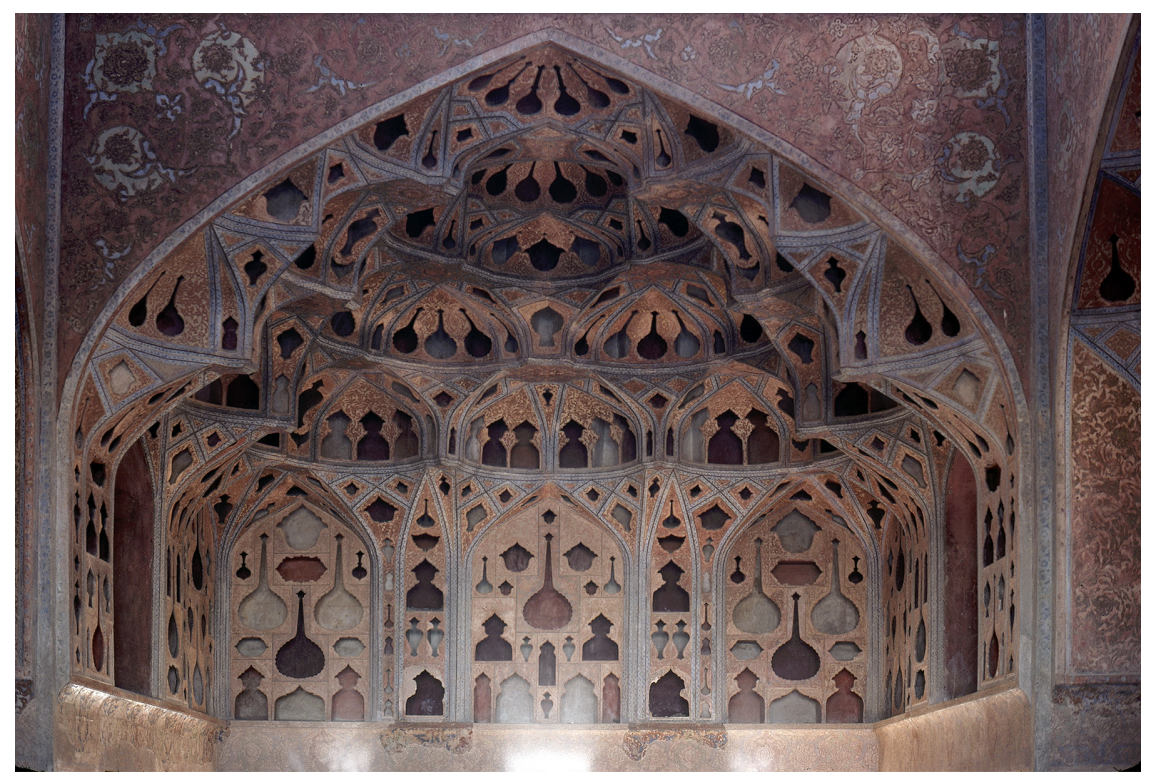

Figure 5. High Wall in the "Music Room" of the "Ali Qapu Palace. Photo by Sheila Blair and Jonathan Bloom.

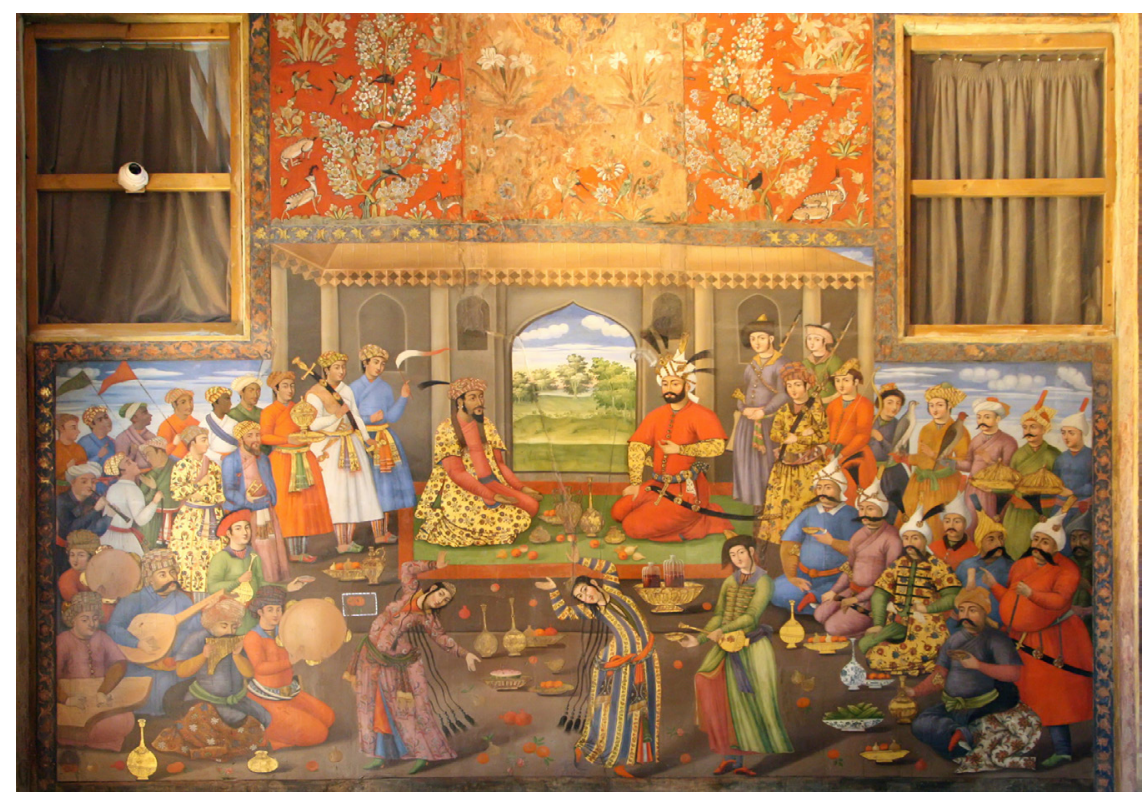

FIGURE 6. Mural of Shah Tahmasp I with Humayun in the Palace of 40 Columns. Photo by Muhammad Mahdi Karim. Licensed GFDL. 


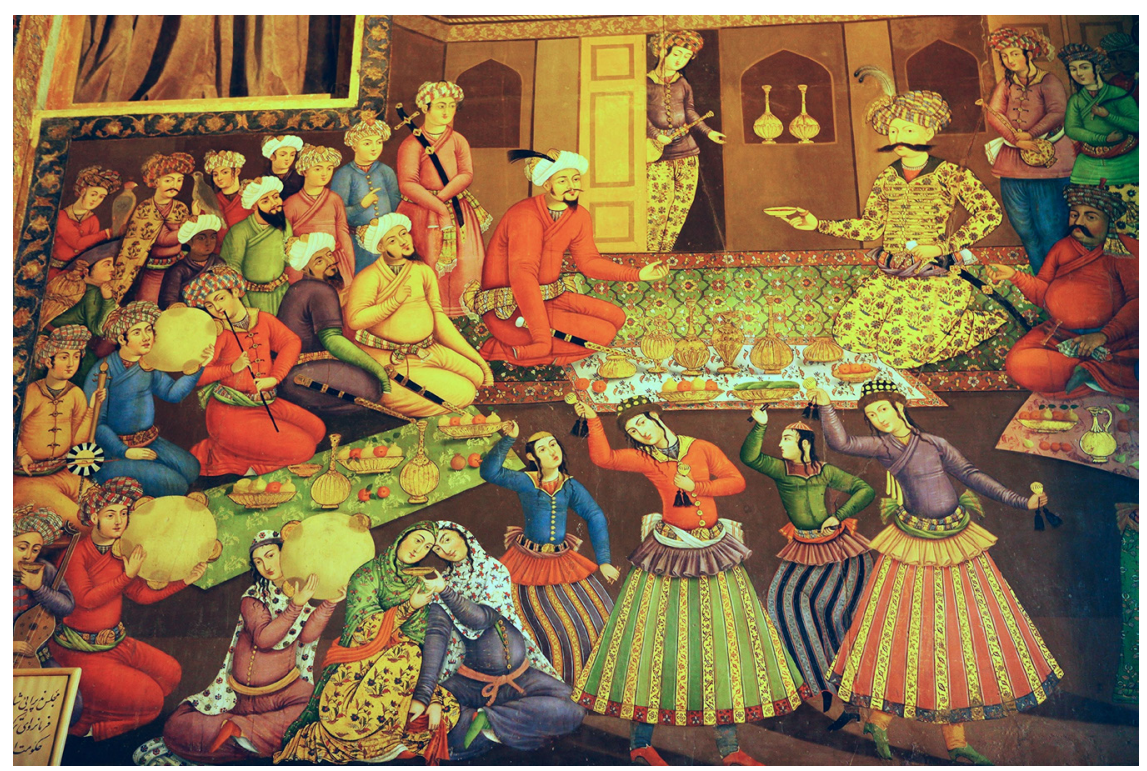

FIgURE 7. Close up of the mural of Shah 'Abbas I with Vali Muhammad Khan in the Palace of 40 Columns. Photo by Kaisu Raasakka.

The visiting rulers are depicted as humbling themselves in front of their Safavid hosts. Such scenes visualize music as part of the depiction of dynastic authority: the vision of the dynast as the sole claimant and controller of an immense bounty of resources, which he benevolently made accessible to those who would subject themselves to his authority.

Speaking with Iranian musicians today, I was surprised to hear that they largely view the Safavid Dynasty as a low point in the history of Iranian music. In current narratives, Persian music was budding anew at the end of the Caliphate in the thirteenth century. The Ilkhanate and its offshoots had a role to play in this, but the musical renaissance reached its zenith under the Timurids in the fifteenth century, with some input from the courts of their Turkmen competitors. This renaissance somehow collapsed at the beginning of the sixteenth century, when the Timurids fully succumbed to the Safavi, whose reign ushered in a period of musical decline. This narrative among Iranian musicians goes back at least as far as the mid-twentieth century, but I found its ongoing resonance curious. Iranian musicologists have done much research on music of the Safavid Empire since 1978, and found much music-making under court patronage during their reign. Timurid art did not feature large murals of Timurid feasting with musical entertainment, nor is there any known Timurid architecture that featured an acoustically distinct room particularly well suited for musical entertainments. Other Mongol and Turkic rulers also did not demonstrate interest in such conspicuous demonstrations of their courts' 
musical consumption. These Safavid predecessors did have miniature paintings within illuminated manuscripts, which depicted various scenes described in the text, among them the same kinds of feasting scenarios valued by the Safavids, albeit on a much smaller scale. The Safavids also had their own elegant illuminations, with beautifully appointed feasting scenes including musicians that, once again, outshine their predecessors. Looking at the visual art, music appears quite valued in the Safavid Realm.

The most common reason musicians cite for Safavid musical decline is the rise of Shi'a Islam. The Safavids' historically unique association with Shi'ism was an important defining feature of their rule, and many Safavid rulers demonstrated a zealous commitment to their particular religious predilections. Indeed, a few Safavid rulers banned music in their courts at various points during their reign. For instance, music was a very active part of Shah Tahmasp I's court, until he decided to dedicate himself more fully to a religious lifestyle. In making this change he did away with his court musicians and those of his princes, though he kept his military band and it seems musicians found their way back into the Safavid court shortly after his death.

In a somewhat more consistent contradiction, there was an active outcry against music (ghina $\bar{a}^{\mathrm{e}}$ ) from multiple Shi a clerics of the Safavid Empire. Indeed, these writings demonstrate a high degree of moral disapproval for music, though the issue was not a settled one in clerical circles. One issue appears to have been the relatively new position of Shi ism as the primary conduit between dynastic and religious authority. Shi'a clerics had to be initially imported to create the structural link between dynast and religion, and Sufism was not so easily replaced in the power structures of empire. Before their rise to power, even the Safavids had been involved in a very heterodox version of Islam that presented a combination of Shi ism and the types of mystical ideas and practices more closely identified with Sufism. While the development of their own Shi a orthodoxy from the beginning of Safavid rule under the Isma il I (1487-1524) specifically put Sufi sects out of the court, Sufism occasionally crept back in, even in the midst of Shi a authority. In this context, Shi a outcry against music using moral rhetoric could not be entirely separated from the new clerical class's need to represent and distinguish their own political power vis-à-vis competition from Sufism. Shi a attacks on music as immoral related closely to Shi a critiques of Sufism, and these critiques had very strong political motivations. ${ }^{1}$

These particular instances of religious equivocating on the question of music's moral acceptability provide the frameworks for Shi' ism to stand as a primary factor in notions of Safavid musical decline. But there were other signs that music's situation had changed within their empire. Sufi writings became scarce in the Safavid Empire, including writings about sama', as Sufism's influence waned in political circles. More significantly, Persian writings about the twelve-maqam system from the Safavid Empire are somewhat different than those written in the 
five centuries previous. Safavid musical writings repeat themes of earlier writings, but do not often elaborate on technical issues. The mathematical quantification of intervals, the systematic construction of scales, and various complicated topics regarding the interworkings of sound and musical instruments largely disappear in the Safavid Realm. There is an intellectual sophistication in writings about music before their rise to power that disappears under their rule.

With complex, technical explanations of music out of the picture, metaphysical tropes became a more central focus of Safavid discussions of the twelve-maqam system. This new focus in writing spent more time drawing basic parallels between the twelve-maqam system and the prophets, the planets, the zodiac, various times of day, seasons of the year, and so on. While the basic idea of these types of associations had precedence in earlier Persian music treatises, they appear as a welldeveloped focal point that comes to define Safavid writings about music. There were even new congruencies, as the forty-eight gusheh had to be accounted for and new aspects of nature were added, such as associations between the twelve maqam and the vocalizations of different animals.

These very symbolic representations of the system appeared with some general reporting on musical forms and song structures that were unique to the Safavid era. But while much writing about the twelve-maqam system from before the Safavid era required a lengthy and dense style of writing, such cerebral writing was less relevant in the Safavid Empire. Conversely, poetic descriptions of the twelvemaqam system increased in Safavid writings about music, which ultimately valued clear structural style over and above a greater degree of detailed musical substance.

Complex questions concerning topics such as the nature of consonance versus dissonance and proper intervallic relationships of pitch had been the legacy of earlier musical thought in Graeco-Arabic writings preceding the twelve-maqam system. Writings about music in the Safavid Realm express no specific knowledge of this philosophical tradition, which had directly informed much writing about the twelve-maqam system in the Persian language before the sixteenth century. It is this lack of conscious education in specific musical concerns of the adjacent past that makes Safavid writings on music appear to be "in decline": they forget so much of the intellectual context for music's conception in previous centuries.

Additionally, representation of the twelve-maqam system waned in Safavid territory as the empire itself declined going into the eighteenth century. Even as this happened, the twelve-maqam system maintained relevance in the Moghul Empire, where it was often put side by side with descriptions of South Asia's rag/ragini system. Thus the twelve-maqam system went from the mostly commonly held understanding of a universal music system, to being just one possible interpretation of such a system in the wake of the Safavids' demise.

Some contingency affected music discourse in the Safavid Realm and its ability to mirror fully past musical priorities. It appears that knowledge of the twelvemaqam system dispersed from the Timurid Empire into the Safavid, Ottoman, 
and Mughal Empires following the Timurids' final fall. One famous example of this dispersal is the family of the self-made musical sage Maraghi, who found themselves practicing music in the Ottoman courts, bringing some of their ancestor's knowledge with them. While this well-documented aspect of Turkish music history is the proverbial elephant in the room of Iranian music history, it was largely business as usual in the history of cosmopolitan Islamic Empire. The musical legacy of the Timurid Empire did not simply descend directly to the Safavids: musicians would ultimately end up in a variety of different courts across several different dynastic realms.

Other key contingencies affecting music in the Safavid Empire related to issues of size and longevity. For all of their visual grandeur, the Safavids had a relatively small and short-lived kingdom compared to their imperial Muslim neighbors. This did not make the Safavids bastions of musical austerity, but it did limit their ability to patronize music to the same extent as their dynastic contemporaries and predecessors, regardless of any Safavid rulers' religious or political predilections. It also meant that musicians who worked in the Safavid courts ultimately would have to move into the courts of the other surrounding empires if they were to survive after the fall of the Safavids in 1722. In the wake of the Afghan invasion, the end of Safavid rule created an unusually large power vacuum, which for several decades left musicians without a new, stable basis for aristocratic patronage in former Safavid lands.

The sixteenth century was a moment of broad political change across Western, Central, and South Asia. The Safavids, Ottomans, and Mughals all ran more centralized empires than had been previously possible even a century before. The changes that allowed for their various approaches to centralization were in part a result of new technologies-including military technology-earning them the title of "gunpowder empires." Thus the ongoing pursuit of the empire for more land and more resources continued, with new mechanisms that gave rulers a greater ability to more directly administer lands and resources under their control. While they all hand some of the same technological tools, each of the three empires centralized their authority in different ways. The Safavids specifically had unique ways of centralizing their control over music. Beyond visual representations of music, musical performance had some new and unique roles to fulfill under Safavid administration. These included Safavid administered Shi'a ceremonies with music, where Safavid shahs could act out their associations with divinity. Recitations of epic poetry in coffeehouses also came under Safavid control for a time, becoming one of several professionalized jobs with a guild organized and administered by the Safavids. ${ }^{2}$ In this context, the Safavids relationship with music was not unique in its moral rejection of music, or failure to patronize it. It was unique because the Safavids often had a more direct political investment in musical activities than their predecessors as well as a greater ability to directly manage music to suit their purposes. 
Even in the midst of this different kind of empire, the basic themes and premise of Safavid writings about music in comparison with writings of the previous Timurid and Ilkhanate realms were not so different. The twelve-maqam system was still the central concept of musical structure, with the additional extension of the gusheh derived from the system's foundational derivative concept. Safavid writings took their primary themes and focus within discussions of the twelvemaqam system from previous trends, with different emphasis on what mattered most in music's structure and expression. Even the positioning of an alternative music system next to the twelve-maqam system had precedence in earlier writings. The differences between the twelve-maqam system under the Safavids and their predecessors was thus significant, but not a wholly separate phenomenon.

In considering how the political changes from the Timurid Period to the Safavid Period affected the twelve-maqam system, topical expression in song is a useful source for analysis. Song texts-the words to songs associated with performance in the twelve-maqam system-tell a story about the life of the court and the aristocracy extending out from dynastic centers of power. Song texts represent a key nexus between music and its cultural contexts within dynastic aristocracies of Islamic Empire. While song text collections are the least common type of premodern musical writing in Persian, they appear next to discussions of the twelvemaqam system and provide strong insight into the pursuits of music's courtly audience. They give a musical voice to the image and interests of the court, laying out what courtiers considered important at any given time. Song texts demonstrate differences between Timurid and Safavid politics consistent with differences in how each dynasty ruled, and the different role of music in relation to each dynasty's distinct dynastic façade. Music in a dynastic context had certain implications for how the twelve-maqam system would be discussed and applied. Conversely, songs from the Timurid and Safavid courts express the different roles music could have within different dynastic contexts, while demonstrating how these differences affected discourse about the twelve-maqam system.

The earliest Persian song text collections that speak to the complications of music in their dynastic political context are from 'abd al-Qader al-Maraghi, who recorded song texts as forty-five courtly gatherings (referred to as majles) in his treatise the Jāmi al-alhān in Herat between 1405 and 1413. Maraghi indicated that courtly gatherings commonly focused on a single theme and thus recorded song texts according to theme in this collection without defining or referencing any performance information about different songs. In this collection, the focus is on the court itself: how it organized its entertainment and approached its reflection on topics of import to the court. A second, smaller anonymous collection attributed to Maraghi contains songs recorded separately, according to their maqam, usul, and musical form. Though there is no name associated with this collection, one song references the year $813 \mathrm{AH} / 1410-1411 \mathrm{AD}$. The date in this song places the collection within Maraghi's years of courtly service and together these two col- 
lections represent the interests of the dynastic aristocracies Maraghi ultimately served in both the Jalayarid and Timurids Dynasties.

Under the Safavids, two different song text collections have survived in a compilation of writings about music that Shah Husayn (r. 1668-1722) ordered to be created by his head of court musicians, Amir Khan Gorji. Amir Khan labeled his official accounting of Safavid musical writings with the year 1697, more than two decades before the Afghan Invasion. In this formal legacy document, Amir Khan included two collections: one that he put together himself and another from Aqa Momen Mosannef. Aqa Momen was the head of court musicians during the first half of the seventeenth century. His collection only included songs he personally wrote for multiple Safavid rulers. Amir Khan was the head of court musicians at the end of the seventeenth century, and as the person charged with creating the compilation he included both his own compositions and those of other musicians. $^{3}$ Most of Mosannef's songs mention the maqam they were sung in, while Amir Khan's songs provide much more information about how the song was performed, including the maqam, the usul, and the musical form.

While music treatises are part of the larger corpus of writings associated with the wisdom produced and maintained by various Persianate Islamic courts, collections of courtly song texts function as more explicit documents of dynastic legacy. While the smaller anonymous collection appears to be a functional reference for the head of court musicians, the rest of these collections are organized to put forth an image of court life for the benefit of the court and the image of the dynasts. They do not contain every song enjoyed at the court, yet they do contain a series of representative poetic content and themes, and key among these themes is the shah, also referred to as the sultan or the king (khusraw). The shah is the ruler of civilization: the one who controls people, land, and resources via military strength, dynastic power, and divine affirmation. It is the representation of the shah in song in the context of other courtly interests that reveals how the realities of the dynastic realm impacted music-making within the twelve-maqam system, and what changed in music from the Timurids to the Safavids.

\section{SINGING FOR THE JALAYARIDS AND TIMURIDS}

Songs with religious themes have a special place in Maraghi's collection of forty-five gatherings. Thus, the first gathering he records begins with the following song:

Praise to God, who created life from nothingness;

From this nothingness shedding light on eternal secrets

He remains in his kingdom, so glorious yet so humble

$\mathrm{He}$ is shelter for every wanderer, help for those who are helpless

$\mathrm{He}$ is the consoler of those who are sorrowful, the forgiver of those who are penitent. ${ }^{4}$ 
Though not the most common themes of the collection, the topics of God, the Prophet, and early Islamic leaders are featured prominently among Maraghi's forty-five gatherings, positioned at the beginning and the end of the collection, where they frame his full anthology. As the opening song text of the first gathering, this song contributes to the only gathering dedicated to honoring God directly. In the midst of devotion to God, the song uses imagery of the shah in order to depict the greatness of God. Thus one section sings:

Oh great shah, still and as yet

Sustainer without limit, creator without death

Your sea of mercy, exonerated of scorn

You are the everlasting king, exonerated of death.

The power of the shah described in this phrase is used to anthropomorphize the power of God. This metaphoric use of the shah extends into gatherings dedicated to the initial founders of the Muslim community, even as the songs begin to reference actual leaders. While the Prophet of Islam is always the Prophet, he is praised alongside his companions, which brings praise for kingly attributes of the early Caliphate. Thus, the third gathering is dedicated to singing the praises of 'Ali, the Prophet's cousin and an early caliphal leader. Here the song utilizes the imagery of battle and military prowess to expound his spiritual qualities. It sings, "His sword is the celebrated illuminating torch of religion; 'Ali is the lively horseman of the battlefield of chivalry."'

This imagery becomes more literal in the final gathering of the collection, which is also dedicated to songs about the companions. In this gathering a song refers to "Ali as "the shah of the people of God" while referring to another companion and caliphal leader, 'Uthman, as "the sultan of the world." The metaphor of the shah is replaced here by veneration of actual rulers of the Islamic community, whose leadership roles relate to the concept of dynastic rule.

In Persian poetry of Maraghi's time, imagery of the shah is used in the praise and description of God, while the emphasis on the kingly qualities of Islam's earliest leaders provides a basis of association between the early leaders of the Muslim community and contemporary rulers. This portends the centrality of the shah in all kinds of song texts recorded by Maraghi. The legitimacy of the shah could be established through religious affiliation, even as the power of the shah imbued religion with authority. While Islamic figures are singled out for unabashed praise in key places in his collection, the generalized trope of the shah is used to ponder many ideas, moods, and occasions throughout songs recorded by Maraghi. Using the title of shah as a symbol of powerful glory is only one side of this trope, with other perspectives being reflective, pessimistic, and even negative as the figure of the shah is used to extrapolate larger issues of the human experience. While God was a shah with everlasting life, songs in Maraghi's fourth gathering are dedicated 
to recognizing the morality of the shah on Earth. In one song, the shah speaks to himself about the limits of his own human power:

I could finally conquer the world like it is my body, within the control of my mind

I conquered thousands of castles with a movement of my arm

I broke thousands of hearts with the tread of one step

Thousands of kings are falling humbly prostrate in front of me

I have thousands of slaves standing prepared ready to obey my orders

At the arrival of death, none of the flags and drums could save me

Neither my Arab nor Turk army nor the army of mourning and crying

Death comes and I do not benefit from my military strength

The army of war cannot help me, nor the officers, nor the ability to retreat. ${ }^{7}$

In this moment of reflection, the resources and military power of the shah are showcased, even as death is positioned as the only thing that could defeat the ruler, just as it defeats all mortal things. In the first gathering, the power of the shah was emblematic of the power of God. In this gathering, he is the conqueror of this world, but not of the next. This use of the shah to emphasize the inescapability of death has a historical dimension. Another song from the fourth gathering sings, "Read the story of the shahs of the world, of Hoshang, Jamshid, and Chingiz-Khan. ... Many obtained the gold, the crown, the throne, and the treasure through great difficulty. But except for a good name they took none of this with them." ${ }^{8}$ The legendary greatness of shahs of the past and their inability to escape death highlight both the inevitability of the shah's death and the ongoing importance of a shah's legacy long after his death.

While the fourth gathering points to the general importance of a shah's legacy after death, the eleventh gathering focuses on addressing the legacy of rulers who mistreated their subjects in the distant past. Here songs single out Persian rulers before the age of Islam as examples of repressive rulers and their ultimate destiny:

Have you heard about the Persian ('ajam) Kings?

They committed injustice against their subjects

Their power and sovereignty did not last

The oppression of the people did not last

Within the endurance of cruelty, injustice might end

Injustice endured and it departed with grievances

The dry lips of the oppressed smile

As they tolerate the cruelty ...

Life passes like the prairie wind

My good, bad, beautiful, and ugly days passed me by

The tyrant thought he was oppressing us for life

Eventually, [though], it ended for us but it will remain on his shoulders for good. ${ }^{9}$

Like the song that referenced Hoshang and Jamshid, this song focuses on the stories of ancient kings from before the time of Islam, even invoking a style of Persian poetry found in Ferdowsi's Book of Kings, dedicated to these legendary 
figures. While stories associated with Ferdowsi's text are generally affirming of the shah and dynastic governance in general, this gathering references a grimmer view of the who these rulers were and what lessons could be learned from their legacies. While the shah is always a figure of great power endowed by both religious and military strength, this power could be used in various ways, good and bad. The power of shah came with perils, including how the bad actions of the shah would be remembered forever, unlike those of his subjects.

In the midst of songs that provide complex perspectives on the shah are gatherings dedicated to the more basic task of celebrating the contemporary rulers according to the specific occasions for a courtly gathering. Thus, in the gathering recorded for the celebration of the springtime new year's holiday (nawrūz), praise for the shah is in order:

Oh, Shah! Have a good time and be happy with your holiday

In the everlasting joy, may your holiday be happy

Oh, imperial monarch! The unparalleled God

Gave you dignity and livelihood, may your holiday be happy

Indeed, today, you are the refuge for the faith

The universe is the body and you are the soul, may your holiday be happy

People are joyful and feasting as long as you are on the throne

Have another round of wine; may your holiday be happy. ${ }^{10}$

Likewise, in the gathering happening upon the birth of a shah, the songs are equally lauding:

It is the birthday of the king of all kings of the world today

The effect of God's kindness is appearing again today

On the throne for all eternity

God giving good tidings of his prosperous fortune

It is the day of the emergence of the symbol of the secret of the two worlds

It is the birthday of the genuine son of Adam

Bravo, Oh goodwill of everlasting delight

Hail, oh dweller of the house of happiness and peace. ${ }^{11}$

Beyond these very formal occasions, the anonymous song text collection contains a song in which the singer pines for the shah in his absence:

When you go to Iraq, Shah, do not forget me

You remain with me in that separation, Shah, do not forget me

You are celebrated; this journey yields your prerogative, victory, and triumph

Return with the gratification of the heart, Shah, do not forget me

All of your work is victory; it is victory and triumph every day

Your day is all light and plenty, Shah, do not forget me. ${ }^{12}$

In all of these ways, the shah is a very prominent, common, trope in the songs of the Timurids and their contemporaries. While there is an ample amount of praise and devotion, there are also texts that reflect on the limits, problems, and 
risks of kingly power. Throughout all of these songs the shah is treated primarily as a concept rather than a specific person. Specific examples of rulers are pulled from history to explain more general themes and lessons for contemporary rulers for whom the songs were written. However contemporary rulers themselves are conspicuously absent. Not even songs voiced directly to contemporary rulers mention anyone by name. The trope of shah in these songs embodies an abstract figure that may be good or bad. He might be a cherished companion or an unapproachable figure of mythic proportions, yet always the shah is central to human existence and powerful up until the moment of death. The kingliness of religious figures represents part of their greatness, even as the shah personifies the greatness of God, and legendary shahs teach lessons about the nature of the institution.

While the shah is the most oft repeated subject of the song texts recorded by Maraghi, many songs address a variety of topics, independent from kingly matters. For instance, in Maraghi's nineteenth gathering songs discuss hospitality for strangers in need of assistance:

To the house that the guest enters

The homa bird (homa) of the lote tree lands on its threshold

What a great thing the prosperity of the lucky star, that one night like the moon

Comes down to my cottage without caravansary and without lord....

While I am the guest at the table of kindness

The strength of injustice is weakened

Be good and generous to the guest

Because it is advised by the Prophet to "serve your guest." 13

In the anonymous collection, one song ponders the short duration of youth and the prospect of growing old:

I have become old and replete with years of existence, yet I remain amazed

That life's sweetness has passed

I am in reflection and amazement of it

Because I do not know any amount of youth; I did not know, I would not know

That life is a valuable source I lost so cheaply

What benefit would wailing and crying bring?

The arrow from the bow is worn

But what is obtained from regretting?

When the bird has flown the cage

Look at the hand, empty and black, yet I am not regretful

I hope for nothing except mercy and repose. ${ }^{14}$

The nineteenth gathering has peripheral references to the shah and religion, mentioning the advice of the Prophet and referring to the luck of the mythical homa bird, which can confer the title of shah upon anyone it chooses. This 
anonymous song reflects on the realities of age and frailty associated with basic humanity. The shah is powerful in life and gone in death, but humanity in general grows weak with old age.

The themes of mysticism and romantic love, while central to the Persian poetry of Maraghi's era, are not more dominant in his collections than the shah. They do, however, make appearances in his collections. Maraghi records only one gathering dedicated to Islamic mysticism, containing a song about sama:

Knowledge of sama' makes one dance

Until the fire of its zeal forces one to sit for a moment

The wise know that the wet nurse at the child's crib

Rocks the cradle the calm the child....

Play in a light-hearted way, oh musician, out of kindness I play

Offer the heavy goblet of the cupbearer; from his hand I am so happy

Who is the musician that tonight comes to this place (maqām)?

Play the melody (pardeh) of 'oshshāq and do not hide behind the curtain (pardeh)

Make the gathering warm with one such melody

So that the wine starts to boil; sweat trickles from the embers

If my heart moves on, talking about different things

It comes around to the right way because it hears his voice

The rebab would not be performed correctly

But for the way his ear tells him to bow

The moon enters the wheel of fate that is the turning wheel of the universe

A face does not see his goodness, even with thousands of eyes. ${ }^{15}$

The song texts in this gathering are some of the few that reference the twelvemaqam system directly, as the songs focus on music and the role of the music in creating a specific experience for those who hear it. The reference to the cupbearer and the ambiguity of meaning in the musical terms maqam and pardeh are all very indicative of this subject matter, yet this is the only gathering where these literary mechanisms appear. Romantic love poetry has better representation in Maraghi's collections, appearing in five different gatherings. Thus, in the thirty-seventh gathering one song sings:

Last night I saw your face in a dream

Seeing the face of the moon is a sign of good luck

Your face, like the sun, is the desire of my heart

This ecstatic heart of mine, oh how sweet, the desire

I see your face everywhere in the mirror of my heart

The mirror of the heart is like the rays of the sun, I do not polish it....

Your eyes are charming, what can I do?

Your hair on your head is starting to seduce, what can I do? 
I was trying not to desire your forearm

Now that it is around my neck, what can I do? ${ }^{16}$

The theme of love in texts recorded from the fifteenth century is at times less romantic and more amusing. A song in the anonymous collection simply states, "When I was young, I had a lot of sex. When I am older, if I have the stamina, I will do it twice as much." ${ }^{17}$ This kind of focus on amusement, fun, and enjoyment apart from dynastic concerns forms the basic premise of several gatherings recorded by Maraghi. His thirty-third gathering is designated for singing anything as long as the song is in a language other than classical Persian. The fortieth gathering is dedicated to nothing but riddles, and the thirty-fourth gathering is an argument between humanity and wine. Here one section of the song presents arguments against the use of wine by a human voice, while in another section the wine replies to speak of its virtues:

He says, "Oh wine! Who are you? Speak!"

The person of religious law has decreed:

Your taste is bitter, your sweetness is sour

You make emptiness and your actions are impious

You deserve the house of the owl, may you be tormented!

[Wine says,] It is permissible to pray with me

My prohibition does not come in the hadith and it does not come in the Qur' an

The Sufi, the person who is inwardly upright; the pious person and the ascetic all

drink me

I do not bring corruption to anyone's door

I solve problems on points of investigation

I make meanings clear in the mind, like the sun. ${ }^{18}$

For all of the various songs that take a somber tone or reflect seriously on the problems of humanity, many of the songs Maraghi records have some amount of levity and wit. Beyond this, several types of songs reflect on aspects of nature, some of which have parallels with writings about the twelve-maqam system. For instance, Maraghi records gatherings dedicated to celebrating different seasons of the year, planets in the sky, and even different times of day, all features of nature tied to the structure of the twelve-maqam system. These topics have a characteristic place in song of the period even as these they contribute to the diversity of interests explored in musical performance.

While the shah stands as the most consistent theme in the songs recorded by Maraghi, the various topics addressed in the songs he recorded are quite diverse. Even the symbolism of the shah has diverse applications. Though always powerful, the shah has paradoxical connotations: he is good, he is bad; he is godlike, he is human; he must be born and he must die; the shah owes much to Islam, and Islam also contains the essence of the shah in its history. Alternatively, the shah could be absent from consideration, as songs and gatherings focused on other topics and 
observations within the human experience. The high degree of abstraction and anonymity found in songs that use the theme of the shah extends to the diversity of topics in Maraghi's collections overall. The beloved is not named in love poetry, and no specific musician is named even when the song is specifically calling upon a musician to play. The audience does not know who is arguing with the wine, and any singer could serve as the voice complaining of getting old.

\section{SINGING FOR THE SAFAVIDS}

While there are significant differences between Safavid songs and the texts of previous collections, there are also some points of commonality. Romantic love and mystical themes are shared between the Safavid and Timurid collections. Amir Khan recorded the following love song in his collection:

The cypresses dance and the roses sway;

Without the starling's song, they bear no delight.

To be with the sweet-lipped and rose-statured lover;

Without a kiss and embrace, it bears no delight

The garden, the rose, and the wine all please, but alas

Without conversation with my love, they bear no delight. ${ }^{19}$

Despite the Safavids' fervent Shi ism, multiple songs reference Sufistic types of mysticism, including sama ${ }^{e}$ and symbolic references to wine:

The mufti has fallen drunk on the seminary door again

His cloak has fallen from his waist, his prayer beads from his hand

The mufti drank from the cup

To nurture his reason and intellect

With each goblet he gave a thousand thanks

To the wine and the wine-seller

Our sheikh drinks the ruby wine to the sounds of the drum and the flute

The town magistrate that plays the tanbur with the flute

Asks for training with the plectrum at the time of prayer ${ }^{20}$

The treatment of romantic love and mysticism in Safavid songs mostly follows trends observable from the previous era. Songs about devotion to God and religious figures, however, are markedly different. This one mystical song is the only song that could be construed as referencing worship of God in the collections of Amir Khan and Aqa Momen Mosannef. Beyond this mystical theme, there is one other that references Islamic figures significant to Shi ism. In another song of Mosannef, one line sings, "Abandon the events of Rostam and Afrasiab. The Shahnameh you must read from is Bu Tarab." ${ }^{21}$ Like Maraghi's eleventh gathering, this line presents a negative view of the legends of pre-Islamic rulers, referencing two kingly names that appear in Ferdowsi's Book of Kings. It further encourages the listener to replace the Shahnameh with stories about 'Ali, a foun- 
dational figure in Shi ${ }^{e}$ a Islam referred to here as Bū Tarab. Despite his significance in Shi'ism, this single reference to Ali is less substantial than the praise he received in Maraghi's gatherings dedicated to praising the companions of the Prophet in general.

It is not only Islam that has less representation in Safavid song. Overall, the songs recorded from the Safavid era do not display the diversity and variety of interests of those recorded by Maraghi. This variety is largely replaced by a greater focus on adoration for the shah, providing florid descriptions of their power and extensive praise for contemporary Safavid rulers. Songs praise specific Safavid rulers in specific ways, often for specific reasons. Even when anonymous, the shah is still overwhelmingly the subject of praise and admiration.

The treatment of the shah in relation to holidays demonstrates the key difference between representations of the shah in Timurid and Safavid song. While Maraghi recorded one gathering generically praising the shah for the celebration of the springtime new year, the Safavid collections contain three separate songs, praising three separate shahs on the occasion of each ruler's specific celebrations of this holiday. Thus, one song sings of Shah 'Abbas II:

In the time of Shah 'Abbas, the shah who established justice

The cupbearer released the wine of justice to the wind

The musician began to play and the lover appeared

Sing two lines, oh nightingale, move around the box tree oh dancer!

It is the day of the new year and the presence of the shah has ignited the gathering

The cupbearers give wine so that in the year there would be such a day

One year comes as the new year grows, may it be blessed

In the feast of the shah, enjoy the delights,

Say to the shah of justice that this is the holiday of the great shahs. ${ }^{22}$

Another song sings of Sultan Husayn:

It is the day of the new year and the drunken flower is in the open meadow. . . .

May the season of spring be to the satisfaction of the king of faith, Sultan Husayn....

He goes like the sun in Aries, the ray of the universe

The shah of faith is in the garden and again the courtyard of the lawn becomes engulfed in light

May the season of spring be to the satisfaction of the king of faith, Sultan Husayn

In the image of the flower, in the embrace of the lover, and feasting in the corner. ${ }^{23}$

While the shah was an abstraction in Maraghi's songs for similar occasions, here the shah is someone specific and this specificity leads to topical redundancy in Safavid songs. It is not that any shah would be celebrated in song on any given occurrence of the new year; it is rather that each specific Safavid shah was celebrated specifically on the new year that they presided over. The natural renewal of spring was tied not just to the dominion of the shah in general, but to the dominion of the specific Safavid ruler in power. Pondering the problems and challenges 
of the ruler was no longer of interest. Praising the Safavid shah and depicting his grandeur were now a primary function of song. Mosannef also recorded a song where the springtime new year served as a royal function granted to a specific shah. Thus, the third song for the new year is a song for Shah Safi (r. 1629-1642), which sings, "they gave you great kingship and divine favor, thankful that the Creator granted sustenance for your renewal; He granted you the new year, conquer, and triumph; my great shah, my heart, may your power be everlasting; the honor of Shah Safi will be the victory of the world; everything his heart wanted, both stated and secret, will happen." ${ }^{24}$

The specificity of both shah and event is also displayed in songs that commemorate specific accessions and victories of shahs. For instance, one song dedicated to the military victory of Shah 'Abbas II in the city of Qandahar sings: "The shah who seized the ground and sky; from the fortune of youth he seized treasure and dignity; Alexander the First is 'Abbas the Second; his blade in an instant seizes heaven and Earth." ${ }_{25}$ This specific praising of a shah in battle reflects Safavid changing topical priorities. The invocation of a historical ruler such as Alexander the Great comes not as a point of reflection, but rather as a device to further praise a Safavid ruler. The reference to 'Abbas II's involvement in heaven and Earth highlights a key aspect of his unique ruling position as a Safavid dynast, who was portrayed as divinity on Earth.

Despite one song containing a short quip against the Ferdowsi's Book of Kings, Safavid song makes use of kingly imagery from the stories in this text in order to depict their dynastic authority. In another song, the justice of Sultan Husayn is compared to that of Nooshirvan, yet another legendary pre-Islamic ruler. ${ }^{26}$ Iran, the legendary domain of ancient rulers such as Nooshirvan, Jamshid, and Hoshang, also becomes a trope that supports the power of Safavid rulers. It is in Safavid song that Iran emerges as a subject of song, standing as a metaphor for the great kingdom that great rulers conquered and controlled. For example, in a song Mosannef wrote to commemorate a victory of Shah Safi's in Iraq, controlling "the army of Iran" validates Shah Safi as a strong dynast, capable of conquering the world:

Telling of the conquest of Baghdad, the story is heard in Rome and India

The shah who took the army of Iran in the direction of Rome

Among the victories of the shah, Najaf was secured and taken

Every individual ponders his person; oh way of respect, move ahead!

The shah won victory and triumph. When Caesar heard, he quit his command. ${ }^{27}$

In this context, the concept of Iran is invoked to represent a great kingdom that the shah controls, which will allow him to conquer more lands. He does not merely rule a place called Iran: he pulls upon it to pursue his conquest of the world. Iran is the proverbial jewel in the crown of the shah, in this case the crown of Shah Safi. 
Iran is featured more prominently in the few generic songs of praise for the shah, where no specific Safavid ruler is named. Thus one song sings:

In traveling the world, I see the countryside

I see scattered ringlets of perfume

Out of season, the dirt yields the rose and the tulip

In the cold season I see spring

May wine and entertainment be abundant for the shah

The world comes from the Iranian king. ${ }^{28}$

Naming no one in particular, this song nevertheless depicts the glory of the shah while using two recurring symbols of Safavid power: control of Iran and the magnificence of spring. The imagery need not be so specific to reinforce the image of Safavid power in song. Mosannef's song for Shah Solomon (r. 1666-1692) uses a more generalized discourse to depict the ruler's power:

Great shah, the condemned planet is not of your command

May everything that is life in the body be your sacrificial offering

The shah is the dome of the crown, the pivot of the kingdom

May you be one of the legs of the throne of Solomon. ${ }^{29}$

Here, Shah Solomon is elevated far above the lowliness of mere physical existence, while the closest the human listener could be to the shah would be to serve as a mere leg on the great shah's throne. It is this nearly deific depiction of the shah that pervades both songs from the collection of Amir Khan and those from Mosannef. While the imagery and context of the shah's greatness vary from song to song, the specificity of praise and admiration for Safavid rule is explicit and detailed. The Safavids wanted more praise for their position in song, and musicians delivered this praise, often in very specific terms.

\section{MUSIC AND THE CHANGING POLITICS OF EMPIRE}

The similarities and differences in topics of song from the Timurids to the Safavids reflect the similarities and differences in the rule of each dynasty and the specific role of music within their distinct discourses of dynastic power. In the context of a ruler's unique ability to engage in military battles and hold great feasts, music had been an aspect of dynastic power's definition in the Persian-speaking world since before the rise of Islam. With Islam came greater interest and ability to maintain and cultivate knowledge as an aspect of dynastic privilege. Music's status as an aspect of knowledge thus became yet another place where it could serve to define and demonstrate the parameters of dynastic power. In both of these capacities, various rulers since the end of the Caliphate adopted the demonstration of control over musical performance and knowledge as an indication of their authority and sovereignty. Turkic and Mongol rulers specifically followed in this tradition with their patronage of music. But the Safavids took these older dynastic traditions and 
used them somewhat differently, focusing less on the cultivation of musical knowledge, and much more on the extent to which music in practice could directly and explicitly voice Safavid power. Rather than passively contributing to the trappings of dynastic authority, Safavid music voiced Safavid dynastic authority in a very literal way: they named and praised specific Safavid rulers, using imagery that referenced tropes of dynastic authority.

The concept of a praise song for a specific ruler was not a regional invention of the Safavids. Long before Maraghi, Mosannef, or Amir Khan, al-Isfahani wrote his extensive Book of Songs (Kitāb al-aghānī), which included many Arabic song texts, including songs of praise for rulers and aristocrats of the 'Abbasid Caliphate. Much larger than the later Persian collections, the Book of Songs covered a wider variety of topics overall, with praise being one of many different possible subjects of song. In this historic context, Safavid praise songs for specific rulers were not something new, even as the lack of such specific praise songs in recorded Timurid and Jalayarid song texts does not mean they were unknown to them or unwelcome in their presence. Yet the disparities between the importance of kingly, musical praise between the two eras highlight shifting priorities. The broad permanence of the shah in the organization and history of human civilization is an important theme in Maraghi's song collections, even as the rarified culture of the courts where he lived valued ownership over a variety of knowledge. Conversely, Safavid court music had a greater emphasis on the glorification of the Safavids in their recorded songs. Kingly praise was the most important priority for songs recorded by Mosannef and Amir Khan. In comparison with Maraghi's collection, the diversity of topics addressed in the songs they recorded decreased, even as overwhelming praise for the shah increased in both quantity and specificity.

The Safavids had more centralized control of their kingdom than their predecessors, and their unique amount of centralized control clearly extended to their music. Whether supporting it or banning music, multiple Safavid rulers were generally more involved in setting a very specific definition of their dynastic personas, and they managed musical output as part of managing very specific aspects of their dynastic visage. They were interested in controlling some details of how music was practiced, at a level of micromanagement unknown to their predecessors. This micromanagement could come in many forms, either actively making music to directly validate Safavid power, or restricting certain types of music to this same end.

As the smallest, most-centralized gunpowder empire, the Safavids directly enacted their power over their kingdom in uniquely performative ways. The historian Kathryn Babayan refers to this as "The Safavi Theater of Authority." ${ }^{\circ}$ Unlike their dynastic predecessors, the Safavids co-opted various types of spaces and community events to demonstrate their kingly omnipotence in the presence of their subjects. Unlike with previous dynasts, the omnipotence of the Safavids included a kind of ambiguous divinity of the Safavids themselves. In making divine power an 
attribute of dynastic power, Shi ism was a key stage upon which the Safavids could act out their divinity. It provided ritual practices the Safavids could co-opt and enact in community space, putting themselves at the center of religious worship. Yet this was not their only stage. From the art and architecture of their capital city to the entertainment in coffee houses and the music of their courts, the Safavids used multiple musical stages to perform their godlike dynastic authority in view of their subjects. In this context, the Safavids would not have songs with religious themes like those of Maraghi. They had separate, performative ceremonies outside of the court to act out their alignment with religious figures.

Before the rise of the Safavids, the relationship between dynasty and Islam was one of mutual confirmation, with religion and empire validating each other. Maraghi documented a song where imagery of shahdom depicted the divinity of God, and another where kingly attributes of the earliest leaders of the Islamic community embodied their greatness as Islamic leaders. Conversely, the Safavids largely position themselves at the center of religious worship. Their predecessors had the kingly trappings of the ruling dynasty as a matter of course, spread out among various cities where branches of the dynastic framework operated. The Safavids tied power very directly to themselves in their capital, where they could control the projection of their power and the acting out of their narrative of divine rule. The fighting and feasting murals and the music room were part of this theater of visually stunning dynastic greatness worthy of worship, in the midst of musical expression that performed this worship.

These differences between Safavid rule and that of their predecessors impacted the written representation of the twelve-maqam system. Before the Safavids, the twelve-maqam system had been discussed in relation to overall knowledge and the complex contemplation of music had been part of a dynasty's unique power over the accumulation and documentation of knowledge in general. It was enough to extrapolate knowledge about music and any number of subjects, giving more complex explanations to demonstrate even more accumulated knowledge. Songs about the shah could highlight this privileged status, yet the control and production of knowledge were more important than using music to provide direct, verbal validation of dynastic rule. Writings about the twelve-maqam system reflect this priority of musical knowledge through to the sixteenth century.

In taking on a new role in the Safavids' theater of authority, musical knowledge for the sake of musical knowledge was not as important. Music's performative power was more important for the Safavids, even as an endless working out of archaic knowledge lost some of its value to more explicit visual representations of power. Thus, writings on the twelve-maqam system in the Safavid empire favored discourse that focused on more idealized visualization of the twelve-maqam system, concentrating on the pattern and schema as well as its idealized power in the world. Even as Shah 'Abbas I sought to make his capital city imitate the appearance of paradise, so too did the twelve-maqam system get caught up in more idealized 
representations of perfection. The basis of its idealized vision predated the Safavids, but it took on an overwhelming dominance in the Safavid domain.

Though the Safavid Dynasty administered their dynastic realm differently than their predecessors, they were still rulers of a dynastic realm, as their songs repeatedly acknowledge. Singing of Iran related directly to aligning Safavid rulers with a history of dynastic legends in the region, even as songs commemorating military victories asserted the Safavids' right to rule far and wide. They were not trying exclusively to rule a place called Iran. Like other empires, the Safavids sought to conquer as much territory as possible. Claiming first and foremost to have conquered the mythological kingdom of ancient kings called Iran bolstered the discourse of their right as dynasts to control any and all lands. Thus, the Safavid capital in Isfahan earned the title "half the world" (nesf-i jahān), and the Safavids pursued the possibility of ruling and subjugating lands over as much of the Asian continent as possible.

The Safavids had to keep pushing out from the lands they could control at any given moment, as Ottoman and Mughal leaders sought their own expansion of power alongside local leaders seeking to assert their own dynastic status. The Russian Empire's expansion into Ottoman and Safavid lands represented one element that contributed to the Safavid's downfall. The Afghan invasion represented yet another direct challenge to the Safavid's right to rule that they ultimately could not withstand.

In the end, the Safavids failed to maintain any significant growth of their kingdom. Despite songs praising specific Safavid victories and the subsequent conquering of new territory, the Safavids did not hold on to much territory they conquered from their imperial neighbors. The extreme centralization of their realm did relate to their inability to expand their domain and protect it from being overtaken. It was simply not possible for a dynast to administer, protect, and expand the realm without some of the more diffuse aspects of empire, especially more diffuse military support.

As more aspects of empire came to be run directly from Safavid palaces in the wake of difficult economic conditions, the Safavids set themselves on a course that contributed to their downfall..$^{31}$ The unique aspects of Safavid rule that contributed to a more direct deployment of music to serve Safavid interests also left the last Safavid rulers too weak to maintain their kingdom against foreign invasion. The Afghan invasion in 1722 ended Safavid rule in a very dramatic fashion, but not before Safavid decisions concerning the administration of their kingdom had left them susceptible to such an invasion.

The particular way Safavid rule ended resulted in a period of subsequent political chaos unique in the history of court patronage surrounding the twelve-maqam system. As a result, it began to lose standing as the focal point of music's conception. The twelve-maqam system had thrived in the midst of relatively consistent dynastic governance, but having a significant portion of its domain lacking stable 
patronage over decades had a significant impact on its relevance in the world. The twelve-maqam system in the eighteenth century was defined by how regularly it appeared alongside other ideas about music's structure. Sometimes it stood as a rhetorical device to legitimate a second music system; other times it stood as a coequal, alternative method of discussing a second music system. Dynastic politics was a key cultural factor that determined many of the possibilities for music's structure and practice, and thus the power of the twelve-maqam system weakened as dynastic institutions weakened. This allowed for other concepts of musical structure to usurp the twelve-maqam system's presence and power, a reality that created a whole new landscape for music in the nineteenth-century court of the Qajar Dynasty. 
PART TWO

\section{The Culture of Dastgah}





\section{Musical Structure, Musical Nation, c. $1800-1950$}

While the Qajar Dynasty would eventually reunite most Safavid territory under their control by the very end of the eighteenth century, the first writings about Qajar music apparently come somewhat later, in the mid-nineteenth century. And even the earliest of these writings document new concepts of musical structure that would ultimately underpin the emergence of the radif-dastgah tradition. Early writings about music associated with the Qajar court describe idiosyncratic models of procedural musical structure. They alternately referred to twelve dastgah or four shadd, which might also be called dastgah. But in both cases writings described a unique, separate procedure of musical development that defined each shadd or dastgah. ${ }^{1}$ There was not one shared superstructure unifying the organization of all dastgah: each one required a separate explanation of how it worked, from the beginning of a performance to the very end. While authors initially described varying numbers and terminology for these performance-based structures, seven dastgah eventually become a common framework for this procedural concept of musical structure. Descriptions of seven dastgah suggest the musical procedures of each dastgah could relate specifically to how instruments were played. Following this logic, a text dated 1912 from an observer named Mirza Shafi Khan described the melodic progression of seven different dastgah in terms of different tunings for strings and changing hand positions over the duration of a performance. This referred to how the music could be played on the tar (tār), a specific long-necked, fretted lute. ${ }^{2}$

However many dastgah there were in the early to mid-nineteenth century, musicians took the seven dastgah of the late nineteenth century and made changes to this particular tradition in the twentieth century. It is the seven dastgah of the 
late Qajar court and their transformation in the twentieth century that define the radif-dastgah tradition as musicologists understand it today. Even musicians with the most direct connections to the earliest practitioners of the seven dastgah in the nineteenth century were engaged in a music tradition steeped in modern musical change.

The centerpiece of the radif-dastgah tradition as musicians and scholars discuss it today is the radif: a specific collection of monophonic melodic material that provides the structure for the tradition's theory, pedagogy, and performance practice. The melodic material of the radif ranges from short motivic fragments to melodies with longer multisectional development, yet all of these different musical pieces and motives have come to be referred to individually as gusheh. The modern radif and current Iranian music theory subdivides the gusheh of the radif into twelve or thirteen subdivisions: subsets of gusheh that are thought to have modal affinity with one another. The primary term for these subsets of gusheh is dastgah, though smaller subsets of gusheh may be referred to as dastgah or avaz. Seven dastgah comprised the original designated structures of the tradition, with smaller avaz-dastgah being designated somewhat later in the twentieth century. Currently musicians vary in their distinction between the original seven and the additional four to five avaz-dastgah. Some treat the original seven dastgah as primary and the avaz-dastgah as secondary and this is often where the question of how many avaz-dastgah exist depends on the particular radif or performer. Others make no distinction between the original seven and the additional, smaller avaz subdivisions, typically referring to all of them equally as twelve dastgah.

The relationship between the gusheh and the dastgah is complex and different musicians and music scholars have described it in different ways. In keeping with the basic premise of the twelve maqam, one common approach to analysis used by musicians is to position each dastgah as an abstract modal framework or scale, and to describe the gusheh associated with each dastgah as being an individual melodic manifestation of a specific dastgah's modality or scale. Within this analysis, each of the seven dastgah and four to five avaz-dastgah represent distinct modal frameworks and each gusheh consists of small musical ideas and larger compositions that express features of the modal framework to which it is assigned. There is some disagreement, however, on how to represent exactly the essential parameters for these distinct modal frameworks. For example, figures 8 and 9 show two different possibilities, one documented by the ethnomusicologist Jean During according to the teachings of Nur 'Ali Borumand (1906-1976) and the other documented by the ethnomusicologist Lloyd Miller according to the teachings of Dariush Safvat (1928-2013). ${ }^{3}$ Each scholar's analysis shows how two different masters of the tradition described slightly different ideas about what constituted the essential features for modal frameworks in the tradition. The names of the original seven dastgah 


\begin{tabular}{|c|c|c|}
\hline $\begin{array}{l}\text { Name of the } \\
\text { Dastgah/Avaz }\end{array}$ & Dastgah & Avaz \\
\hline Shur & lg. & Avaz of Shur: \\
\hline Abu Ata & $\rightarrow$ & 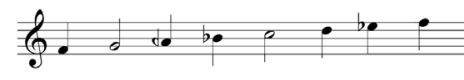 \\
\hline Bayat-i Tork & $\rightarrow$ & 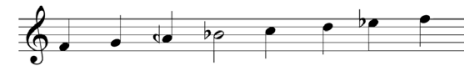 \\
\hline Afshari & $\rightarrow$ & 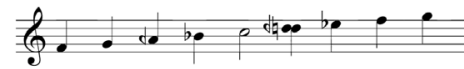 \\
\hline Dashti & $\rightarrow$ & b. $\cdot$ b. \\
\hline Bayat-i Kord & $\rightarrow$ & 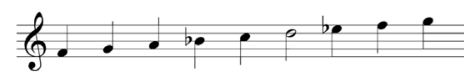 \\
\hline Mahur & $\ell_{*} \cdot \cdots \cdot \cdots \cdot \cdots \cdot b_{\bullet}$ & -- \\
\hline Homayun & 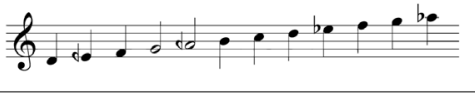 & Avaz of Homayun: \\
\hline $\begin{array}{l}\text { Bayat-i } \\
\text { Isfahan }\end{array}$ & $\rightarrow$ & $g_{\bullet} \cdot d_{\bullet} \#_{\bullet} \cdot e \cdot b_{\bullet}$ \\
\hline Segah & 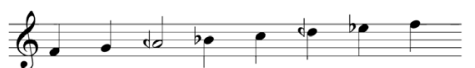 & -- \\
\hline Chahargah & 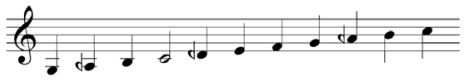 & -- \\
\hline Nava & 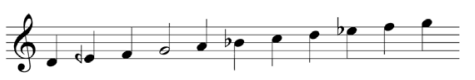 & - \\
\hline Rast-Panjgah & 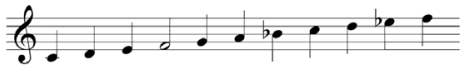 & -- \\
\hline
\end{tabular}

FIGURE 8. Modal interpretation of the dastgah by Jean During based on the radif of Nur 'Ali Borumand

are Shur (shūr), Mahur (māhūr), Homayun (homāyūn), Chahargah (chahārgāh), Segah (segāh), Nava (navā), and Rast-Panjgah (räst-panjgāh). Of the avaz-dastgah, Bayat-i Isfahan (bayāt-i isfahān) is derived from a set of gusheh that originally belonged within the dastgah of Homayun. Dashti (dashti)), Abu 'Ata ( $a b \bar{u}$ ' $\left.a t \bar{a}^{\prime}\right)$, Bayat-i Tork (bayāt-i tork), and Afshari (afshārī) are based on distinct sections of gusheh taken from the dastgah of Shur. One additional avaz, Bayat-i Kord (bayāt-i kord) may be added to the avaz of Shur, or simply counted as a section of Shur. 


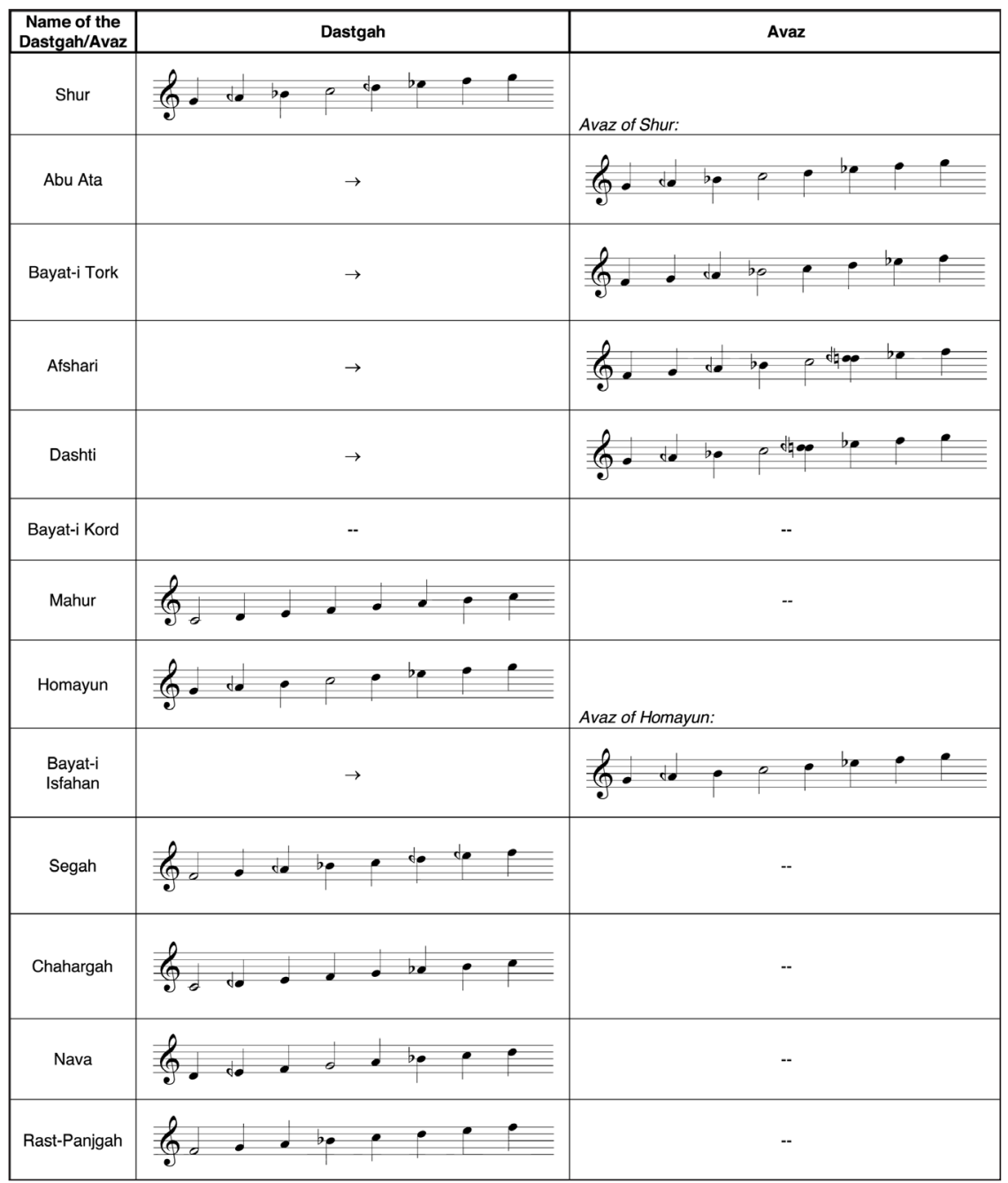

FIGURE 9. Modal interpretation of the dastgah by Lloyd Miller based on the teachings of Dariush Safvat

The complexities of defining distinct modalities for the dastgah and avaz-dastgah extend from the gusheh themselves, which have varying amounts of commitment to a single, shared modal framework when organized within their constituent dastgah. The later designation of the avaz-dastgah extended in part from melodic sections of the original seven dastgah having a degree of modal independence from their source dastgah. The discrepancy in the number of avaz-dastgah extends from disagreements about whether or not four or five distinct modal frameworks can be extracted from the dastgah of Shur. 


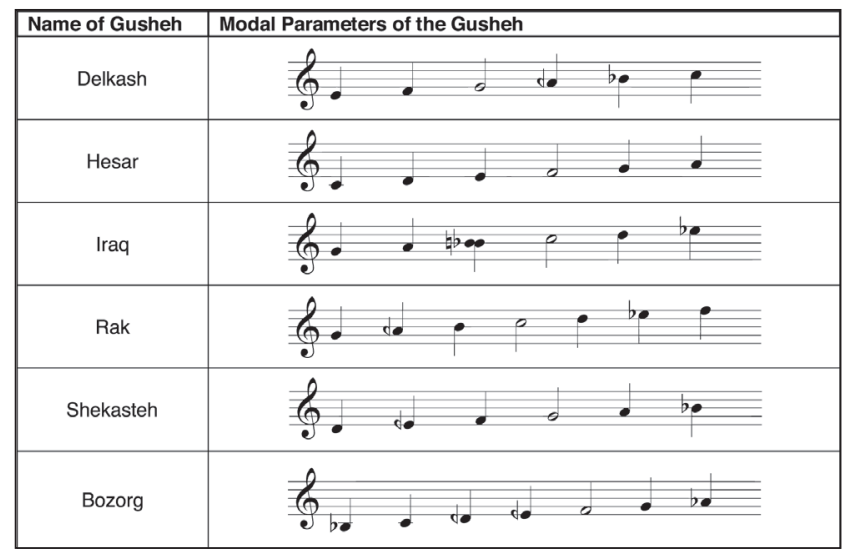

FIGURE 10. Examples of gusheh that exhibit modal independence according to Jean During

While the numbers of notes in each modality vary in During's interpretation of Borumand, Miller and Safvat represent all dastgah and avaz as existing within a set octave framework. Additionally, these models of modality in the system disagree on how to define the tonic (ل) of Shur, Abu 'Ata, Dashti, Homayun, and Segah. These two interpretations also represent Homayun's relationship with Isfahan differently, with During's analysis reflecting different modal parameters for each one, and Miller maintaining they still share the same essential modal framework.

Though there is variation in how musicians and scholars interpret modality in the radif-dastgah tradition, the growing definition and independence of the avaz-dastgah in the twentieth century did facilitate more consistency in utilizing distinct modalities in performance. Even with this adjustment, however, there were still individual gusheh that maintained strong modal independence from the seven larger dastgah in which they appear (see figure 10). While some dastgah contain more modally independent gusheh than others, musicians and scholars consider modulation an inherent part of each dastgah. Shur notably contains less modulation than the rest of the dastgah. ${ }^{4}$ This is likely because large sections of Shur were converted into avaz-dastgah, thus removing large sections of Shur that would have constituted multiple significant modulations.

Despite the modal diversity in the gusheh, teaching and understanding the dastgah and avaz-dastgah as overarching modalities that provide the dominant modal definition in the system are quite common. Conversely, a framework of performance that emphasizes the more complex procedural aspects of the original seven dastgah remains at the core of musicians' conceptions of the fully authentic Iranian music tradition. Thus, traditional Iranian music in its most authentic manifestations of the late twentieth century still emphasized the melodic idiosyn- 
crasy of the individual dastgah. If a musician or a group of musicians with a singer wanted to perform traditional Iranian music in its most authentic form, it would be the radif-dastgah tradition following a detailed procedural model: they would take one particular dastgah and perform the gusheh of it in a fairly set order, with varying degrees of improvisation on the different types of gusheh. This continued emulation of the radif-dastgah tradition's earliest manifestations has maintained an emphasis on each dastgah's idiosyncratic use of pitch in the course of ongoing melodic development even as notions of systematic modality have become a standard part of the tradition.

Within the modal diversity of the gusheh, musicians and scholars locate dastgah modality primarily in the gusheh that comprise the first section of a dastgah performance, referred to as the introduction or daramad (darāmad). The dastgah and avaz-dastgah all have a certain number of gusheh that are performed/ improvised upon first in a performance for the daramad. Most gusheh of the daramad are simply called daramad and then numbered to indicate their order in performance (first daramad, second daramad, and so on). Other gusheh may be considered part of the daramad and the gusheh called Kereshmeh (kereshmeh) is one of the most common gusheh to be included as part of this introductory section. While some are improvised upon more than others what the gusheh of the daramad have in common is their use of a specific, consistent modal range. As the performance continues, gusheh will move away from this range, both in terms of moving higher in range and in terms of modulation. Reiteration of the initial daramad modality at certain intervals knits together the ever-changing pitch usage of individual gusheh. Short codified phrases called forud (forüd) provide restatements of the opening modal range as the performance proceeds. Thus, the modal range of the daramad does provide a consistent modal touchstone throughout the performance.

\section{THE RADIF AS A MUSICAL WHOLE}

Another way of analyzing the system that ethnomusicologists have favored is to focus on the radif as a whole. When scholars have compared gusheh across the system of dastgah and avaz-dastgah they have found a variety of interrelationships between the gusheh. ${ }^{5}$ For instance, many gusheh actually exist in more than one dastgah with only small amounts of modal transposition or rhythmic variation, such as kereshmeh in the daramad. ${ }^{6}$ On another level, all of the dastgah tend to share gusheh that perform a certain function or behave in a certain way. For instance, highly rhythmic gusheh often appear in performance without much alteration, while gusheh with less metered construction are more likely to be improvised upon. Some gusheh are considered central to any performance of a specific dastgah, while others are considered less central and performers have the 
option of including them in their proper place within the dastgah or excluding them altogether.

A majority of gusheh in the radif derive from three concepts that define three possible melodic sections. One central concept is the idea of singing poetry using only its poetic foot as the rhythmic basis of its melody (she $r$ ). Another is the concept of tahrir (tahrir), with is a specific style of vocal improvisation without any words. Additionally, the concept of forud is often folded in with poetry and tahrir. A gusheh may use different combinations of tahrir and poetry, with the forud appearing at the end as a cadential figure. Conversely, forud can also be classified as independent gusheh in and of themselves, as can a single phrase of poetry or tahrir. Using these different types of melodic sections in different combinations can give gusheh a variety of melodic forms throughout the radif, but only a small number of gusheh do not employ them at all. The gusheh that fit this pattern are stylistically vocal, since they take a majority of their organization from poetry and ideas surrounding vocal performance. The emphasis on poetic meter over and above musical meter in many gusheh is key to the overall performance aesthetic. Poetic meter provides most of the rhythmic organization of this type of gusheh, which embodies an approach to rhythm that is ostensibly unmetered in a musical sense, meaning a drum does not accompany the melodies of these gusheh. Their loose, poetry-driven rhythmic structures also relate to using relatively small ensembles. They favor using one main soloist at any given moment in a performance, who makes choices about improvisation that a few additional instruments are able to follow and imitate. ${ }^{7}$

Most of the gusheh that are not derived from poetry, tahrir, or forud belong to a separate category of gusheh that utilizes two different metered forms intended for performance by instruments only: the reng (reng), which is a group instrumental piece in a moderate 6/8-style rhythm, and the chahar mezrab (chahār meżräb), a virtuosic solo instrumental piece usually played in a fast $2 / 4$. In contrast to the stylistically vocal gusheh, these two forms employ a distinct, steady melodic pulse often punctuated by a drum. In the course of performing a particular dastgah or avaz-dastgah, instruments play all types of gusheh, regardless of their stylistic orientations toward vocal or instrumental characteristics. By contrast, if a vocalist is present he or she would only participate in performing stylistically vocal gusheh and not the instrumental gusheh.

Though an analysis of the radif as a whole reveals much structural consistency, modal logic is still often taken by musicians and music scholars as a foundation of the system. Indeed, scholars classify gusheh that do not conform to the modal parameters of their given dastgah as modulatory figures, thus giving their noncompliance with the modal parameters of the dastgah a modal function in the course of performance. ${ }^{8}$ Yet tension remains between the specificity and 
idiosyncrasy of melodic material within the seven dastgah and the framework of abstract modality that many musicians and scholars like to use to describe the dastgah.

The development of more composition within the radif-dastgah tradition facilitated greater exploration and development of dastgah modality. The reng and the chahar mezrab became models for composition, focusing notions of composition on instrumental forms. A new instrumental form also appeared in the course of dastgah performance called pish-daramad ( $p \bar{i}$ shdarāmad). Though the pish-daramad is listed in the earliest available charts of the gusheh, musicians of the twentieth century regarded it as a separate phenomenon that was added later, distinct from the other instrumental gusheh. Like the reng and chahar mezrab, the pish-daramad has both a specific rhythmic count and a specific place in the order of performance. It was played by all instruments in the performance in a moderate $2 / 4$. It was designed to precede the daramad as a kind of overture, thus the name pish-daramad (before-daramad). The expanding application of composition within a largely improvisational performance practice allowed greater exploration of the concept of dastgah modality, as musicians made decisions about the modal parameters they would use to compose a piece that was not defined by any particular sequencing of gusheh or poetic structure.

In addition to the instrumental compositions, the insertion of metered songs (tașiif) into larger dastgah performances gave musicians and poets alike an opportunity to create contemporary compositions. While the vocal gusheh consistently used classical Persian poetry, tasnif could use newly composed melody and text. The tasnif would ultimately become the largest realm of composition. Its placement in the performance of a dastgah presented an opening for changes to performance structure. Tasnif provided moments of metered singing in the middle of a dastgah performance, in the midst of long sections of vocal improvisation. Any and all instruments could also perform tasnif in full heterophony with the voice, as meter allowed for full melodic coordination of an instrumental ensemble with the singer.

In the procedure-focused performance model of the radif-dastgah tradition, a musician or group of musicians would choose a dastgah or avaz-dastgah, and then use the gusheh of that dastgah or avaz-dastgah to give a performance that was typically divided between portions that were improvisation upon the vocalstyle gusheh and portions that consisted of verbatim reiteration of compositions and instrumental forms of gusheh. There are many potential ways of executing a performance within this format, but the instrumental musically metered sections would typically mark moments of transition: the beginning of the performance, the end, and transitions between the longer, unmetered improvised sections in the middle of a performance.

The customary long-form performance common in the early to mid-twentieth century often began with a pish-daramad. After the pish-daramad, the daramad 
introduced improvisation on gusheh that highlighted the basic modality of the dastgah. The daramad was punctuated toward the end by the rhythmic chahar mezrab. As the performance went on after the daramad, additional sections of improvisation on new sets of vocal-style gusheh moved further and further away from the initial modality of the dastgah while also moving higher and higher in terms of register. Forud figures appeared at various points, reiterating the original pitch set emphasized in the daramad. A tasnif composition demarcated the end of an improvisatory section. As tasnif compositions grew in number and popularity, multiple sections of improvisation could be delineated by tasnif, not just forud. Performing the reng marked the end of the entire performance of a dastgah.

The term avaz came to refer to the long sections of improvisation on the vocalstyle gusheh, and these sections were initially the essential core of performance. The dastgah served as a predetermined plan of which melodic materials would be used and in what order, but the concept of avaz governed the actual improvisational performance. Avaz was the procedural execution of the plan outlined for a dastgah in practice.

The radif of Persian music is the totality of the gusheh considered as a full repertoire across all dastgah and avaz-dastgah. There are different versions of the radif that are attributed to particular musicians who taught a particular version of the radif. There are also distinctions between the radifs associated with the voice and those associated with instruments, with instrumental radifs being larger than vocal radifs. Within all of this variation, there have also been attempts to establish the one true single Iranian radif. ${ }^{9}$ The contents of different radif reveal many similar gusheh that are likely to be seen in most radif, plus a certain number that are somewhat rarer and may only be present in one radif.

In looking for the origins of the radif as a phenomenon, musicians and scholars agree that it goes back to a Qajar court musician named Mirza 'Abdullah (18431918), who probably performed using seven dastgah, each with its own distinct progression of melodies. His brother Mirza Husayn Qoli (1854-1916) was also a musician and had a collection of melodies organized into dastgah that was distinctive from that of Mirza 'Abdullah's. Some musicians also mention one of their cousins, Gholam Husayn, as a major figure in the creation of the tradition, though no radif survives that is associated with his name. ${ }^{10}$

Both Mirza 'Abdullah and Mirza Husayn Qoli played the tar (tār): a fretted, long-necked lute with an unusual double-bellied body that was covered with some kind of animal skin attached to a long neck. The tar appears to have always had three courses of strings. The tar had never been described in texts about the twelvemaqam system, yet it ultimately became an instrument shared between Persian speakers and Oghuz-Turkic speakers, and an important instrument in both Iranian and Azeri music traditions in the twentieth century. The tar also appears to have been the instrument of Mirza 'Abdullah and Husayn Qoli's father, Farahani (d. 1821), who was a much-praised court musician in his own right. 
While this instrument is still a central instrument in the tradition today, there were other instruments musicians specialized in playing for the Qajar court that had some record of previous use in the performance of court music and these instruments also became part of the radif-dastgah tradition. These included a trapezoidal hammer dulcimer called santur (santūr) a four-stringed spiked fiddle called kemancheh (kemāncheh), a type of reed flute called nay (nāy), and another fretted, long-necked lute called setar (setār). Similar to the tar, both the setar and the kemancheh appear to have originally had only three strings, with the fourth being added in the modern era. Additionally, the length of the neck on a setar and tar is nearly identical. They also both have the same moveable frets and similar tuning systems. While the former is played with a long-nailed finger and the latter with a plectrum, they are nevertheless very similar instruments. In this context the tar was never a completely novel instrument compared to the setar. The setar simply had a longer documented history.

Beyond these instruments, vocalists were a very large component of the tradition from the very beginning. With poetry and the vocal improvisation of tahrir being key components of how most gusheh were ultimately constructed, the nature of vocal performance defined how performance took place. Musicians developed styles of playing for different instruments to imitate the vocal tahrir and the singing of poetry. Instrumentalists used this imitation either in call and response with the singing or in place of the singing if a vocalist was not present. Singers could also be drummers, accompanying rhythmic passages of a performance on a goblet-shaped drum (zarb) or a frame drum (daf). Beyond these indigenous instruments, the violin became a fairly important instrument in the tradition very early on, with some musicians preferring it to the indigenous spiked fiddle. In some cases, musicians in the tradition also played instruments with more standing in the nineteenth-century Ottoman Empire, including the qanun (qanūn) and the e ud (' $\bar{u} d)$.

Overall, understanding music through the prism of long-form, highly specified musical procedure made the music of the radif-dastgah tradition quite distinct from the music of the twelve-maqam system. Even with a growing emphasis on abstract modality and composition during the twentieth century, the radif-dastgah tradition remained a practice of complex melodic idiosyncrasy associated with a particular long-form performance derived from musical improvisation upon poetry. While the twelve-maqam system distinguished between pitch modality, rhythmic cycles, and their paired application of composition, the radif-dastgah tradition did not initially have these distinct categories of musical action, nor can these distinct categories fully account for the fully formed, poetically metered melodic material of the radif. From the beginning, the seven dastgah were something much more complex than seven distinct melodic modes.

The concept of rhythmic cycle so central to music-making in the twelvemaqam system specifically had a reduced role in the radif-dastgah tradition, as 
vocal-style gusheh and the avaz used no percussion or musical rhythmic cycle. The addition of more compositions created more opportunities for abstract modality to be paired with rhythmic cycles in the twentieth century. Yet the categories of compositional forms were few and distinct when compared to those described in the twelve-maqam system. The ideas concerning the internal structure of composition from the twelve-maqam system no longer applied, and song types defined by the usage of poetry in languages other than Persian disappeared. Perhaps most notably, the radif-dastgah tradition initially relied upon and eventually acknowledged notions of musical improvisation distinct from composition. Discourse concerning musical improvisation-both what it was and how to do it-became more explicitly central to the definition of the radif-dastgah tradition's authentic style of performance practice as the twentieth century progressed. ${ }^{11}$ Conversely, it had no specific meaning as a musical concept and little acknowledged structural significance in twelve-maqam-system performance.

In relation to improvisation, the importance of the avaz in radif-dastgah performance prominently distinguished music-making of the modern tradition from that of the twelve-maqam system. Both before and after the additional modal structures were extracted from the original seven dastgah, the term avaz referred to long sections of music-making based on a procedural working out of both melodic and poetic material. A closer look at the gusheh used in the avaz shows that many gusheh contain one couplet of a single poem, perhaps two, and that the progression of gusheh together often narrates large portions of single poem, with smaller sections of separate poems punctuating this single narration at certain points in the melodic progression. ${ }^{12}$ So it is a specific application of poetry-often explicitly sung, but always underpinning the melodic organization of the gusheh in the avaz-that provides the procedural basis to extrapolate upon melodic material in a section of avaz.

This approach to music-making is different than a suite organization, such as the nawbat murattab from the time of Maraghi, or similar organizations common in the Arabic- and Turkish-speaking areas to the west of Iran, such as the wașla of the Mashreq or the nawbah of the Maghreb. These other performance models string together metered composition into contemporary suites, and modern traditions use unmetered improvisation to connect the distinct compositions. Each composition is a piece or song unto itself created in a specific mode that musicians can then place into the suite organization, depending on which mode musicians decide to use for any given suite in any given performance.

Conversely, the avaz at the core of a dastgah or avaz-dastgah performance has shorter melodic sections (gusheh) that must fall within a melodic progression that is set by poetry. The gusheh themselves are not independent compositions and their relationship with modal consistency is much more complicated because musical progression is largely dependent on poetic progression. In a very real way, poetry sets the musical organization of avaz, rather than music organizing the 
poetry. Metaphorically they are like pieces of a dastgah music puzzle: small, highly interconnected though individually distinct, holding a fixed position that only makes sense in the proper context of a large musical whole. With poetry recitation determining many parameters of the musical whole, the role of metered composition is necessarily different and more limited. Its position is defined by how it best frames the poetic progression of the avaz.

The radif-dastgah tradition is surrounded by similar models of performance, where poetry recitation determines a long-form musical structure organized around procedures that emphasize delivery of the poetry. Of these related traditions, Azeri Mugham is the closest to the radif-dastgah tradition in terms of both structure and historical proximity. Yet similarities can be seen in music traditions stretching from Baghdad all the way to Bukhara. The basic premise of the radifdastgah tradition derived from larger transregional trends in musical performance that were in place in the eighteenth century. But the unique aspects of the Iranian system would be shaped by the particular music practices in the Qajar court in Tehran, the development of the nation of Iran itself, and the place of music within an Iranian national identity. ${ }^{13}$

\section{THE RISE OF THE QAJARS AND THE NATION-STATE}

The Turkic tribes from which the Qajars came had been part of the militant Shi'a Qizilbash, who had supported the Safavids from the beginning of their rule. At the time of the Safavid's fall, they were located in and around the southeast coast of the Caspian Sea. They vied for dynastic control over former Safavid lands, but they were not able to take control of a significant portion of these lands until nearly a century after the Safavids fell from power. The world the Qajars came to rule in at the cusp of the nineteenth century, however, had already changed in significant ways since the fall of the Safavids. The Qajars would not be able to sustain an empire of extracting resources from land and subjects for long. The Ottomans and Mughals were already embroiled in attempts to negotiate their imperial power with the demands of modernity and the Qajars had to quickly adjust to the same modern circumstances their neighbors were confronting.

The devastating circumstances of the Afghan invasion in 1722 created a significant interruption in what continuity had existed for musicians moving from court to court, maintaining a similar conception of music over centuries as dynastic patrons rose and fell. The gap in consistent patronage created by the invasion meant that the Qajars did not come to power and immediately acquire Safavid musicians, nor is it clear that they acquired whatever musicians the smaller Afsharid or Zand Dynasties may have had in their service. They initially kept court close to their home territory in the city of Tabriz, but ultimately chose Tehran as their imperial capital, a place that had not been a major dynastic capital in the past. In attempting 
to build a new capital for their kingdom in a location with little dynastic history, the Qajars did not have the benefit of building off of significant institutions established by dynastic predecessors. They made music an aspect of their dynastic life, using the same venues of dynastic musical performance the Safavid's had. They had music in their court, as well as military music and Shi'a rituals performed in public that also used music. But the types of music used in these venues were not necessarily the same music the Safavids had used. Specifically, they did not seem to have anyone associated with music in their court that had a direct connection to the twelve-maqam system or the specific literate culture that had surrounded it. The radif-dastgah tradition thus emerged out of a unique fissure between Safavid and Qajar court culture. The loss of continuity meant that music had a unique opportunity to change in the courts of the Qajar Dynasty, even as the nineteenth century required musical change in relation to new structural changes of the modern sociopolitical landscape.

In the particular moment the Qajars came to power, a transition that the historian Marshall Hodgson calls "the great transmutation" was well on its way in the Middle East. ${ }^{14}$ The two primary global changes that affected this transmutation into modernity were the rise of a global economic system based on the trade of commodities coupled with the rise of the nation-state system. Added to this were many technological innovations that aided both of these systems while also changing the parameters of military interaction. Pressure on the Qajars to participate in the global economic system came from the center of global trade: Europe. Qajar lands specifically stood between landlocked Russia, the Indian Ocean, and the many valuable commodities Great Britain controlled in South Asia. In the name of their competing economic interests, Britain and Russia brought many modern technologies and institutions to Qajar lands, including a telegraph system and banking system as well as modern military technology, organization, and training. Among the extensive foreign investment in the Qajar military was the first modern school built in the region, a military school called the Dar al-Fonun (Dār al-Fonūn), staffed with European instructors. All of this foreign investment in modern infrastructure facilitated more trade in commodities within and across Qajar territory, with Britain and Russia specifically competing to monopolize on the benefits of Qajar economic development.

The Qajars accepted these innovations and this extreme foreign intervention as part of their need to defensively modernize their empire. They also sought to make short-term economic gains by selling off control of their natural resources and institutions to European powers. The most notorious of these concessions was the D'Arcy Oil Concession of 1901, which gave over most of the profits from oil extraction in Qajar lands to a British company, the Anglo-Persian Oil Company. The extreme amount of control exerted by Russia and Great Britain on the Qajars shaped the ever-hardening borders of their realm. The Qajars lost significant por- 


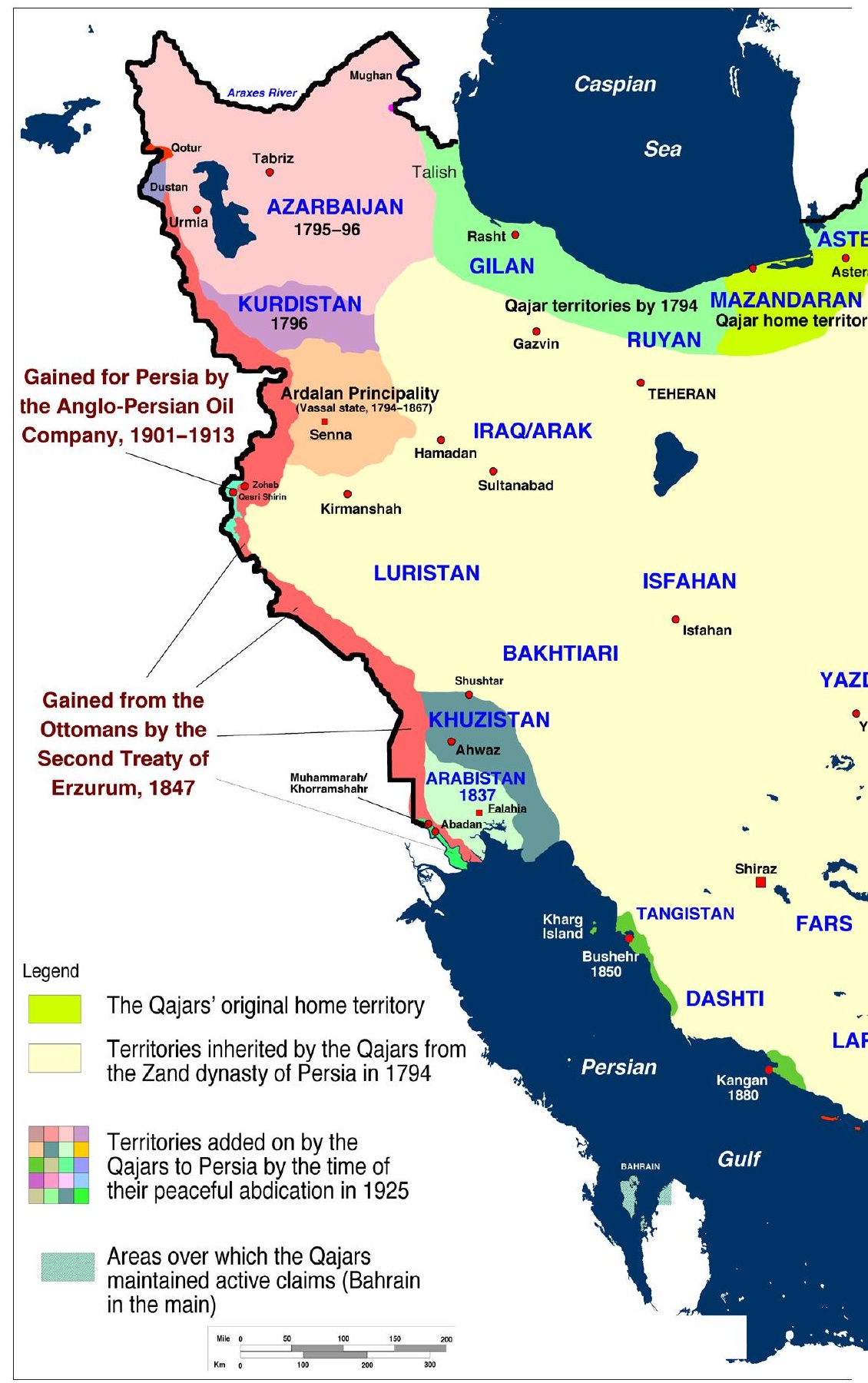

MAP 8. Iran, Qajar Dynasty Territorial Legacy: from the Atlas of the Islamic World and Its Vicinity (web page) by Dr. Michael Izady. This infograph documents how the borders of modern Iran developed out of the many battles, treaties, and other negotiations of the Qajars with other competing powers in the region. 


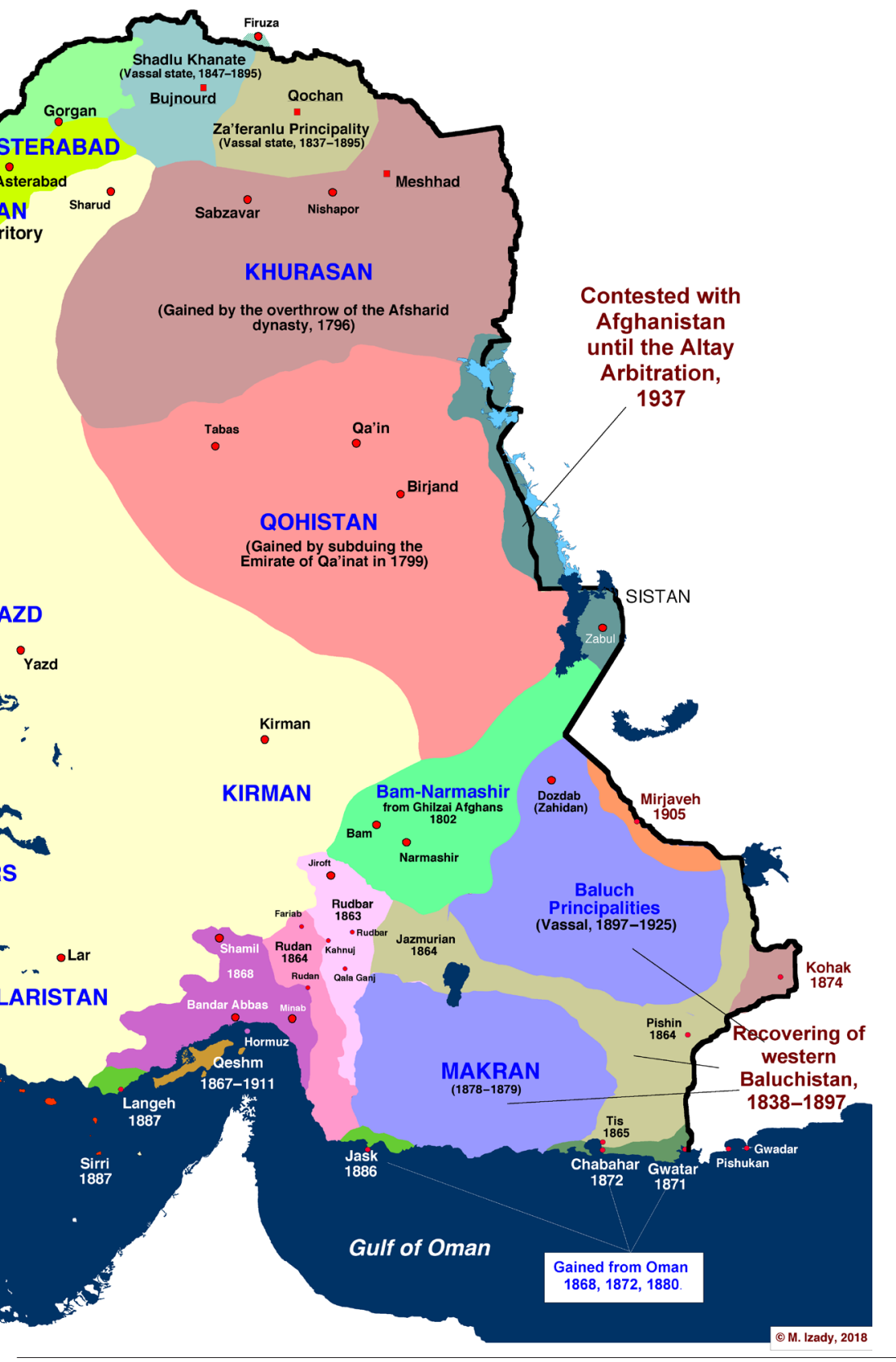


tions of their northern lands to Russia, while Great Britain inhibited their control of lands in the southeast, maintaining a geographic buffer between Qajar territory and their colonial activity in South Asia. The Qajars fought to keep and even gain territory, but in this context of global superpowers they were functionally very weak. The Qajars lost land to both foreign players and their neighbors. Russia and Great British specifically resolved their so-called Great Game over Qajar lands in 1907. They agreed that Russia could control the north of Qajar lands and Britain could control the south, all without any specific consent of the Qajars themselves (see map 8).

This level of foreign interference would remain an issue for Iran throughout most of the twentieth century. Nationalism and the rise of Iran alongside other nations of Central Asia occurred both with and against the conflicting interests of other nations. The Qajars needed the structures of the nation-state to participate in the rising global economic system, to which they had to adapt as a basic means of economic survival. Notions of a world divided into nations and races as well as political concepts of democracy and the rule of law entered Qajar territory via European education. Yet nationalism also served as discourse against foreign interests and in favor of citizenship over subjecthood. The rise of global economic activity had direct impacts on the Qajars' former subjects, some of whom recognized the nation as a means of securing their power in the modern world. As the Qajars' attempted to exert larger degree of control over their subjects to secure the nation-state, subjects becoming citizens pushed back against any notion of supreme dynastic control.

The first people to recognize their citizenship within the Qajar Realm belonged to new classes of people created by the global trade in commodities. These new classes included a new class of independent landowners, a merchant class that traveled to and from Europe to trade commodities, a large worker class that created commodities, and a growing class of educated elites who had access to modern educational institutions both in Iran and in Europe. At times these new classes had enough power to assert their interests against Qajar interests. Their access to modern education and technologies also gave them a means to imagine the nation: the differences between different peoples, the ability of millions of people to share a single identity, and the possibility of a single shared language and culture.

By the early twentieth century, the Qajar Empire largely operated as a nationstate rather than an empire. The push for nationalization coming from the nation's newly realized citizens culminated in the Constitutional Revolution in 1905, which was the first formal call to end dynastic rule in favor of a republic that represented the broader nation. Though this revolution did not achieve its stated goals, it did seat a parliament (majles) and formally adopt more of the trappings of a republic. With the failure of constitutionalism and the onset of World War I, several other competing conceptions of the nation came to the fore. Though the conception of Iran as a nation took hold under the Qajars, large non-Persian-language groups 
like Kurds and Azeris had their own ambitions for nationhood, as did various Qajar provinces, including Khuzastan and Gilan. With these many different competing concepts of nation manifesting as upheaval and revolt, the nation of Iran was not assured a place on the map until its existence became fully enforced under the military rule of Reza Shah Pahlavi beginning in 1925.

THE FULL NATIONALIZATION OF IRAN:

THE RISE OF REZA SHAH

Reza Shah, like many leaders in the Middle East in the early twentieth century, was very inspired by Mustafa Kemal Ataturk's nationalization of Turkey. Coming out of the Russian-run Cossack Brigade of the Qajar military as Reza Khan, he was a relatively unknown military officer when he participated in a coup to formally overthrow the Qajars. In his push to become the autocratic ruler of Iran, he used the Cossack Brigade to put down nationalist insurrections that threatened notions of Iranian sovereignty, and set out to create a larger, more systematic national government bureaucracy for Iran. Not wanting to present himself as a copy of Ataturk, Reza Khan changed his name to Reza Shah and kept the imagery of dynastic governance, declaring himself Reza Shah Pahlavi of the newly created Pahlavi Dynasty. He borrowed the Pahlavi name from the pre-Sassanian Empire, of which ruins and artifacts had recently been excavated by European archeologists. This move signaled the direction of his government's nationalist conception of the Iranian nation. Iran became a fully recognized nation-state with an identity tied to pre-Islamic Empire that could validate secular autocratic rule, first under Reza Shah and then under his son, Mohammad Reza. Reza Shah's autocratic rule initially reduced the influence of Islamic leaders, as power over society became concentrated in the hands of the state. In discourse there was a connection between reducing the influence of Islam and the popularity of the Aryan hypothesis. Between World War I and World War II the Aryan hypothesis had a great impact on discourses surrounding Iranian national identity. Reza Shah emphasized Aryan superiority by insisting on naming the nation Iran and not Persia, which had been its label on many maps made in Europe. Choosing a name that could be translated as "land of the Aryans" played on Europe's own modern racialized view of the world, placing Iran in a strong racial category vis-à-vis notions of Indo-Europeans' Aryan superiority and Semitic peoples' inferiority.

Reza Shah tried to curb the strong intervention of Russia and Great Britain. He asked other countries, including the United States and Germany, for various types of foreign assistance, which increased the number of countries involved in Iran and diluted some Russian and British control. In emulation of Ataturk's policies in Turkey, Reza Shah worked to centralize control over the country by expanding and improving the army as well as increasing the size of government bureaucracy. He nationalized numerous industries, thus ensuring state monopoly control over 
such things as the mining of natural resources and factory production. By the late 1930s, the Iranian government controlled sugar refineries, spinning mills, weaving mills, food-processing factories, vegetable oil plants, grain mills, and tobacco farming. ${ }^{15}$ The one industry the government did not control was the petroleum industry, which remained a concession to the Anglo-Persian Oil Company, which changed its name to the Anglo-Iranian Oil Company in keeping with the official name of the nation. The Iranian government also invested in improving the country's modern infrastructure. Reza Shah initiated the building of power plants to increase the population's access to electricity and electric light. He also sought to improve existing roads and build new roads in addition to nationalizing and expanding the railroad system.

Reza Shah also pursued government-sponsored public education and dissemination of information throughout the country. Persian-language education increased substantially as access to public education grew. After the Dar al-Fonun, Reza Shah inaugurated the first modern university, the University of Tehran, in 1935. He also established the region's first radio station, Radio Iran, which gave the nation access to a single shared source of information, which members of the nation consumed simultaneously.

Reza Shah's reforms came at a heavy price for Iranian citizens. Because most industries were run as government monopolies, Reza Shah's reforms enriched the government often at the expense of the population, who did not necessarily experience significant economic benefits even as they did experience a consistently heavy tax burden. Poverty became a national issue as wealth became concentrated among an ever-shrinking number of government elites. Political dissent was consistently stifled, with Reza Shah imposing strict censorship on political speech and removed anyone in government whom he suspected of opposing his plans. He used the army to continue to suppress independence movements, prevent local uprisings and settle some nomadic peoples.

The amount of direct control the national government asserted on the population was extreme compared to the amount asserted during dynastic rule a century earlier. In 1929, Reza Shah famously began controlling what the population wore, decreeing that men had to abandon all customary regional dress, including religious clothing, and wear European attire. This decree was extended to women in 1936, when headscarves and veils also became illegal.

For all of his attempts to quell British and Russian interference, Reza Shah was forced to step down during World War II when both British and Russian forces invaded in order to secure oil lines for Allied Forces. Reza Shah was replaced by his son Mohammad Reza Pahlavi. Mohammad Reza pushed for even more modernization, while discontent with the modernization among the population continued to fester. Foreign interference in national affairs in the name of protecting the economic control of oil remained a touchstone of citizen frustration. It formed the basis of resentment over the coup that unseated Prime Minister Mohammad 
Mosaddeq in 1953. It also played a role in the revolution against Mohammad Reza Pahlavi beginning in 1978.

By the 1940s, Iran was a fully functional nation and had put down most other nationalist movements questioning its legitimacy. The conception of the Iranian nation derived from the historical unity of its newly defined ethnolinguistic Persian culture. While there were different ways to imagine the history of Persian culture, some version of this shared ethnolinguistic history was the legitimizing factor, whether the nationalist narrative was from the official government image of Iran or alternative narratives coming from the Persian-speaking population. Education proved key to the success of this nationalist narrative: creating and sharing a consistent narrative regarding Iran's existence and historical legitimacy and spreading the use of the Persian language to create a more consistent, shared linguistic basis for the nation. In this context, music could become part of the shared knowledge and praxis of the nation, which demonstrated its historical validity in the modern world.

\section{MUSIC AND MODERNITY: THE CHANGING PLACE OF MUSIC AND MUSICIANS IN MODERN IRAN}

The initial integration of Qajar domains into the global economic system and the global nation-state system directly affected the status of professional musicians performing within the system of patronage that served the ruling dynasty and its concomitant aristocracy. Though the radif-dastgah tradition initially emerged as a court-patronized music much like the twelve-maqam system, Qajar court musicians aligned very early on with contexts that no longer served dynastic interests, gradually adapting their work to new modern spaces both public and private. After the 1920s, dynastic patronage died out completely and these spaces became the new locations for musical education and performance. By the time Reza Shah came to power in 1925 , musicians performing the radif-dastgah tradition were no longer court musicians at all: they were private citizens performing and teaching a national music tradition of Iran.

By the mid-nineteenth century the Qajars had both indigenous and European forms of music in their control. The modernization of the Qajar military involved replacing all indigenous practices and organizing everything in imitation of how European militaries were organized, including European military music. Conversely, performers of the radif-dastgah tradition initially consisted primarily of musicians of the inner and outer court, performing in closed settings or on outings as their patrons dictated, as musicians had done for centuries. The Qajars also maintained the ta ${ }^{\text {z }}$ ieh, a distinct genre of Shi ${ }^{\circ}$ a musical theater the Safavids had ritualized as part of their rule. Musicians from both the court and the military bands could appear together in Qajar ta ${ }^{\mathrm{z}}$ zieh. The ta ${ }^{\mathrm{C}}$ zieh singers specifically were often singers in the court and thus could be performers of the radif-dastgah tradition. ${ }^{16}$ 
The end of the nineteenth century changed the situation for musicians patronized by the Qajar court and aristocracy significantly, giving some of them historically unprecedented agency over their performance and movement in society. Initially, this agency stemmed from the large amount of interest of the aristocracy in playing the music themselves as amateur students and performers. As Qajar elites received modern education from European sources, music had a new role to play in proper intellectual and moral development of Iran's growing intelligentsia. Music was no longer merely the work of servants or an occasional hobby for a prince: it was a source of education and enculturation for the Iranian nation. The association of the radif-dastgah tradition with the early development of an Iranian intelligentsia meant that many musicians of the tradition gained access to the new modern higher echelons of national existence, regardless of their own educational status. For instance, texts cite a Qajar court doctor, Mirza Mehdi-Khan Montazam al-Hokma, as a strong practitioner of the tradition who also taught it. ${ }^{17}$ Another Qajar minister who held multiple posts under multiple Qajar rulers, Mehdi Qoli Hedayat, also practiced and wrote about the tradition. ${ }^{18}$ These types of elite amateurs were at work alongside professionals like Mirza 'Abdullah and Hoseyn Qoli, and this meant that the musicians in professional service to the Qajar court and aristocracy were sometimes able to gain access to some of Iran's first institutions of modern education. In some cases court musicians who played in radif-dastgah tradition were able to attend the Dar al-Fonun, which had a music faculty. Evidence that musicians of the radif-dastgah tradition attended the Dar al-Fonun came from the French military musician Alfred Jean Baptiste Lemaire (1842-1907), who headed the music faculty there and made transcriptions of the radif, which he eventually published. ${ }^{19}$ In 1915 , the music faculty at the Dar alFonun became a separate government music school (madreseh-i mūsìqi), which functioned as the first modern school of music in Iran.

During the early twentieth century, musicians dependent on Qajar patronage who played in the radif-dastgah tradition and musicians from the Qajar military came together to form their own private secret society, the Society of Brotherhood (anjuman-i ükhovat). The Society of Brotherhood was founded by Safi 'Ali Zahir el-Dowleh. Though little is known about Zahir el-Dowleh himself, he was both a member of the Qajar aristocracy and member of the Safi Sufi Order. Sufi sama practices had historically provided a consistent venue for music-making that had a religious identity apart from dynastic contexts and thus the Society of Brotherhood reinterpreted this legacy to create a civic organization dedicated to promoting musical performance beyond the reach of dynastic authority. In addition to conducting meetings and performances in private homes, the Society of Brotherhood also sponsored one of first public concerts independent of the court, which included the radif-dastgah tradition, at the cusp of the Constitutional Revolution. According to the Iranian musician and historian Ruhallah Khaleqi (1906-1965), the Society of Brotherhood provided this concert for free in the spirit of the Con- 
stitutional Revolution so that all people, including the poor, could have access to the music. ${ }^{20}$

Many people in Tehran were joining secretive civic groups, referred to as anjuman, during Qajar rule. Though they had different purposes, what they shared was a dedication to spreading new ideas and practices while maintaining some amount of secrecy. The secrecy surrounding anjuman related to their political nature, which threatened Qajar authority. Much secrecy was required for anjuman that promoted modern political ideas and movements, such as representative democracy and constitutionalism The modicum of secrecy surrounding the Society of Brotherhood demonstrated the political nature of taking music performance away from the dynastic aristocracy and giving it to the modern intelligentsia, who could then give it to whomever they wished. Giving a large public audience access to Qajar court music and musicians was an act of charity that was also politically subversive.

This movement of music from the court into the budding Iranian citizenry was not always a question of charity. It could be to the benefit of musicians, who in some cases could make a better living performing on the open market, playing for whoever would pay them. Khaleqi recounted a story about the radif-dastgah musician Darvish Khan (1872-1926) that conveys the political context of this move from court patronage to free agent. Darvish Khan discovered he was able to make his own money performing for people outside of the court rather than just playing for the Qajar prince, who was his patron. When the prince found out his musician was performing beyond his dynastic discretion, the prince threatened to cut off Darvish's hands. Darvish Khan sought sanctuary in the British Embassy to avoid this punishment, and the embassy eventually won his safe release from Qajar service. ${ }^{21}$

Darvish Khan's story demonstrates the impact of the global economic system on musicians, who were beginning to operate within this new economic model, with ever-lessening regard for the centuries of court patronage that had given them professional work. The development of new classes of people allowed music to be taken out of the court but changing parameters of the economy also pushed music into a broader marketplace. This push was met with some resistance by the Qajars, who still saw control over courtly musical performance as their dynastic right. The loss of that right, like so many others, could actually come in the context of foreign interference. The power of foreign governments to undermine Qajar authority - a pervasive problem in the Qajar's political and economic matterscould even extend to musical matters.

The move away from dynastic contexts was not only one of performance, but also one of education. As members of Iran's modern intelligentsia took on amateur study of music as part of modern education, teaching music took on an important economic function for musicians who could count on the emerging elite to become their new patrons by becoming their students. In this way, teaching became another way that musicians could make a living beyond the court. This 
culture of teaching further solidified the radif-dastgah tradition's relationship with a broader Iranian society distinct from dynastic structures, while also positioning it within the earliest manifestations of modern educated classes.

While acts of music performance outside of the court may or may not have intended to undermine Qajar power, there are examples of musicians operating in proximity to political opposition to dynastic authority. Letters from Bahaallah (Bahäallah or Baháu'lláh) Mirza 'Abdullah indicate that the musician's work had meaning to the nineteenth-century millenarian movement known initially as Babism. Both Islamic authorities and the Qajars viewed Babism's modern messianic nature as a threat to the historical order of Islamic Empire, and the Qajars executed the first prophet of Babism, Sayyed 'Ali-Mohammad Shirazi, in 1850. This execution brought about a series of Babi uprisings against the Qajars, including an assassination attempt in 1853 against a major Qajar ruler and music patron, Nasir al-Din Shah. Baha'allah arouse as a new prophet in Babism who tried to quiet the animosity between Babis and the government, and ultimately became the founder of the Baha'i religion. Though it is unlikely that Mirza 'Abdullah had the literacy to read letters from Baha'allah, they indicate an awareness of musicians in the radif-dastgah tradition among the Babi movement, which had its own origins in modernity and participated in the modern struggle for citizen autonomy against dynastic authority. ${ }^{22}$

In some cases, musicians directly attacked the Qajars as part of the growing political opposition to dynastic rule that culminated in the Constitutional Revolution. A Qajar noble who was also a musician, Hassam al-Saltaneh, wrote a tasnif criticizing Mozzafar al-Din Shah for bringing famine and plague upon his subjects. ${ }^{23}$ The modern Persian poet ${ }^{~}$ Aref Qazvini (1882-1934) also composed multiple tasnif criticizing the Qajars and praising the nation of Iran. This criticism of the Qajars was part of a larger public criticism of the Shah and call for constitutionalism, to which Mozzafar al-Din Shah (r. 1896-1907) eventually acquiesced. When Mozzafar al-Din's successor Muhammad 'Ali (r. 1907-1909) would not honor the constitution and dismissed the parliament, the musician 'Ali Naqi Vaziri (1887-1979) joined with fighters from Tabriz to depose Muhammad 'Ali, and restore Parliament in 1909. ${ }^{24}$

Beyond the specific happenings on the ground in Qajar territory, musicians and students of the radif-dastgah tradition also took the unique step of traveling very long distances to and from Europe in order to give concerts and make modern recordings. Before World War I, bands that included musicians such as Darvish Khan and Mirza 'Abdullah's brother Husayn Qoli traveled to places that included Tbilisi, Paris, and London in order to perform live and have European recording companies produce recorded discs of these recordings for sale in the framework of global trade. ${ }^{25}$

That musicians in the radif-dastgah tradition were positioned in close proximity to historical events shaping modernity placed them among the privileged 
elites of the nineteenth and early twentieth centuries. For all of the concern about making music accessible to the people at large, the radif-dastgah tradition had a unique, privileged standing in the growing sphere of modern music performance. Musicians who performed more broadly in urban spaces outside of the educated elite came to be derided as lower-class performers, referred to as motreb (motreb). Though motreb in premodern writings generally maintained a connotation ranging from positive to neutral when referring to any musician, in modern times its meaning shifted to denote a lower-class musician that lacked the education and higher class position of the radif-dastgah tradition and European musical traditions. Music had a certain value to the modern educated classes, yet this was part of the growing access to professional music performance throughout the population overall. As music became a commodity that could be bought and sold by anyone willing and able to pay for it, the radif-dastgah tradition had to operate in a field with multiple music genres all competing for the public's attention. In this field the radif-dastgah tradition's elite distinction related to both ideas concerning its Iranian authenticity and its place in educated society.

While informal teaching circles existed early in the twentieth century, the first formal private school of the tradition opened in 1923. Print publication of educational materials started growing around the same time, with different musicians developing teaching texts so that educated Iranians could self-teach. These teaching manuals imitated European manuals, with sets of books to study the dastgah for beginner, intermediate, and advanced students. Consistent, public live performance took somewhat longer to develop. In 1924, the private salon called Klub Musical largely replaced the Society of Brotherhood as the premiere private organization of both traditional and military musicians. Elites also continued to sponsor public performances for specific charitable causes at different public spaces around Tehran. ${ }^{26}$ Even with the rise of radio in the 1930 along with increasing opportunities for musicians to perform in live concert venues for public audiences, private performances remained an important venue for the tradition's performance throughout the twentieth century.

Under Reza Shah, new national institutions and bureaucracy created new spaces for elites to push their various musical agendas within the formal trappings of the Iranian nation. Though music education represented an essential part of modern progress even before Reza Shah, his bureaucracy directly established and controlled multiple institutions that formalized its place in educated Iranian society. Under Reza Shah, the Ministry of Education took an active interest in the music curriculum at public schools and later invested in improving the government music school and turning it into a full-scale conservatory (honaristān- $i$ $m \bar{u} s \bar{i} q \bar{i})$, which stood alongside a music faculty at the University of Tehran. Musicians worked within government ministries as well as in the new public schools, where music was part of a core curriculum children had to learn. Additionally, the rise of Radio Iran in the late 1930 s provided even more employment and exposure 
for musicians and music through government institutions. Radio benefited multiple types of music, including the music of the motreb and Western music. Musicians of the radif-dastgah tradition were not necessarily the primary beneficiaries of this first big step forward in mass media distribution, yet they were involved in radio early on, even as they cultivated stronger ties with modern institutions for music education and notions of elite amateurism.

\section{CONCLUSION}

The radif-dastgah tradition emerged at the heart of the sudden and drastic transmutation of modern society in the nineteenth century. Its initial position at court and later position in the upper echelons of Iran's modern urban landscape situated the practice and development of this music system at the heart of where modernity first emerged and developed in relation to the nation of Iran. Modernity created new public and private space as well as a new economic model and new types of social classes. The radif-dastgah tradition moved into and operated within the parameters of these major social, political, and economic transmutations.

These changes did not take hold everywhere in the Middle East at the same time. Initially, large portions of what became modern Iran were not experiencing the impacts of modern education or modern technology the way Tehran and other urban centers did. Many areas of Iran struggled to integrate into the global economy, even as the discovery of oil turned Iran into a de facto rentier state on the outermost edges of the economic system. Grand nationalization and modernization initiatives from both Reza Shah and Mohammad Reza Shah did not result in a uniform experience of modernity throughout the nation. But they did put a Pahalvian vision of Iran on the map and undermine any other nationalization efforts that questioned the legitimacy and the integrity of the Iranian nation.

This meant that, while urban elites could consistently imagine a uniformly Persian nation of Iran at the turn of the century, this Iranian national imagination was still in its early stages even by the 1920s. The movement of musicians who performed the radif-dastgah tradition from Qajar control into the modern educated elite positioned them to both experience and participate in the modernization process in its earliest manifestations. This early access related to their original place within the dynastic court and proximity to the dynastic aristocracy, where musicians related to government structures that were the focus of the first push for modernization. Courtiers took an interest in the tradition and courtiers were also some of the first to turn into and interface with the modern intelligentsia, even as they moved from being courtiers to operating in the national sphere.

In this context, the radif-dastgah tradition came out of a unique moment in history. Political and military contingencies of the eighteenth century interrupted the continuity of past court music traditions, opening up space for new traditions during the earliest phases of Iranian nationalization. The radif-dastgah tradition 
presented unique musical opportunities to adapt to a new temporal space, as music now needed to relate to modern identities and experiences well beyond the parameters of the court. The foundations of the twelve-maqam system would no longer have the same meaning in this modern context, even as the idiosyncrasies of the radif-dastgah tradition came to define a unique Iranian identity in the modern world. Conversely, the twelve-maqam system itself would ultimately return to serve as a conceptual point of national interpretation and reinterpretation for the radif-dastgah tradition. As Iranians sought to locate their national music history and trace the national origins of the radif-dastgah tradition in Iranian history, the twelve-maqam system became a symbol of Iran's glorious musical past. Discrepancies between the two methods of music-making became a source of change for the radif-dastgah tradition, which at first was tasked with verifying modern Iranian identity generally, while eventually needing to account for more detailed conceptions of Iranian history. 


\title{
7 \\ The Nation's Music \\ Discovering and Recovering the Dastgah
}

\begin{abstract}
It is not secret or hidden that what was discussed about the names of the twelve maqam and the relation of each one to the twelve houses of the zodiac-and the organization of each of them from other notes and the times of playing them and the affect of each of them-is completely in the idiom of the ancient wise men; and the assemblies of men know all of the aforesaid music writings mentioned. However, it is not hidden from the masters of knowledge and insight-it is no secret that, in this time, most of these aforementioned ideas are not in common use, but rather have been abandoned. ${ }^{1}$
\end{abstract}

The statement in the epigraph came from the poet Nasir "Forsat" al-Dowleh Shirazi, writing about music he observed in the Qajar court in Tehran during a visit he made during the rule of Nasir al-Din Qajar Shah from his native city of Shiraz. Forsat had contact with both writings about the twelve-maqam system and the Qajar musicians and courtiers who performed using seven dastgah, and he observed that though some knew of writings about the twelve-maqam system, it was a music of the past and not what contemporary musicians of the Qajar court were using. The political instability of dynastic patronage in the eighteenth century had not erased knowledge of the twelve-maqam system from all memory in the lands Qajars had conquered. But the weakening of dynastic power had undermined its relevance to such an extent that it was no longer relevant to music of the late Qajar courts. As the Qajars went on to confront the final deconstruction of dynastic governance and the rise of nation-states, the court culture of dynastic realms and its central model of musical expression were disappearing simultaneously.

As the court disintegrated in the late nineteenth century and its musicians and music moved into both private and public spaces of the budding Iranian nation, music had a different role to play among the newly realized Iranian people. Idiosyncratic, procedural musical structures initially fulfilled this role much better than a universal, compositional system and Forsat called the procedural system 
he found in the Qajar court "the system of seven" or "seven dastgah" (dastgāh-i hafteh-gāneh). Indeed, Mirza Shafi' Khan also wrote describing seven dastgah as seven distinct long-form musical procedures somewhat earlier that Forsat, specifically discussing them in relation to Qajar musicians like Husayn Qoli. ${ }^{2}$ As the narrative of the nation developed, the seven dastgah became central to demonstrating the existence and continuity of Iran's great legacy of Persian music. Conversely, the writing of Iran's national music history initially depended on discovered writings about the twelve-maqam system from before the seventeenth century, which questioned the dastgah's procedural model of music performance. In recontextualizing the twelve-maqam system within Iranian history, systematic modality became a key tenant of Iran's historic legacy of Persian music, even as the seven dastgah presented an approach to music-making that was not dictated primarily by systematically abstracted modes. The early twentieth century thus consisted of efforts to preserve Iran's newly discovered ancient Persian melodies within the uniquely Iranian structure of the dastgah, while reorganizing the dastgah to better fit within notions of systematic modality that could demonstrate continuity in Iranian music history.

The reimagining of the radif-dastgah tradition as a dual system of pitch modalities (dastgah/avaz-dastgah) and interconnected repertoire of melodies (radif) ultimately related to an ongoing manipulation of an indigenous approach to musical procedures within the radically changing sociopolitical landscape of the nineteenth and twentieth centuries. The interpretive qualities of procedural models for music performance that gained standing in the eighteenth century provided an active, malleable basis for Iranians to imagine and reimagine a unique national history via music's repertoire, structure, and performance practice. Ongoing renegotiating of ideas about Iran's national Persian history affected change in music from the Qajar court even as the united nation of Iran fully replaced all trappings of polyglot dynastic reality.

Forsat's writing about music initially sought to follow in the footsteps of premodern writings about music associated with the court. As an educated poet, he wanted to write about the relationship between poetry and music. He began writing mostly about poetry and only later included significant discourses about music that initially focused on literary tropes found in older treatises about the twelve-maqam system. But he was fascinated by a musical practice he witnessed while visiting the Qajar court in the 188 os, which did not relate to the twelve-maqam system. He recorded both his knowledge of older ideas about poetry and music and his contemporary observations of this new Qajar court music in a single text, which he had published in Bombay in 1914 under the title Buhūr al-alhān.

While Forsat's book was one of the first Persian writings about music to be printed on a modern printing press for mass distribution in the Qajar Realm, he 
was not alone. Actual students of Qajar court musicians also began producing their own texts about the seven dastgah for mass distribution in the early twentieth century. While Forsat merely sought to report the nature of the seven dastgah he observed in Tehran, writings from practitioners of the seven dastgah forwarded new analyses and structural frameworks for the seven dastgah, based on their changing notions of Iran's Persian culture and history.

One of the most prominent Qajar courtiers to write in this vein was Mehdi Qoli Hedayat, who wrote about the seven dastgah in his text the Majma al-advār. Hedayat, the son of Qajar courtiers, started playing setar at a young age while at court in Tehran at the turn of the century. ${ }^{3}$ He received some education in Iran before he went to Europe to be educated, eventually returning to Iran and taking positions in both the constitutional government of the late Qajar era and the modern bureaucracy of the early Pahlavi state.

Hedayat's access to modern education greatly influenced his access to the history of music in the region, and his education in Europe shaped how he understood this history within the history of Iran and the music he had learned in the Qajar court. Hedayat described his initial lack of language literacy and subsequent undertaking of rigorous language education in Persian and Arabic, in part to read writings he found from 'abd al-Qader al-Maraghi. ${ }^{4}$ He learned both languages well enough to read all of the writings of Maraghi, Qutb al-Din Shirazi and Safi alDin Urmawi and he wrote extensively about them in Majma al-Advar. While his text was one of the first Persian writings on music to reference any of these older writings in several centuries, it was the first time so many of these texts had been written about together with great specificity, focusing on a totality of Persian musical writings as containing a discursive set of Persian musical ideas.

His knowledge of these older writings about the twelve-maqam system notwithstanding, Hedayat's education in Europe exposed him to modern ideas about history and culture that ultimately determined how he understood both the twelve-maqam system and the dastgah he encountered in the Qajar court. He viewed both of these different approaches to music-making within the framework of Iran's emerging national history and he wrote Majma al-advār partly in imitation of the writings of Maraghi, Safi al-Din, and Qub al-Din, and partly as an imitation of the writings on music from both Orientalists and scientists in nineteenth-century Europe. In this text he outlined two different ways of analyzing the seven dastgah that he used to demonstrate its ancient Iranian historicity. These analyses derived from his interpretation of what modern European intellectuals were saying about the nature of music vis-à-vis humanity and the history of Persian music specifically.

He also wrote a short epilogue for his Majma al-advār that reflected on structural similarities between the dastgah tradition and music he encountered in Europe. He further included a small music-teaching text (dastūr) that focused on 
his understanding of how to use music notation. In this teaching text, Hedayat aligned the notation he had seen in writings about the twelve-maqam system with the notation system of Europe.

Hedayat's specific ideas about the relationship between the seven dastgah, the twelve-maqam system, and Western music did not gain widespread usage among other musicians in the twentieth century. One musician who did manage to take the idea of an Iranian national music and spread new approaches to the dastgah based on new narratives of national history was 'Ali Naqi Vaziri (18871980). Vaziri was a prolific music educator who produced the first widely published teaching texts about the seven dastgah. In publishing his modern teaching manuals and using them to teach in modern classroom settings, Vaziri taught an approach to understanding modality within the seven dastgah that negotiated the contradictory requirements of an Iranian music tradition in the modern world. Several of his students went on to create their own teaching manuals based on his understanding of dastgah modality and many of his students went on to teach even more students of the tradition. This situation made many of the particular ideas and approaches he originally taught some of the most influential throughout the tradition by the 1940 .

As the son of an army officer and social activist, Vaziri grew up at the forefront of modernization at the end of Qajar rule. He initially took an interest in European-style military music while in the Russian-trained Cossack Brigade. His primary exposure to the seven dastgah appears to have come from playing tar with the Society of Brotherhood after his time in the Cossack Brigade. Here he met the progenitors of the seven dastgah, including Mirza 'Abdullah, Husayn Qoli, and Darvish Khan. ${ }^{5}$ Like Hedayat, he was ultimately educated in Europe, both France and Germany, and this education greatly informed his construction of Iran as a distinct historic entity and the Iranian people as a nation. He used these ideas to determine which concepts of music's structure were most relevant to a proper reorganization of the Qajar dastgah tradition: a reorganization that could recover lost aspects of Iranian music history. This framework for understanding the relationship between music and culture fostered a new model of musical structure, which in turn related to multiple interpretations and variations on how the radifdastgah tradition was understood and practiced in the late twentieth century.

Vaziri made no secret of his work to change the musical life of Iran and he harnessed modern venues of communication early on to present his "reform" of Iranian music as a key aspect of improving Iran's national character and position in the modern world. Today, Iranian musicians and musicologists often regard Vaziri as a nationalist, who specifically acted as a proponent of Iranian music's Westernization. As a composer and performer, this provides an accurate assessment of his legacy later in the twentieth century. In his teachings from the first part of the century, however, Vaziri portrayed the concepts of a unique Iranian dastgah 
modality and a fully distinguished Iranian radif repertoire as two important parts of Iran's distinct cultural history that needed to be maintained for Iran to prosper in the modern world. Vaziri believed in the importance of the European system of tonal harmony, which he referred to as international music (mūsiq $\bar{i}-i$ bayn al-melal) and considered open to all peoples. Both Hedayat and Vaziri discussed this international music side by side with the seven dastgah, yet the distinction of Iran's culturally defined music of the radif-dastgah tradition stood as the unique demonstration of Iran's distinct history and culture. In this context, Vaziri cast his approach to the radif-dastgah tradition as a purely indigenous realization of what Iranian music had embodied for thousands of years. Many musicians both learned and accepted the basic principles he taught concerning the radif-dastgah tradition's unique Iranian structure, and many of the specific perspectives he promoted remain part of a standard indigenous understanding of the radif-dastgah tradition today.

Vaziri produced some of the first modern teaching manuals for the seven dastgah, where he taught his initial approach to the basic tenants for organization and analysis of the seven dastgah. They first appeared in his elementary teaching manuals for specific instruments, starting with his teaching manual for tar, Dastūr-i tār, which had its first major publication run in 1923. He followed this text with a similar manual for violin in 1934, followed by a revised manual for teaching tar and setar in 1936. He provided his most detailed exploration of the new presentation of the radif-dastgah tradition in his teaching manual for more advanced students of music, Mūsìqì-i nazarāi, in 1934.

In the ongoing project to discover or otherwise construct modern Persian music's ancient Persian past, each of these three authors approached the dastgah tradition they learned from Qajar musicians in different ways. No longer subject to the universal rules that could affect meaning throughout the cosmos and humanity, the seven dastgah related to ever-changing notions of a single Persian people and the idiosyncrasy of this people's unique history, eventually aligned with notions of race and the nation of Iran. In this context, there was more than one way to imagine this history and reimagine the music. By the mid-1940s, standards of the full radif-dastgah tradition were still in dispute, yet the conceptual framework of these disputes was first confronted in the early twentieth century. Descriptions and analysis of the tradition from Forsat, Hedayat, and Vaziri demonstrate the modern parameters of identity that defined the radif-dastgah tradition in all of its structural variations as the twentieth century progressed.

\section{FORSAT'S PERSIAN MUSIC IN THE BUHÜR AL-ALHĀN}

Though Forsat introduced his text as a treatise that addressed the historic relationship between music and the structure of Persian and Arabic poetry, the second 
half of his text abandoned this initial interest. After being immersed in the court music of the Qajar court, he turned the second half of this text to documenting the knowledge of music in the Qajar court. This included both factual knowledge about the twelve-maqam system and actual practices of the new music tradition of seven dastgah. He attempted to document the new seven dastgah with as much detail as he could, with a special focus on the poetry sung in the new tradition.

The knowledge of the twelve-maqam system Forsat encountered in Tehran reflected the system's dominant discourses from the time of the Safavids, with some reference to ideas that had dominated previously. The twelve-maqam system he described had the additional gusheh component, and Forsat focused on the metaphysical and cosmological alignments for each of the avaz, maqam, sho beh, and gusheh. He did not document any systematic calculation of pitch usage or scales, and he mentioned al-Farabi in passing as only a symbolic musician of legend. Knowledge of the twelve-maqam system in the turn of the century Qajar court was thus largely based on the discourses from the previous three centuries.

After establishing that the twelve-maqam system was a relic that contemporary members of the court had only read about, Forsat described the new seven dastgah, which could only be learned by studying with specific masters in the Qajar court. ${ }^{6}$ He explicitly described the seven dastgah of these masters as new and fresh (jadìd and tāzeh) compared to the twelve-maqam system. In explaining what was new about the seven dastgah, Forsat pointed to the organization of melodic material in each of the seven dastgah and drew seven charts to show the idiosyncratic use of melody in each one. He described the dastgah as generally containing a collection of different types of melodies alternately referring to these melodies as ahang (ähang), naghmeh (naghmeh), avaz, or gusheh. The charts he drew for each dastgah represented a particular progression of melodic material, listing the names of different melodic sections and placing them into the progression that defined each dastgah's performance. Figures 12 and 14 show Forsat's original representation of Shur, Nava, and Mahur. Figures 13, 15, and 16 provide translated interpretations of his charting for these three dastgah, following a scheme of representation explained in figure 11.

He gave additional instructions in his prose to further explain the procedural nature of the dastgah. He described the melodies named daramad in each chart as starting the performance in the basis (zamineh) of the dastgah. His description of forud referred back to this idea of a dastgah's basis, and he noted that where forud appeared in the charts, the basis outlined in the daramad would be repeated. He distinguished between mandatory melodic sections of the dastgah and optional sections, which could be added or passed over in the performance, though they could not be moved from their relative position in a dastgah's melodic sequence. Forsat further noted that some of these sections appeared in more than one dastgah, though he indicated that this was somewhat controversial among 


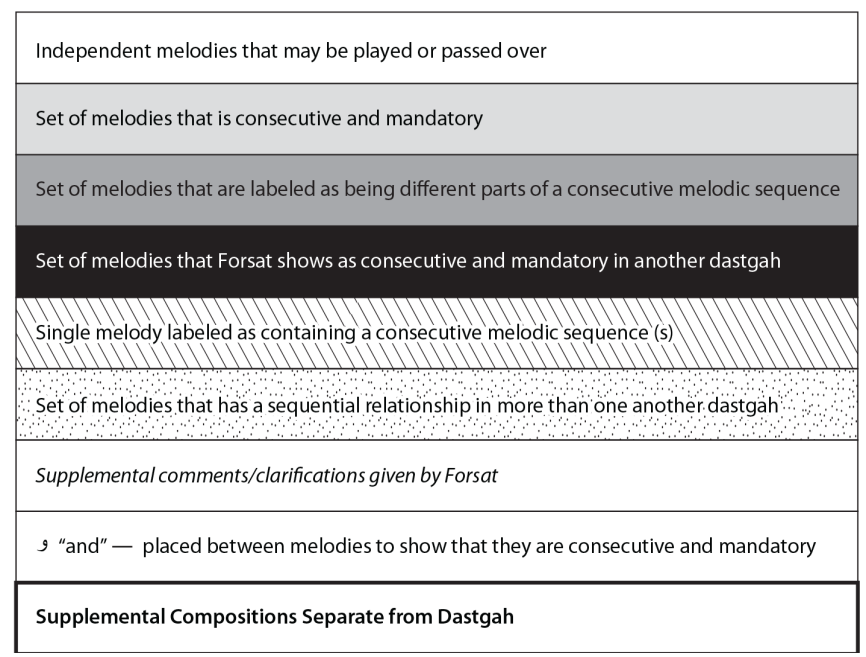

FIGURE 11. Legend for figures 13,15 , and 16

some practitioners of the tradition.7 In the charts Forsat positioned the reng as a unique category of melodies, listing them as a supplemental section at the end of each dastgah.

While each chart demonstrated a progression of named melodic segments in keeping with the parameters Forsat set out in prose, he wrote parenthetical text in and around the charts, which provide further insight into the distinguishing features of each dastgah. For instance, Forsat noted halfway through the chart for dastgah Shur that the entire second half of Shur consisted of related sections (muta alliqāt), which could be used or skipped over in their entirety. Among these he named Abu 'Ata, which he referred to as a forud of Shur. Forsat also noted where one or more sections could be inserted into the dastgah as an optional possibility in addition to the official charting of the dastgah. Thus he stated that a section called Gavri or Zabol-i Gavri could be added at the end of the dastgah Chahargah, and he also wrote that it was desirable to use the Jameh Daran to complete the dastgah Homayun, but Bayat-i Isfahan was also used. ${ }^{8}$ Forsat created the shortest chart for the dastgah of Segah, in which he wrote a note stating that most of Segah was borrowed from the organization of melody in Chahargah.

When addressing why the dastgah system worked in this complicated way, Forsat gave two frameworks of reference. He stated that a musician told him that they adopted this new organization for music because it was superior $(a w l \bar{a}) .{ }^{9}$ This statement gave no explanation of where it came from, only that the dastgah represented some kind of musical improvement. His more extensive explanation described these improvements as providing a basis to organize the remnants of ancient Persian melodies for contemporary performance. Forsat described the 


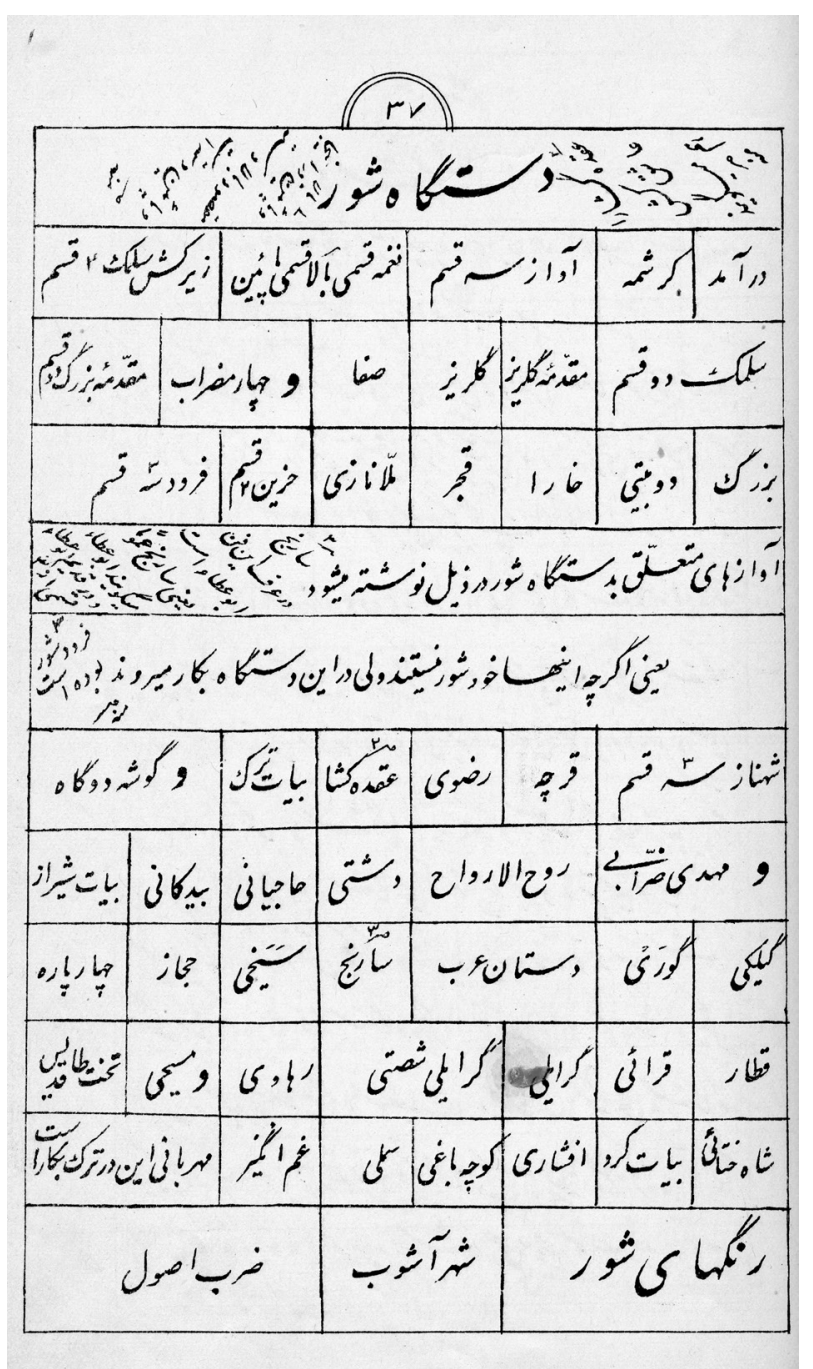

FIGURE 12. The dastgah Shur in the Buhūr al-Adḥān

twelve-maqam system as the ancient system (dastgāh-i qadiman) that had been reorganized into the seven dastgah. ${ }^{10} \mathrm{He}$ further summarized the melodic contents of the seven dastgah as a mixture of old Persian melodies with new Persian melodies, pointing directly at the Persian names of the melodies to explain this conclusion. He stated that while there were new melodies in the dastgah that had new names, there were also new melodies in the dastgah that had very old names, while there were also very old melodies in the seven dastgah that had new names. 


\begin{tabular}{|c|c|c|c|c|c|c|}
\hline Darāmad & Kereshmeh & \multicolumn{2}{|c|}{ Avāz seh qesm } & \multicolumn{2}{|c|}{$\begin{array}{l}\text { Naghmeh qesmī } \\
\text { bālà qesmī pā'īn }\end{array}$} & $\begin{array}{c}\text { Zirkesh-i salmak chahār } \\
\text { qesm }\end{array}$ \\
\hline \multicolumn{2}{|c|}{ Salmak do qesm } & $\int_{\text {golrìz }}^{\text {Moqademeh-i }}$ & Golriz & Șafā & $\begin{array}{c}\text { Chahār } \\
\text { Meżrāb }\end{array}$ & $\begin{array}{c}\text { Moqademeh-i bozorg do } \\
\text { qesm }\end{array}$ \\
\hline Bozorg & Dobaytī & Khārā & Qajar & $\begin{array}{l}\text { Mollā } \\
\text { nāzī }\end{array}$ & $\begin{array}{l}\text { Hazin do } \\
\text { qesm }\end{array}$ & Forūd seh qesm \\
\hline
\end{tabular}

The dependent melodies (äväzhä-i muta alliq) in the dastgah of Shür are written below, meaning that although they are not themselves Shür, they are used in this dastgah. Säranj in the common practice of this art is Abü 'Atā, meaning for Säranj they usually say Abū 'Atä and it was three sections (seh qesm) of the forūd of Shür.

\begin{tabular}{|c|c|c|c|c|c|c|c|}
\hline \multicolumn{2}{|c|}{ Shahnāz seh qesm } & Qarcheh & Rażawī & $\begin{array}{c}\text { Oqadeh } \\
\text { goshā }\end{array}$ & $\begin{array}{l}\text { Bayat-i } \\
\text { tork }\end{array}$ & \multicolumn{2}{|c|}{$\stackrel{9}{\text { Gūsheh-i dūgāh }}$} \\
\hline \multicolumn{2}{|c|}{$\stackrel{9}{\text { Mehdi żarrābī }}$} & Rūh al-arwāḥ & Dashtī & Heàjiāāi & Bīd kānī & \multicolumn{2}{|c|}{ Bayat-i shīrāzī } \\
\hline Gilakī & Gūrī & \multicolumn{2}{|c|}{ Dastān-i árab } & Sāranj & Sayahkī & Ḥijāz & $\begin{array}{l}\text { Chahār } \\
\text { pāreh }\end{array}$ \\
\hline Qațār & Qorāì & Grāylī & \multicolumn{2}{|c|}{ Grāylī shaștī } & Rahāwī & $\stackrel{9}{\text { Masihịi }}$ & $\begin{array}{l}\text { Takht-i } \\
\text { tăqdis }\end{array}$ \\
\hline $\begin{array}{l}\text { Shăh } \\
\text { khoțā }\end{array}$ & $\begin{array}{l}\text { Bayāt-i } \\
\text { kord }\end{array}$ & Afshārī & $\begin{array}{l}\text { Kūcheh } \\
\text { bāghī }\end{array}$ & Samalī & $\begin{array}{l}\text { Gham } \\
\text { angīz }\end{array}$ & \multicolumn{2}{|c|}{$\begin{array}{c}\text { Mehribāni (This is } \\
\text { used in Tork) }\end{array}$} \\
\hline \multicolumn{2}{|c|}{ The Rengs of Shür: } & \multicolumn{3}{|c|}{ Shahr-āshūb } & & \multicolumn{2}{|c|}{ Żarb-i uṣūl } \\
\hline
\end{tabular}

FIGURE 13. Interpretation of the dastgah Shur's representation in the Buhür al-Adhān

With all of this mixing and matching of melodies with names, he observed that no one had really investigated the historical origins of the melodies themselves. In pondering where the old melodies came from, Forsat traced a historical path from the Qajar court all the way back to the Sassanian Empire using the Persian language. He surmised that since some of the names of melodies could be found in very old Persian dictionaries, some of the melodies must have come from the time of the great legendary musician Nekisa and the Sassanians. He stated that no one really knew where any of the melodies came from, but if someone researched it, they would be able to find both new melodies in the dastgah and older melodies with connections to this ancient Persian past. ${ }^{11}$

Thus, Forsat framed the seven dastgah as a new innovation that had evolved out of a larger Persian history of music, with musical roots as far back as pre-Islamic 


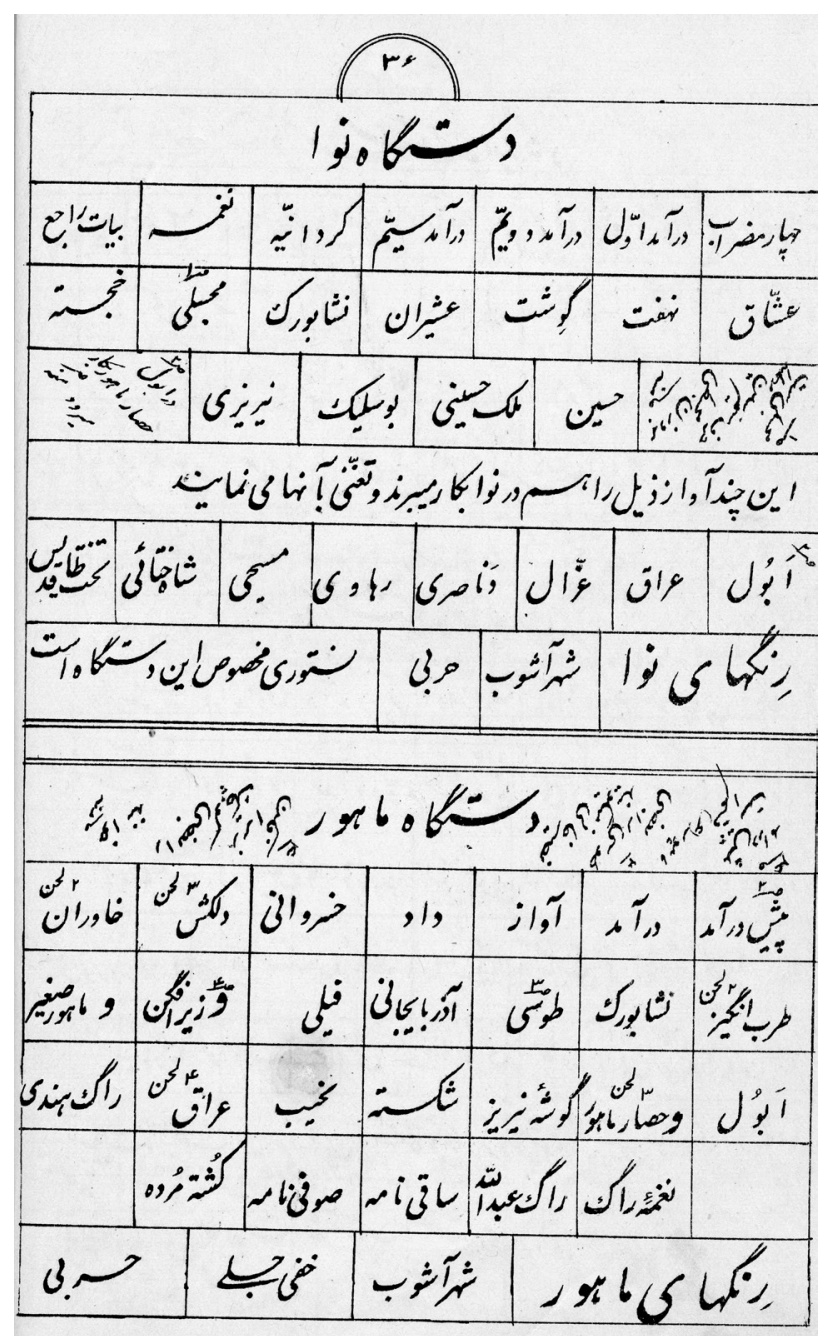

FIGURE 14. The dastgah of Nava and Mahur

Persia. He placed the twelve-maqam system within this Persian music history, even as he emphasized the new innovation of the seven dastgah deriving from both ancient Persian melodies and modern Persian innovation. This understanding of the seven dastgah facilitated the unity of Persian music history past and present. In this framework, no maqam, avaz, sho'beh, or other abstract melodic or rhythmic structure had survived from the twelve-maqam system to be used in the seven dastgah. Rather, a random assortment of fully formed melodic material created using the historic Persian system of the twelve maqam had survived and been placed into the seven dastgah, alongside newer melodic materials. 


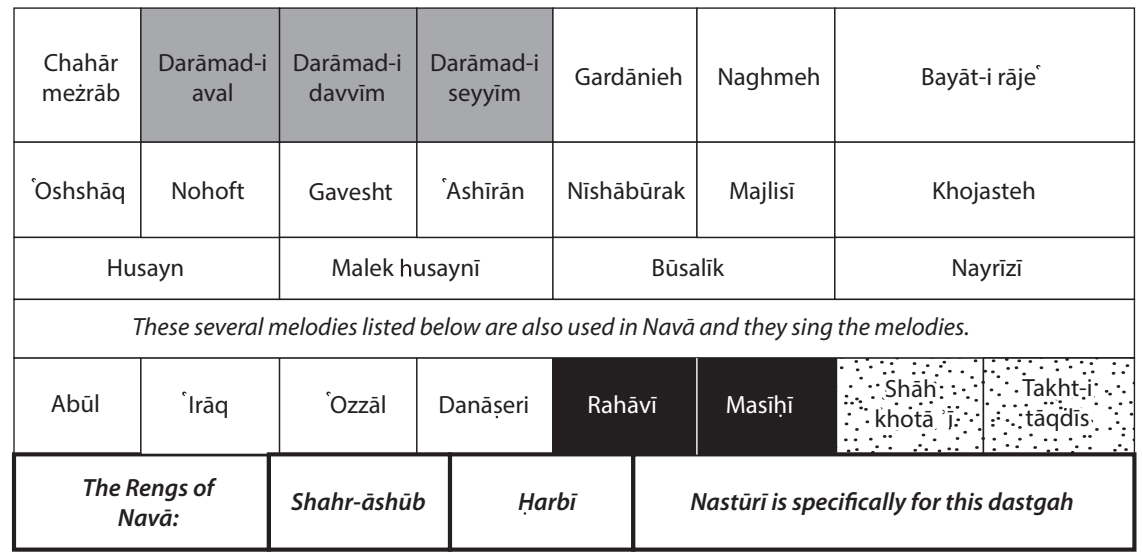

FIGURE 15. Interpretation of the dastgah Nava's representation in the Buhür al-Adhān

\begin{tabular}{|c|c|c|c|c|c|c|}
\hline $\begin{array}{c}\text { Pīsh } \\
\text { Darāmad }\end{array}$ & Darāmad & Avāz & Dād & Khosrovānī & Delkesh & Khāvarān \\
\hline $\begin{array}{l}\text { Ṭarab } \\
\text { angīz }\end{array}$ & Nīshābūrak & Ṭūsī & Āžarbayjānī & Fīlī & $\begin{array}{c}9 \\
\text { Zïrafkand }\end{array}$ & $\begin{array}{c}9 \\
\text { Māhūr-i } \\
\text { șaghīr }\end{array}$ \\
\hline \multirow[t]{2}{*}{ Abūl } & $\begin{array}{l}\text { Heșār-i } \\
\text { māhūr }\end{array}$ & $\begin{array}{c}\text { Gūsheh-i } \\
\text { nayrīz }\end{array}$ & Shekasteh & Naḥīb & Irāq & Răki hindi \\
\hline & Naghmeh-i & $\begin{array}{l}\text { Rák-1 } \\
\text { Abdullah }\end{array}$ & Sāqī nāmeh & Ṣūfĩ nāmeh & $\begin{array}{l}\text { Koshteh } \\
\text { mordeh }\end{array}$ & \\
\hline \multicolumn{2}{|c|}{ The Rengs of Māhūr: } & \multicolumn{2}{|c|}{ Shahr-āshūb } & Khafi jelī & \multicolumn{2}{|c|}{ Harbī } \\
\hline
\end{tabular}

FIGURE 16. Interpretation of the dastgah Mahur's representation in the Buhür al-Adhān

The specific question of which sections of the dastgah represented ancient melodic material and which represented new was not so important as the general explanation that the new seven dastgah were somehow created out of the older twelve-maqam system, uniting these two music systems into a single history defined by the Persian language. The twelve-maqam system represented an ancient era of musical renaissance in this Persian history, and the seven dastgah represented a way of reviving and reorganizing musical remnants from that history. 
As a poet, Forsat dedicated the most space in his discussion of the seven dastgah to simply listing poems and noting which dastgah would be used to sing them. Before doing this, he noted that the use of these dastgah had many variations beyond the composite representation in his charts, and that he consulted with multiple musicians in order to identify the most likely aspect of the dastgah used to perform different poems. ${ }^{12}$ He organized his listing of poetry by genre, including the Persian ghazal, ruba'i, and dobayti, and Jalal al-Din Rumi's Masnavi. For most of these genres, he gave rather vague assessments of where they would appear in a performance in the seven dastgah. For the ghazal, however, Forsat named at least one aspect of the seven dastgah that musicians used for each poem's musical performance. For these he often listed more than one melodic possibility and he wrote out the full text of each ghazal.

In naming which dastgah musicians customarily used to perform specific poetry, Forsat demonstrated the great variability of usage of melodic material from the seven dastgah. The dastgah did not always dominate as models of performance in his listing of poetry. For instance, Forsat listed dastgah Chahargah as the most commonly used framework for singing ghazal, associating it with ninety-nine different ghazal. Four more names of dastgah completed his top five most-used dastgah: Shur with sixty-one ghazal, Rast-Panjgah with sixty, Homayun with fortynine, and Nava with thirty-three.

He also listed many smaller melodic sections of dastgah as primary melodic frameworks for performing entire ghazal. In some cases these shorter melodic sections were used more than the dastgah. For instance he associated dastgah Mahur with only five different ghazal, yet he listed multiple short melodic sections of other dastgah used more than five times: Tork, Nishabur, Kord, Maygoli, Shahnaz, Rak, Hijaz, Bakhtiari, and Gilani. For dastgah Segah he listed only one ghazal and there were several smaller sections of dastgah that could have been used for one or two ghazal, including Qatar, Hesar, and 'Iraq. The tendency to use smaller portions of the dastgah also applied in other genres of poetry. Forsat stated generally that they performed all ruba'i poetry using Rak, Qatar, and Afshar, while masnavi poetry was best performed in Dashti, Bakhtiari, and Quchani. ${ }^{13}$

While Forsat used the term dastgah in these lists to refer to the seven primary frameworks he previously charted, he also used the names of the dastgah with labels such as avaz, naghmeh, and ahang, alongside smaller melodies also covered by this terminology. The term avaz is the term he used the most to refer to what the melodic frameworks of the ghazal were, whether a previously named dastgah or some smaller portion of a dastgah. He sometimes referred to ghazal as being performed in related divisions of a melodic entity (muta alleqāt). So while he listed many ghazal as sung using Chahargah, he listed two that were sung using related divisions of Chahargah. While he listed two ghazal sung in the melody of 'Iraq, he listed one sung in the related divisions of ${ }^{e}$ Iraq. 
Forsat's description of the seven dastgah, both the charts and his listing of poetry, emphasized idiosyncratic musical procedure inherent in the new music tradition he found at the Qajar court. While each of the seven dastgah had certain procedures in common, each dastgah also has its own unique progression of melodic material to use in performance, with unique options of what melodic material to include or exclude. There was not one fully organized system to explain how all of the dastgah worked. Forsat had to chart out each one separately to properly demonstrate the intricacies of each dastgah's melodic progression.

The lack of purely modal systemization was also clear in the poetry listing Forsat gave for the dastgah. Whole dastgah were the dominant frameworks of performance, but musicians could also consider smaller melodic sections of the dastgah common frameworks for performance. Furthermore, all seven dastgah were not of equal importance. Musicians could even be using smaller melodic sections more often than a dastgah in its entirety. Forsat's listing of copious amounts of poetry generally pointed to the central role of specific poems in determining the nature of a performance, above and beyond a purely modal concept of music's organization.

Yet the notion that the dastgah were organized out of Persian melodic materials grounded in an ancient Persian past lent cultural legitimacy to focusing on smaller parts of a dastgah. The dastgah represented a new innovative organizational structure that allowed smaller pieces of Persian music to be organized into a single unit of performance, but it was the smaller melodic units within the dastgah that represented the core of Persian musical identity. They had conceptual standing independent of the dastgah, as either the remnants of Persian music originally created using the twelve-maqam system, or as innovations of Persian music masters from the Qajar court. The large-scale structures of the seven dastgah knit together ancient and modern Persian music in such as way as to provide long-form performance procedures for classical Persian poetry. But the mere pairing of any Persian melodic material with ancient Persian poetry was enough to define a proper performance structure for the new tradition.

\section{HEDAYAT AND IRANIAN MUSIC: MAJMA` AL-ADVĀR}

The contrasts between Forsat's Buhūr al-alhān and Hedayat's Majma al-advār document the quickly changing world influencing the musical conception and application of the seven dastgah. Like Forsat, Hedayat cited the concept of seven dastgah as the central idea within the music tradition of his time in the Qajar court. He referenced Motazem al-Hokma, but also professional musicians, including Mirza 'Abdullah and Husayn Qoli. ${ }^{14}$ While Forsat's understanding of the seven dastgah required a protonational conception of a single Persian people engaging in a continuously active existence from ancient times into the modern world, 
Hedayat defined their continuous active existence as the nation of Iran. In this context, Hedayat explicitly cast the seven dastgah as a product of Iran's people and its historic Persian culture.

Though both Forsat and Hedayat observed large contrasts between the seven dastgah and past knowledge of the twelve-maqam system, Hedayat sought to uncover musical similarities and connections between them that demonstrated their shared cultural origin in Iran's Persian history. Immersed in ideas from turnof-the-century Europe, Hedayat read the work of Orientalists and wrote about what Orientalists were saying in their research on the music and the ancient races of the Near East. Orientalists such as Jan Pieter Nicolaas Land and Raphael Kiesewetter specifically focused his attention on the writings of Safi al-Din, Qutb al-Din, and Maraghi, whom Orientalists considered significant cultural figures. With Maraghi specifically marking the height of Persian musical development, the history of Persian music after his death in the fifteenth century could be cast as a period of severe decline. Hedayat thus treated the seven dastgah as modern Iran's cultural recovery of its great Persian music, which had last been documented in the fifteenth century.

On this basis, Hedayat began writing the Majma al-advär as a modern compendium of musical knowledge, meant to address the main themes discussed by Safi al-Din, Qutb al-Din, and Maraghi in their writings about the twelve-maqam system, as if they were ancient analogs to European musical thought and modern science. He used the first section to reiterate concepts discussed by the German scientist Hermann Helmholtz in his late-nineteenth-century text On the Sensations of Tone as a Physiological Basis for the Theory of Music. The second section addressed two systematic approaches to musical production, which he referred to as advar. The first was Safi al-Din's systematic schema of scale creation from the thirteenth century, which produced a large collection of scales ( $a l-a d v \bar{a} r)$. The second was Western music theory and its conception of pitch organization and scales, which he referred to as "the new foreign advar" ( $a d v \bar{a} r-i$ jadī $d-i$ farangī). Hedayat saved his description of the seven dastgah for the third section, proposing hypothetical ways of analyzing the seven dastgah in order to locate possible alignments between the dastgah and the twelve-maqam system. Though difficult to establish and legitimate, such alignments were fundamental to Hedayat's conception of a single, perennial Iranian culture.

In beginning his neomedieval text, Hedayat cast Helmholtz as the primary authority on the new science of music, which Hedayat defined as existing within the modern fields of acoustics, physiology, psychology, and aesthetics. He dedicated the first section of his texts to recounting information from On the Sensations of Tone, beginning with experiments described by Helmholtz related to acoustics and physiology. These experiments provided detailed explanations of sound production, some of which contained general points of similarity with explanations 
of sound production provided in Arabic and Persian writings on music before the sixteenth century.

Hedayat copied Helmholtz's writings about acoustics and physiology almost verbatim, including the illustrations. For instance, Hedayat reiterated and drew Helmholtz's explanation of nodal lines: the different patterns of lines that one can observe on a sound-producing body that demonstrate how the sound produced relates to different possible modes of vibration (see figures 17 and 18 ). ${ }^{15} \mathrm{He}$ described and drew Helmholtz's namesake resonator, explaining how it amplified one tone while dampening others when placed in the ear (see figures 19 and 20). ${ }^{16}$ He repeated Helmholtz's experiment that demonstrated how the differing wavelengths of different pitches could be observed and drawn using a tuning fork (see figures 21 and 22). ${ }^{17}$

In this way, Hedayat recast the historic notion of music as ilm within the definition of natural sciences that Helmholtz traced through Europe. While this first consisted of copying exactly On the Sensations of Tone's discussion of sound acoustics and physiology, Hedayat turned to a more selective and interpretation of Helmholtz when it came to questions of aesthetics and psychology. He focused heavily on what Helmholtz discussed regarding the role of race in determining aesthetic musical preferences. While this topic had a relatively short description in On the Sensations of Tone, Hedayat gave much more emphasis to the idea that different races had different methods of musical expression and preferences for musical aesthetics that were in keeping with each race's unique psychology. This idea formed a fundamental truth of human existence, and was scientifically demonstrable in sound wave frequencies. Hedayat described this concept on the very first page of his text referencing a statement he attributed to Confucius: "one can understand the condition of every race's development from the composition of that race's music."18

Hedayat privileged the idea of cultural relativity much more than Helmholtz, but he also had to address how Helmholtz specifically placed Persian music into an evolutionary paradigm. In keeping with nineteenth-century European thought, Helmholtz did not simply maintain that different races had different types of music because their psychologies were different. These different psychologies represented different levels of human development. On this basis all races were not equal, nor were all musics. Musical science and sophisticated music theory were indications of a highly developed racial psychology, and Helmholtz classified European music as the highest evolved with the greatest amount of scientific thought and the most complex music theory. He placed Persians and Arabs in an evolutionary category just below Europe. From Helmholtz's perspective, Persians did have a science of music and music theory historically, but neither was as great as Europe's.

Hedayat provided his own interpretation of this evolutionary model, which suggested Persians could be on par with Europeans in the history of racial-musical evolution. He concentrated his argument on Helmholtz's criticism of Europe's tem- 
FIG, 14.
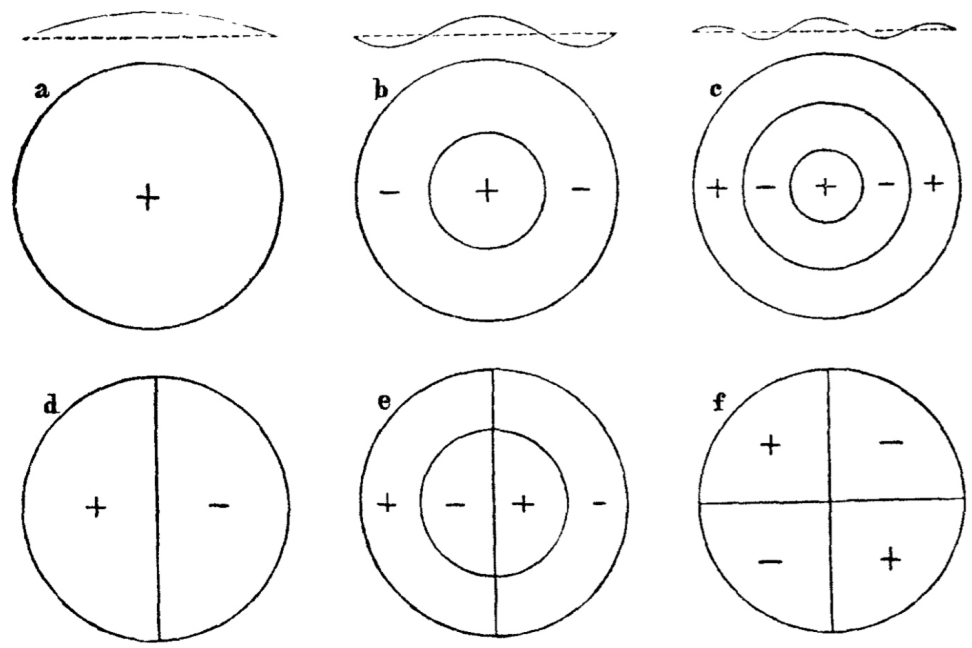

FIGURE 17. Helmholtz's illustration of nodal lines in On The Sensations of Tone
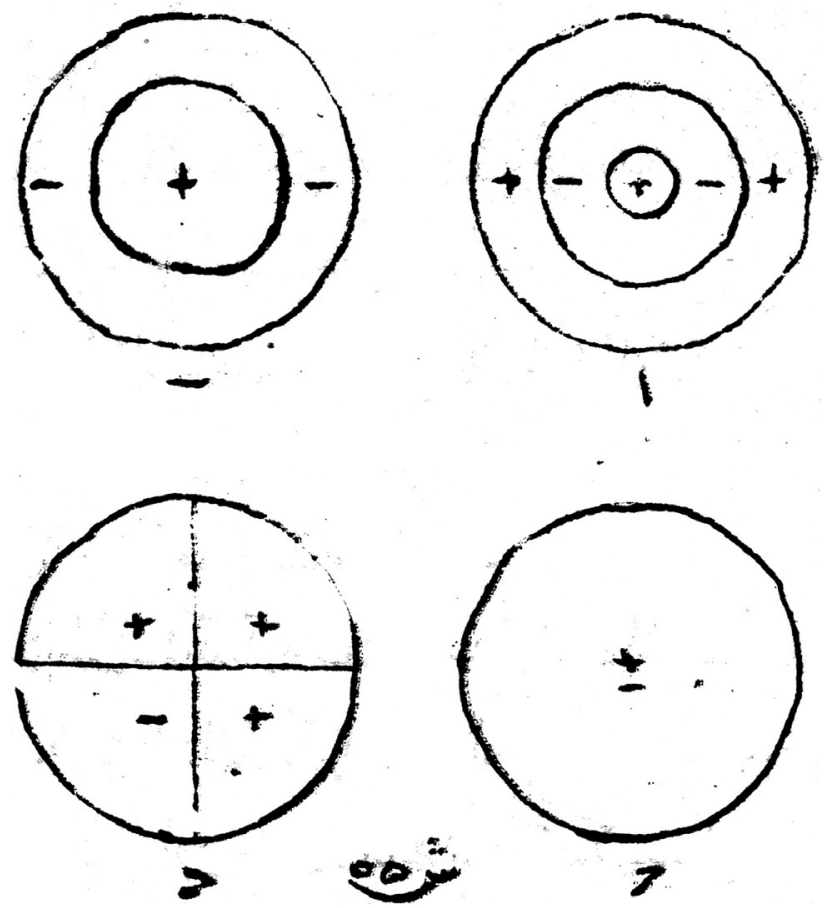

FIGURE 18. Hedayat's illustration of nodal lines in the Majma 'Al-Advār 


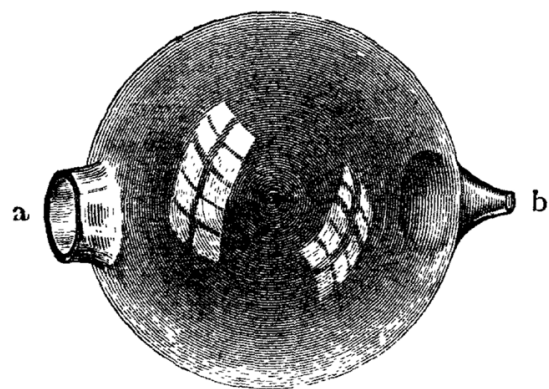

FIGURE 19. Helmholtz's illustration of his namesake resonator in On The Sensations of Tone

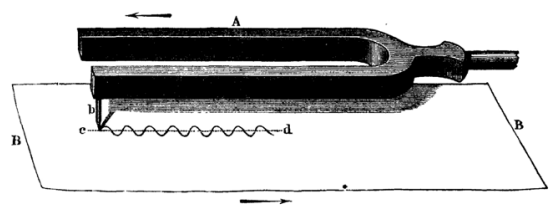

FIGURE 21. Helmholtz's illustration of tuning fork experiment in On The Sensations of Tone

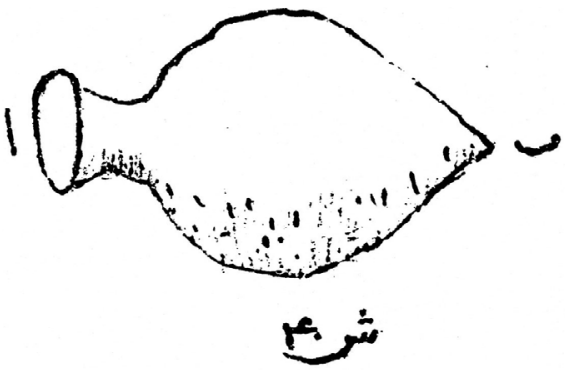

FIGURE 20. Hedayat's illustration of a Helmholtz Resonator in the Majma Al-Advār

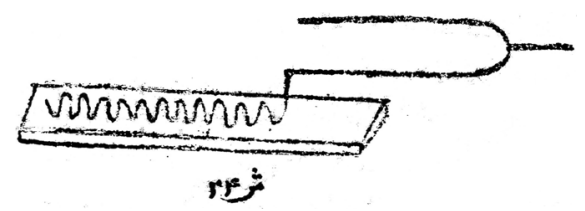

FIGURE 22. Hedayat's illustration of tuning fork experiment in the Majma 'Al-Advār

pered scale, which violated natural frequency patterns of air vibration. Hedayat believed that Persian music used intonation that better represented the naturally occurring pitch intervals Helmholtz described, and he used this logic to describe Persian music as having greater scientific accuracy than European music. In doing this, Hedayat was making the general observation that neither the historical scales he had read about nor the contemporary music he played from Tehran used European tempered intonation. From this general observation of intonation differences, Hedayat surmised that Persians were psychologically predisposed to create intervals between pitches that were closer to the natural frequency patterns of sound production, while Europeans were psychologically predisposed to violating these patterns. ${ }^{19}$ By not following European intonation, Persians showed that they had a different preference for pitch organization that was more natural than that of Europe, and thus more scientifically accurate. ${ }^{20}$

To demonstrate this idea, Hedayat used the second chapter of his text to outline Safi al-Din's advar side by side with Western music theory, in order to provide a display of two racially distinct approaches to music that were each highly systematic and scientific in their own way. In summarizing Safi al-Din's advar and commentaries on it from Qutb al-Din Shirazi and 'abd al-Qader al-Maraghi, Hedayat laid out the historic music system of peoples in the East (mashreq zaminīann), 
attributing this Eastern music system to the Iranians (ìrānīān) and the Persians ( $f \bar{a} r s \bar{i} \bar{a} n$ ). In laying out an overview of tonal harmony next to this Eastern music, he demonstrated that Iran had fostered a sophisticated music system that suited the peoples of the East much earlier than Europe had developed its great system that suited people of the West (maghreb zaminīän). The dominance of Europe in the modern world partly masked this reality, as did the failure to consider fully how racial difference would alter the nature of music in different parts of the world.

Within his explanation of these two systems, Hedayat returned repeatedly to the idea of racial relativity in musical expression, stating that "Different races (qaum) are different in their selection of tones ... and in their compilation [of tones] into melodies they create differences and behave according to their taste and style." ${ }^{21}$ In summary, he noted:

In order to distinguish music of one ethnicity from another and understand each in its context, it is necessary to know the mental conditions and customs of every ethnicity and every epoch. For example, in architecture, which is nothing more than a combination of shapes and forms, there is a style for every group, such as Greeks, Byzantines, Arabs, Iranians, ancient peoples, contemporary peoples. ... The modern peoples' derision of the music of ancient people is due to the lack of familiarity with the ancient style and modern peoples' attachment to their own customs. In other words, according to Helmholtz, modern people are accustomed to the artificial modality [and] they criticize the natural modality. ${ }^{22}$

It was in this much-expanded modern context of racialized music history that Hedayat confronted the seven dastgah and its lack of congruency within the twelvemaqam system as discussed by Safi al-Din, Qutb al-Din, and Maraghi. In the same way that Forsat had to begin his discussion of music anew with the seven dastgah, so too did Hedayat. He thus began his description of the seven dastgah tradition in a separate, third section of the Majma al-advār by acknowledging large disparities between his construction of Iran's Persian musical past with its advar and the tradition that was now treated as Iran's Persian musical present. He felt that the dastgah system was somehow guided by modern science, in the same way the twelvemaqam system had been guided by science. ${ }^{23}$ Even so, Hedayat had to find novel ways of locating both the historical and the intellectual connections between Iran's past and present to establish Iran's cultural legitimacy and scientific standing next to European music.

Even with significant disparities between the twelve-maqam system and the seven dastgah, the assumption of Iranian cultural relativism and the Orientalist narratives of Iran's ancient history gave Hedayat narrative tools to construct the twelve-maqam system as Iran's Persian past and the seven dastgah as Iran's Persian musical heritage in modern times. For this narrative of Iran's national music history, three hundred years of cultural decline stood between the twelve-maqam system and seven dastgah. He surmised that much Persian music must have been 
lost in that time. ${ }^{24}$ In this context, the seven dastgah stood as a restoration of as much music from the Persian musical past as possible, alongside as much unique, systematic Persian musical practice as could be salvaged. In explaining how this restoration of the great Persian musical past began, Hedayat noted that "Recently some masters were found again, and they poured the music that was in their hands into the molds of seven dastgah." ${ }^{25}$

Hedayat's separate description of the seven dastgah initially began by listing the names of melodies played in each one, in the particular order they would be used. This provided a representation of the dastgah that had many structural similarities with Forsat's description of the dastgah. Tables 1, 2, and 3 show how Hedayat described Shur, Nava, and Mahur, describing a similar long-form procedural framework for each one. In explaining how these dastgah related to the Persian music of ancient times, however, Hedayat described them as being constructed in imitation of the ancient nawbat murattab: the suite he had read about in Maraghi's writings. ${ }^{26}$ Hedayat suggested that just as the nawbat murattab suite consisted of certain compositional forms performed in a specific set order, so too did the dastgah follow its own type of suite model for performance.

The similarity that Hedayat saw between the seven dastgah and the nawbat murattab was simply one of assigned musical progression. In both scenarios, there was a certain order of musical events, though the actual musical events themselves

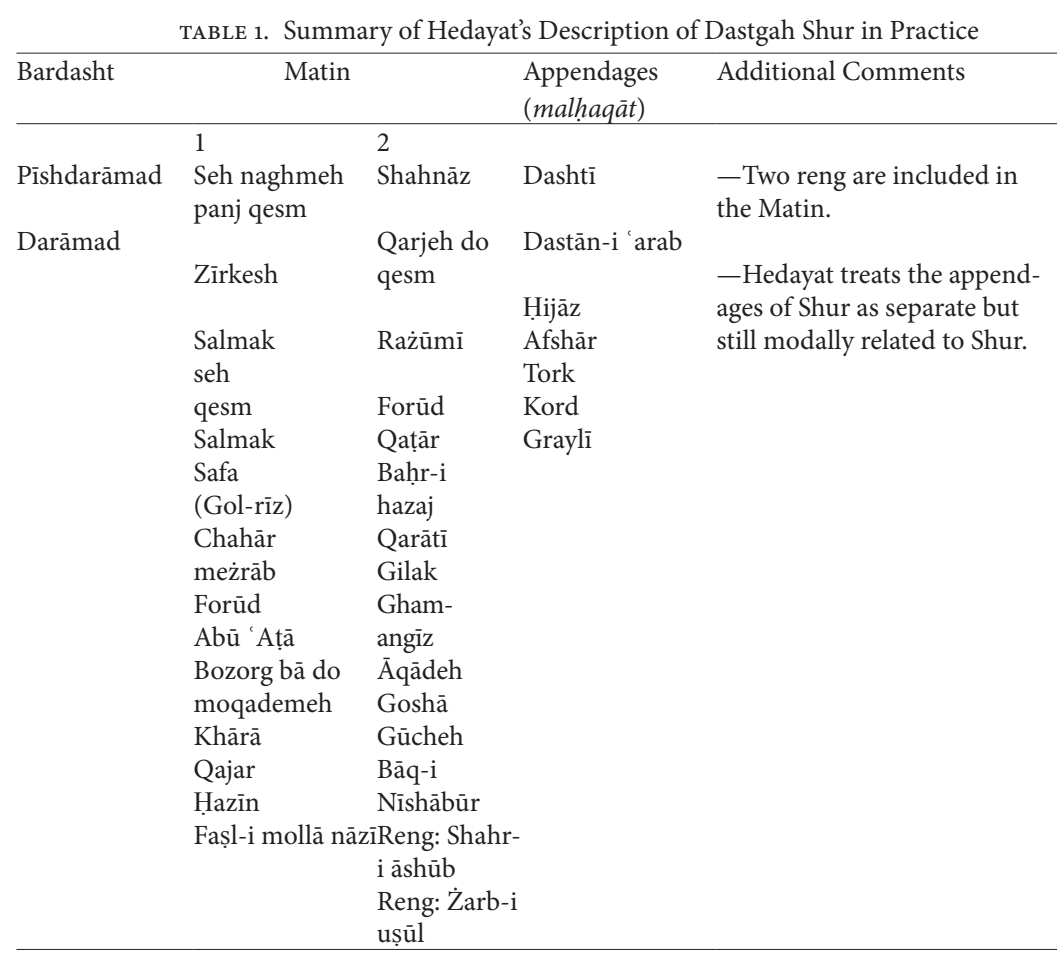


TABLE 2. Summary of Hedayat's Description of Dastgah Mahur in Practice

\begin{tabular}{|c|c|c|c|}
\hline \multirow{4}{*}{$\begin{array}{l}\text { Bardasht } \\
\text { Pīshdarāmad } \\
\text { Darāmad-i aval }\end{array}$} & \multicolumn{2}{|l|}{ Matin } & \multirow[t]{2}{*}{ Additional Comments } \\
\hline & 1 & 2 & \\
\hline & & & —The pisshdarāmad of Mahur is more \\
\hline & Avāz + forūd & Ṭūsì & $\begin{array}{l}\text { structured and modern than the } \\
\text { darāmad. }\end{array}$ \\
\hline \multirow{25}{*}{ Karāghalī } & Dād + forūd & Azzarbayjānī & \\
\hline & & & —Khavārazam Shāhī is a piece from \\
\hline & $\begin{array}{l}\text { Khosrovānī } \\
+ \text { forūd }\end{array}$ & Fìlī & $\begin{array}{l}\text { Aqa Husayn Qoli that is not used by } \\
\text { everyone. }\end{array}$ \\
\hline & & Zïrafkand & \\
\hline & $\begin{array}{l}\text { Delkash + } \\
\text { forūd }\end{array}$ & $\begin{array}{l}\text { Māhūr-i } \\
\text { saghīr }\end{array}$ & $\begin{array}{l}\text {-Ṭarab-angīz, Rāk, Shekasteh, } \\
\text { and Khavārazam Shāhī are modally } \\
\text { distinct from Mahur. }\end{array}$ \\
\hline & $\begin{array}{l}\text { Khavārazam } \\
\text { Shāhī }\end{array}$ & $\begin{array}{l}\text { Abd al- } \\
\text { shāmel }\end{array}$ & \\
\hline & $\begin{array}{l}\text { Khāvarān }+ \\
\text { do forūd }\end{array}$ & Heșār-i & \\
\hline & Țarab-angīz & māhūr & \\
\hline & Nīshābūrak & Naghmeh & \\
\hline & & Zangūleh & \\
\hline & & Gūsheh & \\
\hline & & Nayrīz & \\
\hline & & $\begin{array}{l}\text { Shekasteh }+ \\
\text { forūd }\end{array}$ & \\
\hline & & Bāz & \\
\hline & & Nahịib & \\
\hline & & 'Îrāq & \\
\hline & & Mahūr & \\
\hline & & Ashūr & \\
\hline & & İșfahān & \\
\hline & & Hazīn & \\
\hline & & Naghmeh & \\
\hline & & Zangūleh & \\
\hline & & Rāk & \\
\hline & & Sāqī nāmeh & \\
\hline & & Șūfĩ nāmeh & \\
\hline
\end{tabular}


TABLE 3. Summary of Hedayat's Description of Dastgah Nava in Practice

\begin{tabular}{|c|c|c|c|}
\hline \multirow{3}{*}{$\begin{array}{l}\text { Bardasht } \\
\text { Chakāvāk }\end{array}$} & \multicolumn{2}{|l|}{ Matin } & \multirow[t]{2}{*}{ Additional Comments } \\
\hline & Nava Proper & Optional Additions & \\
\hline & Avāz & Shekasteh & - The optional additions are melodies \\
\hline & Gardānyeh & Bozorg & from other dastgah that may appear in \\
\hline & Naghmeh & Raẓavī & Nava. Many are from Shur. \\
\hline & Bayāt-i rāje & Samalī & \\
\hline & Panjeh & Gabrī & -He treats Bayāt-i rāje', Gavasht, and \\
\hline & Mūyeh & Farānī & Ashīrān as being modally distinct from \\
\hline & 'Oshshāq & Gilakī & Nava. \\
\hline & Nohoft & Kord & \\
\hline & Gavasht & Hijāz & -Bāl-i Kabūtar is a type of forūd. \\
\hline & Ashīrān & Afsharī & \\
\hline & Nīshābūr mofaṣel & Dashtī & \\
\hline & Majlisī & Dastān-i 'arab & \\
\hline & Husayn & Rahāvī & \\
\hline & Malek husaynī & Shāh Khanā'ì & \\
\hline & Būsalìk & Tork & \\
\hline & Nayrīz & Bāl-i Kabūtar & \\
\hline
\end{tabular}

were quite different. The similarities he observed between the nawbat murattab and the dastgah were so general that he further connected both of them to the European fugue, a contrapuntal compositional form that also had yet another distinct progression of musical development. ${ }^{27}$ Hedayat gave his own analysis of the procedures represented in his lists of melodies for each dastgah in order to demonstrate a logical progression of events. In each dastgah's ordered list of melodies, he grouped smaller sections of the melodies into three possible categories: the bar-dasht (bar-dāsht), the matin (matn), and in some cases the foru-dasht (forudāsht). The bar-dasht in Hedayat's analysis represented the opening section of the dastgah. This section mostly included the daramad melodies and references to the pish-daramad, though he also included a handful of other melodic aspects for some dastgah. The matin came after the bar-dasht and it represented the core of the dastgah. Hedayat described it as the section where performers could "flaunt their desires" according to set musical parameters. ${ }^{28}$

For some dastgah, he described one set of melodies in the matin, with possible additions. In other dastgah, he subdivided the matin into several parts. In this latter category, he indicated a coda section of the matin in some dastgah: a set of melodies that acted as an addendum to the matin proper. He also used the term foru-dasht to reference key closing melodic phrases used throughout the matin. This term referred to the forud, which Forsat had also described, yet adding the word dasht to forud referenced a separate musical form that had been used in the nawbat murattab to close the full suite.

In his analysis, Hedayat took the melodic procedures of the seven dastgah that Forsat observed and cast them as an Iranian musical revival of past Persian music 
practices. From Hedayat's perspective, the seven dastgah were recent but their contents were not new: masters of Persian music had appeared out of the ether with Persian music from time immemorial, and they had organized performance of this music into the dastgah, which somehow echoed the structural principles of the ancient Persian musical past. Hedayat saw a Persian cultural decline as separating modern Iran from the glory of a scientific Persian musical past and positioned the seven dastgah as part of Iran's cultural revival in the modern world.

In furthering the narrative of the seven dastgah's ancient Persian origins, Hedayat posited that some remnants of ancient maqam modes could be located within the melodies of the seven dastgah. On this basis, Hedayat gave another analysis of the seven dastgah, showing which remnants of the actual maqam scales he believed existed in the modern tradition. Hedayat listed what he believed were the twelve scales of the twelve maqam using his own interpretation of the scales and intervallic notation he found in the writings of Safi al-Din, Qutb al-Din, and Maraghi. Next to these scales, Hedayat listed aspects of the dastgah in which he believed these maqam scales were being used, based on what he saw being used within the complex melodic sequencing of the dastgah in practice.

In this analysis, Hedayat saw nine distinct scales from the seven dastgah that he considered to be analogous to scales of the twelve maqam (see figures 23 and 24). Hedayat identified five dastgah as containing a maqam scale: Mahur, Shur, Nava, Homayun, and Chahargah. He aligned four more maqam scales with smaller melodic aspects within the dastgah: 'Iraq, Rak, Tarab-angiz, and Bayat-i Isfahan. In addition to these nine, Hedayat listed three scales as simply "additional" (izäfeh), apparently indicating that these maqam scales were not specifically used anywhere in the dastgah, but they were additional, hypothetical options for the modern dastgah tradition because of their use in the twelvemaqam system.

While Hedayat applied his bar-dasht/matin/foru-dasht analysis to the dastgah as they existed among practitioners of the tradition, he presented his analysis of modality as a theoretical exercise. If knowledgeable musicians looked hard enough, they could find some of the ancient Persian modes of the twelve-maqam system being expressed in the melodies of the dastgah. And Hedayat was not deterred by his inability to locate all of the modes he attributed to the twelve-maqam system. In the three hundred years of decline Hedayat placed between Maraghi and the nineteenth century, much Persian music had been lost, and the ability for Hedayat to perceive any amount of congruency between Iran's ancient and modern music validated the national narrative. The seven dastgah represented remnants of the old Persian system, and a combination of both lost and found modes legitimized the tradition as an authentic piece of Iranian national history.

Hedayat presented a distinct valuation for the dastgah based on their congruency with notions of ancient Persian scales and possible analogies with the new foreign advar of Western music theory. He also cast Segah as simply a transposi- 


\begin{tabular}{|c|c|c|}
\hline NAME & INTERVALS & NOTES \\
\hline Mahur & ب طططبط طط & $C D E F G A B C$ \\
\hline Iraq & ططب طب طط & $C D E F G A b B b C$ \\
\hline Additional & ب به جطبط ط & $C D E F G A d B C$ \\
\hline Shur & ط ج ج ط ج جط & $C D E d F G A d B b C$ \\
\hline Additional & ج ط ج ط ج جط & $C D E d F G$ Ad $B d C$ \\
\hline Additional & ط ط ب ط ج جط & $C D E d F G A b B b C$ \\
\hline Nava & ط ططب طط ج ج & $C$ Dd Eb F G $A b B b C$ \\
\hline Homayun & ط ب ه جط ج ج & $C$ Dd Eb F GdA Bb C \\
\hline Rak & ططب ططب ج & $C$ Dd E F G $A b B b C$ \\
\hline Chahargah & طب ط جب ج & $C \operatorname{Dd} E F \operatorname{Gd} A B b C$ \\
\hline Tarab-angiz & ط طب طط طب ط & $C D E b F G A b B b C$ \\
\hline Bayat-i Isfahan & طط ب ط جط ج & $C$ DdEdF $G$ A Bb C \\
\hline
\end{tabular}

FIGURE 23. Hedayat's presentation of the scales the seven dastgah should have, based on the history of the twelve-maqam system

\begin{tabular}{|c|c|}
\hline Sign & Meaning \\
\hline$b$ & whole step \\
\hline+ & half step \\
\hline$ج$ & $\begin{array}{c}\text { neutral } \\
\text { second }\end{array}$ \\
\hline$\circ$ & $\begin{array}{c}\text { augmented } \\
\text { second }\end{array}$ \\
\hline
\end{tabular}

FIGURE 24. Legend for figure 23 
tion of Shur's distinct scale, which he labeled as one of the many Iranian variations of the minor scale. Specific smaller sections of dastgah had greater standing vis-à-vis the seven dastgah because of their ability to be cast as the embodiment of specific scales found in the advar associated with the twelve-maqam system. Yet Segah's transposition of Shur's distinct scale made it one of the many Iranian variations of the minor scale, thus applying Western notions of scales to the dastgah. ${ }^{29}$ In either case, Hedayat went to great lengths to show how much systematic modality mattered in establishing Iran's narrative of Persian music, from the twelve-maqam system to the seven dastgah. This mattered for creating a single narrative of Persian musical development in the context of Iran's national history. But it also mattered for demonstrating the strength of Persian culture in relation to the idea of European racial superiority.

Yet in applying various types of analysis to the seven dastgah, Hedayat also demonstrated a significant degree of incompatibility between the tradition he knew from modern Tehran and what he found in writings about the twelvemaqam system. He performed two completely different types of analysis to show this connection. First he tried to show it by demonstrating general alignments between the dastgah in practice and approaches to compositional form associated with the twelve-maqam tradition. Then he showed how the twelve maqam themselves could be partially located within the seven dastgah. Both of these analyses were unique to Hedayat's own explanation of the seven dastgah and presented novel ways to use music in the construction of a larger narrative of Iran's national history.

The dominance of European music in the modern world loomed large in the Majma al-advār, even as Hedayat sought to establish Iran's unique cultural legacy of Persian music vis-à-vis tonal harmony. At the end of his magnum opus, Hedayat attached a short teaching manual about music notation (dastūr-abjad), where he outlined his understanding of the alphabetical system of notation he saw used by Safi al-Din, Qutb al-Din, and Maraghi, while also explaining how to use European music notation. Hedayat cast the abjad notation he discovered in ancient Persian writings on the twelve-maqam system as a demonstration of the great sophistication of ancient Persian music, even as the disappearance of this notation demonstrated the historic decline of Persian music and the seven dastgah's inability to fully reflect the ancient Persian music that related to a type of notation. Hedayat praised Europe's use of notation, noting that something that took six months to learn without notation could be learned in only a month with it. This notation could preserve music for long periods of time and ensure its retention..$^{30}$

He posited the question of why Europe had two modes with endless numbers of melodies and many different musical forms in those modes, while Iran had twelve possible modes but then only a certain number of melodies organized into seven dastgah. He bemoaned the oral nature of the seven dastgah and the lack of music notation for so many centuries previous to the seven dastgah, noting that 
"because we did not have a tradition of writing, everything that flowed from our master's creative nature was lost within their chests." ${ }^{31}$ In Hedayat's narrative of Iranian music history, the seven dastgah could never fully embody the twelvemaqam system. They could only encapsulate a small amount of the ancient Persian music that had survived through an imperfect oral tradition.

In his final thoughts, Hedayat reflected on how Iranian music needed to change in order to better embody the great Iranian legacy of the past, while also considering modern innovation. Based on the idea that Iran had a unique cultural basis that music had to both adhere to and expand, he concluded:

We are not prohibited from new things, except by the capacity of our natural disposition and dialect; we would not bend our language and all at once not play according to our usual ways-Iranian music is in compliance with the Persian language $(f a \bar{r} \bar{s} \bar{l}$ - - this is not an obstacle-so we remember the ancient [and] we are also able to produce the new. ${ }^{32}$

'ALI NAQI VAZIRI AND THE MUSIC OF

A THOUSAND YEARS

Forsat and Hedayat both documented a tradition of seven dastgah in the music of the Qajar court and expressed variations on the notion that these seven dastgah contained remnants of a long-lost Persian music tradition. Hedayat's more specific association of this Persian music history with modern Iran and Iranians reflected practitioners' conception of the seven dastgah as the twentieth century progressed. Yet the question of how to imagine the seven dastgah as the musical embodiment of Iran's Persian musical past did not have one definitive answer. Hedayat's specific ideas and analyses were unique, but their conceptual premise demonstrated the impetus to reimagine the seven dastgah as an aspect of Iran's timeless Persian culture. His ideas further revealed the issues involved in constructing a nationalist narrative of Iranian music history. Iran's historic Persian music must have a contemporary repertoire of Persian melodies that somehow traced its origins back through Iran's ancient Persian music history. Yet these melodies needed some kind of systematic modal derivation. Notions of systematic modality could tie the seven dastgah to a distinct Persian past embodied in the twelve maqam system, in order to create a cohesive narrative of Iranian music history. Systematic modality could also give Iran a recognized indication of indigenous cultural superiority in the modern world.

It was around this dual conception of Persian melodies (radif/gusheh) on one hand and Persian modes (dastgah) on the other that the seven dastgah of the Qajar court became the radif-dastgah tradition of the twentieth century. And while this bifurcated music system could be imagined in different ways, 'Ali Naqi Vaziri acted as a major influencer on how to think about the seven dastgah reorganized 
around these structural concepts, which he explicitly tied to the national history of Iran. Through his extensive work in music education and that of his students, his whole conception of the radif-dastgah tradition as a historical and structural phenomenon of Iranian music framed many musicians' ideas about the tradition. Even musicians who did not subscribe to Vaziri's specific ideas were nevertheless dependent on concepts he popularized to create their own frameworks for understanding the tradition.

Unlike Forsat or Hedayat, Vaziri did not engage in the specifics of the twelvemaqam system in any of its specific incarnations, nor did he puzzle over the differences between Iranian music past and present. The unique, perennial unity of Iranian culture and its Persian legacy writ large provided enough evidence to support the assumption that Iran had a singular history of Persian music, and the lack of music notation for most of this history fully explained the lack of continuity between modern Iranian music and that of its glorious past. Vaziri also framed the seven dastgah as a modern amalgamation of ancient Persian melodic material, and he did not shy away from taking this melodic material and analyzing it in terms of systematic modality in order to better align modern Iranian music with his general understanding of music history in the region. Within this nationalist reasoning, he taught a reinterpretation of the seven dastgah meant to balance the known practices of the tradition with a relatively unique conception of systematic modality, which very generally connected Iran's contemporary Persian music to past conceptions of music in the Persian-speaking world.

Vaziri's specific ideas about Iran and its music were influential because he conveyed them using modern institutions and modern technology and he was specifically dedicated to being a modern educator for Iranian music. Rather than simply writing one text for general reading, he produced multiple teaching manuals for different instruments. These manuals were designed to teach the seven dastgah to students of music performance, using systematic pedagogy to help students understand both the music system and instrumental techniques. It was in these teaching manuals that Vaziri's nationalist goals for Iran manifest as highly functional ideas about the seven dastgah's structure and execution in practice. While Vaziri initially used these manuals in his own private music school, many of his students became musical educators themselves and taught their students referencing the method of analysis Vaziri had taught them. In this way, Vaziri's concept of Iranian music gained an immense amount of influence in twentieth-century Iran.

Vaziri's writings were some of the first to document a consistent use of a distinct Persian repertoire called radif and a consistent concept of dastgah being tied to abstract modal frameworks rather than specific melodic progressions. While Forsat and Hedayat used a variety of different terms to characterize the smaller melodic sections of a dastgah, Vaziri consistently used the term gusheh to talk about all of these melodies, which all belonged to the radif, but were organized in performance according to the abstract modal structures of the dastgah. Even 
within Vaziri's analysis he could not actually account for all of the gusheh in each dastgah applying one systematic modal schema, yet he did portray the greatest amount of modal rationalization possible and taught musicians how to play in the tradition using the idea of dastgah modes as a basic feature of the system. He even documented changes to the dastgah that facilitated greater alignment between each dastgah and a specific modality. These changes marked a full conversion of the seven dastgah of the Qajar court into the radif-dastgah tradition of modern Iran.

Though vague and somewhat ambiguous, Vaziri's understanding of Iran's Persian music history placed the beginning of Iranian musical greatness before the rise of Islam, with the ancient Persian empires. From pre-Islamic times he traced Persian music into the medieval Near East via research in modern Europe. Thus, in his first teaching manual for tar he observed that

The original Iranians-the civilization of Iran-dated from before the birth of Greece. They have established this from the historical documentation of this art, which is the greatest keepsake of Eastern lands [that] originated from Iran; and they know that music of the East is an example of the outgrowth of Iranian thought and talent. ... There are many translations of those manuscripts into current European languages. They acknowledge that Iran had collections of arranged music and musicians. ${ }^{33}$

Tracing pre-Islamic Iranian music through the rise of Islam, Vaziri mentioned in passing al-Farabi, ibn Sina, Safi al-Din, and Maraghi, stating that contemporary Iranian music was one and the same with the music they discussed. ${ }^{34}$ Yet Vaziri also discussed Iranian music as a largely lost art. Like Hedayat, he ended the history of Iran's musical renaissance with Maraghi in the fifteenth century. Still, in discussing the seven dastgah tradition as unequivocally Iranian, it was Vaziri who stated that "our music today is a music of a thousand years of which elements of it have not been touched." ${ }^{35}$

Like Hedayat, Vaziri also saw separately defined culture groups as central to defining differences in musical sound structures. While Vaziri valued European music for its high degree of systemization, he thought that every nation required its own historically defined music as part of its own physical survival. Vaziri thus positioned a distinct Iranian music as an important aspect of Iran's survival in the modern world, and the building of an ever-greater Iranian civilization. ${ }^{36}$ Vaziri's classification of music as art (honar, son'at) contrasted with Hedayat's focus on science, connecting music more closely to human expression independent from objective understandings of sound. His understanding of the seven dastgah developed within his personal campaign to educate Iran about its unique national arts and the unique artistic basis of music in Iran's Persian history.

Vaziri also saw the lack of congruence between Iranian pitch and European pitch as an important musical distinction that demonstrated the difference 
between two legitimate cultures. Rather than following Hedayat's logic and trying to find direct congruencies between the twelve-maqam scales and pitch usage in the seven dastgah, Vaziri focused on the general idea that Iran's Persian music had always had systematic scales with pitches that fell outside of the European system of chromatic half steps. Pitches outside Europe's concept of intonation existed in both the seven dastgah and the twelve-maqam system in some capacity, and this general phenomenon demonstrated Iran's distinct use of pitch both past and present. In imagining a systematic way to organize a unique concept of Iranian intonation, Vaziri took the concept of Europe's chromatic half steps and surmised that Iran's full chromatic pitch measurements moved in quarter steps. On this basis he described quarter tones (rob pardeh) and made this concept the distinctive cultural factor that defined the unique history of Iranian music. Comparing the discovery of Iranian quarter tones to the discovery of minerals buried for centuries in the ground, he praised them, saying that “The environment of the Iranians' music is truthfully one of the great quarries." ${ }^{37}$

Vaziri surmised that Iran was only using some of the quarter tones in modern times. He theorized that a full chromatic Iranian scale would use the quarter step as the smallest possible interval instead of the half step, and these quarter steps would be evenly divided within the same octave defined for European music. This approach to intonation kept all of the pitches used in European music, but added additional pitches to account for Iranian music's smaller intervallic relationships. European notation was designed to indicate every possible pitch as having three possible versions, natural, flat, or sharp. To describe the more expansive use of pitch in the Iranian quarter tone system, Vaziri added the possibility that every pitch also had a half-flat he called koron (koron) and a half-sharp he called sori (sorī).

By addressing the history of pitch usage in Iranian music using generalities, Vaziri avoided confronting the complicated issue of consistent systematic pitch usage that Hedayat had encountered in his more specific construction of Iran's Persian music history organized around the twelve-maqam system and seven dastgah. Vaziri cast both systems as using quarter tones in various ways that evidenced a shared Iranian system of quarter tones. He thought that the full spectrum of Iranian pitch usage had been lost over time, and thus treated his scale as a re-creation of Iran's ancient concept of pitch. Though he derived his scale from his knowledge of contemporary pitch usage in the seven dastgah and European music, Vaziri's highly generalized notion of pitch and scale organized around the discourse of indigenous intonation allowed him to position his approach to quarter tones as the ancient foundation of Iranian music.

From the basis of a unique Iranian chromatic scale, Vaziri focused on Iranian scales for specific aspects of the seven dastgah that could ultimately be applied consistently in practice. Vaziri positioned these scales as both essential to the seven dastgah and distinct from the radif: the specific melodies and their sequence in each dastgah that both Forsat and Hedayat had ultimately determined were at 
the core of actual performance. Setting aside the burden of specifically aligning the organization of pitch in the dastgah with that of the twelve-maqam system, Vaziri focused on a general system of scales that indicated a unique approach to systematic pitch organization based on what the seven dastgah themselves could facilitate. Thus, while he described each Iranian scale as being a combination of two tetrachords (dāng), he focused on extracting whole sets of eight-note scales from the seven dastgah and finding patterns of note usage that would work in practice. From this he further discussed secondary scales (called alternately naghmeh or avaz) with varying numbers of pitches that bore no particular relation to the systematic application of tetrachords.

The Iranian scales Vaziri taught changed over time, but certain basic principles remained the same. Overall, the scales he taught contained eight notes in the octave and a distinct set of functional notes in practice that could systematically explain the creation of melody in any scale. On this basis, Vaziri designated Iranian scales as having several different types of functional notes, with three types emerging as the most important in the creation of melody: the shahed (shähed), which was one particular note of the scale that would reoccur frequently in its melodies; the motighayyer (motighayyer), which was one specific note in an Iranian scale that could be changed, moving somewhat higher or lower, in the creation of its melodies; and the ist (ist), which was a note typically repeated in succession at various points in the creation of melodies using a particular Iranian scale.

In focusing on the organization of pitch and unique aspects of pitch organization, Vaziri was seeking to construct the primary scales of Iranian music, focusing on the idea that each of the seven dastgah was first and foremost a specific scale defined by a specific application of certain pitches. The secondary scales he discussed derived from relatively long melodic sections of the original seven dastgah that did not conform to the scales defined for the original seven dastgah. These secondary scales partially addressed the conundrum of insisting that each dastgah was primarily defined by a unique scale, even when a dastgah could be seen as containing multiple modal structures.

Vaziri's various attempts to represent the seven dastgah as a rational system of pitch modality demonstrate the difficulties Hedayat also encountered in trying to make a system of scales work in relation to the melodies of the dastgah (see figure 25 and figure 26). For instance, in his first teaching manual, Vaziri focused on establishing primary scales for the seven dastgah, and then addressed two additional secondary scales. He extracted each of the two secondary scales from two different dastgah, one from Homayun and the other from Shur. But he did not address the extensive melodic material of each dastgah documented by Forsat and Hedayat, nor did he locate all three of his key functional notes in every scale he designated. He only identified a shahed note in every scale. While he indicated a motighayyer note for most of the scales, he did not indicate an ist note for any of them. Instead, Vaziri included a variety of other ideas for designations for functional pitches. In some cases, he identified a changing interval between two pitches 


$$
\begin{aligned}
& \mathrm{s}=\text { shāhed } \quad b=\text { full flat } \\
& \mathrm{m}=\text { motighayyer } \quad d=\text { half flat (qoron) } \\
& \mathrm{i}=\text { iss } \\
& \mathrm{K}=\text { ending note (khātimeh) } \\
& \mathrm{KF}=\text { final ending note (kāmel-i forūd) } \\
& \mathrm{M}=\text { changing interval (mokhtalef) } \\
& \mathrm{ST}=\text { starting note (shurū') }
\end{aligned}
$$

FIGURE 25. Legend for figure 26

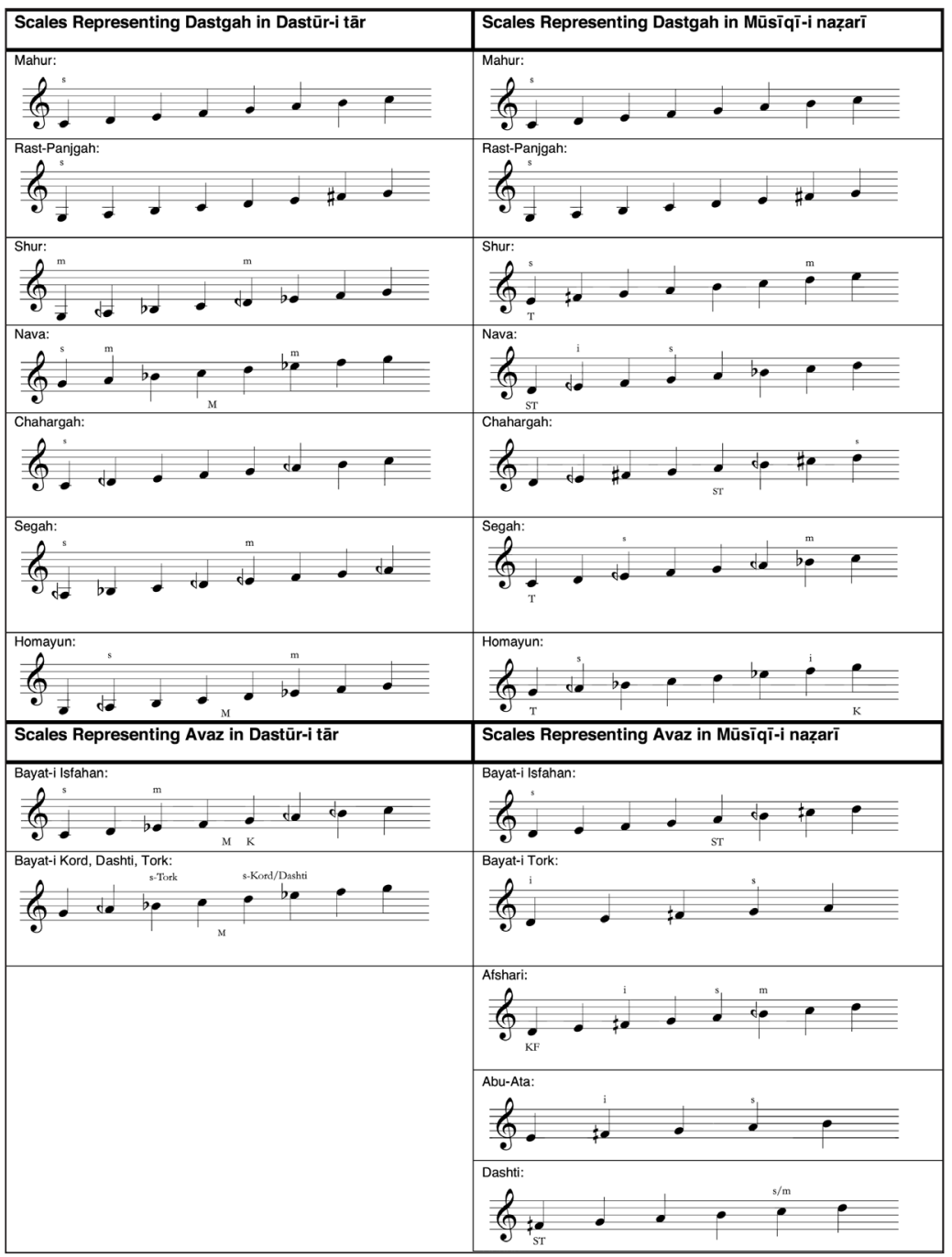

FIGURE 26. Vaziri's changing representation of the dastgah scales 
of a scale (mokhalef). He also designated an ending note in the secondary scale Bayat-i Isfahan, but in no other scale.

A decade later, in $M \bar{u} s \bar{i} q \bar{i}-i$ nazarī, Vaziri presented the primary scales of Iranian music again, with some alterations..$^{38}$ There were the seven primary scales of the dastgah, now with some acknowledgment of transposition. He still included two secondary scales that also had eight pitches, again extracted from Homayun and Shur. In addition to these, he extracted three more scales from Shur that only had five or six pitches. This further extraction of scales from Shur altered his ideas about which naghmeh/avaz of Shur had eight pitches. In Mūsīqī-i nazarī, he only identified Afshari as having all three primary, indigenous functional note designations, a shahed, motighayyer, and ist. He still identified a shahed note for each scale and a motighayyer for some but not all scales, though in some cases the scale degree for each of these changed. He kept the designation of a final pitch in some scales but eliminated his designation of a changing interval. He also added several more designations, including the possibility of a tonic note (toni $k$ ) or a starting note $($ shurūe $)$.

The changes Vaziri made to his presentation of scales in Mìsīqì-i nazari related to the text's acknowledgment of avaz: the core aspect of dastgah performance where musicians improvised upon unmetered melodic materials in a particular sequence. Accounting for the avaz led Vaziri to give detailed analysis of gusheh: the actual melodies used as the basis of avaz in a dastgah, which also represented the ancient remnants of Iran's musical past. Vaziri mostly avoided explaining the full breadth of melodic material associated with the dastgah in his teaching manuals for specific instruments. Focusing on the abstraction of scales as the primary basis of the seven dastgah, Vaziri mainly analyzed the daramad melodies of a dastgah in most of his teaching texts. When focusing on the details of many different gusheh in each dastgah in Mūsīqì-i nazarī, Vaziri struggled to account for the gusheh in relation to systematic modality just as Hedayat had. His most specific definition of a gusheh was that they were "melodies (ahang) that are in the range of one tetrachord (dāng) or pentachord (panjom), but they usually transgress this range to a certain extent and many different notes may be altered in the course of playing one so that you cannot define their specific scales." 39

This definition lent systematic terminology to the concept of gusheh, even as Vaziri confronted their apparent lack of consistent pitch systemization. Within the principles of the scale that Vaziri sought to systematize, the gusheh should have used a limited number of set pitches in a systematic way vis-à-vis the scale of their respective dastgah. In practice this was not necessarily the case. Vaziri limited his discussion of gusheh beyond the daramad to this more advanced text for this reason: the gusheh of each dastgah did not necessarily conform to the dastgah and naghmeh/avaz scales. The gusheh associated with each dastgah thus greatly complicated the basic scale ideas Vaziri wanted to instill in music stu- 


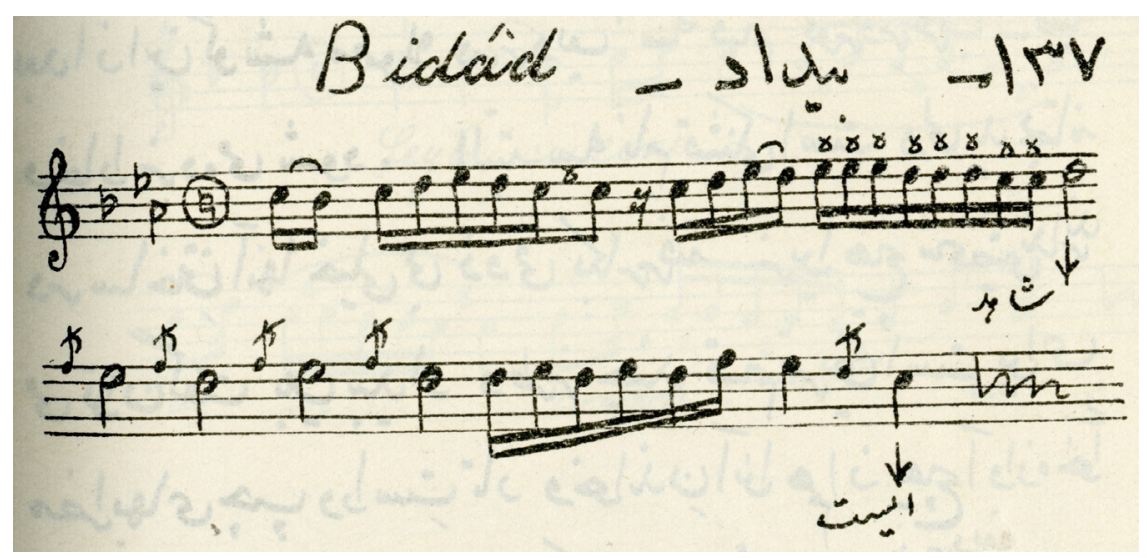

FIGURE 27. Vaziri's analysis of the gusheh Bīdād, showing its shahed and ist. This was one of many gusheh Vaziri thought had its own unique scale.

dents and he waited to teach it until after they already understood his approach to teaching Iranian scales.

Mūsìqīi nazari presented an overview of the radif: each set of gusheh that Vaziri associated with each distinct Iranian scale. In doing this, Vaziri only occasionally notated a daramad. Instead, or in addition, Vaziri often wrote out a sketch (engāreh), a notation of a melody that was distinct from the daramad, which he used to demonstrate the pitch parameters of a dastgah or naghmeh/avaz scale. While Vaziri usually notated each gusheh in the radif as a specific melody, he did occasionally give sketches for specific gusheh, indicating their distinct pitch parameters in contrast to the dastgah in which they were used.

Vaziri also demonstrated some direct ambivalence concerning the secondary scales he designated as either naghmeh or avaz, and other scale possibilities that he could see in the gusheh. He wrote that the gusheh named Bidad (bìdād) used a unique scale, even indicating a distinct shahed and ist within it (see figure 27). He made a similar observation about the set of gusheh in the dastgah Mahur that all had some variation on the name Rak (räk). In explaining why some scale possibilities had been identified and developed as secondary scales while others had not, he spoke of how only certain sections of gusheh were commonly excerpted and performed independently from their constituent dastgah in practice. The growth of composition using certain abstracted scales and not others was also a factor. Vaziri noted that "Afshar, Bayat-i Tork, and Dashti have become independent in the new music of Iran because it is customary to have pish-daramad, tasnif, and reng specifically composed for them." ${ }^{40}$

Vaziri acknowledged that he could have extracted more unique scales from the material of the gusheh, but in practice not every scale possibility was being actively used as such in practice. He named scales based on whether or not they 
constituted a unique set of gusheh that was being used to perform a shorter version of the long-form procedural model of a larger dastgah. These shorter excerpts from dastgah also had to have modal structures extracted from them, which were then used to write new, metered compositions. On this basis, some smaller portions of dastgah with unique pitch usage were defined as embodying a unique scale, while other portions of dastgah with unique pitch usage were not.

Even with a very different approach to pitch analysis, Vaziri's analysis of the seven dastgah still confronted many of the same issues Hedayat encountered in his analysis. For both Vaziri and Hedayat, the gusheh were the melodic proof of Iran's ancient music. They had become Iran's music of a thousand years. Yet as modern Iranian musicians learned more about the historical emphasis on systematic pitch modality in Persian texts about the twelve-maqam system, systematic modality became the missing piece of Iranian musical heritage. In locating this missing piece, both Hedayat and Vaziri had to alter the original seven dastgah, which did not conform to either musician's conception of proper Iranian pitch organization in comparison with the newly discovered Iranian music history. Yet different ideas about what Iran's newly discovered Persian music history meant for the conception and practice of music in modern Iran led to different conclusions about how Iran's Persian music should look in the modern world.

In $M \bar{u} s \bar{q} q \bar{i}-i$ nazari Vaziri provided a metaphor to explain to students how the gusheh related to the dastgah, even though they did not consistently conform to the scale of the dastgah. He described the seven dastgah as seven countries (mamlekät) that contained many houses (gusheh), and some cities (naghmeh/ avaz). Vaziri's metaphor referenced the modern standard of each nation's unity and idiosyncrasy in order to explain how the dastgah could be the primary unit of organization (the country), with every gusheh representing a unique manifestation of a dastgah (the houses). Naghmeh/avaz being cast as the cities acknowledged that sections of the dastgah contained clusters of gusheh that were distinct unto themselves, but could nevertheless be considered as an extension of a particular dastgah. ${ }^{41}$ Here the modern assumption of the nation as the fundamental organizational unit that was a cohesive whole despite significant amounts of diversity became the model for the music itself, which needed to reflect both the nation's unity and its idiosyncrasy.

CONCLUSION: PERSIAN MELODIES VS.

IRANIAN MODES

The rise of the Qajars brought with it a new access to and emphasis on idiosyncratic melodic organization. The seven dastgah initially represented a method of music-making with no strong distinction between an abstract modality and 
a fully formed melodic sequence. It was this melodically ambiguous context and the seven dastgah's specific musical praxis that became a key location to create the uniqueness of the Iranian nation and its legitimate distinction in the modern world. It was the basis for a method of music-making like no other in the world that was Iran's and Iran's alone.

Yet the modern nation required both cultural idiosyncrasy and historical legitimacy. Iran's right to exist in the modern world was premised in discourses of its ancient existence across epochs. The procedures of the seven dastgah could offer evidence of a unique Iranian culture, yet the entire concept of how to perform within the tradition contradicted the documented history of the twelve-maqam system that had dominated Persian discourse for centuries. Vaziri, Hedayat, and Forsat all looked back at Persian writings about music and found different ways to conceive of the idiosyncrasy of the seven dastgah as a demonstration of Persian history's continuity. Vaziri and Hedayat further extrapolated Iran's existence from this history. But the more musicians understood about music history and the requirements of modernity, the more they needed to extrapolate further from the dastgah to find a historic Persian musical legacy that embodied both Iran's long Persian history and its modern cultural renaissance. Questions about how to reconcile the twelve-maqam system with the seven dastgah were central to reconciling the Persian musical past with the Persian musical present in order to create a music for the modern Iranian nation. Negotiating these two contradictory requirements ultimately fostered a transformation of the seven dastgah into the radif-dastgah system as the twentieth century progressed.

The emergence of the radif-dastgah tradition thus marked the full intellectual and musical extinction of the twelve-maqam system in a newly defined modern space, even as previously abandoned priorities in the twelve-maqam system took on new rhetorical meanings and functions vis-à-vis the radif-dastgah tradition in modern Iran. The twelve-maqam system's disappearance grew out of the hobbling of its context within the political structures of dynastic rule, even as the contingent political circumstances that defined its demise led to equally contingent changes in music of the Qajar court of the nineteenth century. Looking to the court as a source of national music was logical, yet the particular idiosyncrasies of the seven dastgah offered some specific basis to begin imagining the Iranian nation in relation to the Persian language, its history, and its geography.

While the twelve-maqam system had stood as an ongoing discovery of the timeless existence of musical truth, musicians negotiated the seven dastgah in terms of human variability and idiosyncrasy. The pursuit of a single set of music structures with the power to affect the whole of humanity was over as the modern world became defined by the diversity of cultures. Modern music required a map of distinct cultural units that transgressed the twelve-maqam system's transregional reach. But this racialized view of culture did not value diversity equally. 
With this in mind, changing music could relate to improving culture, and such changes could mean adopting or otherwise creating new indigenous musical norms. Forsat presented the seven dastgah as an intentional improvement that Persian music needed, while both Hedayat and Vaziri spoke of the dastgah as modern creations for preservation of Iran's music, most of which had been lost. As musical practitioners of the seven dastgah, both Hedayat and Vaziri presented different changes to the seven dastgah that could better represent Iran's Persian musical past and revive its glory in the modern era. In this context, the twelvemaqam system was recast as a placeholder in Iran's history of Persian music. It was a demonstration of Iran's historic musical greatness against which the radif-dastgah tradition could be measured. In refashioning the radif-dastgah tradition to better represent Iran's historic musical legacy, musicians tried to make it more like the twelve-maqam system, while preserving the ancient Persian melodies of the original seven dastgah. Musicians approached this project differently, depending on how they understood Iran's newly discovered national history. Yet the concepts of radif and systematic modality ultimately became core aspects of how musicians reorganized the seven dastgah in order to create a music that demonstrated core aspects of Iran's Persian identity.

The changes that systematic modality introduced were significant. Vaziri's description of the naghmeh reflects the creation of the avaz-dastgah, and the extent to which small sections of dastgah began to separate from the dastgah in relation to creating systematic modality. Extracting naghmeh/avaz-dastgah from the dastgah of Shur's particularly extensive and complex melodic progression facilitated a more defined modal structure for Shur, as well as a subset of modes related to the melodies of Shur that displayed their own distinct modal tendencies. The same reorganization happened with Homayun, where musicians removed a section of its melodies based on differing use of pitch. These avaz-dastgah scales gained greater standing in the radif-dastgah tradition as the twentieth century progressed. With abstract pitch modalities distinguished from the radif, composition became more viable, and the use of avaz-dastgah scales to compose initially reinforced their standing as scales that could have as much standing in the system as the scales that came to be associated with the original seven dastgah.

The value of distinct modal structure created additional revaluations of the dastgah. The dastgah Rast-Panjgah, which Forsat represented as a commonly used dastgah, was a much rarer dastgah for performance in the late twentieth century, while the use of the dastgah Mahur increased significantly compared with Forsat's observations from the turn of the century. The idea discussed by Hedayat that Mahur was a $\mathrm{C}$ major scale made it a core aspect of the entire radifdastgah tradition. Conversely, the melodic progression of Rast-Panjgah had the most diverse representation of pitch usage of any of the dastgah. Neither Hedayat 
nor Vaziri could designate a distinct scale for Rast-Panjgah, and musicians settled on a small portion of its gusheh being based on an F major scale, which was then classified as a mere transposition of Mahur. Any widespread usage documented by Forsat was curtailed by Rast-Panjgah's inability to conform to the association between dastgah and distinct modality required as the twentieth century progressed. Between the publication of Forsat's book and Vaziri's Mūsìqì-i nazarī, the value and usage of Mahur and Rast-Panjgah inverted. Students had to learn Mahur early in their training, and learn Rast-Panjgah much later, or perhaps never learn it at all.

Segah's position also changed. All three authors regarded Segah as a variant of Chahargah's melodic content. Forsat named Chahargah the most used of any of the dastgah and described it thoroughly, but he had very little to say or demonstrate for Segah, because it was merely a different way of realizing Chahargah's melodic sequence. While Hedayat and Vaziri recognized this idea, they focused on Segah's unique use of pitch. What made Segah distinct from Chahargah was the way it transposed the pitch organization of Chahargah's gusheh, and this transposition implied that Segah had its own scale, which gave it more value. Apparent modal redundancy could reduce a dastgah's usage, but Segah's ability to be cast as a distinct modality increased its standing. As new compositions could be written using Segah's designated modality, Segah no longer stood as merely a variation on Chahargah's sequence of melodic material.

Beyond what the most educated people thought about the place of modality in Iranian music, similar patterns of modal development appeared in the earliest audio recordings of the tradition. Writing about the early development of the music recording industry in Iran, Mohsen Mohammadi has noted that while recordings of Iranian music initially focused on the seven dastgah, they came to focus on aspects of the dastgah that could function as distinct modal entities: five modes that could be extracted from the dastgah, and five more extracted from smaller sections of the dastgah that eventually came to represent the avaz-dastgah. ${ }^{42}$ The short length of audio recordings required some type of reduction in what the long-form procedural practices had been, and musicians organized their reductions for recording around expressing the systematic modality. Composition also became more important with the rise of recording and radio, as it also related to the growth of systematic modality and the need for shorter models of performance. Recorded music and radio had immense power to influence how Iranians heard themselves and the world. Recordings were marketed and sold according to national audiences, and radio was a national enterprise all its own. Hedayat and Vaziri developed their own specific ways of understanding systematic modality in relation to the context of Iran's musical identity, but they were simply expressing a broader context that was both necessitated and facilitated by multiple aspects of modernity. 
As musicians reimagined their modal identity, the number of gusheh that could stand as independent frameworks for performance decreased. Modal variation within the dastgah was curbed by the distinction of the avaz-dastgah and then downplayed where it still existed. Gusheh with distinct modal tendencies could be labeled modulatory, and a dastgah like Rast-Panjgah with no achievable modal consistency became an odd exception. Changes to the seven dastgah's structure reduced modal variation within individual dastgah, but what remained could often be rationalized.

The changes made to the original seven dastgah opened up possibilities for more change, and concerns about too much change. Indeed, the competing interests of preserving historic Persian melodies and utilizing distinct Iranian modes facilitated a diversity of practice in the radif-dastgah tradition. Iranian modes facilitated more composition, while the concept of radif kept the principles of the seven dastgah's initial procedural approach to performance alive, as the gusheh themselves also demonstrated authentic Iranian music. Musicians also came to recognize the radif as a symbol of their Iranian culture independent of long-form dastgah performance, even as the use of systematic modality also confirmed the nation's continuity with its Persian musical past. Vaziri's specific ideas about pitch modality were extremely influential, but they represented a broader change in the conception of music among practitioners of the radifdastgah tradition.

Like Hedayat's analysis, Vaziri's ideas were only one possibility for how to reimagine the seven dastgah within the modernity of Iranian national identity. There was no highly specified conception of how the radif-dastgah tradition should embody distinctions of melody and modality in keeping with the Persian identity of the Iranian nation. Yet even musicians who did not accept Vaziri's specific approach to the tradition were dependent on the same basic frameworks laid out by both Vaziri and Hedayat. Musicians could claim to be the most traditional by upholding the radif repertoires while still applying various conceptions of systematic modality. The avaz-dastgah became universally accepted by all musicians with differences of opinion surrounding only what they should be called and how many there were. Any commitment to long-form performance models in keeping with the Qajar tradition was defined by a commitment to preserving the integrity of Iranian identity. Yet concepts of radif and systematic modality were also tied to upholding Iranian identity.

The decision to take up the seven dastgah and maintain them as a Persian tradition of Iran resulted from the radical transmutation of the modern era, which included a significant amount of European cultural intervention. Both Hedayat and Vaziri delved extensively into European music in their musical work, yet they held up the radif-dastgah tradition as a key pillar of their musical identity as Iranians because they saw it as an authentic expression of their indigenous history and psychology. This intentional dedication to notions of indigenous 
culture and national identity was as much an aspect of modernity as aesthetic Westernization. The development of the radif-dastgah tradition happened in the shadow of modern Europe, and it represented a modern commitment to strengthening indigenous culture in the face of marginalization within the modern political and economic systems. The very idea of Iran having a great history of music that legitimated its existence in the modern world fostered new indigenous approaches to music-making. It was thus that the national imagination defined the radif-dastgah tradition, while also providing for a variety of different types of interpretation based on different ways of imagining modern Iran's distinct music and history. 


\title{
Music and Morality
}

\author{
The Recovery of a Nation, c. 1880-1940
}

The modern need for music to embody the unique history and cultural strength of the Iranian nation brought with it a unique framework for moralization concerning the proper nature of musical structure and performance. Every aspect of music's performance had the potential to improve or harm the nation: to solidify, improve, or defile Iran's unique national character. The power of the radif-dastgah tradition was not cosmological as the twelve-maqam system's had been. Its power was humanistic, originating from and relating to the particular character of a particular human population. The connection between music and the nation meant that music could maintain, advance, or hurt national character. On this basis, the morality of every aspect of the radif-dastgah tradition concerned how it would benefit or harm Iran and its people. In a world where Iran struggled to survive against the power and influence of Europe, the question of how to rediscover and maintain authentic Persian music was a question of improving Iran's cultural position in the world. It inspired impassioned moral discourse as musicians pursued different ideas about the best way to perform music in support of Iran, through the creation and maintenance of Persian music with a proper Persian character.

During the twentieth century, musicians involved in the radif-dastgah tradition often self-identified their moral positions as either maintaining or modernizing traditional culture. ${ }^{1}$ The key to Iran's cultural survival could be maintaining the music labeled "authentic Persian music" in a form that represented Iran's history. Traditionalist practices in the radif-dastgah tradition thus became stereotyped as remaining as close to the original seven-dastgah practice of the Qajar era as possible. Conversely, the key to Iran's cultural survival could be to make changes to improve the Persian music tradition, which was not historically sufficient to sus- 
tain Iranian culture in the modern world. Both of these positions pointed to Iran's Persian history as the source of their logic. While maintaining it implied that the original Qajar-era tradition needed to continue as it had been since the nineteenth century, changing the tradition could also be cast as simply rediscovering Iran's lost Persian music history, for which the radif-dastgah tradition could not fully account. Failing to maintain authentic Persian musical practices could hurt Iran. Failing to revive Persian music in relation to the nationalist narrative of Iran's historic golden age and modern decline could also hurt Iran.

While the moral positions of traditionalists and modernists often had different musical goals within the radif-dastgah tradition, they operated within the same assumptions about music's relationship with culture. Both sides tried to occupy the moral high ground of maintaining or improving Iran's national culture, and both critiqued the morality of the other for failing to sustain Iran's authentic culture. Musicians could also change their minds about music's correct moral path, as they continued to evaluate the progress of the nation and how music could best facilitate national progress.

'Ali Naqi Vaziri voiced his opinions about the best moral path for music in Iran extensively. His particular approaches to changing music in Iran also attracted vocal criticism because many musicians saw him as changing Iranian music in ways that harmed the authentic character of the nation. One of his most passionate critics was the poet and tasnif writer 'Aref Qazvini. Both of these participants in the tradition voiced strong opinions about what music should be vis-à-vis its nation, and passed strong moral judgment against musical expression that did not conform to their standards of national progress. Their conflicting moral arguments highlight the exact importance of the radif-dastgah tradition in the context of the Iranian nation, and the notion of a polarized modernist-traditionalist discourse surrounding the radif-dastgah tradition. Music had the power to give Iran a proper national existence in the modern world. Yet how it could do this was not an agreed-upon fact. It was, however, something to be extensively discussed and argued, as the future of the Iranian nation was at stake in its musical structure and performance.

\section{'ALI NAQI VAZIRI VS. 'AREF QAZVINI}

'Aref Qazvini was born in 1882 and died in 1934. Vaziri's life was much longer than that of his poet nemesis. He was born in 1887 and did not die until 1979. Vaziri spent his very long life building institutions he believed improved music education, while also speaking at length on his ideas about exactly how music had to be dealt with in order to ensure its moral benefit to the nation. Vaziri made statements about music's morality in his teaching texts, speeches, and articles produced over decades. 'Aref wrote about his ideas on these same subjects in the much more 
limited context of his divan, though he wrote with the same passion displayed by Vaziri, and took contrary positions on how the radif-dastgah tradition could best support the nation. While the arguments of Vaziri and 'Aref follow a modernist vs. traditionalist framework in many ways, they demonstrate the breadth of cultural considerations modernity presented in considering the best moral direction for indigenous music in the modern world. Both asserted that Iran had a great culture grounded in ancient times and both insisted that music could either benefit or harm this ancient culture. They differed in how they thought Iranian culture could best benefit from its music, but their moral outrage stemmed from the notion that Iran had already imperiled its existence by not maintaining its culture (including music) throughout history. In making decisions about how to address this problem, all decisions about how to make music had moral implications for the nation as a whole. Both Vaziri and 'Aref were concerned about maintaining the integrity of Iran in the modern world, and both dwelled extensively on how music could best revive the greatness of Iran in modern times.

'Aref was a famous poet, singer, and composer both during and after Iran's Constitutional Period. He started studying to be a mullah, but he eventually rejected this path and moved from his home in Qazvin to Tehran. He worked briefly in the Qajar court, where he first had contact with the court musicians performing in the radifdastgah tradition. Like other long-term servants of the Qajar court, 'Aref went on to a successful performance career within the public at large. In addition to being a famous poet and singer, he was a vocal political militant. He spent some time in exile in Istanbul with other anti-Qajar militants around 1916, and openly spoke out against dynastic rule in favor of the sovereignty of Iranians writ large. ${ }^{2}$ The tasnif he composed were often highly nationalistic, and many of them remain part of the radifdastgah tradition today. His politics defined his tasnif compositions, which were often specifically critical of the dynastic elite, and adoring of the Iranian nation suffering under their despotic rule. 'Aref cast himself as the voice of the Iranian people, advocating for the ancient Iranian people who were the heart of the Iranian nation.

'Ali Naqi Vaziri came from a family of activists and military men. The son of the women's activist Bibi Khanom, Vaziri followed his father into the military, where he served in the Cossak Brigade for a time and achieved the rank of colonel. While 'Aref undertook a customary religious education, Vaziri studied in Europe, and generally occupied a position closer to European influence in Iran. His time in the Society of Brotherhood seems to have been crucial to his perceptions of the radif-dastgah tradition's importance in relation to Iran. The Society of Brotherhood no longer existed by the time he opened his own private music school in 1923, which spurred him to start another private group for music performance called Klub Musical in 1924. After the fall of the Qajars, Vaziri held multiple positions in the government of Reza Shah. In 1928, he was appointed head of the Government School of Music (Madreseh-i mūsiqī). ${ }^{3}$ In 1935 he became professor of literature and aesthetics at the newly established University of Tehran. Though 
Vaziri remained a professor at the University of Tehran for the rest of his life, he gained and lost various other government appointments between 1940 and 1946. These included an appointment to Iran's National Radio High Council of Communication and a brief reappointment to head the Government School of Music, which had been renamed the Conservatory of Music (Honaristān-i mūsīqī).

'Aref first published his divan as a modern autobiography in 1924, with his collected poetry spread out between stories about his life, his broader philosophies, and perspectives. In it he wrote about his philosophies vis-à-vis those of Vaziri within his collection of texts he wrote for his tasnif. 'Aref directly addressed Vaziri in his writings, criticizing him as immoral for changing the music tradition in dangerous ways. Though Vaziri was an active music teacher, performer, and composer for most of his life, most of his discourse on the subject of music and its role in bolstering the nation was confined to writings and speeches from before 1950. He spoke with the greatest intensity on this subject from the 1920s to the 1940s. 'Aref's criticism thus came quite early in Vaziri's public career.

Vaziri himself tended to make more general moral criticisms of bad music and the dangers of failing to develop proper musical expression in Iran, rather than criticizing specific musicians by name. While Vaziri's training in European music had important implications for his career as a composer, it was the philosophical ideas of Europe that framed his understanding of the radif-dastgah tradition and music's overall impact on the morality of the nation. In this context, 'Aref was not merely suspicious of Vaziri's musical inclinations. Though 'Aref's philosophical and political positions were dependent on many concepts emanating from Europe, he saw Vaziri's more explicit adoption of European philosophies as a threat to Iran's national integrity.

\section{VAZIRI: THE MODERNITY IN THE ANCIENT}

Vaziri valued the radif-dastgah tradition as the remnants of Iran's great Persian music history, much of which he thought had been lost for lack of proper preservation and teaching methods. In considering how to restore some of what had been lost, Vaziri focused on the idea that the radif-dastgah tradition contained ancient Iranian scales that had survived since before Islam. He aligned the notion of Iran's ancient music with Europe's notion of classic societies and traced Iranian music's initial origins to the Achaemenid period. This allowed him to cast Iran's great history as an extension of music history in ancient Greece. Vaziri bemoaned the perceived loss of ancient Iranian music, but also claimed that the radif-dastgah tradition contained some of these ancient Iranian scales essentially unchanged since ancient times. ${ }^{4}$

Vaziri believed that this ancient period of Iranian musical domination was briefly interrupted after the rise of the religious tendencies of the Ummayad Caliphate, but quickly returned under the rule of the ${ }^{~ A b b a s i d ~ C a l i p h a t e . ~ O n ~ t h i s ~}$ 
basis, he also connected modern Iranian music to the early Islamic treatise-writing tradition. In his first teaching manual, Vaziri claimed that the intervallic structure of Iranian music in his day followed the exact rules for intervallic structure outlined by al-Farabi. ${ }^{5}$ While tracing Iranian music back to pre-Islamic times, Vaziri also described the radif-dastgah tradition as following the rules of intonation described by 'Abbasid and post-'Abbasid authors who wrote about musicincluding al-Farabi, ibn Sina, Urmawi, and Maraghi. ${ }^{6}$ He further referenced the Iranian legacy of these early Islamic music writers when he stated in reference to the radif-dastgah tradition that Iranian music was directly tied to the music discussed in these older texts. This concept of Iranian music history allowed him to state that "our music today is a music of a thousand years of which the elements of it have not been touched."

Vaziri established the value of indigenous Iranian music based on a belief in its ancient origins and authentic Iranian character since pre-Islamic times. The questions of morality he raised concerning Iranian music thus related to the failure of Iranians to properly preserve their ancient music until the modern era, and the need for Iranians to recover the principles of their ancient music culture as part of their larger societal efforts to improve Iran's cultural strength in the modern world. Despite his assertions that the radif-dastgah tradition contained remnants of ancient Iranian music, Vaziri recognized the disparity between ideas about music expressed by writers like al-Farabi and Maraghi and the modern practice. He complained about the loss of much Iranian music, noting that many ideas about music discussed in early Islamic times "remained in the corner" unused. ${ }^{8}$ In discussing Iranian music from the early twentieth century, he also contradicted his assertion that Iranian music had been preserved since ancient times, noting that "there is nothing in the hands of the people from before the last fifty years; and if something from before the Constitutional Period exists, it is only in the minds of a limited number of older people."9

Vaziri tied the loss of much ancient Iranian music in part to a lack of motivation and a decline in Iran's national character over centuries. From his perspective, Iranian culture had failed to invest in its music and the moral character of its musicians. This resulted in only a small number of people involved in the radifdastgah tradition preserving only a small amount of ancient Iranian music. Vaziri complained bitterly about what he saw as the low quality of music performance in modern Iran overall. He stated that most musicians barely had any musical ability: they were like grapes struggling to enter even the early stages of development but never ripening. Vaziri described many musicians as being tainted with the problems of gambling, alcohol, and lust, and admonished the unsophisticated parties of the lower, uneducated classes. ${ }^{10}$ Vaziri generally categorized music as either good, sophisticated, and moral or bad, unsophisticated, and immoral. He classified most Iranian musicians of his time within the latter category, but placed the radif-dastgah tradition in the former category alongside the more dominant 
music of Europe, which he thought of as international music. In Vaziri's opinion, international music was not beholden to any one culture, and could be used anywhere. It was not inherently harmful to indigenous music and could even be used to improve the cultural standing of music in any nation.

For all his praise of ancient Iran, Vaziri spoke of modern Iran as a lazy nation and spoke of Iranians in modern times as having a lazy soul. He believed the reason that music in Iran did not receive the exalted status that it had in Europe was because his contemporary countrymen slept too much and did not pursue work with any seriousness. ${ }^{11}$ Indeed, while Vaziri perceived the successful nations of Europe to be full of people working hard to achieve their goals, he complained that modern Iranian society had abandoned these tendencies and become fatalistic. He tied this idea to his complaints about low-quality music in Iran, which he saw as decreasing Iran's standing in the modern world. ${ }^{12}$

Besides the problem of motivation and laziness, Vaziri blamed the perceived loss of most ancient Iranian music on the poor teaching and preservation methods that were indigenous to Iranian history:

Despite all of the efforts of Iranian teachers [Maraghi et al.] one may accept that the method of teaching and learning of ancient music was very difficult and it is the same method that is still common today: the students must kneel on two knees for many hours in front of the master, and obtain the learning of the melodies one on one. Of course because of this arrangement and its great difficulty, many of the melodies were lost because they were not written in notes. ${ }^{13}$

Based on what he learned in Europe, Vaziri was able to conclude that Iran had a great ancient culture, including music, that had been lost over time as a matter of moral decline and lack of consistent preservation. He did not see written notation as a foreign imposition on the radif-dastgah tradition, but rather as a neutral tool of teaching and preservation that could have prevented Iran's musical and cultural decline. While he believed Europe had done a superior job of maintaining their culture, which had resulted in their cultural and musical dominance throughout the modern world, he did not believe it was desirable or even possible for Iranians to abandon their culturally determined musical destiny. Iranians needed to revive and cultivate their indigenous music as a matter of their own cultural strength. Insisting on this fact, Vaziri stated that

Music is not like a hat and clothes, which anyone can change and imitate as they like. Music is a demonstration of feelings and emotions. Our music must be a demonstration of our morals and our tastes. Familiarity with European music must not be a cause for us to deprive ourselves of our national art. ... That which we lost in the past we must find again. ${ }^{14}$

In charting the path for the contemporary success of Iran vis-à-vis European cultural hegemony, Vaziri positioned the preservation of unique Iranian musical features as paramount because of their unique ability to embody the essence of the 
Iranian nation. Conversely, he saw the seven dastgah of the Qajar courts as mere remnants of what Iranian music had been, which lacked the systematic, prescriptive framework for music that he believed was the basis for ancient Iran's music. In light of the correlation between Europe's economic and cultural hegemony and their use of systematic musical structures, Vaziri took the idea of creating some semblance of systematization for the radif-dastgah tradition as being both a revival of ancient Iranian music principles and a form of productive modernization. This was the philosophical basis for his systematization of the quarter tone and his specific method of extracting scales from the dastgah.

Vaziri attempted to balance the idea of maintaining the unique reality of Iranian civilization with more general principles of what made a culture a superior civilization. He spoke of Iran needing to reestablish its former cultural greatness but he also spoke of a more general moral revolution that needed to occur in order for Iran to reattain its former glory. ${ }^{15}$ At the heart of this revolution was the notion of art and the modern concept of art as a transformative force within society. As one of the fine arts (șanāy $\bar{i}^{-}-i$ zarîfeh), music was not merely a form of entertainment or intellectual amusement. It was, rather, a significant force that could shape society for the better. In using this force in specific ways, Vaziri believed that Iranian society could be improved very quickly on a mass scale.

Vaziri discussed art as the ultimate goal of musical expression, which served the greater good of society and benefited society's spiritual life. He stated that "The word art (son ${ }^{\circ}$ at) is explained in a complete way as the means of life itself. . . . It feeds, educates, advances, and elevates the soul of humanity." ${ }^{16} \mathrm{He}$ asserted that "[music] does work in the ear and the soul of humanity. . . Sophistication, character, emotion, and heart are completely involved in it." ${ }^{17}$ Within this definition of music's role in society, Vaziri believed that European countries had achieved social superiority over other civilizations, and they had achieved this in part by prioritizing music and art in general within everyday life. He praised France, noting that "In civilized countries like France the spiritual life takes precedence over the physical life of the body. During leisure time, they are listening closely to music." 18 The strength of art to elevate the human experience beyond basic physical needs could thus provide a means for a culture to survive even in the midst of great social disaster and suffering. He described Germany after World War I as being in a state of physical desolation and poverty, but because they did not abandon performing and attending music concerts at least twice a week, they easily survived because music sustained them even more than food. ${ }^{19}$

In equating the consumption of music as art with the investment in a nation's spiritual needs and physical survival, Vaziri valued music as a fundamental necessity for the success of the nation. In speaking about the importance of art Vaziri stated:

It is the most precious among the works of humanity, and the nation that does not make an effort in the permanency of its art is causing permanent weakness in its na- 
tionality.... Art is the greatest work of humanity's endeavors. Art is the best educator of morals.... Art is the monument of the labor of every nation's great ancestors and one of the most precious things that one must take pains to do; and the attention of every nation must be used in order to promote and sustain it. ${ }^{20}$

Vaziri believed that investment in art determined the success of a nation, positioning the spiritual success of art as the determinant of a nation's success in the physical world. This meant that art had a positive affect on the economy. To cite examples of this he spoke of the great wealth artists could generate. Examples he cited of this included Georges Bizet, who accrued much wealth from his popular opera Carmen, and the great wealth of the famous Italian singer Caruso. ${ }^{21} \mathrm{He}$ used these anecdotes to connect the spiritual activity of art to economic success.

Based on his experience in Europe, Vaziri set out to improve the cultural, moral, and economic standing of Iran via the cultivation of indigenous music as art, which could elevate Iran's existence to the level of a civilized nation like those in Europe. At the heart of Vaziri's crusade to cultivate great Iranian art in the name of bettering the Iranian nation was his investment in music education. Vaziri had three goals in increasing music education in Iran. First, he believed that making music education available to as many people as possible would ensure that Iranians had the spiritual education that music provided, which would in turn create a more civilized Iranian society. Second, he wanted to spread a more systematic, rigorous approach to Iranian music in order to elevate more Iranian music to the standard of fine art. Third, he wanted Iran to make use of as much of its artistic genius as possible to the benefit of the nation, and this genius could only be discovered with education. In explaining how education in general and music education specifically improved society Vaziri wrote:

Education represents the intellectual and practical exercises that connect humanity
to the outside world and make them familiar [with the world]; it brings progress,
advancement, and achievement so that maybe humanity will eventually arrive at the
highest level of eternal happiness. This education in the world of today has two parts.
One is the aspect of education that is for material progress.... The other is the educa-
tion for spiritual understanding and moral progress, meaning it works for familiarity
with the peace of conscience and the life of humanity; those schools [of education]
include literature, music, painting, and other [arts].2

In imagining how art education in Iran would improve its standing in the world, Vaziri stated that "Today in Iran we need art and we especially need fine art and educated art (șon $\left.{ }^{\circ} a t-i{ }^{\top} \bar{u} l \bar{u} m \bar{\imath}\right)$ that not only works from the standpoint of cultivating the souls of the nation, but also works so that it has influence in other nations, until finally it comes to comprise the education of the entire world." ${ }^{23}$

It was in emphasizing how fine art was a true source of the moral path that Vaziri tied notions of great spirituality and morality to vague notions of respectable beauty. Hence he judged art that met his concept of respectable beauty to be 
moral and spiritually uplifting for the nation, while judging art that fell outside of this category to be morally questionable and having a negative impact on society. Vaziri emphasized this point to his students in his teaching manual for violin: "Once the artist knows that beauty and goodness are one, it is clear he has arrived at the top level of his purpose; and it is in this instant that he becomes an educator of others. He must join the cause of moral education." ${ }^{24}$

Vaziri's conception of how music could improve the moral and spiritual condition of a nation was also closely tied to his ideas about music's ability to promote national unity and build national sentiment. He referred to his first music school and any similar modern institution of music education as "a treasure of national emotions and the propagator of the spiritual properties of one nation among all nations. It is the conduit of humanity wherever it comes into existence, the creator of emotions and good works, which creates conscientious artists (honarmand) that are the spiritual educators of the nation." ${ }^{25}$ In declaring artists to be the "spiritual educators of the nation" Vaziri proclaimed artists to carry a great amount of power and responsibility in society. From this perspective, Vaziri saw encountering music in a casual way as unacceptable and morally negligent.

The dual conception of artists as spiritual educators of the nation and Iran as a once great nation that was now in decline greatly influenced Vaziri's instruction for music students. In his teaching texts for violin, tar, and setar, Vaziri emphasized training and hard work, giving students drills to practice, and insisting that they dedicate at least half of their practice time in a day to exercises, rather than actual pieces of music. He also emphasized the need for daily practice, even suggesting that the student practice twice a day. Additionally, Vaziri stressed that students should not move quickly through the study of music, but rather study every aspect thoroughly and judiciously. ${ }^{26}$

Vaziri emphasized the importance of art education for the entire nation. He discussed opening a music school for orphaned children in Iran, citing the amount of great genius discovered among even this population and the great benefit that Iran was missing by not cultivating art education among orphaned children. Vaziri also specifically addressed the need for women to be taught music. In emphasizing the extreme importance of women's education in the arts, Vaziri noted their special role in educating the nation, referring to them as "mothers of this country's future" and emphasizing that "the first education of the people is still while they are in the laps of their mothers. [Women] are the basis of all people's tender emotions and feelings." ${ }^{27}$

Vaziri had many opportunities to put his education policies into practice via his private teaching and official positions granted him by Reza Shah. In addressing his successes in the Reza Shah's Ministry of Education, Vaziri summarized the ultimate goal of his efforts in art education: "It is hoped that the Iran of today, like in very ancient times when it was the mother of the fine arts in the East, will again obtain its high status." ${ }^{28}$ 
Despite his belief in the importance of the radif-dastgah tradition to the survival and success of Iran-and despite his initial interest in teaching it broadly as part of improving Iranian culture-Vaziri came to be known as an ostensibly European-style composer in the mid- to late twentieth century. While he worked to cultivate his own style of "international music" that reconciled tonal harmony with the quarter tones he greatly valued as uniquely Iranian, a European aesthetic came to defined his oeuvre as a composer. Yet promotion of purely European music aesthetics was not the goal of Vaziri's work as an educator of the Iranian people. Vaziris efforts in education pushed for an improvement in Iranian society via a more fully restored Iranian music tradition. While he also felt that an investment in international music was essential to bolster Iran's artistic efforts, he believed very strongly in cultivating indigenous Iranian music. His work in education demonstrated his interest in the radif-dastgah tradition and his belief that it had an important role in educating the Iranian nation, even beyond purely musical concerns. His work in education was as much about improving the character of the Iranian citizenry as it was about creating high-quality musicians. Vaziri saw no separation between these two goals, and the radif-dastgah tradition was something that both Vaziri and his students taught as part of a larger project focused on strengthening Iranians as a nation.

\section{'AREF QAZVINI: SAVING THE NATION FROM VAZIRI}

Vaziri's many publications and official administrative positions in Iran's system of arts administration allowed him to spread his ideas about the radif-dastgah tradition as well as art in general far and wide in Iran's education system. Vaziri was a prominent figure in the artistic life of his nation, yet his philosophies of art were not the only philosophies being cultivated in Iran. Vaziri had detractors who disagreed with his ideas. As the twentieth century progressed, much music-making in Iran turned toward fully Westernized aesthetics and against indigenous aesthetics completely, a position Vaziri opposed. In other cases, Vaziri's ideas could be treated as too influenced by Europe and too removed from authentic Iranian culture. 'Aref was one of the earliest to express the latter criticism clearly vis-à-vis his own ideas and philosophies in relation to the radif-dastgah tradition. The poetmusician expressed very strong nationalist ideas regarding Iran, and Vaziri himself praised 'Aref specifically because he assisted in building up Iranian society by composing patriotic songs. ${ }^{29}$ Aref, however, saw Vaziri as a threat to the integrity of Iran and its unique cultural heritage. Both musicians felt strongly that Iran had to maintain and bolster its unique music culture of the radif-dastgah tradition in order for Iran to be successful in the modern world. Yet they did not agree on how best to use the radif-dastgah tradition toward this goal.

Like Vaziri, 'Aref was dismayed at the perceived decline of the Iranian nation from its great civilization in ancient times. The goal of 'Aref's tasnif was in part to 
create Iranian cultural unity, something he saw as lacking in the modern world, even as it had been foundational to the existence of Iran since ancient times. In discussing the importance of his own music in creating Iranian identity, he directly stated:

I composed patriotic (vațani) tasnifs because not one Iranian of ten thousand individuals knew what the homeland (vatan) was. They imagined that the homeland was only the city or village where they were born. It was in such a state that if, for instance, a person from Kerman went to Isfahan and he did not enjoy it there, with absolute homesickness he would sing, "my heart is not happy being away from home."30

Both 'Aref and Vaziri used music to unite the nation as part of a vision to restore Iran's cultural strength in modern times. Much of the disagreement between 'Aref and Vaziri lay in their differing ideas about who and what was to blame for the decline of Iranian culture and how best to recover from it. Vaziri saw Iranians as having declined into a subpar state of existence over the centuries through their own thoughts and actions. By contrast, 'Aref saw the Iranian people as being only partially responsible for Iran's historic decline and socioeconomic problems. To a large extent, 'Aref held Iranians blameless in their own demise, blaming instead the corruption of dynastic rule and the contemporary Qajar rulers, as well as the evil hegemonic oppressors from outside of Iran who stole Iran and ruined its former glory. In contrast with Vaziri, 'Aref believed that the Iranian people would thrive as soon as they realized their own unity of purpose and escaped the repression of monarchy and foreign hegemony.

'Aref wrote his critique of Vaziri in his preface to his collected tasnif, where he specifically chided Vaziri for teaching the seven dastgah in a way that was very different from how 'Aref understood it based on the teachings of its initial progenitors. He wrote as if he was speaking directly to Vaziri. For instance, when 'Aref criticized Vaziri's first teaching manual he stated:

Before you went to Europe, you stole from the deceased Mirza 'Abdullah-who is worthy of being called the first teacher of the twentieth century-the names of Iranian melodies (avāz) according to his teachings (dastūr). . . . You abruptly wrote a book referring to Iranian music. You recorded the opposite [of Mirza 'Abdullah] there, but this nation will not carelessly forget [Mirza 'Abdullah]. . . Basically, you wanted to efface the music of Iran and forget it; are you ridiculing great individuals of his type and the deceased Mirza Husayn Qoli? ${ }^{31}$

In this statement 'Aref rebuked Vaziri for his approach to the seven dastgah, which was focused on scales rather than the melodies of the dastgah. 'Aref accused him of stealing the music of Mirza 'Abdullah and Husayn Qoli, and using it to create a wholly different type of music that was a disgrace to the original tradition. 'Aref complained that Vaziri treated the radif-dastgah tradition as if it had a very limited emotional range in comparison with European music. He complained that Vaziri had described Iranian music as sounding inherently sad. Vaziri had said this and blamed the persistent sadness of Iranian music on Iranian 
history: the fall of Iranian civilization and years of Arab domination. ${ }^{32} \mathrm{He}$ even described his interest in a full systematic use of quarter tones as coming from his interest in increasing the emotional diversity of Iranian musical expression as an aspect of reestablishing the strength of Iranian civilization. ${ }^{33}$ In the course of demeaning this idea, 'Aref asked:

From the twelve dastgah of music, which were organized according to the twelve houses of the zodiac before the coming of the Arabs [and] of which one aspect has been totally lost and these six or seven remain_in Mahur, from the beginning of the daramad of the dastgah of Mahur through Delkash and Iraq . . which one of the melodies of it is sad? What part of Chahargah is sad? Or Segah? ${ }^{34}$

In the midst of criticizing Vaziri, 'Aref connected the seven dastgah of his time to the twelve-maqam system of premodern times even as he acknowledged that the dastgah of Mirza 'Abdullah could not possibly be a full embodiment of this older system. Like Vaziri, 'Aref believed much of Iran's Persian music had been lost to history. But he believed that Vaziri's actions to address this loss of music and music culture were detrimental to Iranian culture. In explaining that Vaziri went too far in changing the original seven dastgah, 'A ref quipped with a short poem: "I give you the axe to chop wood; I did not say to chop down the wall of the mosque." ${ }^{35}$ "Aref believed Vaziri had taken some ideas that might be useful in some capacity, but by applying them with vigor to the sacred radif-dastgah tradition of Mirza 'Abdullah, he did harm to Persian music and Iranian culture.

'Aref emphasized the importance of how the seven dastgah represented music handed down to the modern era from the ancient past. For ${ }^{\circ}$ Aref, maintaining the seven dastgah in the most ancient form would preserve the integrity of the Iranian nation. 'Aref attacked Vaziri for being too Europeanized and pushing too many European ideas onto the radif-dastgah tradition, while ignoring the customary seven dastgah that ${ }^{`}$ Aref associated with authentic Iranian identity:

Dear Professor! In the same way it is not possible for the language of one nation to change to a foreign language, the music of one nation is not changeable and variable.... Oh friend! Choose perfection or life! These two guests cannot be contained in the same house. ${ }^{36}$

Even though Vaziri expressed similar sentiments as this statement from 'Aref, Vaziri believed that the historic legacy of Persian music could be reconstituted more completely with some changes to the radif-dastgah tradition. 'Aref disagreed and thought that changing the radif-dastgah tradition could damaged the integrity of Persian culture. Vaziri sought to create a more perfect Persian music, but to 'Aref this was not possible even if it seemed desirable. Whatever musical remnants remained from Iran's Persian past had to be largely maintained as they were in order to preserve the remnants of authentic Iran's music.

Both Vaziri and 'Aref embraced the notion that musical expression was determined by the parameters of a given nation, and thus was an inherent aspect of that 
nation. 'Aref specifically referred to music as "a distinguished object and a racial indicator, educator, and agitator of the national soul. And every nation that has a soul [but] does not have this life-giving force does not have the truth of life." ${ }^{77}$ "Aref believed that a particular nation needed to make efforts in its own indigenous music in order to be successful in the modern world, but Iranians needed to be very careful about introducing innovation in these efforts, because many innovations could harm the authenticity of the music, and by extension they could harm the nation itself. While complaining directly to Vaziri, 'Aref promoted maintenance of the Qajar court tradition without any significant analysis or systematization of the original seven dastgah. Mirza 'Abdullah and Husayn Qoli represented the authentic Iranian tradition that was as close to the ancient Iranian music as could be found in the modern world. It was better to preserve this music as it was, rather than to go searching for alternative methods of reconstituting Iranian music via alterations to the original seven dastgah.

On this basis, 'Aref greatly resented Vaziri's treatment of the radif-dastgah tradition and his teaching of it. Vaziri believed that his analysis and systemization of the seven dastgah merely revealed what was inherent in Iranian music from ancient times. 'Aref saw him as an innovator who must be stopped from ruining the only authentic music Iranians had. In citing models to emulate, 'Aref praised specific musicians with strong connections to the nineteenth-century Qajar court: the kemancheh player Husayn Khan Isma il-Zadeh (th. 1890) and Husayn Qoli's son, 'Ali Akbar Shahnazi (1897-1985). 'Aref praised Isma'il-Zadeh for playing an "ancient instrument of Iran" while Vaziri "trained two hundred students of the violin but did not train even two individual students of the kemancheh so that later this instrument would be lost." ${ }^{8}$ While "Aref accused Vaziri of killing the traditional bowed string instrument of Iran even as Isma il-Zadeh tried to preserve it, he also accused Vaziri of dismissing 'Ali Akbar Shahnazi as "nothing." "Aref protested this greatly, asserting that there had been no better tar player than Shahnazi since the instrument had been invented. ${ }^{39}$

In the midst of praising musicians who 'Aref thought represented a greater commitment to the original seven dastgah, 'Aref ultimately positioned himself as the supreme defender of the tradition going forward. In describing himself as both a musician and tasnif composer he asserted that

I more than anything else have an interest in the music of Iran and I have the truth of the mastery of it; and as long as I live no one has the ability to take this truth away from me. .. They know me-the one who strives hard to be most learned in this art-and because of that the Iranian blood courses through the veins of the youth and they are following my pure emotions. They know my interest is only in national spiritual matters, which led me to write these lines [of tasnif]. ${ }^{40}$

In this way, 'Aref presented the music of Iran as something that possessed an unalterable truth, which he preserved and Vaziri distorted. 'Aref positioned him- 
self as representing the interests of the Iranian people, while positioning Vaziri as an interloper, who was changing Iranian music to conform to an imagined perfect ideal based on foreign ideas he learned in Europe.

\section{CONCLUSION}

The significance of the diametrically opposed discourses of Vaziri and 'Aref is both the shared basis of their disagreement and the strong moralistic dimensions of their positions. Both 'Aref and Vaziri were invested in the preservation of Iran's cultural integrity. Both saw the radif-dastgah system of their time as the remnants of Iran's great historic past and believed that keeping the cultural artifact of the dastgah alive was key to ensuring Iran's future existence and integrity. Conversely, neither 'Aref nor Vaziri believed that the seven dastgah associated with the musicians of the Qajar court was a complete record of Iran's past musical glory. The dastgah passed down from Mirza 'Abdullah and his brother Husayn Qoli only represented a certain portion of Iran's musical past. Though Vaziri never criticized any musician by name in his speeches and writings, he did harshly criticize the music culture of Iran as generally being insufficient to maintain a culturally relevant music that could sustain the integrity of the Iranian nation. 'Aref understood that Vaziri learned to look down on his fellow Iranians while in Europe. Knowing this, 'Aref lashed out at Vaziri because 'Aref saw him as the proverbial wolf in sheep's clothing. Vaziri claimed to have the best interests of Iran at heart, but 'Aref saw all of his work as killing the Iranian nation by twisting and distorting its authentic musical heritage.

Conversely, Vaziri did not see his ideas as particular to European societies, but rather as universally applicable and useful for increasing Iran's standing in the modern world. He also did not advocate for the abandonment of Iranian music. Like 'Aref, Vaziri believed that abandonment of Iranian music would be to the detriment of Iranian society, and teaching the radif-dastgah tradition as Iranian music comprised much of his first major work in the public sphere. The radifdastgah tradition was the only music of Iran Vaziri considered to have strong cultural standing for the nation. It therefore became the most important music to be strengthened and disseminated in the name of creating and re-creating Iranian culture. Vaziri saw the lack of attention to music in his nation as hurting the nation's moral and cultural development in the modern world. He sought to improve the morality of Iran by more fully reconstituting proper Iranian music and spreading knowledge of it throughout the nation.

While differences in their education informed their differing positions on the correct moral path for the radif-dastgah tradition, Vaziri and 'Aref also occupied different positions within in the radif-dastgah tradition. Though they both composed, 'Aref was primarily a poet and a singer, and Vaziri was an instrumentalist. As the first person to provide a functional model for dastgah modality that substituted scales for the individual gusheh themselves, Vaziris approach to teach- 
ing the radif-dastgah tradition largely focused on standardizing features of pitch in relation to instruments. He focused on scales more than gusheh and he also tended to focus on fully metered types of instrumental pieces in his beginner and intermediate teaching, because he felt that pieces metered without the influence of poetry (pish-daramad, reng, and so on) were more accessible, while the unmetered melodic structures common to the poetry-based vocal gusheh in the seven dastgah represented a more advanced repertoire that students should learn later in their studies.

While he reduced the centrality of these vocal/poetic gusheh, he also failed to acknowledge their basis in classical Persian poetry, which 'Aref considered the very heart of Iranian civilization. 'Aref saw Vaziri's failure to connect the radifdastgah tradition to the classical Persian poetry of the gusheh as one of his greatest moral failings. 'Aref specifically complained that Vaziri turned his back on "seven hundred years of the great poetry of Iran-the type written by Sa di, Hafez, Ferdowsi, Nazami, and maybe two thousand other poets." ${ }^{41}$ As a poet and singer, 'Aref had a particular vested interest in the idiosyncratic organization of the radifdastgah tradition created by the individual progressions of gusheh in each dastgah, which were dominated by vocal-poetic gusheh. Preserving the poetry of the gusheh was at least as important as preserving their music in relation to bettering the Iranian nation. From this perspective, to ignore and forget ancient Persian poetry was a sin against the nation, both immoral and unconscionable.

While many aspects of Vaziri's analysis of the dastgah would come into popular use, a constituency of musicians remained dedicated to keeping their music more closely aligned with the Qajar version of the tradition, which came to be associated with the radif. 'Aref cited Shahnazi as an example of what would become identified as the traditionalist approach to the tradition in the twentieth century. Ahmad Ebadi, the son of Mirza 'Abdullah, also followed in the more traditional line of Qajar practice, according to what 'Aref outlined in his divan. As the twentieth century progressed, there were both practitioners of the tradition that had learned and taught in the conservatory or the university and those who had learned primarily or solely through private instruction. There was never a fully accepted, standardized approach to teaching or playing in the radif-dastgah tradition, yet variations in practice followed differences in opinion concerning the most authentically Iranian way to perform the tradition.

The traditionalist-modernist split did not exist as a hard line between one approach or another, but as a gradient with many variations. For instance, though 'Aref praised Isma il-Zadeh for his commitment to the Iranian kemancheh and scorned Vaziri for teaching violin, Isma il-Zadeh taught at least one violinist with European music training, Rokn al-Din. ${ }^{42}$ Even the most Qajar-oriented of musicians did not necessarily scorn or avoid musicians playing European music. Though so-called traditionalists might not agree with Vaziri's particular modal analysis of the dastgah, the notion that the Iranian tradition was both a set of distinguishable 
melodies and created out of abstract modes - both radif and dastgah-became standard throughout the tradition. The distinction Vaziri embraced between the modes of the dastgah and the radif was not an idea he invented. The modality of the tradition would ultimately be pursued by multiple musicians in various ways. Traditionalists focused more on the development of a fully distinguished radif, with modality being significant in the context of the radif. Traditionalist used both the seven dastgah and the avaz-dastgah and generally recognized shifts that had occurred in the dastgah's organization. But their choice to make the radif central to their practice also introduced its own changes. The search to compile different radif from different musicians and ultimately one definitive radif-as well as the ability to just play the radif and nothing else-represented its own major shift in musical practice and conception.

Being a traditionalist also did not preclude composition. 'Aref's extensive tasnif compositions were part of an increase in composition that related to the construction of systematic modality within the tradition. Choices he and others made about how to compose related to which parts of the dastgah would be developed as independent modal frameworks. An increase in composition changed the relative importance of different parts of the system. 'Aref engaged in much traditionalist discourse, but even he acknowledged changes to the tradition and engaged in change. Often musicians occupied space between the traditionalist and modernist extremes.

One example of a musician who occupied the ideological and musical space between 'Aref and Vaziri was Abol Hassan Saba (1902-1957). Saba began music instruction at home and eventually studied with Mirza 'Abdullah, Darvish Khan, Shirazi, and Isma'il-Zadeh, among others. A multi-instrumentalist, Saba went on to attend Vaziri's music school and study the radif-dastgah tradition as Vaziri taught it, focusing on the violin. Saba worked closely with Vaziri and eventually taught at an extension of Vaziri's school in Tehran established in the city of Rasht.

Saba taught using Western music notation and in many ways conformed to Vaziri's idea of a musician observing the best practices of Iranian music. Despite Saba's apparent modernist turn, his early diverse one-on-one training with Qajar court musicians often gave him unique pathways to innovation that could be perceived as highly traditional. Though he played violin in violation of 'Aref's traditionalist commitment to the kemancheh, he played the violin in such a way as to imitate the timbre and phrasing of the kemancheh. He compiled his own radif, creating a collection of melodies for the dastgah that was demonstrably larger than the number of melodies included in earlier documentation of the dastgah. Thus, though he clearly added new material to his radif, his interest in the radif comported with the traditionalists' commitment to the fully formed melodic material of the dastgah, which represented the remnants of ancient Iranian music. Thus, though Saba took on much influence from Vaziri and engaged innovation, he came to be broadly regarded as respectful of both traditionalist and modernist 
tendencies in the tradition. Traditionalists did not ultimately disdain Saba the way 'Aref disdained Vaziri.

These different negotiations of the categories of traditional and modern represented both aesthetic and ideological positions. Musicians who felt that authenticity was the most important factor in sustaining the nation maintained moral judgment against musicians who prioritized musical sophistication and systematization. Likewise, modernists maintained moral judgment against musicians who refused to consider ways of bolstering an incomplete Iranian music in order to sustain the nation in the modern world. The radif-dastgah tradition stood at the center of these moral debates, and its parameters were molded by these different approaches to music's nationalization in modern Iran.

The moral quandary surrounding the radif-dastgah tradition developed along very different lines than the moral quandaries debated during the time of the twelve-maqam system. The moral challenges presented by the twelve-maqam system arose from music as an extrahuman phenomenon that could be objectively controlled, yet also had the capacity to enter the human ear and affect a person without their awareness or consent. As something that derived from the realities of the broader cosmos, music could exercise seemingly autonomous power over the whole of humanity. People needed to be knowledgeable and wary of its universal power in order to ensure its proper affect on the human condition writ large.

The moral discourse surrounding the radif-dastgah tradition addressed whether or not musical ideas and practices were properly supporting the nation. The question of what made music morally good or bad stemmed from music's relationship to the nation, and the ability of music to help or hurt the nation. In this context, the moral criticism could in some ways be much harsher and extensive. The ability to control music was within the agency of humanity, which made people directly responsible for actively using it in moral and immoral ways. In the world of the radif-dastgah tradition, Iranians themselves controlled their own musical destiny as part of their unique cultural basis. Iran's survival in the modern world depended in part on its musical survival, and this was within the control of Iranians. Iranians were in fact uniquely positioned to make the best decisions about the survival of their unique culture. Within this modern reality, musicians had to negotiate their creative choices within the morality of cultural preservation and improvement. This morality derived from music's ability to determine Iran's existence, or its ultimate destruction, in the modern world. 


\title{
Singing the Nation
}

\author{
Words of the People, Music for Iran
}

For all of the distinctions of structure and performance between the music of the radif-dastgah tradition and the twelve-maqam system, the sung texts were initially similar in many respects. While the role of systematic modality appeared in early documentation largely as an imposition upon the initial dastgah practice, this modality was imposed on top of music structured around long-form poetry recitation. In the earliest documentation of the system, poetry stood at the heart of the practice, and the poetry that structured the dastgah tradition relied heavily on pre-seventeenth-century Persian poetry, mainly the genre of poetry known as ghazal. ${ }^{1}$ Whatever approach to pitch organization the seven dastgah originally had, it related to how music was used to present sequences of poetry as a single, continuous musical performance.

While not composed specifically for musical performance, ghazal poetry appears to have a long history in the music performance of Central and South Asia. Ghazal appear in Maraghi's song text collections and he did mention it as a genre with its own song form. ${ }^{2}$ Yet ghazal poetry had a much longer polyglot history. It began as an Arabic genre of poetry, and was eventually adopted by poets writing in many other languages. But the form thrived in Persian, where it took on some new structural features. The Persian form of ghazal became the basis for Urdu ghazal, and these two languages would ultimately define many of its various uses in music over centuries. The specific Persian ghazal of the radifdastgah tradition were part of the era that many Iranian came to define as the golden era of Iranian music and literature, between the time of Safi al-Din and Maraghi. Yet the choice to use very little contemporary poetry, and to reach so far back in history as to find the tradition's poetic focus, distinguished the radif- 
dastgah tradition's poetry choices from those of the twelve-maqam system. For all appearances, Maraghi's song text collections focused on poetry proximate to the possible timeframe of performance. The later Safavid song texts often named the contemporary composer who wrote the song and the specific ruler for whom it was composed. The twelve-maqam system depended on the wisdom of the ancient past to legitimate its musical logic, but its song texts clearly had a large degree of temporal proximity to its musical practice. Conversely, the radif-dastgah tradition skipped over several centuries to go back in time and find its core poetic voice.

The radif-dastgah tradition's structural dependence on demonstrably ancient poetry contextualized the music within the project of Iranian nationalization. The sung texts of the tradition embodied the ancient poetry of Iran's great Persian past. This alone, however, was not sufficient to make the tradition a proper contributor to the building and maintenance of modern Iran. The tasnif thus developed as an addendum to the poetic procedural model of the dastgah. Tasnif came to be defined by their fully metered structure and their use of contemporary poetry. The poetry of the tasnif could directly address the Iranian people, their current experiences, struggles, and hopes for the future.

Initially both the original seven dastgah and additional metered song compositions relied heavily on ghazal. While the term tașnif was not mentioned in the earliest writings about the tradition, Forsat did mention kar and 'amal (kāro 'amal). These two terms had referred to various types of metered songs at different points in premodern Persian writings on music, and Forsat listed them together a few times, suggesting that the phrase referenced a metered song framework associated with the dastgah. ${ }^{3}$ What began as a metered song setting for ancient poetry more in keeping with compositional forms of the twelve-maqam system developed into the tasnif tradition with its own modern poetic themes. Though borrowing from the symbolic imagery of the ancient poetry remained a feature of tasnif, their poetry came to focus on topics and symbolism more relevant to urban society in early-twentieth-century Iran.

Initially, the dastgah appear to have been a musical framing for poetry recitation, which focused on ghazal, but generally involved poetry being sung and improvised upon in short sections. Couplets from ghazal and some other types of poetry were parsed out into individual melodies (gusheh) that were interspersed with various types of musical interludes, such as tahrir or chahar mezrab. Poetry constituted the core of the avaz and the question of how the gusheh of a dastgah were organized related in part to how the couplets would be presented in the avaz: what order they would be sung in, which ones would be improvised upon, which ones were dominant versus those that were secondary. How melody was constructed in a dastgah involved a complex dialectical relationship between poetry and pitch. Choices about melody needed to provide an appropriate frame for the poetic foot of specific couplets, but also a sense of logical progression from one 
section of poetry to the next: a sense of beginning, ongoing development, and eventual finality at the end of a performance.

The ghazals of the dastgah focused on the poetry tradition that developed after the Mongol Invasion and with the rise of Persian as the lingua franca of Islamic empire in place of Arabic. Two prolific Persian ghazal writers of this era, Hafez (1315-1390) and Sa di (d. c. 1291), were thus the focus of dastgah performance. Other poetic repertoire from outside the ghazal that consistently appeared included specific sections of the Masnavi of Rumi (1207-1273) and a few poems from the short dobayt genre, usually taken from the oeuvre of Baba Taher Orian, who lived no later than the thirteenth century. One short excerpt from the Ferdowsi's Book of Kings (Shāhnāmeh) also regularly appears, though Forsat did not document this particular poem as having a place in the seven dastgah of the Qajar court.

Regardless of how new or old the poetry used in the performance, the focus of topics shifted far away from the shah, sultan, or king, and strongly toward love poetry and the mystical allegories of Sufism. Indeed, while writers like Maraghi and Amir Khan Gorji compiled song texts as part of their duties within dynastic courts, the radif-dastgah tradition was defined by the disintegration of the court and court musicians' movement into modern spaces both public and private. The first people to record texts used by court musicians were not affiliated with the Qajar court as either servants or courtiers: they were outsiders to the Qajar ruling class.

In this context, the Qajars initially patronized musical expression in keeping with the general practices of previous dynastic eras, yet the texts used for singing in the radif-dastgah tradition did not honor this patronage as music slipped away from dynastic control and moved into the citizenry of the nation. Like the Safavids, the Qajars had their own works of art depicting themselves in their dynastic glory, including depictions of musicians and dancers as part of the Qajar display of their courtly majesty. Yet as dynastic patronage ended altogether, the ruling dynasty did not find favor in song, and even became a subject of sung disdain from the citizenry. While the premodern poetry used in the dastgah largely eliminated kingship as a theme for musical expression, tasnif eventually came to actively reject kingship and anything else that impeded the agency of the Iranian nation. Tasnif sang of Iran as an entity unto itself, a nation distinct from any dynast, in need of cultural revitalization and government reform.

\section{THE POETICS OF IRANIAN HISTORY-THE GHAZAL, THE TASNIF, AND THE DASTGAH}

The stylistic features of ghazal from the twelfth and thirteenth centuries were typically encompassed within between five and fifteen couplets. They used a monorhyming scheme, and the opening couplet (motla ${ }^{e}$ ) was distinguished by the rhyming of its sequential hemistiches. After the first couplet, only the second 
hemistich of each couplet rhymed with the second hemistich of each succeeding couplet. One possible variation on this structure would be for a ghazal to have a repeated word, phrase, or suffix involved in each rhyme, which is referred to as radif, referencing the refrain quality of the repetition.

Ghazal could be set in many different poetic meters (buhür) from the defined rules of poetry that Persian inherited from Arabic ('arüż). The ghazals' variations in poetic meter were a contributing factor to the rhythmic aesthetic in the radifdastgah tradition, specifically in the avaz portion of the performance, where the ghazal dominated. As the core poetic repertoire of the avaz, the musically unmetered feeling of these gusheh related in part to their to accommodation of the variety of poetic meters used in ghazal. Conversely, the gusheh in the avaz that derived from other poetic forms often contained more rhythmic consistency. For instance, two other genres of poetry that most commonly supplemented the ghazal in the avaz were Rumi's Masnavi and the dobayt, both of which were usually organized around eleven-syllable poetic meters. With a consistent count of syllables in every poem, gusheh could have a greater amount of rhythmic consistency while still adhering to poetic meter over musical meter. The ghazal gusheh were also much more likely to be the subject of improvisation in performance, although some were more likely to be used as a source of improvisation than others. ${ }^{4}$

The focus of ghazal in the dastgah was romantic or erotic love and Islamic mysticism, the latter of which could be addressed through double entendre with the former. Ghazal took a series of common tropes used to describe the beloved in Persian poetry and developed them into a complex symbolic representation that could relate to aspects of human love and the pain of separation from the beloved. These tropes could also address mystical themes, including the pain of humanity's separation from God and the ecstatic experience of divine reunion. Ghazal also adopted poetic references to wine and wine-drinking, which could also be taken either literally in reference to drunkenness or as a symbolic reference to romantic infatuation or the ecstasy of unity with the divine.

The types of symbols and themes found in ghazal were not unique to this specific genre of poetry. Much more unique to ghazal was the ongoing mixing of these two themes with other points of focus, and the complexity of metaphor involved with thematic reflection. The ghazal genre of Persian poetry developed into an esoteric literary form, with statements that often embodied many different possible interpretations well beyond the double entendre of human and divine love. Another issue that could add to the complexity of interpreting the meaning of ghazal is the way its couplets often represent complete, independent thoughts and thus could be separated and rearranged. Oral versions of ghazal used in the dastgah did not always match modern edited editions, with variations in the number of couplets and the couplet ordering, as well as some differences in actual text.

In the performance of a dastgah and later the avaz-dastgah, couplets taken from a single ghazal could be the primary organizing factor for gusheh in the first part 
of the performance, with other poetry delineating the second portion of the performance. Yet the use of the ghazal did not necessitate narrating a single ghazal in a set order before moving on to other poetry, nor did a single ghazal have to be used. Most of the gusheh of the radif were designed to accommodate only one or two couplets of poetry at a time. Thus couplets of multiple ghazal could be variously arranged in a dastgah's gusheh sequence. Other gusheh based on other poetic forms could also intervene earlier in the performance, in between couplets of ghazal.

Forsat provided a detailed listing of specific ghazal in his text the Buhur alAlhan, including which melodic framework he would use to perform the specific ghazal he listed. The ghazal take up most of the text's presentation of poetry he associated with the seven dastgah. In describing other types of poetry associated with the seven dastgah, he had much less to say and spoke in generalities about several other genres of poetry and what their melodic framing would be. In listing which melodic aspects of the seven dastgah could be used to perform specific ghazal, Forsat noted that he was simply trying to account for what the musicians of the Qajar court most commonly did in practice and thus often lists more than one melodic possibility at the top of each ghazal poem, accounting for some possible variations in practice.

By the late twentieth century, the poetry of the radif-dastgah tradition appears to have become more narrowly defined. While Forsat's listing of poetry provided a limited perspective on how the poetry would be rendered in the dastgah, the vocal radifs of the twentieth century provide some significant insight, as the vocal versions of radif matched specific poetry to specific melodic progressions. The most important vocal radif historically is that of Abdollah Davami (1891-1980). Davami's radif is one of the oldest available radifs to be recorded by the originator, Davami himself. Davami's late-nineteenth-century birth places his initial performance career in the early to mid-twentieth century and he recorded his radif as well as tasnif he knew later in the twentieth century. Davami organized his radif to account for the dastgah vs. avaz-dastgah distinction, and he did not use one set of poetry for each dastgah or avaz: the radif he recorded encompassed multiple possibilities for what poetry could be sung. Indeed, the other vocal radif from Davami's student Karimi (1927-1984) came later in the twentieth century and provided a larger vocal radif, which included poetry options that Davamis recorded radif did not. Though both radifs use far less poetry than Forsat suggested, they both demonstrate some consistent aspects of structure, and specific variations that demonstrate how poetry created much of the basis for the dastgah's original structure.

Forsat presented ghazal as the core poetry of the tradition, and the vocal radifs confirm the centrality of the ghazal from its earliest practice. One key difference between the vocal radifs and those from instrumental performers was their focus on the melodies that had poetic texts. The two vocal radifs were smaller than the instrumental radifs assigned to early musicians such as Mirza Abdullah and Hossein Qoli, and much smaller than radifs of the later twentieth century. Yet the overlap between basic core gusheh organization in the vocal radifs and instrumen- 
tal versions-as well as similarities between the modern radif and Forsat's charting of each dastgah's melodic progression-places the poetry in general and the ghazal specifically as the organizing factor of the basic melodic organization of any dastgah performance.

The poetry of the dastgah demonstrates both the ultimate origins of the procedural nature of the dastgah and the extent to which the tradition avoided themes of kingship while also fostering a Persian musical tradition distinct from dynastic authority. Literal, figurative, and symbolic reference to kingship can be found throughout the ghazal of Hafez and Sa di, as well as the collections of other ghazal writers. These themes also make prominent appearances in other poetic genres found in the radif-dastgah tradition. But in the specific poems used in practice for the radif-dastgah tradition, kings and references to kingship are very rare, and when they occur, they are metaphors to describe a beloved person or otherwise frame the existence of a beloved person. The tasnif tradition took this move away from kingship one step further, reframing Iran as a freestanding nation independent from dynastic authority, a type of government that could actually harm the Iranian nation.

\section{ANCIENT POETRY AND MELODIC STRUCTURES}

\section{OF THE DASTGAH}

Forsat's listing of poetry indicates that, while he saw a focus on the ghazal of Sa'di and Hafez, he saw no rules for which ghazal were performed with which dastgah. He specified which melodic entities associated with the seven dastgah were likely to be used to perform specific, individual ghazal in practice, while describing other types of poetry in generalities. For instance, he did not list different sections of the Masnavi as being customarily performed in any specific dastgah. Instead, he generally stated that any poetry from the Masnavi would be best performed in Dashti, Bakhtiari, and Quchani, which were cast as melodic entities that belonged to the dastgah. ${ }^{5}$ Though the specific poems and parameters for poetry Forsat outlined do not always specifically align with poetry in Davami's radif, Forsat did indicate the general model of poetry's relationship with dastgah in practice. The couplets of one specific ghazal would dominate the structure of dastgah performance, with the addition of shorter melodic sections based on excerpts from other poetic genres.

Davami's two different versions of Chahargah demonstrate both the centrality of poetry to performance organization and the variability in how the ghazal were sequenced vis-à-vis the progressions of gusheh that underpinned their performance. In the first version of Chahargah provided by Davami (shown in table 4), the poetry focused on Hafez's ghazal with the opening couplet of "Know the value of time as much as you can; the fruit of life is this moment, my dear, if you would just notice it" (vaqt rā ghanimat dān ān qadar keh betavānī; hāṣel az hàyat ey jān yek dam ast agar dānī). The genres of poetry occurring later in Chahargah include 
TABle 4. Division of Poetry in Chahargah According to Davami, First Version

\begin{tabular}{|c|c|}
\hline Gusheh Name, Section of Poetry & Poetry Translation \\
\hline 1st DARAMAD ${ }^{* *}$ tahrir $^{* *}$ & ${ }^{* *}$ no poetry ${ }^{* *}$ \\
\hline $\begin{array}{l}\text { 2nd DARAMAD } \\
\qquad \text { First couplet }\end{array}$ & $\begin{array}{l}\text { Know the value of time as much as you can } \\
\text { The fruit of life is this moment, my dear, if you } \\
\text { would just notice it }\end{array}$ \\
\hline $\begin{array}{l}\text { ZABOL } \\
\qquad \text { Ninth couplet }{ }^{* *} \text { tahrir }^{* *}(\text { Muyeh })\end{array}$ & $\begin{array}{l}\text { Speak not of the ruffian (rendi) in front of the } \\
\text { ascetic } \\
\text { One cannot tell his secret pain to a stranger physi- } \\
\text { cian }\end{array}$ \\
\hline Tenth couplet & $\begin{array}{l}\text { As you are walking, your eyelashes are shedding } \\
\text { people's blood } \\
\text { You are walking too fast, my dear. I fear you will } \\
\text { become exhausted }\end{array}$ \\
\hline $\begin{array}{l}\text { MOKHALEF } \\
\end{array}$ Third couplet & $\begin{array}{l}\text { Gardener, when I pass away for shame if you plant } \\
\text { any cypress in my place other than my friend }\end{array}$ \\
\hline Shahnameh (Ferdowsi) & $\begin{array}{l}\text { A king had one daughter who looked like the } \\
\text { moon; } \\
\text { It is possible that the moon has two black eyes? } \\
\text { In the corner of her eye was a beauty spot } \\
\text { That her own eyes also looked after }\end{array}$ \\
\hline $\begin{array}{l}\text { HODI } \\
\text { Masnavi, introduction (Rumi) first and } \\
\text { second lines }\end{array}$ & $\begin{array}{l}\text { Listen to the flute made of reed, how it tells a tale, } \\
\text { complaining of separation } \\
\text { Saying: "Ever since I was parted from the reed-bed, } \\
\text { my lament has caused man and woman to moan" }\end{array}$ \\
\hline $\begin{array}{l}\text { PAHLAVI } \\
\text { Masnavi, introduction (Rumi) } \\
\text { third, fourth, and fifth lines } \\
\text { (order when sung: } 3 \text { rd, } 5 \text { th, } 4 \text { th) }\end{array}$ & $\begin{array}{l}\text { I need a chest burst from the separation } \\
\text { To explain the pain of yearning } \\
\text { In every group I uttered my wailing notes } \\
\text { I consorted with the unhappy and those who rejoice } \\
\text { Any one shared pain with me } \\
\text { But they did not seek secrets inside me }\end{array}$ \\
\hline $\begin{array}{l}\text { MANSURI } \\
\text { (New Ghazal) } \\
\text { First, second, third, } \\
\text { and eighth couplets }\end{array}$ & $\begin{array}{l}\text { My heart is the private dwelling of her love } \\
\text { My eyes are mirrors held before her face } \\
\text { I, who would not bow for the two worlds, } \\
\text { Have my neck under the burden of indebtedness } \\
\text { to her } \\
\text { You and paradise, I and the beloved's stature } \\
\text { Each person's thought is as great as his aspiration } \\
\text { Majnoon's time has passed, and now it is our turn } \\
\text { Each person has her turn for only a few days }\end{array}$ \\
\hline
\end{tabular}


a short quatrain associated with Ferdowsi's Shahnameh, and the opening lines of the introduction to Rumi's Masnavi. The switch from ghazal to other poetic genres occurs with the gusheh named Rajaz where the poetry of Ferdowsi appears, which in turn leads to the gusheh of Hodi and Pahlavi that each convey sequential lines of the Masnavi. After the Masnavi, Mansuri introduces more ghazal poetry, this time from a different ghazal of Hafez, with the opening couplet "The heart is the private dwelling of her love, my eyes are mirrors held before her face" (del sarā pardeh-i mahabat-i üst / dìdeh ìneh dār-i tal' at-i ūst).

Davami's radif provides some interesting insight into how this early poetrycentric model of dastgah performance influenced the radif-dastgah tradition as the twentieth century progressed. In Bruno Nettl's analysis of Chahargah's performance in the later twentieth century, the multiple gusheh that were built upon the presentation of a specific ghazal still stood as the central defining gusheh of Chahargah: the Daramad, Zabol, Hesar, Mokhalef, Maghlub, and Mansuri. ${ }^{6}$ This was true even when Chahargah was performed instrumentally without a vocalist.

Muyeh was also an important gusheh in Chahargah. But while the other core gusheh appeared consistently as a set sequence, Muyeh's position could change in the melodic sequencing of the dastgah or it could be omitted altogether. ${ }^{7}$ Hodi and Pahlavi were also specific to Chahargah and needed to be performed in succession, but these two gusheh and Rajaz were also more optional than the initial progression that carried the multisectional presentation of the ghazal.

The gusheh mentioned by Forsat that also had melodic equivalents in Chahargah in the radifs of the late twentieth century were shared across various dastgah and not specific to Chahargah or the multisectional presentation of ghazal: Zanguleh, Naghmeh, Baste-Negar, and Kereshmeh. Of these gusheh, only Kereshmeh had a melody-type typical for singing ghazal. The rest appear to function as secondary melodic sections providing different types of musical interludes to the primary presentation of poetry.

In comparing table 4 with Nettl's observations, Davami's renderings of Chahargah seem to maintain many features Nettl observed. There are also some notable differences. For instance, the position of Hesar moves, breaking up the ghazal sequence by placing it after Rajaz and Hodi-Pahlavi. One larger difference is the use of Mansuri. Mansuri acted as a foundational gusheh of Chahargah in the late twentieth century, and it was also a ghazal-derived gusheh. In this version of Chahargah, Davami sang it with a fairly long section of a separate ghazal distinct from the initial ghazal, and positioned it after the Masnavi. This is distinct from the perspective of practice in the later twentieth century. Even in other parts of Davami's radif, or the dastgah charts of Forsat, the Masnavi and other nonghazal poetry most commonly come after the ghazal poetry in the avaz.

Davami's second version of poetry for Chahargah (shown in table 5) further points to complexities of variation in poetry usage. In this poetic variation of Chahargah, the poetry of the daramad is based on a love poem from the Ghaznavid 
TABle 5. Division of Poetry in Chahargah According to Davami, Second Version

\begin{tabular}{|c|c|}
\hline Gusheh Name, Poetry Section & Poetry Translation \\
\hline $\begin{array}{l}\text { DARAMAD } \\
\text { Farrukhi Sistani } \\
\text { Unknown poetic genre }\end{array}$ & $\begin{array}{l}\text { I wanted two kisses from the rubies of the sweetheart } \\
\text { Raise this mean creature with this kiss } \\
\text { She said: One is enough, if you get two } \\
\text { You will rebel. This I know from much experience. } \\
\text { My kiss is a second life, never has } \\
\text { Anyone received another life. }\end{array}$ \\
\hline 5th couplet & $\begin{array}{l}\text { I do not know the reason for no condition of familiarity } \\
\text { with sweethearts with black eyes, and moon-like faces }\end{array}$ \\
\hline $\begin{array}{l}\text { PANJREH MUYEH } \\
{ }^{* *} \text { tahrir }^{* *}\end{array}$ & ${ }^{* *}$ no poetry ${ }^{* *}$ \\
\hline $\begin{array}{l}\text { RAZAJ } \\
\quad \text { Shahnameh (Ferdowsi) }\end{array}$ & $\begin{array}{l}\text { A king had one daughter who looked like the moon; } \\
\text { It is possible that the moon has two black eyes? } \\
\text { In the corner of her eye was a beauty spot } \\
\text { That her own eyes also looked after }\end{array}$ \\
\hline HODI-PAHLAVI & $\begin{array}{l}\text { Listen to the flute made of reed, how it tells a tale, } \\
\text { complaining of separation } \\
\text { Saying: "Ever since I was parted from the reed-bed, } \\
\text { my lament has caused man and woman to moan" } \\
\text { In every group I uttered my wailing notes } \\
\text { I consorted with the unhappy and those who rejoice }\end{array}$ \\
\hline Last couplet & $\begin{array}{l}\text { Nothing wrong can be said about your beauty except for this } \\
\text { That there is no foundation of affection and loyalty within } \\
\text { your loveliness }\end{array}$ \\
\hline $\begin{array}{l}\text { MOKHALEF } \\
\text { Third couplet } \\
\text { First couplet (Saa'di) }\end{array}$ & $\begin{array}{l}\text { Was it the vanity of your beauty, oh rose, that prevented you } \\
\text { From inquiring about the lovesick nightingale } \\
\text { In reality, I do not know what creature in this world you } \\
\text { resemble } \\
\text { The world and everything in it is the body, and you are } \\
\text { the soul }\end{array}$ \\
\hline $\begin{array}{l}\text { MAGHLUB } \\
\text { First couplet }\end{array}$ & $\begin{array}{l}\text { Gentle breeze, kindly tell the elegant gazelle } \\
\text { It was she who made us head toward the mountains and the } \\
\text { deserts }\end{array}$ \\
\hline $\begin{array}{l}\text { NAGHMEH-YE MAGHLUB } \\
{ }^{* *} \text { tahrir }^{* *}\end{array}$ & ${ }^{* *}$ no poetry ${ }^{* *}$ \\
\hline HUZZAN ${ }^{* *}$ tahrir ${ }^{* *}$ & ${ }^{* *}$ no poetry ${ }^{* *}$ \\
\hline $\begin{array}{l}\text { PANJREH MUYEH } \\
{ }^{* *} \text { tahrir }^{* *}\end{array}$ & ${ }^{* *}$ no poetry ${ }^{* *}$ \\
\hline $\begin{array}{l}\text { MANSURI } \\
\text { Second and eight couplets }\end{array}$ & $\begin{array}{l}\text { Why does the sugar-seller, may his life be long } \\
\text { Never treat the sugar-eating parrot } \\
\text { It is no surprise, if in the heavens the words of Hafez } \\
\text { Venus's song cause the Messiah to dance }\end{array}$ \\
\hline
\end{tabular}


poet Farrukhi Sistani (c. 980-1037), which opens with the phrase "I wanted two kisses from the rubies (the beloved's lips)" (khāstam az delbārī do būseh). Subsequent gusheh were organized around all but two couplets from Hafez's ghazal with the opening couplet "Gentle breeze, kindly tell the elegant gazelle; it was she who made us head toward the mountains and the deserts" (sabā beh lotf begū àn ghazāl-i ra nā rā / ke sar be kūh o bìyābān to dādeh-i mā rā). There is also one couplet from a Sa di ghazal.

The ordering of the gusheh in this version of Chahargah is also somewhat different. The nonghazal poems of Rajaz, Hodi, and Pahlavi appear in the middle of the ghazal, separating Zabol from Hesar and Mokhalef and splitting the ghazal into two sections instead of making it one continuous narration. In this version, Davami also provided more gusheh consisting of just the vocalization of tahrir. One of these gusheh, called Panjreh Muye, appears in two different places, first after the gusheh of Zabol and before Rajaz and then again at the end of an extended tahrir section divided between three gusheh not included in the first version of Chahargah: Naghmeh-ye Maghlub, Huzzan, and finally Panjreh Muyeh. In this version of Chahargah Mansuri still ends the dastgah after this tahrir section, yet this version of Mansuri does not use a separate ghazal, but instead continues using couplets from the ghazal upon which most of the dastgah is based.

These two different versions of Chahargah's poetry demonstrate the extent to which a dastgah's overall melodic organization relied on its poetry, the way the poetry was parsed out into smaller sections as well as degrees of poetry variation permitted. While it was possible for one ghazal to dominate in any poetic conception of a dastgah, the organization of its presentation could vary considerably. Its couplets might begin the dastgah and proceed in a progression of gusheh that allowed it to be presented uninterrupted by other poetic forms, which appear mostly after the dominant ghazal. A ghazal that would dominate the first part of performance would start the dastgah in or close to the daramad, but not always. While the different versions of Chahargah demonstrate a major shift in the presentation of poetry within the same dastgah, the addition of the gusheh Kereshmeh to either of Davami's versions of Chahargah could introduce a smaller change. As another gusheh that would facilitate a couplet of ghazal, Kereshmeh could be used to begin the narration of a ghazal that would go on to dominate a performance, or it could introduce a couplet from a separate ghazal that preceded or interrupted a dominant ghazal.

\section{POETIC THEMES AND SYMBOLISM IN THE POETRY OF THE DASTGAH}

The poetry used in both of Davami's versions of Chahargah also provides a strong sampling of the themes that dominate the poetry of the dastgah overall. While the 
ghazal used in the first version of Chahargah opens with a couplet reflecting on the passing nature of time, it quickly moves on to references of mysticism and tropes of the beloved. Mystical references include Hafez's signature contradictory alignment of a truly pious ascetic who rejects the hypocrisies of orthodoxy with a ruffian who also rejects orthodoxy and is hence more pious than the orthodox. The tropes of eyelashes and the cypress tree invoke the beauty of the beloved's eyes and stature, even as the narrator is ignored or otherwise separated from the beloved. This focus of the narrator on the beauty of the beloved and his separation from the beloved is also the focus of the couplets used for Mansuri in Davami's second version of Chahargah. The reference to the ecstasy of wine is both the worldly experience and a reference to the experience of a higher divine reality. The beloved is both a human trope of unattainable communion and a symbol of humanity's ongoing, painful separation from God that the narrator wishes to bridge.

The short passage attributed to Ferdowsi continues with the common tropes of the beloved, using black eyes, a moon-like face, and a beauty spot to demonstrate the beauty of the king's daughter. This short passage is the only poetry used in the radif-dastgah tradition associated with Ferdowsi's Book of Kings. While the focus on love and the beloved is notable in the choice of ghazal, it is more prominently displayed in this short passage. Eschewing the primary focus of Ferdowsi's work on the life and works of specific rulers, the poetry of the radif-dastgah tradition focused on a small reference to notions of the beloved. Here the king is a secondary actor, while his daughter without title or specified dynastic standing is the focus for her ability to embody the idealized qualities of the beloved.

The positioning of this short passage in Rajaz ahead of Hodi and Pahlavi creates a separate, sequential representation of love poetry and mysticism. Hodi and Pahlavi present the now famous opening to Rumis Masnavi, which uses the transformation of a reed growing in the ground into a flute (nay) to represent the sadness and unnatural state of humanity's separation from divinity. This is one of two passages from Rumi's Masnavi found in the texts of the radif-dastgah tradition. The other recounts a story of Moses admonishing a shepherd who engages in blasphemy when he tries to honor the humanity of Moses over and above the divinity of God. ${ }^{8}$ Both texts use parables to describe different aspects of humanity's imperfect state of suffering in their separation of God, with no use of love poetry symbolism.

While the second version of Chahargah kept the poetry of Ferdowsi and Rumi, its focus on Hafez's fourth ghazal highlights additional symbols of the beloved, including rubies representing the beloved's lips and the rose and the gazelle as metaphors for the beloved's beauty. Sugar also references the beloved's lips in the primary ghazal in table 5, focusing more on the ways that the beloved mistreats and ignores the narrator who pays her close attention, as represented by the sugar seller who ignores the sugar-eating parrot. The vain rose surrounded by thorns ignores the lovesick nightingale, further referencing how the beloved ignores the narrator despite his adoration. 
In the capacity of the rose, poetry can dwell on both the beauty and the cruelty of the beloved. While the rose represented beauty to be admired, a rose's thorns hurt the admirer and kept him at bay. Thus the thorn itself could reference the hurtful disdain of the beloved, while the nightingale could represent the admirer who sings to the rose but is nevertheless rejected. The suffering of the admirer is a central aspect of love poetry discourse. While the narrator can directly complain about being spurned, the admirer often cries, sometimes a river of tears, sometimes blood and other times jewels, all of which demonstrate the immense suffering of the admirer unable to attain the beloved.

Some of the other symbols that appear in the poetry of the dastgah that are codified in the premodern lexicon of Persian love poetry include other flowers. While the tulip more commonly referenced the beauty of spring, the narcissus aligns with the beloved's beautiful eyes. The eyes were often the focus of describing the beauty of the beloved, but could also be a source of pain. In the first couplet of a ghazal from Foroughi Bastami that Davami used in both Mahur and Rast-Panjgah the narrator states: "My heart is afflicted by your eyes, which are half closed. .. . Cure the pain of someone who is more helpless than anybody else."

Descriptions of the beloved move back and forth between metaphors for beauty and a concrete description of beauty that has standard features. Black curly hair typically matched the black eyes and eyelashes to create a fully idealized frame of beauty on the beloved's face, which also had a mole. The gusheh Saqi-nameh in Davami's Homayun and the gusheh Chekavak in his version of Rast-Panjgah both use the same couplets from Sa di verses about Leyli and Majnun, a story about the unrequited love of Qays b. al-Molawwah b. Mozahem for a woman named Layla/ Layli, where Qays took on the title majnun (majnūn), connoting his lovesickness. The verses from Sa di used in the dastgah begin with an opening statement from Qays about Layli's beauty: "Oh curls, every one of you is a noose. Your eyes have an amorous look of fascination."

The obsession over the beautiful features of the beloved and the beloved's inability or unwillingness to reciprocate or even acknowledge the feelings of the narrator form the basis of being lovesick. The beloved was both very superior to the admirer and disdainful of him. Within this narrative frame, the beloved could be cast as an idol (bot or sanm), an entity to be worshiped beyond the humanity of the admirer. Because the admirer cannot actually speak to the beloved, he speaks with the morning wind, which acts as a messenger between the lowly admirer and the worshiped beloved. ${ }^{10}$

While the pain of separation from the beloved could be a central point of metaphor for separation from God, the ecstatic feeling of infatuation or divine communion aligned with notions of drunkenness and intoxication. The presence of wine and its larger context - the tavern, the goblet or cup, and drunkenness-introduce multiple layers of meaning. These references could simply refer to drinking and 
drunkenness. They could also refer to the intoxication of beauty and love, or the ecstatic experiential knowledge of God.

The centrality of specific ghazal to defining the radif-dastgah tradition thus focused attention on a very complex poetic genre that was also much older than the music tradition itself. While thematically esoteric, the structural organization of the radif-dastgah tradition originally deriving from poetry gave the music itself considerations for its organization that were not purely musical. With poetic meter itself being central to rhythmic organization of avaz rather than clearly defined musical rhythm, the poetry was indelibly caught up in defining the melodic contours of music performance.

\section{TASNIF: FROM ESOTERIC GHAZAL TO SONGS \\ OF THE PEOPLE}

The metered songs that became known as tasnif were added into a dastgah performance at the end of the avaz and some of the earliest tasnif of the tradition were simply musically metered settings of specific ghazal poetry. From a poetry standpoint, ending the avaz with a gusheh like Mansuri could become redundant once performing a tasnif at the end of the avaz became standard. Yet these metered songs did not remain strictly dedicated to ghazal, though the symbols used in ghazal-and a style of discussing the beloved and romantic love derived from premodern Persian poetry-were an initial starting point for the modern poetry of the tasnif. Davami associated one of the earliest ghazal-based tasnif with Bayat-i Isfahan, a tasnif that derived from four couplets of a ghazal from Hafez:

Oh great shah of the beautiful ( $p \bar{a} d s h a h-i k h \bar{u} b \bar{a} n$ ), what grief loneliness is

My heart is dying, it is time for you to return

Oh pain, you are a cure, in my bed of discontent

Oh memory you are a companion in my corner of loneliness/illness

Last night I was complaining to the wind about her curls

It said, you make a mistake and give up this melancholic thought

The flowers of the garden are not always lush

Pay attention to the weak when you are young and able. ${ }^{11}$

The phrase "great shah of the beautiful" provided yet another metaphoric reference to the beloved. The notion of kingship was thus introduced in passing as a representation of the beloved's privileged position vis-à-vis the isolation, loneliness, and weakness of the onlooking narrator. Once again, kingship framed the beloved rather than being a dominant theme in and of itself. 
While tasnif initially could simply be a metered setting for a ghazal, it was not the only source of metered song texts. New songs were composed referencing similar themes of the beloved from Persian poetry, but with simpler language and representation. While the meaning of a ghazal's progression of couplets did not have to follow a fully logical line of thought throughout, songs composed of similar themes often did follow a single line of reasoning, greatly simplifying the possible readings of the poetry itself.

Musicians often accredit one of the oldest known tasnif that is not a ghazal to a woman at the Qajar court known as Sultan Khanom. Sultan Khanom worked as a musician in the women's quarters of the Qajar court. She eventually married a member of the Qajar ruling elite, 'Ali Naqi Mirza A tizab al-Saltana, and Hedayat remembered her after her marriage as a friend to his mother. ${ }^{12}$ Whether she composed the song before or after her marriage is unclear, but her tasnif for Chahargah used historic metaphors and tropes related to the beloved's beauty:

Oh idol of my affections, oh idol,

I am crazed (majnūn) and beguiled from sorrow over you

Oh idol, idol, my eyes are like the river Oxus from sorrow over you

Morning wind, tell the happy elegant youth, don't make me crazy

With me, oh idol, with me, oh idol,

Until when, beloved, will you be far from me (dear one),

Why are you sitting with charlatans (dear one),

Morning wind, go to the dear one, to the dear friend (my dear one),

Deliver a message of happiness. ${ }^{13}$

The symbolism this song shared with ghazal and other premodern Persian poetry included references to the beloved as an idol, the Oxus River representing tears flowing from the eyes, the morning wind speaking as a messenger to the beloved, and the reference to majnun, the insanity of infatuation. In the oldest tasnif, such references to the literary tradition of the ghazal could be direct, or somewhat more removed from older poetic traditions. One early tasnif associated with the poet Sheyda (1843-1906) also for Bayat-i Isfahan similarly reflected on the separation from the beloved:

From the sadness of love, Sheyda's heart is broken

As the flask of wine on the darkest night is broken

Since I walked over the thorn of the desert so much

Deserts are all over my feet, dear one of my heart,

We are all eyes and you are light, May the evil eye be far from you

When you scatter your curls across your face

You shatter the peace of so many people 
And the worst happens to Sheyda's heart

I cannot be far from you anymore

I cannot wait anymore for you ${ }^{14}$

The composer that musicians and scholars have most often credited with effectively balancing the elegant symbolism of the ghazal with more simplified, accessible poetic framing for the radif-dastgah tradition was Sheyda. While little is known about the details of his life, Sheyda was a poet with a mystical background. He was a follower of Zaher el-Dowleh and a member of the Society of Brotherhood. ${ }^{15}$ Some of his tasnif compositions related to performances by the Society of Brotherhood, which placed his tasnif at the intersection of court music's move out of the court and the development of modern civic organizations both by and for the Iranian people. Songs associated with Sheyda include both ghazal texts set to music and songs composed with Sheyda's own poetry.

Sheyda wrote many songs that kept older symbolism with references to fewer complex metaphors. For example, one song Davami attributed to him, also composed for Bayat-i Isfahan, used many of the standard symbols of beauty for the beloved, but in a much-simplified setting:

The moon is the slave of your lovely face

The moon is the slave of your lovely face

The cypress tree is your servant, oh my love

The cypress tree is your servant, oh my love

All lovesick confused hearts gather around you, oh my dear

At the curly end of your ringlets oh my dear

Oh luminous moon

Oh, your lips are sugar

Continually sugar is the best, oh my beloved, continually sugar, oh my dear

As are your laughing lips, oh my love, continually sugar, are your lips, oh my love $\mathrm{e}^{16}$

In this song, Sheyda used many of the symbols of beauty cultivated in the ghazal to describe the beloved. Yet Sheyda also reduced the number of thoughts being communicated by the words, even as he limited the possible interpretations that could be applied to symbols he used. By limiting the complications of metaphor in his poetry, Sheyda avoided the complexity of the many layers of comparison, symbolism, and allegory that ghazal espoused as each couplet could introduce new levels of meaning and distinct, independent thoughts.

While this type of simplified reformulation of premodern symbolism was a hallmark of early tasnif, the repurposing of older poetic symbolism and the development of new symbolism to engage in reflection on the modern world also became fundamental aspects of tasnif poetry early on. The new, modern points to 
be made often directly addressed the political problems and aspirations of modern Iran and reflected on the changing political climate at the turn of the twentieth century. Another song that both Davami and Khaleqi attributed to Sheyda appears to be associated with a concert that is generally considered one of the first public concerts given by Iranian citizens rather than the dynastic government, given by the Society of Brotherhood on the birthday of the Shi'a Imam 'Ali. ${ }^{17}$ This tasnif for the dastgah Segah celebrated the unity and commonality of the people at the gathering, focusing on the lack of distinction between the poor and the dynast:

The newborn prophet is God's beloved

This birth is the reason for Sufi celebration

I am proud for such a feast that is put together

It is in the unity of the sultan and the beggar in peace

Oh what a shah! Oh what a moon! Oh what a pleasure! Oh what fidelity!

Lute, drum, and flute are chanting a sufi hymn

Chanting of his holy soul

I am proud for such an event where a king and a dervish

Are sitting together in one heart, one religion, as one. ${ }^{18}$

This tasnif was a departure from the themes of the ghazal upon which the dastgah were organized, yet it also was one of the first musical poetic expressions related to the radif-dastgah tradition that focused on the image of a dynastic ruler as a central actor. The imagery of the ruler in this tasnif reversed the pre-nineteenth-century image of the ruling dynast. It did not invoke the image of the sultan, shah, and king within the historical framework of the ruler's superiority and supremacy over human affairs. To the contrary, this song praised the notion that a dervish and a king could be equal, and that piety was a supreme quality, over and above any special standing of a ruling dynast. The song emphasized the equality and a shared human experience between people on two opposite ends of power. The importance of the celebration was the shared confraternity of many different people, from the greatest to the lowliest.

Though not explicitly political, the song above presented a reframing of power as it had been understood within the dynastic realm. The tasnif celebrated the giving of a musical concert to the larger community, who did not have access to such performances historically. The religious framing of the celebration could cast this redistribution of dynastic resources as an act of charity, even as the court did not actually grant the charity. The musicians themselves were able to decide without court consent to give the music to people historically undeserving of such performances. 
After Sheyda, tasnif that utilized fewer references to the symbolism of premodern Persian poetry, or redefinition of the symbolism to negative ends, became more common. Many tasnif spoke strictly in modern terms about the modern improvement of the nation of Iran, often recasting the meaning of premodern poetic symbolism or avoiding it to pursue modern themes. In Safavid song, Iran represented a kingly domain that embodied the power of the shah. Iran appeared in the tasnif of the radif-dastgah system as a sovereign entity unto itself. Iran was not a prestigious reference to kingly power, or a kingdom subject to dynastic control. Instead, Iran was an independent nation, struggling to maintain itself and survive by itself in the modern world.

Another tasnif for Bayat-i Isfahan, with text from the poet Bahar (1886-1951) and music composed by Darvish Khan, pondered the sources and solutions to Iran's suffering and difficulties in the modern world:

Oh Iran! It is time to work! Stand up and watch...

Your fortune is waiting! Do not sit! Iran!

Martyrs' blood is spent, that is the price of freedom

Promises were violated, freedom is turned to blood

God frees us from our pain and sorrow, God liberates the desires of our hearts

Consider what the realm of the world will do with us?

Consider the love of nation, what tumult it makes!

Oh, what tribulations befall you Iran

Alas, you did not attain the desire of your heart, Iran you did not see anything except sadness

God frees us from our pain and sorrow, God liberates the desires of our hearts

How long should I not be young at heart, like the elderly

Give me a cup in the memory of my nation, to the peace of Iran!

So that I may embrace cries of freedom from the heart

Oh, what tribulations befall you Iran

Alas, you did not attain the desire of your heart, Iran, you did not see anything except sadness. ${ }^{19}$

The tasnif above focused on Iran as a nation that was at once a victim of circumstances it could not control, while also being subject to the actions of its people, who could act to its benefit or detriment. The tasnif mostly abandoned the symbolism of premodern Persian poetry. Even the one reference to a cup speaks of toasting the peace of Iran, invoking none of its past metaphoric meaning. There was no sultan, shah, or king ruling or conquering Iran, no beloved or adoring admirer experiencing private yearning. Iran, its people, and their terrible situation 
are the focus, and only Iran's people or God could improve the nation's situation and determine its proper destiny.

Themes related to modernity and the modern political transformation of Iran, both veiled and explicit, hold a key place in the tasnif repertoire and 'Aref Qazvini was a champion for these topics. 'Aref was one of the most active revolutionaries of the radif-dastgah tradition and he regularly addressed modern political issues, both with and without the reinterpretation of themes from premodern Persian poetry. 'Aref's belief in the Iranian nature of the radif-dastgah tradition stemmed directly from its use of premodern Persian poetry. Initially he complained about the quality of song writing in his own time, stating that songs often had simple themes of no importance compared to the profound complexity of the poetry like the premodern ghazal. Yet expressing more important ideas in song also required such ideas to be understandable to the average Iranian, for whom the ancient poetry was still largely inaccessible. He credited Sheyda with finding a balance between worthy poetic subjects and simple yet profound poetic expression for modern Iran. ${ }^{20}$

In his own tasnif, it did not suffice for 'Aref to cast older themes and symbolism into simpler, accessible text. He voiced the opinion that modern Iranian public needed more explicit education on their identity. ${ }^{21} \mathrm{He}$ used his tasnif to both teach Iranians who they were and educate them on the problems of modern Iran along with possible solutions. 'Aref was aware of the gap between the expectations of modern identity for the nation of Iran and the historical realities of identity. Even as Vaziri saw music as a tool for proper education that would bring the Iranian nation into a prosperous state of modernity, 'Aref used his tasnif to the same ends, but focused on specifically calling out the problems facing Iran in the modern world. While 'Aref bemoaned the ignorance of Iranians regarding their great history and lost culture, he called out corrupt rulers and foreign interference in Iranian affairs as the ultimate source of Iran's lack of standing in the modern world. The Iranian people would have to stop the exploitation of Qajar rule and the intervention of foreign powers in order to recover the greatness of ancient Iranian civilization in the modern world.

In one of his most popular tasnif, "From the Blood of the Youth of the Country," composed for Dashti, the nightingale becomes an observer of the sad state of the nation. Thus the chorus sang:

From the blood of the youth of the country, the tulips bloom

As the cypress tree mourns their eminence, the cypress bends

In the shadow of the flower, the nightingale sits hidden from this grief

The flower in its sadness, like me, rends its garment. ${ }^{22}$

Here a flower of spring, the tulip, represented the new day that would dawn from the long-fought struggles of youth. The cypress tree stood as a witness to their sacrifices, even as the nightingale was too grief stricken to sing. 'Aref used multiple symbols of the beloved's beauty and the narrator's admiration in this tasnif to represent 
the modern struggles of the nation. In this tasnif, 'Aref also eventually abandoned symbolism to directly address a particular problem of the nation:

The ministers sleep, and the governors sleep

They steal all of Iran's silver and gold

They do not allow us one ruined house

Oh God, take justice from the rulers and give it to the poor. ${ }^{23}$

This verse framed the sacrifices of the youth as occurring against a backdrop of government corruption that robbed Iran of its riches, even as the Iranian people suffered and sacrificed to better the nation. The glory of the Iranian nation 'Aref saw being destroyed came from pre-Islamic times. 'Aref's conception of Iran's national history positioned notions of pre-Islamic Iran as the golden age of the nation, while positioning later impositions of control from forces outside of Iran as leading to its downfall. Nations coming from the outside to divide, conquer, and exploit Iran were a recurring theme in his tasnif, along with complaints that the Qajars did nothing to stop this foreign exploitation in modern times. In another tasnif for Dashti that 'Aref wrote while in exile in Istanbul, he specifically complained about attempts to make Azerbaijan an independent Turkic nation with more connections to Turkey than Iran:

The temporary government, what does it do? Who do you listen to?

The house of Jamshid is conquered by a foreign face

The palace and the royal court went to the wind, the dirt

Silence comes from Behistun, because the palace is destroyed

(It becomes a wheel of Turkey, it becomes a wheel of Turkey)

The women of the shah in front of the women and powerful people said:

Where are the leaders of Iran, the heroes of Iran?

What happened so that not even one brave individual remained from the warriors of Iran? ${ }^{24}$

While 'Aref had changing ideas about the shah as a figure of praise or disdain, pre-Islamic rulers do appear in some of the tasnif of 'Aref as figures to be praised. Here the mythical pre-Islamic king Jamshid represents the greatness of Iran that has been lost to foreign intervention. 'Aref references the ruins of long-abandoned palaces as evidence that Iran had fallen to foreign invasion and control. In referencing Behistun, a mountain just south of Kurdistan, 'A ref refers to the ruins of a palace complex that included a multilingual cuneiform rock relief recounting the exploits of the Achamedid ruler Dariush the Great from the era of his rule $(522$ $\mathrm{BC}-486 \mathrm{BC})$. He attributed its abandonment to Turkey's influence in the region, and the Qajar government's inability to assert control over Iranian territory. 'Aref contrasted the temporary government of his time with the eternal greatness of Iran's past glory, even as he complained that heroic rulers like Jamshid could no longer be found in Iran. 
'Aref's problematic relationship with kingship stemmed from his opposition to dynastic rule in his lifetime. While Sheyda offered hope that equality in society was imminent, 'Aref saw nothing but corruption in the rulers of his time, corruption that hurt the Iranian people. In a tasnif for Afshari titled "Crown of the Great King's Head" he wrote:

Oh, Crown, you, the Crown of the Great King's Head

Seeing your drunken eyes, the world drowns

What can you ask about the poor?

What do you know of how the sufferers' pain sounds? $?^{25}$

'Aref did at times mention the Qajars by name in his poetic criticism of Iran's modern demise, a practice that eventually led him to seek exile in Istanbul for a time. 'Aref was appalled not only by the Qajars' simple denial to the Iranian people of the power and resources they deserved, but also by the amount of foreign control the Qajars gave over to the British and the Russians, resulting in foreign intervention that could only be to Iran's detriment. In his divan, he recorded a tasnif that actually spoke in favor of foreign intervention to the extent that it helped the Iranian people against Great Britain and Russia. The tasnif was about William Morgan Shuster (1877-1960), an American lawyer hired by the newly formed constitutional government to help with its finances after the Constitutional Revolution in 1906. The new parliament brought Shuster in to help them learn how to fund the constitutional government, which included trying to resolve the Qajars' debts and to curtail the financial demands of Great Britain and Russia. Shuster was ousted in 1911, when Russia shelled the Iranian parliament in direct response to Shuster's appointment and financial management.

In this tasnif for Dashti, 'Aref begged and pleaded with Iran not to let Shuster go. 'Aref cast Shuster as the only person who had the Iranian people's interests at heart: the only person standing against the corrupt Qajars, the Russians, and Great Britain. Rather than a foreign intruder, 'Aref cast Shuster as a guest:

Shame on the house from whose table a guest leaves

Sacrifice your life for him, do not let the guest leave (leave)

Iran will go with the wind if Shuster leaves

Oh youths! Do not let Iran go

You are life in a dead body, you are the life of the world

You are eternal life, you are a treasure like gold

Let's hope you hold on, hold on, hold on, hold on. ${ }^{26}$

The tasnif went on to alternately blame the government for corruption and appeal to Iranians to not give up on Shuster:

Our goblet is now full of impatience

The thief intends to burgle our home with violence

It will be a historic world catastrophe, this occurrence 
If we let Shuster leave Iran

You are life in a dead body, you are the life of the world

You are eternal life, you are a treasure like gold

Let's hope you hold on, hold on, hold on, hold on. ${ }^{27}$

'Aref fully transformed the goblet, which had been meant to represent the container of ecstatic experience and intoxication of beauty, into a new metaphor unattached to the older symbolism. The thief burgling the home provided a modern metaphor for both the Qajars and foreign interests making off with Iran's riches. While the nation of Iran was itself a treasure like gold, it would have to fight to keep Shuster and avert tragedy.

While 'Aref bemoaned the loss of Iran's ancient glory, he had less criticism for the nation of Iran in this regard, and more for its rulers and foreign interventions that he believed caused Iran's downfall. Still, Iranians needed to be educated on their former glory and their shared cultural legacy. His tasnif about Azerbaijan provides the stark example of 'Aref specifically reeducating the Iranian population about their identity. In this case, he focused on how the region of Azerbaijan was a key part of Iran, and not a separate national entity. In continuing to voice concerns about Turkey's interest in establishing a separate Turkic Azeri state, 'Aref came out and specifically wrote a tasnif for the dastgah Nava about Azerbaijan's key position in the Iranian nation:

May life be sacrificed for Azerbaijan

May the cradle of Zoroaster become the font of tranquility

Wish his limbs paralyzed, his tongue tied

A scoundrel who called you limp, paralyzed

You are Iran's key, Iran's hope, Iran's martyr

Hail to your spirit from good men's souls, from forefathers

And lo, may the world and the soul be sacrificed for your soil

O morning wind, tell the people of Tabriz for me

[Tell] all who remind us of wild lions, the bold

Avoid the Turk and the Turkish language

Do not forget your own language

As Zoroaster told

Do not put out the flame with water ${ }^{28}$

This tasnif carried a message about Azerbaijan to the Iranian people and specifically the Azeris. 'Aref used this song to criticize anyone who said Azerbaijan was Turkish or even simply just in the periphery of Iran's cultural identity. In keeping with notions of Iran's pre-Islamic greatness, 'Aref referenced Zoroastrianism, the dominant religion before the rise of the Islam. He invoked the symbolism of Zoroastrianism's prophet and fire temples to argue that Azerbaijan was a key geography within Iran's great pre-Islamic cultural legacy. He referred to the Persian language as "our language," and entreated Azeris to maintain Persian while aban- 
doning Azeri Turkish, framing the latter as their real language and the former as an imposter language.

\section{CONCLUSION}

The radif-dastgah tradition's basis in long-form musical procedures initially derived from its basis in long-form poetry recitation. The musical structure of a dastgah, or even smaller melodic sections within dastgah, depended first and foremost on the type of poetry performed and the placement of poetry in a performance. This approach to musical structure differed from concepts of applying a particular mode or scale in the course of composing an organized suite. Poetic form determined musical form, rather than musical form accommodating poetic form. This distinction had a significant impact on musical structure. The original seven dastgah were organizations of many smaller melodic sections designed to present sections of poetry in a set order, with customary rules for the progression of melody that accounted for placement of poetry and the timing of purely musical interludes between poetic sections. This was the basis of the gusheh and the performance of avaz, which constituted the core of music performance.

Within this concept, musical sections with no reference to poetry or the voice had a role to play in framing the poetic performance. In his description of the dastgah, Forsat listed fully instrumental sections as occurring either at the very beginning or at the very end of the dastgah. While the solo instrumental chahar mezrab would ultimately be placed after the daramad, placing larger metered pieces for multiple instruments either before or after the avaz remained the norm.

The proliferation of tasnif to perform after the avaz was one factor in the increasing application of systematic modality that came to define the radif-dastgah tradition beyond the seven dastgah. Davami and 'Aref both sang tasnif with pitch frameworks that were smaller than the dastgah. Besides Bayat-i Isfahan and Dashti, older tasnif were composed for Shahnaz (Shur), Rak, and 'Iraq (Mahur). 'Aref also wrote tasnif using Shushtari from the dastgah Homayun as the melodic basis. Forsat listed Shahnaz as being in three sections and Davami described it as being able to accommodate up to four couplets of a ghazal, making it quite large for a single gusheh. By the late twentieth century Shahnaz was still a very large, multisectional gusheh of Shur. Nettl classified Shushtari and 'Iraq as still being used as independent frameworks for performance in some instances, almost threatening to become their own avaz-dastgah. Rak also remained quite modally distinct and thus could function as a separate mode. ${ }^{29}$

The early choices regarding pitch usage in tasnif highlight the move toward a conception of distinct pitch modalities even as musicians could have different 
ideas about which modalities should be used for frameworks of composition. There were multiple possibilities within the dastgah that tasnif composers could draw on for their song compositions. Despite these many options, only certain pitch modalities ultimately became distinguished as the separate avaz-dastgah. Tasnif composed using pitch frameworks that never came into common use in composition were subsumed into the dastgah from which they came. Thus a tasnif in Rak belongs to Mahur, while a tasnif in Shushtari belongs to Homayun.

While the song text collections associated with the twelve-maqam system were skewed toward kingship, the poetry of the dastgah was skewed toward love, beauty, and mystical experience. Indeed, though the poetry of the radif-dastgah tradition was initially taken from eras adjacent to the song texts of Maraghi-and though Maraghi had become an important figure in the modern national conception of Iran's music history-the themes represented between the two collections of poetry were quite different. The world of song Maraghi described was vastly different from the world of song created for the radif-dastgah tradition.

When practitioners of the radif-dastgah tradition started writing new poetry for tasnif, the modern reality to which the radif-dastgah tradition adapted came into full view. Safavid songs referenced Iran with some regularity, yet Iran was only significant to the extent that it served as a great kingdom over which a great king ruled. Iran was not separable from the dominance of kingship, and it had no place in the world without kingship. In the tasnif, Iran became defined by citizenry of the nation, even as kingship became obsolete and even disdained. While dynastic governance focused on managing resources, the nation focused on managing its resources and its citizenry. Who would control the citizenry was a central question of the modern nation. 'Aref disdained the control of the Qajars as corrupt, and supported constitutionalism, which would give the citizenry more control over their own destiny. Poets like Bahar and 'Aref wrote tasnif in favor of revolution and democracy, and musicians associated with the radif-dastgah tradition sang them long after his death. These ideas were indispensable in modern tasnif, yet they had no place in music or poetry even a century earlier.

The premodern and modern song texts of the radif-dastgah tradition embodied the Janus-faced reality of a modern nation, pointing backward to various conceptions of a glorious Iranian past, while looking forward for improvement of the nation to retain this past glory in the modern era. These texts spoke not only to the modern conception of the nation, but to the initial logic of the radif-dastgah tradition's structure. Without a specific conception of distinct modalities to be used in composition, a customary practice of poetry recitation served as the primary basis for conceiving of the dastgah's musical structure. Yet a growing conception of systematic modality produced more opportunities for composition, which facilitated more direct political speech about the modern area. Even with the growth of composition, however, the older poetic texts could not be abandoned, as both 
the ancient and the modern needed to be present to foster a proper nationalist narrative of modern Iran. The tension between the music that invoked Iran's great history and the music that invoked its present reality would ultimately frame multiple possibilities for performing in the radif-dastgah tradition as musicians made different decisions about how to best negotiate their own artistic identities as well as the larger question of Iranian identity in the modern world. 


\section{History, Agency, and the Power of Music}

The music system that came to represent modern Iran's authentic and historic Persian culture originated from a set of musical customs distinct from the twelvemaqam system. It ultimately became a method of music-making organized around the notion of a distinct music tradition for the nation of Iran, and with this changing view of music's meaning came new options for its organization and execution. In its earliest documented form, the initial seven dastgahs' poetic-procedural approach to musical performance related to broad transregional trends in contexts that appear to be nonliterate. Such was the historical reality of West and Central Asia beyond the contexts relating directly to dynastic rule, the contexts that controlled the erudite written word and the twelve-maqam system.

Modern Iran's active intervention with the particular music tradition of Mirza 'Abdullah and Hossein Qoli would ultimately change the seven dastgah of the Qajar courts into the radif-dastgah tradition of the Iranian nation. Yet the modern creation of the nation and the ongoing construction and reconstruction of its identity did not provide one answer for how music could best demonstrate Iran's Persian identity and history. There would ultimately be more than one way to perform music in the radif-dastgah tradition, depending on which aspect of its Iranian-ness was emphasized: the idiosyncratic Persian musical material of the radif, systematic modality in imitation of what had existed in the twelve-maqam system, or the poetry of Iran's medieval golden age. The delineation of these three distinct elements in the twentieth century changed the music's structural definition, while also providing flexibility in its modern interpretation. This flexibility allowed musicians to vary the music's conception and performance practice, even as different variations could reflect different ideas about the correct expression of 
Iranian culture. Their decisions about how to perform and teach the tradition were artistic and subject to individual artists' concepts of indigenous musical expression. Yet they were also fundamentally political decisions, with moral implications for the nation as a whole.

In this sense, the radif-dastgah tradition did not simply appear suddenly as a contrived phenomenon of the modern era. Modernity did not entail complete amnesia about indigenous musical praxis; rather, it required a particular reexamination of indigenous culture on specifically modern terms, and this reexamination began in the dynastic courts, which had recently been affected by significant localized political instability shortly before modernity's global structures came to be dominant political realities of the region. This contingent situation opened up the Qajar court to new possibilities for musical entertainment, both indigenous and European. Qajar entertainment ultimately provided a cultural basis for music's interpretation and reinterpretation within the modern framework of Iranian nationhood, and the seven dastgah held a special place in this renegotiation of culture. The Iranian nation's need for its own unique musical heritage of ancient import placed much emphasis on music's indigenous idiosyncrasy, yet developing narratives about the nation's history and culture would raise questions about how to resolve this idiosyncrasy with the twelve-maqam system, as this older concept of music came to define Iran's musical past.

Ultimately there would never be one agreed-upon way to approach the radifdastgah tradition to properly balance the need for cultural idiosyncrasy with historical consistency within Iranian identity. At the turn of the twenty-first century, musicians were still finding new ways of analyzing and approaching the radif-dastgah tradition that reframed the question of melodic procedures versus systematic modality in different ways. ${ }^{1}$ While in Iran in 2003 , I studied the seven dastgah with a musician whom my Iranian musicologist colleagues consistently described as a "radif player": a musician who strictly maintained the gusheh of the seven dastgah as a set canon that must be taught and executed with little room for embellishment or alteration. This practice was perfectly normal in Tehran while I was there, but was also criticized by Iranian musicologists and musicians alike. Certainly the earliest practice never intended for a strict memorization of the melodies as a repertoire overall, distinct from poetry and the dastgah performance context. Yet the radif is now a central codified repertoire that actively demonstrates the existence of Iranian identity and history. Playing it as a set musical whole is a way for musicians to perform Iranian identity in the twenty-first century. From this perspective, radif-playing is no less culturally legitimate than any other approach to performing in the radif-dastgah tradition.

Since the Islamic Revolution in 1979, musicians of the radif-dastgah tradition like the tar and setar master Hossein 'Alizadeh (b. 1951) and the kemacheh master Kayhan Kalhor (b. 1963) have found significant audiences for their music both in Iran and overseas via the world music market of the West that emerged during 
the 1980s. ${ }^{2}$ Hossein 'Alizadeh's long career began before the revolution and he is strongly based in performing with the procedural model, where the gusheh of the radif serve as a starting point for a larger improvised performance framed by composition within a dastgah or avaz-dastgah. Yet over his career he has also composed and improvised using dastgah as abstract modality in many different frameworks, at times alternating between his full knowledge of radif, procedural performance, and abstract modality. Kayhan Kalhor's recording career began after the revolution while based overseas. His first album, Scattering Stars Like Dust, relied heavily on his own particular style of improvisation upon abstract modality. ${ }^{4} \mathrm{Kal}-$ hor's greater use of abstract modality has facilitated a larger amount of work on the world music market in fusion collaborations with non-Iranian performers, including Indian fusion with the Hindustani musician Shujaat Khan, a Turkish collaboration with Erdal Erzincan, and a Kurdish and German Jazz collaboration with Aynur, Salman Gambarov, and Cemîl Qoçgirî.. Being able to think of Iranian music as a set of modes with only general parameters of pitch facilitates greater collaboration with other music traditions, where Iranian musical identity can be put in conversation with other identities.

Despite concerns about losing the long-form, procedural model of performance to radif-playing and abstract modality, both 'Alizadeh and Kalhor began performing together primarily using the procedural model in the early 200os. As the core instrumentalists in the Masters of Persian Music, they performed live with the singer Mohammad Reza Shahjarian (b. 1940) and his son Homayun Shahjarian (b. 1975), who both sang and played percussion. While considered a niche format with limited audience appeal, the procedural model of performance remains compelling because it privileges the voice and the fusing of musical representation with linguistic representation, where music facilitates ancient poetry at the heart of Iran's modern cultural identity. Within this setting, increasing the use of tasnif can further create a musical frame for ancient Iranian poetry that acknowledges the realities of Iran in the modern world. Bringing together top performers in the tradition to perform using what is now considered an older, traditional form was a winning concept. The performances of The Masters of Persian Music were greeted with large audiences and much acclaim in Iran and overseas. ${ }^{6}$

While different approaches to performing the radif-dastgah tradition of Iranian music are subject to interpretation, the development of specific ideas for its systematic modality concretely rearranged aspects of the original seven dastgah. For instance, the extraction of the avaz-dastgah created more consistent modal frameworks and specifically removed large amounts of modal difference from Shur. With its newly created modal consistency, Shur became a central dastgah over and above seemingly more common dastgah in the past, such as Rast-Panjgah and Chahargah. While some musicians still attached some kind of special importance to Chahargah later in the twentieth century, any possible larger role of Rast-Panjgah in the initial seven dastgah would be rendered irrelevant 
once consistent shared pitch structure became a defining feature of the system. ${ }^{7}$ While it seemed as if certain gusheh were evolving toward becoming their own avaz-dastgah in the late twentieth century, these gusheh were reflecting an older manifestation of the tradition, where more modal variation could be part of the normal framework of performance. These gusheh behaved in relation to the tradition's past rather than an ever-evolving future, yet were reinterpreted to represent "modulation" in order to give them a rational place in the conception of dastgah as primarily rational modes.

In this sense, which modal frameworks musicians ultimately chose for composition determined which parts of the dastgah were separated into avaz-dastgah. The avaz-dastgah of Shur and Homayun took on musical lives of their own, with strong modal identities that were as applicable in composition as the modal frameworks musicians identified for the dastgah from which they were extracted. For instance, in the old tasnif recalled by Davami, there were twenty for Bayat-i Isfahan, but only nineteen for Homayun, the dastgah from which Bayat-i Isfahan was extracted. As a modal framework for composition, Bayat-i Isfahan had become equal to Homayun in importance. Being one of the original seven dastgah did not guarantee consistent dominance in performance once systematic modality became a key conceptual framework in the tradition. The avaz-dastgah became as popular as many of the dastgah for use in performance, and even more popular than the least modally consistent dastgah of Nava and Rast-Panjgah.

The avaz-dastgah could not be considered truly independent, however, without their own fully formed procedures to deliver the ancient poetry. Once listed as single specific melodic sections within the dastgah, the avaz-dastgah developed with their own unique short series of gusheh, with their distinct daramad apparently added later. Just as each dastgah's performance was designed to accommodate multiple couplets of ghazal, the avaz-dastgah encompassed similar if shorter poetic formats. The development of the avaz-dastgah demonstrated that, while the tendency to compose in specific smaller aspects of dastgah played a key role in what parts of dastgah would become avaz-dastgah, each smaller aspect of a dastgah also needed to be able to facilitate the sequencing of ancient poetry in the same format of the dastgah. Even with the increase of composition and the application of new poetry in the tasnif, the ancient poetry never stopped being a factor in the tradition even with significant change. Poetry itself acted as its own, third consideration, next to systematic modality and the radif that musicians could manipulate to define the music's structure in light of Iranian identity.

While having these three distinct categories of analysis to manipulate has allowed for the music to change in a variety of ways. changes in systematic modality, the radif, and poetry also can influence and inhibit one another in interesting ways. New gusheh in the radif could be added and classified based on systematic modal application. While new gusheh could facilitate poetry, they often did not. Instrumental radifs grew in size and proliferated as the twentieth century pro- 
gressed, adding more and more melodies of vague origin, yet tied concretely to the actual modern borders of Iran. While Forsat spoke of the melodies of the dastgah being historically Persian and ancient in some general sense, the idea that different regions of the actual modern nation of Iran were or should be represented in the radif fed into the development and documentation of different instrumental radifs in the twentieth century. With instrumental versions coming to contain more melodies than vocal versions, the distinction of systematic modality facilitated the inclusion of new gusheh melodies independent of poetry and an ability to imagine how music could represent the entirety of Iranian culture as a single musical whole. Within this concept of the tradition, the original place of poetry in the music's organization could be marginalized by the more abstract representation of identity that music could provide.

But systematic modality also facilitated more composition, including more instrumental pieces and the tasnif, which opened up avenues of modern literary expression in the tradition. Tasnifs were open to use language the citizenry could understand, and addressing the citizenry of Iran became a standard aspect of tasnif poetry. Thus composition could also marginalize the notion of radif. Distinguishing abstract modes from distinct melody, and a category of composition that specifically contrasted with the concept of improvisation, could also deem the radif irrelevant. A musician could simply take a scale and improvise upon it or use it to compose, without reference to the melodies of the radif. Musicians did not have to learn all the melodies of the radif, if they could just create new melodic material using modes.

By distinguishing between these three categories of the music's structure and performance, musicians created three ways to change the tradition. Each category of change could validate Iranian identity in different ways. But in distinguishing these structures in relation to modern Iranian identity, musicians had choices to make about how to approach the system. If musicians wanted a system of fully systematized modality, they would lose the ancient Iranian melodies and the ancient Iranian poetry. If musicians wanted to focus on radif, they could not apply systematic modality as they pleased, and they needed to abide by the procedures of the melodies themselves. If ancient poetry was central to performance, the number of melodic possibilities could decrease.

With so many different factors validating the Iranian nature of the music, it would not ultimately become a fully rationalized system of systematic modality. Some dastgah kept sections that lacked modal consistency. Not all modal possibilities became distinct models for composition and performance. While Karimi's later version of the vocal radif was larger than Davami's, it did not deviate from the basic organizing principles of the original tradition: the same genres of poetry still mattered. Yet the notion of radif increased the importance of melodic procedure, with or without reference to poetry. It came to embody its own grant design of melodic organization. 
In all these ways, the radif-dastgah tradition has been engaged in a modern negotiation of Iran's national identity and this negotiation has framed multiple approaches to performance in its relatively short history. Actions taken regarding the radif-dastgah system's structure and application in practice have had a unique role in shaping the nation of Iran. While many tasnif addressed the state of the Iranian nation very early on, the music itself also addressed the Iranian nation and spoke on its behalf. The radif-dastgah tradition had to specifically speak to the Iranian people, their history, and their culture on a variety of levels both implicit and explicit. The radif-dastgah tradition told Iranian audiences and the world about Iranian identity, both affirming this identity and educating audiences on the nature of the identity. It is not merely a practice of custom. It is a performance of the nation, which made and continues to make Iran a real place. In a modern world with so many mapping possibilities for nation-states, the radif-dastgah tradition validates one particular nation and provides evidence of its legitimacy in the modern world.

\section{THE TWELVE-MAQAM SYSTEM IN HISTORICAL PERSPECTIVE}

The world of the radif-dastgah tradition ultimately emphasizes the subjectivity of music in relation to Iranian identity, yet the twelve-maqam system represents a way of thinking about music grounded in notions that music is distinct from any one human context, while objectively relating to the laws of the natural world and humanity as a whole. While musicians of the radif-dastgah system pursued answers to questions about what the true Iranian music was or should be, the concept of music that made the twelve-maqam system relevant asked questions about the natural order of the universe, and the most perfect organization of music that could be aligned with this natural order.

The twelve-maqam system existed within certain geographies and temporal spaces, yet its definition was built on a concept of proper existence that was universal and timeless. But anyone familiar with the twelve-maqam system was capable of understanding when another method of music-making was different. The universality of the twelve-maqam system defined it as relevant to polyglot populations and writings about the twelve-maqam system acknowledge that there are many different kinds of people in the world. Yet there was no notion that there was a world of nations or races that produced distinct music traditions according to their distinct identities. Regional variation grounded in changing subjective preferences was not a desirable basis for music-making and thus the same musical and cosmological concepts often underpinned musical difference. Even when music was different from the twelve-maqam system, somehow it was the same.

Historically, the subjectivity taken for granted in the radif-dastgah tradition was a problematic weakness that needed to be managed vis-à-vis musical expres- 
sion. The problem of musical morality in the world of the twelve-maqam system was the extent to which music's inherent power could help or harm humanity in light of their imperfect, subjective perceptions. Divinity and evil existed in a state of cosmic objectivity for which the twelve-maqam system attempted to account. Yet the totality of cosmic existence was beyond the capacity of human subjective perception. In this framework, humanity judging the world using its own, imperfect subjectivity was an imperfect and dangerous proposition. With proper demonstrable ties to the cosmos, music could help a person overcome limited subjectivity to find contact with the divine. Yet the weakness of human subjectivity could also pervert a person's ability to engage properly with any source of power that influenced humanity via the ears.

While writings about the radif-dastgah tradition indicate the modern political reality taking shape in the nineteenth and early twentieth centuries, sources on the twelve-maqam system connect it to a separate political order. For as much as the radif-dastgah tradition had to relate to a unique conception of Iranian culture and history, the twelve-maqam system provided a model of musical structure that related to the cosmopolitanism of empire at its dynastic centers of power. The dynastic courts of its patronage related to the contingencies of how empires rose and fell in Western Asia between the thirteenth and nineteenth centuries. The extent to which any given dynasty maintained continuity - and the extent to which new empires took on the trappings and resources of the empires they defeateddetermined the geographical distribution of the twelve-maqam system over time. As musicians moved from one court to another, the twelve-maqam system moved with them. In the same way that music did not maintain a specific relationship with any one ethnolinguistic culture, it also did not maintain a fixed geographic location or operate according to regional or linguistic exclusion.

The dynastic realm as a model of governance was not static, and though new dynastic realms were typically built out of the institutions of older realms, they also embodied distinctions of rule over time. The Islamic Empires that grew out of Turkic and Mongol rule in West, Central, and South Asia introduced the most dramatic changes to the dynastic model of governance beginning in the sixteenth century. The Safavid Empire's particular approach to rule at this time had unique implications for music. The importance of the ruling dynast initially intensified in Safavid music culture within their centers of power, and the need to directly perform Safavid dynastic power changed the priorities of music-making. As the Safavids developed a highly performative approach to demonstrating their power, music gained standing as an explicit actor in the portrayal of Safavid power. Their fall in the eighteenth century effectively weakened the relevancy of the twelvemaqam system, as its dynastic context fell into a period of disarray that was unprecedented in this music system's period of dominance. These contingencies of Safavid rule resulted in a strong break in court music between the Safavids and the Qajars. 
The structural differences between concepts inherent in the twelve-maqam system and those underlying even the earliest versions of the seven dastgah reflect an initial distinction between music traditions that had long held strong connections to dynastic life and those that did not. The twelve-maqam system's context was unusually literate, as dynastic aristocracies maintained higher levels of literacy than their largely nonliterate subjects. Just being able to read and write about music was an exceptional phenomenon. For whatever regional musical features the twelve-maqam system embodied, its emphasis on a high degree of codified structure reflected its literate dynastic context. It likely was not the most common approach to music-making for most Persian-speakers historically, or Arabicspeakers, or Turkic-speakers. It was the music of the dynastic ruling class, and dynastic rulers existed above and beyond the realities of their subjects, within a plane of knowledge and power intentionally restricted and kept apart from dynastic subjects. In this sense, it's possible that procedural models of practice are much older than what written documentation suggests. They represent an indigenous approach to music-making that could be more broadly accessible than the twelvemaqam system and highly functional in strictly oral contexts.

Regardless, the goal of any dynastic realm was universal domination of territory and resources. On this basis, the twelve-maqam system's representation of a universally applicable music system matched the political realities of the porous, ever-changing borders of empire. It represented a specific musical reality of an equally specific cultural order, a cultural order that required universal applicability, even as music remained a much more localized activity in most of the world. Music for dynastic rule had to accommodate the political goal of conquering as much land and as many resources as possible. With divinely endowed power and military might validating rule over any number of places and subjects, the music of the political aristocracy had to relate to both structural realities of the cosmos and any given dynast's push for universal dominance.

\section{PERSIAN MUSIC IN HISTORICAL PERSPECTIVE}

Writings about the twelve-maqam system model a high degree of ideal structural consistency over time, as do the concomitant writings about sama ${ }^{\circ}$. There are several basic categories of information any text may address, and very little information is included outside of these categories. They could be built out from a certain core model of presentation, but even the addition of topics followed a certain logic and had set limitations. In this way, the topics covered and how they were discussed demonstrate a great degree of consistency within their variety over several centuries. The universalism at the center of how music was conceived was equally central to how music's content and meaning were analyzed.

From the very beginning, writings about the radif-dastgah tradition followed no particular model and demonstrated more variety of content and structure 
over a much shorter period of time. They used a variety of structures and presented a variety of goals and interests. All of this variety was further grounded in modern concerns. These concerns included reporting on the common practice of specific musicians, dictating modern scientific knowledge, reinterpreting musical norms, reorganizing and moralizing historiographic narrative, and developing pedagogical processes in relation to national history.

Reading these texts seeking to understand music culture provides a very different view of history than reading them to understand a more narrowly defined truth of musical practice. In pursuing the truth of what musicians "were really doing" with the twelve-maqam system, culture often takes on a marginalized role in understanding the music. Texts have to be parsed to find the information modern scholars want concerning how people made music in the past, even as this leaves most statements about music unaccounted for. Statements deemed unuseful for understanding musical practice in real time are the missing information that reveals what made broader categories of music's conception and practice possible. They relate to the essence of the music culture itself and demonstrate the connection between music and the broader context in which it operates.

These broader contextual questions define the possibilities of musical practice in larger temporal spaces, where music is unlikely to be practiced in a single way. In the same way Iranian music could be structured in various ways to address the modern Iranian context, the twelve-maqam system did not have to have one specific version or fully realized idealization that was universally correct for the duration of its dominance. Broader context provides a framework for understanding a music's cultural epistemology, and the parameters of musical possibility any particular epistemology can facilitate.

Many of the specific details of musical practice throughout history are simply unknowable. But the temporal-cultural order is often knowable and can provide a framework for understanding the limits of music's conception and practice. Rather than assuming that there is a single Persian music, and imposing a specific a priori cultural category on music historiography, music itself can provide a window into what culture was historically, and provide a more specific definition to the relationship between music and culture that is demonstrable on specific terms. Most significantly, it can account for change and demonstrate music's active role in cultural production at different points in time.

From this perspective, the study of music history as an analysis of the cultural construction of events presents a useful framework for music history in the Middle East. In this methodology of historiography, music stands as something much more than a perennial marker of ethnolinguistic identity, delimited further by a fixed political or religious order. People can use music to both maintain and change the cultural order in active responses to specific historical realities. In this context, neither music nor people are static entities. Though either or both could exist in a relative state of stability within any given space, both have a perennial 
ability to change. The focus of music history within this framework becomes the active ways music interacts with the stability and instability of human life. Music is both an active subject of cultural adaptation and stability, as well as a contributor to adaptation and stability. This analysis reveals a more detailed conception of music's relationship with identity over time, even as it acknowledges the place of agency and the broader phenomena of contingency in relation to specific factors that can foster cultural stability and cultural change.

In considering the ways humanity can use music to actively create its context, Persian-speaking people become active participants in the cultural order, rather than passive recipients of an unchanging, preestablished cultural reality. Their adoption and application of different conceptions of music and musical practices occurred at the intersection of established cultural order, historical events, and the need to adapt to new social, economic, and political realities over time. When faced with the need for change, peoples of the Middle East did not simply stay the same, nor did they adopt new cultures wholesale. An indigenous cultural order provided materials and strategies for confronting change, and thus indigenous cultural practices like music became a first source of adaptation. Cultural orders of the region underwent multiple historical transformations before the rise of modernity, and each time indigenous cultural practices were a site to negotiate between established norms and new circumstances of existence.

It was within this type of process that modern peoples of the Middle East adopted many new musical ideas and practices, while also turning to indigenous ideas and practices to begin constructing indigenous forms of musical modernity vis-à-vis the West. Any number of contingencies could intervene, yet people still needed indigenous music aesthetics and had enough agency to interpret them in such a way as to support modern norms of existence.

Though modernity's global economic system brought extreme amounts of global power to the Western world, it also brought the presumption of cultural difference. Modernity fostered notions of race and nation that necessitated musical difference as part of the modern global order. Even as many Western norms of culture were adopted in different parts of the world, the need to preserve indigenous musical identity also stood as a part of modernization. Nationalist narrative put the golden age of the Iranian nation somewhere in the ancient past, but so did Orientalists from Europe. In this sense, Europe did not always come to destroy indigenous culture in favor of modern institutions and affect, nor did indigenous people adopt European perspectives on their history with no reference to indigenous experience. For all of their European education, neither Mehdi Qoli Hedayat nor 'Ali Naqi Vaziri advocated for mere abandonment of indigenous practice in favor of European music, or absolute maintenance of Iranian music in its imagined premodern state. Neither did they think about Orientalist perspectives and ideas exactly as Orientalists had presented them. Instead, European ideas fed into indigenous frameworks of mod- 
ern understanding, even as indigenous music changed in ways unique to the modern Iranian experience.

The influence of European music on the radif-dastgah tradition has been the focus of some scholarly speculation, and scholars have often tied the question of how modern the tradition is to the question of how much Western musical influence it adopted. For the disciplines of both ethnomusicology and Iranian musicology, musical modernity is often diagnosed using the introduction to Western music aesthetics within modern colonial settings. Yet core structures of the radifdastgah tradition were not conceived of in Western musical terms per se, nor were changes to its structures an introduction of mere imitations of ideas from Western music. They were specific imaginings of what Iranian music was and what it should be in relation to changing understandings of Iran's national history in a world of distinct national histories. Musicians were not always attempting to imitate Western music: they were also seeking to establish their own unique music in keeping with modern parameters of identity. In this sense the radif-dastgah tradition is as modern as any music produced over the past two hundred years in the West. It depends on modern concepts of identity and history and is defined by the project of modernity even in its most traditional forms of practice.

The anthropologist Marshal Sahlins was critical of the idea that capitalism and Western imperialism presented an existential threat to the existence of indigenous cultures. For all the West's power, Sahlins asserted, indigenous people outside of the West were still people with cultures and agency to act within and adapt to modern situations in culturally unique ways. He positioned modernization as a historical event that multiplied forms of cultural existence. He pondered this idea in the context of considering how many of the practices of indigenous peoples that anthropologists had originally considered ancient were in fact quite modern. In defining traditions as "culturally specific modes of change," he positioned tradition as something that had an explicit role in adapting to any historical event, and a specific role in indigenizing modernity. ${ }^{8}$

The notion of tradition as a location for culturally specific modes of change in the modern world is especially relevant to Iran, where the government has conspicuously couched its modern national identity using multiple conceptions of tradition: ancient Persian kingship for much of the twentieth century, and Shi a Islamic jurisprudence from the end of the twentieth century until today. Within the national awakening and creation of modern Iran, newly realized Iranians looked to the cultural practices in their midst to address the challenges presented by modernity, and to answer questions about their place in the modern world. Music became a focus of culturally moded change that could foster various degrees and types of indigenization within the context of modernity. Doing this helped create Iranian identity as a national cultural phenomenon.

In this more detailed context of tradition's relationship with culture and agency, the radif-dastgah tradition developed as a way of making music that spoke specifi- 
cally to the modern era in both conception and intent. The radif-dastgah did not evolve out of the twelve-maqam system, nor is such a model of ongoing evolutionary development viable or useful. Conversely, the radif-dastgah tradition is not a secondary system to the twelve-maqam system, or a lesser-developed system growing out of Iran's cultural decline because Iranians lost track of the twelvemaqam system in their music history. The radif-dastgah tradition is a method of music-making that lives within the indigenous negotiation of modernity.

The twelve-maqam system's dependence on universality could stand as a model of how things used to be done and musical proof of Iranian cultural history, but it lacked the structural idiosyncrasies needed to define it as uniquely Iranian. Within this modern push for national Iranian identity, the radif-dastgah offered options for musical interpretation that the twelve maqam could not offer, and these options proved significant in developing an indigenous music tradition for modern Iran. Within its own context, the radif-dastgah tradition became a more appropriate method of music-making than anything someone like Safi al-Din or Maraghi could have conceived. No amount of premodern musical training, intellectual study, or even pure genius could create a music system as appropriate to the modern Iranian experience as the radif-dastgah tradition.

The differences between the twelve-maqam system in its various guises and the radif-dastgah tradition in all its variations ultimately come to reflect different contexts of human existence that occupy distinct cultural spaces, as people interact with music in relation to different realities that exist at different points in time. From this perspective, scholars can discuss broadly shared trends in the musical practices of the Middle East throughout history, and many specific differences between the musics of regional and ethnolinguistic groups in modern practice. But narrating evolutionary models of music history where one music tradition gradually morphs into another over time in a single line of ethnolinguistic cultural development obfuscates the cultural differences that different methods of music-making can relate to at different points in time. In understanding that music is indeed part of and subject to culture, its relationship with specific conditions of existence cannot be ignored in any given time and place, nor can one understand music's meaning at any point in history without understanding the terms of human agency and the contingencies of history. 


\section{NOTES}

\section{CHAPTER 1. ANCIENT MUSIC, MODERN MYTH}

1. During, Mirabdolbaghi, and Safvat 1991, 33; Nettl 1987, 1992, 3; Tsuge 1974, 29.

2. During 1988, 181-191; 1991, 63.

3. Nettl 1992, 15-18.

4. During, Mirabdolbaghi, and Safvat 1991, 39-41; L. C. Miller 1999; Nooshin 2009, 32; Zonis 1973, 17-40.

5. Asadi 2001a, 2001b; Fallahzadeh, Karami, and Amin 2009; Fatemi 2001; Maysami 2002; Mohammadi 2001.

6. Seeger 1971.

7. Hedayat 1938; Vaziri 1923.

8. Farmer 1942a, 1942b.

9. Racy 2015.

10. Farmer 1977, 2783.

11. Farmer 1977, 2804.

12. Bohlman 1986, 166, 172-173.

13. Kiesewetter 1842, 13.

14. Wright 1992b, 6.

15. Blum 2015b; Powers 1989.

16. Powers 2000.

17. Shannon 2015.

18. Schofield 2010; Wade 1998.

19. Clifford and Marcus 1986; Jameson 1991; Marcus and Myers 1995; Sahlins 1995.

20. Marashi 2003; Tavakoli-Targhi 1990, 2001.

21. Beeman 1976.

22. Mashun 2001; Farhat 1965. 
23. Youssefzadeh 2000.

24. Black and Deghan 2010.

25. Seeger 1993, 23.

26. Blum 1969, 1974, 2006; Massoudieh 1988.

27. Qazvini 2002, 343.

28. UNESCO 2009.

29. Massoudieh 1996.

30. Shiloah 1995, 45-67.

31. Foucault 1970, 1972.

32. Lucas 2014.

33. Sahlins 2000, 353, 361-362.

34. Sahlins 2000, 476.

CHAPTER 2. MUSICAL EMPIRES

1. Nishaburi 1995, 39.

2. Farmer 1965.

3. Urmawi 2001, 103-109, 144-170.

4. Wright 1978, 81-91.

5. Nishaburi 1995.

6. Urmawi 2001, 147-170.

7. Maraghi 1987, 216-218.

8. Gorji 2005, 86-87.

9. Wright 1995a, 1995b; Neubauer 1997.

10. Maraghi 1987, 251.

11. Maraghi 1987, 250.

12. Gorji 2005.

13. Pourjavady 2003.

14. Feldman 1996.

15. Binesh and Dariush 1989, v-xii.

16. Huart and Massé 2012.

17. Feldman 1996, 177.

18. Massoudieh 1996, 3 .

19. Feldman 1996, 65-67.

20. Massoudieh 1996, 216, 280-283.

21. Muzaffar 1763.

22. Pourjavady 2006.

1. Shiloah 1995.

2. Alsted 1650.

3. Qutb al-Din 1991, 94.

4. Amuli 2001, 131-316. 
5. Kashani 1992, 94.

6. Urmawi 2001, 84, 185.

7. Kaykavus ibn Iskandar ibn Qabus 1967, 194.

8. Razi 1993, 103.

9. Ghaznavi 2003, 131-132.

10. Anon. Or. 8116, 6 b.

11. ibn Voshmgir 1967, 88.

12. al-Herawi 1666, 53a.

13. Ghaznavi 2003,62 .

14. Anon. c. $1658,17 \mathrm{~b}$.

15. Anon. c. 1410b, 64b; c. 1410c, 63a.

16. Maraghi 1987, 205-209.

17. ibn Fakhr al-Din Muhammad 1975; Muzaffar 1763; Qays 1899; Taba-Taba 1882.

18. Pourjavady 2005, 21-22.

19. ibn Munajjim 1273, 154a-156a.

20. For instance, Anon. 1996; Nishaburi 1995.

21. For instance, Anon. 2003b; Anon. 2005; Ghaznavi 2003; Ludi 1680; Tabrizi 1804.

22. For instance, Mosannef 2005; al-Na ri 1973.

23. For instance, Gorgani c. 1700; Sofrachi 1582; Zahiri c. 1600.

24. Me'mar 1989.

25. Kawkabi 2003, 45-49.

26. Zayla 1048.

27. Anon. 2003d, 185-186.

28. Ghaznavi 2003; Gilani 1577; al-Herawi 1666; Sofrachi 1582.

29. Sofrachi 1971, 191.

30. Zahiri c. 1600, 3 a.

31. Nishaburi 1995, 63 .

32. Maraghi 1987, 1966.

33. Maraghi 1987, 1:204, 222.

34. Maraghi 1987, 207, 210, 227-230.

35. Amuli 2001; Kawkabi 2003.

36. Maraghi 1987, 241-243.

37. Mosannef 2005, 195.

38. Qazvini 2003, 90.

39. ibn Sina and 'Ubaydallah 1992, 3-29; Jami 1492, 572a-581a; Kashani 1992, 56-128;

Kawkabi 2003, 5-103.

40. Jami 1492; Khayyam 1967.

41. Ahmed 2016, 10-18.

\section{CHAPTER 4. MUSIC AND MORALITY: LISTENING TO DANGERS INHERENT IN THE COSMOS}

1. Farmer 1929; 1939a, 2784-2795; 1965; Mashun 2001, 78-81; Zonis 1966, 180.

2. Newman 1999.

3. Anon. c. 1500; Isfahani 1646. 
4. Hujviri 1957, 508-510.

5. Ghazzali 198ob, 881-882.

6. Ghazzali 1975, 436-439.

7. Bakharzi 1966, 181.

8. Qushayri 1982, 595.

9. Bakharzi 1966; Ghazzali 1975, 198ob; Ludi 168o; Suhrawardi 1985.

10. Bakharzi 1966, 186-187.

11. Bakharzi 1966; Ghazzali 198ob; Qushayri 1982; Suhrawardi 1985.

12. Bakharzi 1966; Hujviri 1957.

13. Suhrawardi 1985.

14. Bakharzi 1966, 198.

15. Hujviri 1957, 536.

16. Ghazzali 1975, 441.

17. Qushayri 1982, 593.

18. Ghazzali 198ob, 798 .

19. Ghazzali 198ob, 831; Razavi 1619, 4b.

20. Anon. c. 1500, 539.

21. Ghazzali 1975, 440.

22. Razavi 1619, 4a and 8 b.

23. ibn Abi al-Dunya 1938, 42-43.

24. Kubra 1984, 37; Suhrawardi 1985, 91.

25. ibn Mutahhar 1964, 88.

26. Hujviri 1957, 523.

27. Hujviri 1957, 521.

28. Bakharzi 1966, 195.

29. Qushayri 1982, 612-614.

30. Qushayri 1982, 516.

31. Qushayri 1982, 610.

32. Kashani 1946; Qushayri 1982.

33. Suhrawardi 1985, 94.

34. Kashani 1946; Qushayri 1982.

35. Kashani 1946, 191.

36. Hujviri 1957, 528, 530; see also Bakharzi 1966, 198; Razavi 1619, $11 a$.

37. Bakharzi 1966, 199.

38. Bakharzi 1966, 186.

39. Mustamli Bukhari 1912, 91.

40. Bakharzi 1966, 202.

41. Ghazzali 198ob; Ludi 168o; ibn Mutahhar 1964; Qushayri 1982.

42. Qushayri 1982, 597.

43. Kashani 1946, 89.

44. Anon. c. $1600 a, 4 b$.

45. Ghazzali 1975, 451-453.

46. Ghazzali 1975; Kashani 1946; Qushayri 1982.

47. Ghazzali 1975, 442.

48. Ghazzali 1975; Kashani 1946; Qushayri 1982. 
49. Bakharzi 1966; Ghazzali 198ob.

50. Bakharzi 1966, 198.

51. Bakharzi 1966, 100-101.

52. Qushayri 1982, 192.

53. Bakharzi 1966, 91, 181.

54. ibn Mutahhar 1964, 88.

55. Bakharzi 1966; Suhrawardi 1985; Qushayri 1982.

56. Bakharzi 1966, 233.

57. Kashani 1946, 187.

58. Qushayri 1982, 600.

59. Qushayri 1982, 594.

6o. Ghazzali 1980a, 826-827.

61. Bakharzi 1966, 208.

CHAPTER 5. THE POLITICS OF SONG: MUSIC FOR KINGS, MUSIC FOR EMPIRE, C. 1400-1722

1. Newman 1999.

2. Babayan 2002, 163-165.

3. Pourjavady 2005, 13-16.

4. Maraghi 1987, 20.

5. Maraghi 1987, 25.

6. Maraghi 1987, 197.

7. Maraghi 1987, 33.

8. Maraghi 1987, 28.

9. Maraghi $1987,66$.

10. Maraghi 1987, 99.

11. Maraghi 1987, 116.

12. Anon. 1410a, 66b.

13. Maraghi 1987, 92.

14. Anon. 1410a, 65b.

15. Maraghi 1987, 124.

16. Maraghi 1987, 156-157.

17. Anon. 1410a, 65a.

18. Maraghi $1987,147$.

19. Gorji 2005, 317.

20. Mosannef 2005, 241.

21. Gorji 2005, 276.

22. Mosannef 2005, 205.

23. Gorji 2005, 308 .

24. Mosannef 2005, 207.

25. Mosannef 2005, 202.

26. Mosannef 2005, 275.

27. Mosannef 2005, 251.

28. Mosannef 2005, 250. 
29. Mosannef 2005, 298.

30. Babayan 2002, 230.

31. Foran 1992.

CHAPTER 6. MUSICAL STRUCTURE, MUSICAL NATION, C. 1800-1950

1. Mohammadi 2004, 73-80.

2. Mohammadi 2004.

3. Borumand and During 1991; L. C. Miller 1999.

4. Nettl 1992, 26-27.

5. For instance, Farhat 1965; Nettl 1992; Sadeghi 1971; Zonis 1973.

6. Nettl 1992, 23-24.

7. Tsuge 1970 .

8. Nettl 1992, 13, 18-24.

9. Ma 'rufi and Mehdi 1963; Davami and Sasan 2006; Shahnazi and Asadi 2003; Tala'i 2000; Vohdani 1997.

10. Safvate and Caton 1966, 219-220.

11. Nooshin 2009.

12. Hajarian 1999.

13. Blum 2015b.

14. Hodgson 1993.

15. Keddie 1981, 100.

16. Khaleqi 1954, 215, 293, 332.

17. Hedayat 1938, 1, 10; Shirazi 1988, 19.

18. Hedayat 1950, 3 .

19. Khoshzamir 1979, 39-44; Lemaire 2003; Mohammadi 2015, 90-93, 288-291, 381-383.

20. Khaleqi, 1954: 88.

21. Khaleqi 1954 303-305.

22. Caton 1984.

23. Khaleqi 1954, 259.

24. Khoshzamir 1979, 55.

25. Kinnear 2000.

26. Khaleqi 1954, 61-62; Khoshzamir 1979.

\section{CHAPTER 7. THE NATION'S MUSIC: DISCOVERING AND RECOVERING THE DASTGAH}

1. Shirazi 1914, 26.

2. Mohammadi 2004, 76-80.

3. Hedayat 1950, 2, 37.

4. Hedayat 1950, 32, 37.

5. Khoshzamir 1979, 51-56.

6. Shirazi 1914, 30-31.

7. Shirazi 1914, 31-33.

8. Shirazi 1914, 34-35. 
9. Shirazi 1914, 29.

10. Shirazi 1914, 28.

11. Shirazi 1914, 28-29.

12. Shirazi 1914, 38-39.

13. Shirazi 1914, 263, 294.

14. Hedayat 1938, 1:10.

15. Hedayat 1938, 1:28, 49; Helmholtz 1895, 40.

16. Hedayat 1938, 1:85-86; Helmholtz 1895, 43, 85 .

17. Hedayat 1938, 1:91-96, 88-102.

18. Hedayat 1938, 1:4.

19. Hedayat 1938, 1:134-135.

20. Hedayat 1938, 1:133, 1:185, 3:4-5.

21. Hedayat 1938, 2:78.

22. Hedayat 1938, 2:79.

23. Hedayat 1938, 3:21.

24. Hedayat 1938, 1:3.

25. Hedayat 1938, 3:81.

26. Hedayat 1938, 3:5-6.

27. Hedayat 1938, 3:83, 121-122.

28. Hedayat 1938, 3:83.

29. Hedayat 1938, 3:31-34.

30. Hedayat 1938, Dastur, 3.

31. Hedayat 1938, Dastur 18.

32. Hedayat 1938, Epilogue 1.

33. Vaziri 1998d, 28-29.

34. Vaziri 1998g, 248.

35. Vaziri 1998g, 1937, 249.

36. Vaziri 1998m, 291.

37. Vaziri 1934a, 184.

38. Vaziri 1934b.

39. Vaziri 1934b, 20-22.

40. Vaziri 1934b, 35.

41. Vaziri 1934b, 20.

42. Mohammadi 2017, 233-309.

CHAPTER 8. MUSIC AND MORALITY: THE RECOVERY OF A NATION,

C. $1880-1940$

1. Khoshzamir $1979,5-6$.

2. Matini and Caton 2011.

3. Khoshzamir 1979, 60-63.

4. Vaziri 1998j, 297; 1998k, 274.

5. Vaziri 1998d, 30.

6. Vaziri 1998g, 248.

7. Vaziri 1998g, 249. 
8. Vaziri 1998a, 73.

9. Vaziri 1998g, 254.

10. Vaziri 1998c, 412-413; 1998d, 38; 1998a, 78.

11. Vaziri 1998a, 73-74.

12. Vaziri 1998a, 74-75.

13. Vaziri 1998d, 32.

14. Vaziri 1998m, 291.

15. Vaziri 1998a, 89.

16. Vaziri 1998i, 44.

17. Vaziri 1998h, 145.

18. Vaziri 1998g, 252.

19. Vaziri 1998a, 75.

20. Vaziri 1998a, 69.

21. Vaziri 1998a, 76.

22. Vaziri 1998e, 137.

23. Vaziri 1925, 8.

24. Vaziri 1998f, 162-163.

25. Vaziri 1998e, 138.

26. Vaziri 1998f, 155; 1998b, 18o-181.

27. Vaziri 1998b, 186.

28. Vaziri 1998b, 186.

29. Vaziri 1998g, 255.

30. Qazvini 2002, 295.

31. Qazvini 2002, 301.

32. Vaziri 1998d, 29.

33. Vaziri 1998k, 274-275.

34. Qazvini 2002, 301-302.

35. Qazvini 2002, 301.

36. Qazvini 2002, 302.

37. Qazvini 2002, 299.

38. Qazvini 2002, 301.

39. Qazvini 2002, 301.

40. Qazvini 2002, 302-303.

41. Qazvini 2002, 302.

42. Khaleqi 1954, 327.

CHAPTER 9. SINGING THE NATION: WORDS OF THE PEOPLE, MUSIC FOR IRAN

1. Hajarian 1999.

2. Maraghi 1987, 242.

3. Pourjavady 2003, 11-31.

4. Nettl 1992, 22-24.

5. Shirazi 1988, 305.

6. Nettl 1992, 41-42. 
7. Nettl 1992, 44-48.

8. Davami and Payvor 2011, 61-62, 146.

9. Miller 2012, loc 550, 4762, 5762.

10. Davami and Sepanta 2006, 141-142.

11. Davami and Payvor 2011, 165.

12. Hedayat 1950, 2-5; Khaleqi 1954, 106-107.

13. Ansari 2005.

14. Davami and Payvor 2011, 175.

15. Khaleqi 1954, 66-67.

16. Davami and Payvor 2011, 186.

17. Khaleqi 1954, 82-9o.

18. Davami and Payvor 2011, 348.

19. Davami and Payvor 2011, 181.

20. Qazvini 2002, 291-293.

21. Qazvini 2002, 295.

22. Qazvini 2002, 316.

23. Qazvini 2002, 317.

24. Qazvini 2002, 343.

25. Qazvini 2002, 309.

26. Qazvini 2002, 313-314.

27. Qazvini 2002, 314.

28. Qazvini 2002, 349-350.

29. Nettl 1992, 24, 27, 86.

CHAPTER 10. HISTORY, AGENCY, AND THE POWER OF MUSIC

1. Tala'i 2000.

2. Taylor 1997.

3. For instance, Alizadeh 1993, 1994, and 2007.

4. Kalhor 1998.

5. Kalhor, Khan, and Chaudhuri 1997; Kalhor, Dogan, Gambarov, and Qoçgirî 2016; Kalhor and Erzincan 2013.

6. For instance, Shajarian et al. 2002, 2003.

7. Nettl 1992, 34 .

8. Sahlins 2000, 476, 95 . 


\section{I S C O G R A P H Y}

Alizadeh, Hossein 1993. Torkaman. Los Angeles: Kereshmeh Records.

- 1994. Neynava: Song of Compassion. Los Angeles: Kereshmeh Records.

2007. Sallaneh. Tehran: Mahoor Institute of Culture and Art.

Ansari, Khosro. 2005. Six Songs from the Qajar Period. Tehran: Mahoor Institute of Culture and Art.

Davami, 'Abdullah, and Sepanta Sasan. 2006. Radīf-i avāzì-i va tașnīf-hā-i qadìmì beh ravāyat va ejrā-i ostād 'Abdollāh Davāmī. M.CD-111. Tehran: Mahoor Institute of Culture and Art.

Jewish Music Research Centre. 2006. Music of the Mountain Jews, Anthology of Music Traditions in Israel, Vol. 10. Jerusalem: Hebrew University Jerusalem.

Kalhor, Kayhan 1998. Scattering Stars Like Dust. New York: Traditional Crossroads.

Kalhor, Kayhan, Aynur Dogan, Salman Gambarov, and Cemîl Qoçgirî. 2016. Hawniyaz. Harmonia Mundi S. A: Osnabrück.

Kalhor, Kayhan, and Erdal Erzincan. 2013. Kula Kulluk Yakisir Mi. Universal Music.

Kalhor, Kayhan, Shujaat Khan, and Swapan Chaudhuri. 1997. Ghazal: Persian \& Indian Improvisations. Newton, NJ: Shanachie.

Shajarian, Mohammad Reza, Hossein Alizadeh, Kayhan Kalhor, and Homayoun Shajarian. 2002. Without You: Masters of Persian Music. Osnabrück: World Village.

- 2003. Faryad: Masers of Persian Music. Osnabrück: World Village. 


\section{REFERENCE LIST}

Abbadi, Muzaffar ibn Ardashir. 1968. al-Tasfìyeh fī ahvāl al-mutasavvifeh: Süfìnāmah/ta'līf-i Quțb al-Dìn Abū al-Muzaffar Manșūr ibn Ardashīr al-'Abbādī; bi-tashịh-i Ghulām Husayn Yūsufī. Tehran: Intisharat-i Bunyad-i Farhang-i Iran.

Abrahamian, Ervand. 1982. Iran between Two Revolutions. Princeton, NJ: Princeton University Press.

Ackerman, Phyllis. 1977. "The Character of Persian Music." In A Survey of Persian Art from Prehistoric Times to the Present, edited by Arthur Upham and Phyllis Ackerman Pope, 2805-2817. Tehran: Soroush Press.

Advielle, Victor. 1885. La musique chez les Persans en 1885. Paris: L'auteur.

Afkhami, Gholam Reza. 2009. "A Celebration and a Festival." In The Life and Times of the Shah, 404-422. Berkeley: University of California Press.

Afshar, Iraj, and al-Dowleh Zahir. 1972. Khäterāt va asnād-i Zahīr al-Dowleh. Tehran: Ketab-ha-i Jibbi.

Ahmed, Shahab. 2016. What Is Islam? The Importance of Being Islamic. Princeton, NJ: Princeston University Press.

Alai, Cyrus. 1995. "Persia or Iran? What Do the Maps Say?” Map Collector 70:12-17.

al-Azmah, 'Aziz. 1993. Islams and Modernities. London: Verso.

al-Bukhari, Qasim bin Doost Ali. 1556. Kashf al-Ūtār. British Library (London): Or. 2361, $24 \mathrm{ob}-246 \mathrm{a}$.

al-Farabi, Abu Nasr Muhammad bin Muhammad bin Tarkhan. 1976. Kitāb al-mūsīqā alkabìr. Cairo: Dar al-Katib al-Arabi lil-Tibah wa-al-Nashr.

—. 1999. Kitāb-i mūsīqī-i kabìr. Tehran: Pazhuhishgah-i 'Ulum-i Insani va Mutala at-i Farhangi.

al-Faruqi, Lois Ibsen. 1980. "The Status of Music in Muslim Nations: Evidence from the Arab World." Asian Music 12 (1): 56-85.

_. 1985. "Music, Musicians and Muslim Law." Asian Music 17 (1): 3-36. 
al Faruqi, Lois Ibsen, and Yūsuf Qaraḍāwī. 1994. Music: An Islamic Perspective. Minna, Niger State, Nigeria: Islamic Education Trust.

al-Herawi, Inayatallah bin Mir Haj. 1666. Tohfat al-advār. Bodleian Library, Oxford: Ouseley $20,50 b-53 a$.

Alizadeh, Hossein. 1993. Torkaman. Los Angeles: Kereshmeh Records.

-1994. Neynava: Song of Compassion. Los Angeles: Kereshmeh Records.

2007. Sallaneh. Tehran: Muassasah-i Mahoor Institute of Culture and Art.

al-Kindī. 1962. Mu'allafāt al-Kindī al-mūsīqìyah. Edited by Yusuf Zakariya. Baghdad.

al-Kindi, Abu Yusuf Ya qub Ishaq. n.d. Risālah fì tartīb al-naghm al-dällat 'ala tabā’̀̄. Staats-

bibliothek Preussischer Kulturbesitz zu Berlin: No. 5530.

al-Na ri, 'Imad Muhammad. 1973. Țūtīnāmeh: Javāhir al-asmār. Tehran: Intisharat-i Bunyad-i Farhang-i Iran.

al-Safa', Ikhwan. 1957. Risā’il ikhwān i-șafä'. Beirut: Dar Beirut.

—. 1992. "Mujmal al-hikmat." In Seh resāleh fārsi dar mūsīqī, edited by Taqi Binesh, 31-56. Tehran: Markaz-i Nashr Danishgahi.

Alsted, Johannes Heinrich. 1650. Mukhtișar-i mūsīqī. Bodleian Library (Oxford): Ouseley

65. This is a Persian translation of the Compendium Musicae.

al-Tabary, abu Ja 'far Muhammad ibn Jarir, and P. Brown John. 1849. "Et-Tabary's Conquest of Persia by the Arabs." Journal of the American Oriental Society 1 (4): 435, 437-505.

al-Tusi, Ahmad ibn Muhammad. 1981. Samāe va futuvvat. Tehran: Ketabkhanah Manuchiri. al-Tusi Nasir al-Din Muhammad ibn Muhammad Yusuf. 1964. Risālah Nasir al-Din al-Tusi $f_{\bar{i}}{ }^{\circ} i l m-i$ mùsìqì. Cairo: Dar al-Qalam.

al-Tuzi al-Ghazzali, Ahmad ibn Muhammad ibn Muhammad ibn Ahmad. 1938. "Bawāriq al-ilmāe ." In Tracts on Listening Music, edited by James Robson, 119-184. London: Royal Asiatic Society.

Amanat, 'Abbas. 1993. Crowning Anguish: Memoirs of a Persian Princess from the Harem to Modernity. Washington, DC: Mage.

-1997. Pivot of the Universe: Nasir al-Din Shah Qajar and the Iranian Monarchy, 18311896. London: Tauris.

Amanat, 'Abbas, and Farzin Vejdani. 2012. Iran Facing Others: Identity Boundaries in a Historical Perspective. Vol. 1. New York: Palgrave Macmillan.

Amnon, Shiloah. 2004. "Musical Concepts in the Works of Saadia Gaon." Aleph 4:265-282.

—. 2008. "Musical Scenes in Arabic Iconography." Music in Art 33 (1/2): 283-300.

Amoretti, B. S. 1975. "Sects and Heresies." In Cambridge History of Iran, edited by J.A. Boyle, 481-519. Cambridge: Cambridge University Press.

Amuli, Muhammad bin Mahmud Shams al-Din. 2001. Farhang-i ișțilāhāt va ta rỉfät (Nafā' '̀s al-funūn). Tehran: Ferdaws.

Anderson, Benedict. 200o. Imagined Communities. Vol. 2. London: Verso.

Anon. Or. 1015. Haža risālah fī 'ilm-i mūsìqī. University of Leiden Special Collections.

—. Or. 8116. Resāleh-i mūsìqī. British Library (London).

—. Ouseley Add. 6o. Resāleh-i 'ilm-i mùsīqū. Bodleian Library (Oxford).

—. 1410a. Pers. d. 17. [Untitled.] Bodleian Library (Oxford).

—. c. 1410b. Sāz-i alvāh ke az pūlād sāzand. Leiden University Special Collections.

—. c. 1410c. Sāz-i qaț āt-i chìnī. Leiden University Special Collections.

c. c. 1500. Rafíq-i tawfìq. University of Tehran Central Library. 
(London).

_. c. 1658. [Untitled]. Ms. No. 1974, 1a-3ob University of Tehran Central Library.

1939. A Chronicle of the Carmelites in Persia and the Papal Mission of the XVIIth and XVIIIth Centuries. London: Eyre \& Spottiswoode.

—. 1996. "al-Mukhtișar al-mufīd fī bīyān al-mūsīqī va ușūl-i aḥkāmeh.” In Ma arif, edited by Amir Hosein Pourjavady, 16: 49-55.

—. 2001. "Resāleh dar bīyān-i chahār dastgāh-i aẓam." Edited by Amir Hosein Pourjavady. Mahoor Music Quarterly 12:81-92.

—. 2002. "Resāleh dar 'ilm-i mūsīqī." Mahoor Music Quarterly, edited by Amir Hosein Pourjavady, 14:101-114.

—. 2003a. "Dar bāyān-i 'ilm-i mūsīqī va dānistan-i sho bāt-i ū." Mahoor Music Quarterly 15:49-70.

—. 2003b. "Resāleh-i mūsīqī." In Seh Resāleh-i mūsīqī-i qadìmī-i İrān, edited by Mansourah Sabetzadeh, 145-266. Tehran: Society for the Appreciation of Cultural Works and Dignitaries.

—. 2003c. "Resāleh-i mūsīqī." In Seh resāleh-i mūsīqì-i qadìmì-'İrān (2003), edited by Mansourah Sabetzadeh, 145-266. Tehran: Society for the Appreciation of Cultural Works and Dignitaries.

—. 2005. "al-Resāleh dar 'ilm-i mūsīqī." In "The Musical Codex of Amir Khan Gorji," by Amir Hosein Pourjavady. PhD diss., University of California, Los Angeles, 180-192.

2006. Nasīm-i țarab. Edited by Amir Hosein Pourjavady. Intisharat-i Farhangistan-i Honar.

—. 2012. "Risāleh-i davāzdah dastgāh: matnī arzeshmand darbāreh-i mūsīqī-i dūreh-i

Fath 'Ali Shāh." Edited by Mohsen Mohammadi. Payāam-i Bahāristān 4 (14): 930-947.

Ansari, al-Herawi 'abd Allah ibn Muhammad. 1979. Sad maydān. Tehran: Ketabkhanah-i Tahuri.

Ansari, 'Ali M. 2014. Perceptions of Iran: History, Myths and Nationalism from Medieval Persia to the Islamic Republic. Vol. 37 of International Library of Iranian Studies. London: I. B. Tauris in association with the Iran Heritage Foundation.

Anwar, A. 2011. "Anjoman-e Oknowwat." In Encyclopeedia Iranica, II/1, 88-89, available online at http://www.iranicaonline.org/articles/anjoman-e-okowwat.

Asadi, Hooman. 2001a. “Az maqām tā dastgāh.” Mahoor Music Quarterly 11:59-75.

_. 2001b. "Nokteh darbareh-i zịlī bar maqāleh-i az maqām tā dastgāh." Mahoor Music Quarterly 12:64-79.

Avenary, Hanoch. 1952. "Abu'l-șalt’s Treatise on Music." Musica Disciplina 6 (1/3): 27-32.

Avery, Peter. 1965. Modern Iran. London: Ernest Benn.

Awde, Nicholas, and Fred James Hill. 2003. A History of the Islamic World. New York: Hippocrene.

Babayan, Kathryn. 2002. Mystics, Monarchs and Messiahs: Cultural Landscapes of Early Modern Iran. Cambridge, MA: Harvard University Press.

Bakharzi, 'abd al-Mafakhir Yahya. 1966. Avrād al-aḥbāb va fuṣūṣ al-ādāb. Edited by Iraj Afshar. Tehran: Intisharat-i Danishgah-i Tehran.

Bamdad, Mahdi. 1968. Sharḥ-i ḥāl-i rejāl-i İrān. Vol. 6. Tehran: Zavvar. 
Bana'i. 1989. Resāleh dar mūsīqī, edited by Nasrallah Pourjavady. Tehran: Markaz-i Nashr Danishgahi.

Banani, Amin. 1961. The Modernization of Iran, 1921-1941. Stanford, CA: Stanford University Press.

Barkechli, Mehdi. 1974. "Recherche des degrés de la gamme iranienne à patir de la sensation subjective de consonance." In Commémoration Cyrus: Hommage Universel III, 339-360. Leiden: E. J. Brill.

Bausani, A. 1968. "Religion under the Mongols." In The Cambridge History of Iran, edited by J.A. Boyle, 538-549. Cambridge: Cambridge University Press.

- 2007. "Religion in the Saljuq Period." In Cambridge History of Iran, edited by Sir Harold Bailey and Peter Avery. Cambridge: Cambridge University Press.

Bayat, Mangol. 1983. "The Cultural Implications of the Constitutional Revolution." In Qajar Iran: Political, Social and Cultural Change, 180o-1925, edited by Edmund Bosworth and Carole Hillenbrand. Edinburgh: Edinburgh Univeristy Press.

Beeman, William O. 1976. "You Can Take Music Out of the Country, but ... : The Dynamics of Change in Iranian Musical Tradition." Asian Music 7 (2): 6-19.

Bihruzi, Shapur. 1988. Chehreh-ha-i mūsīqī-i İrān. Tehran: Shirikat-i Ketab-i Sara.

Binesh, Taqi. 1987. Introduction to Jämie al-alhān. Tehran: Muassasah-i Mutala at va Tahqiqat-i Farhangi.

Binesh, Taqi, and Safvat Dariush. 1989. "Introduction to the Resāleh dar Mūsīqī of Mi'mar 'Ali bin Muhammad known as Bana'i.” In Resāleh dar mūsīqī, edited by Nasrallah Pourjavady, v-xxii. Tehran: Markaz-i Nashr Danishgahi.

Black, Ian, and Saeed Kamali Deghan. 2010. "Iran Lays Claim to British Museum's Cyrus Cylinder." www.theguardian.com/world/2010/sep/15/iran-cyrus-cylinderbritish-museum.

Blacking, John. 1977. "Some Problems of Theory and Method in the Study of Musical Change." Yearbook of the International Folk Music Council 9:1-26.

Blum, Stephen. 1972. "The Concept of the 'Āsheq in Northern Khorasan." Asian Music 4 (1): $27-47$.

_. 1974. "Persian Folksong in Meshhed (Iran), 1969." Yearbook of the International Folk Music Council 6:86-114.

—. 1993. "Prologue: Ethnomusicologists and Modern Music History" in Ethnomusicology and Modern Music History. Edited by Stephen Blum, Philip V. Bohlman, and Daniel M. Neuman, 1-20. Chicago: University of Illinois Press.

_. 2006. "Navā’i, a Musical Genre of Northeastern Iran." In Analytical Studies in World Music, 41-57. New York: Oxford University Press.

_ 2015a. "Foundations of Musical Knowledge in the Modern World." In The Cambridge History of World Music, edited by Philip V. Bohlman, 103-124. Cambridge: Cambridge University Press.

- 2015b. “The Persian Radif in Relation to the Tajik-Uzbek Šhašmaqom.” In This Thing Called Music: Essays in Honor of Bruno Nettl, edited by Victoria Lindsay and Philip V. Bohlman Levine, 167-179. London: Rowman \& Littlefield.

Bohlman, Philip V. 1986. “R. G. Kiesewetter's 'Die Musik der Araber': A Pioneering Ethnomusicological Study of Arabic Writings on Music." Asian Music 18 (1): 164-196.

_ 1987. "The European Discover of Music in the Islamic World and the 'Non-Western' in 19th-Century Music History." Journal of Musicology 5 (2): 147-163. 
—. 2002. "World Music at the 'End of History." Ethnomusicology 46 (1): 1-32.

Borumand, Nur Ali, and and Jean During. 1991. Radīf-i tār va setār Mirza 'Abdullāh. Tehran: Chapkhaneh-i Soroush.

Bosworth, C. E. 1968. "The Political and Dynastic History of the Iranian World (A.D. 10001217).” In The Cambridge History of Iran, edited by J. A. Boyle, 1-202. Cambridge: Cambridge University Press.

_ 2002. "Central Asia: In the Islamic Period Up to the Mongols." In Encyclopedia Iranica. V/2, 69-172, available online at http://www.iranicaonline.org/articles/central-asia-iv

Bouterse, Curtis. 1979. "Reconstructing the Medieval Arabic Lute: A Reconsideration of Farmer's 'Structure of the Arabic and Persian Lute." Galpin Society Journal 32:2-9.

Boyle, J.A. 1968. "Dynastic and Political History of the Il-Khans." In Cambridge History of Iran, edited by Sir Harold Bailey and Peter Avery, edited by J. A. Boyle, 303-421. Cambridge: Cambridge University Press.

Brown, E. G. 1956. A Literary History of Persia. Cambridge: Cambridge University Press.

Cachia, Pierre. 1973. "A 19th Century Arab's Observations on European Music." Ethnomusicology 17 (1): 41-51.

Cahen, Claude. 1975. “Tribes, Cities and Social Organization.” In Cambridge History of Iran, edited by R. N. Frye, 305-328. Cambridge: Cambridge University Press.

Caton, Margaret. 1972. "The Kamanche Style of Ustad Faydullah of the Province of Gilan, Iran." MA thesis, University of California, Los Angeles.

—. 1983. "The Classical Tasnif: A Genre of Persian Vocal Music." PhD diss., University of California, Los Angeles.

— 1984. "Baha'i Influences on Mirza 'Abdullah, Qajar Court Musician and Master of the Radif." In Studies in Babi and Baha’i History, edited by Juan R. Cole, 30-64. Los Angeles: Kalimat Press.

Chehabi, H.E. 1999. "From Revolutionary Tasnif to Patriotic Surud: Music and NationBuilding in Pre-World War II Iran.” Iran 37:143-154.

Clifford, James, and George E. Marcus. 1986. Writing Culture: The Poetics and Politics of Ethnography. Berkeley: University of California Press.

Cole, Juan R.I., and Deniz Kandiyoti. 2002. "Nationalism and the Colonial Legacy in the Middle East and Central Asia: Introduction." International Journal of Middle East Studies 34 (2): 189-203.

Curtis, John, and St. John Simpson. 2010. The World of Achaemenid Persia: History, Art and Society in Iran and the Ancient Near East: Proceedings of a Conference at the British Museum, 29th September-1st October 2005. London and New York: I. B. Tauris.

Darvishi, Mohammad-Reza. 1995. Negāh be gharb, Bahısì dar tāsīr mūsīqì-i gharb bar mūsīqì-i İān. Tehran: Mahoor Institute of Culture and Art.

—. 1996. Sonnat va bigānegī-ye farhangī dar mūsīqī-i İrān. Tehran: Hozeh-i Honari.

Davami, 'Abdullah, and Faramarz Payvor. 2011. Radîf-i avāzī-i va taṣnīf-hā-i qadìmī beh ravāyat va ejrā-i ostād 'Abdollāh Davāmì. Tehran: Mahoor Institute of Culture and Art.

Davami, 'Abdullah, and Sepanta Sasan. 2006. Radîf-i avāzīi va taṣnîf-hā-i qadìmī beh ravāyat va ejrā-i ostād, 'Abdollāh Davāmī. M.CD-111. Tehran: Mahoor Institute of Culture and Art.

Dean, Mitchell. 1994. Critical and Effective Histories: Foucault's Methods and Historical Sociology. London and New York: Routledge. 
Dihbashi, Ali. 1998. Yādnāmeh-i 'Abol Hassan Sabā. Tehran: Nashr-i Vida.

Djani-Zade, Tamila. 2001. "Music of Azerbaijan." In Garland Encyclopedia of World Music, edited by Scott Marcus, Dwight Reynolds, and Virginia Danielson. New York: Routledge.

During, Jean. 1984. La musique iranienne: tradition et evolution. Paris: Recherches sur les Civilisations.

- 1988. La musique traditionelle de l'Azerbayjan et la science des mugams, Collection détudes musicologiques/Sammlung musikwissenschaftlicher Abhandlungen. BadenBaden: Valentin Koerner.

—. 1991a. "Structures modales des avazs et ancients gushes." In Radîf-i tār va setār Mirza 'Abdulläh, 37-48. Tehran: Chapkhaneh-i Soroush.

—. 1991b. "The Traditional Repertory." In Radîf-i tār va setār Mirza 'Abdullāh, 59-76. Tehran: Chapkhaneh-i Soroush.

During, Jean, Zia Mirabdolbaghi, and Dariush Safvat. 1991. The Art of Persian Music. Washington, DC: Mage.

During, Jean, and Rudy Steibel. 2005. “Third Millenium Tehran: Music!” Iranian Studies 38 (3): 373-398.

Dzhumajev, Alexander. 1992. "From Parda to Maqām: A Problem of the Origins of the Regional Systems." In Geschichte und Gegenwart: Materialien der 2. Arbeitstagung der Study Group "Maqam" des International Council for Traditional Music vom 23. bis 28. März 1992 in Gosen bei Berlin, 145-161. Berlin: ICTM.

Eliyahu, Piris. 1999. The Music of the Mountain Jews: Eastern and Northern Caucasus. Jerusalem: Jewish Music Research Centre, Hebrew University of Jerusalem.

Elsner, Jūrgen, and Gisa Jähnichen. 1992. Regionale Maqām-Traditionen in Geschichte und Gegenwart: Materialien der 2. Arbeitstagung der Study Group "Maqām” des International Council for Traditional Music vom 23. bis 28. März in Gosen bei Berlin, Conference Source. Berlin: Humboldt-Universität (Institut für Musikwissenschaft und Musikerziehung).

Ertan, Deniz. 2007. "Cycles and Peripheries: An Ottoman 'Kitâb el-Edvâr." Asian Music 38 (1): 31-6o.

Fallahzadeh, Mehrdad, Davrah Karami, and Muhammad Amin. 2009. Two Treatises, Two Streams: Treatises from the Post-Scholastic Era of Persian Writings on Music Theory. Bethesda, MD: Ibex.

Fārābī, and E. Neubauer. 1998. Kitāb al-mùsīqā al-kabìr. Vol. 61, Publications of the Institute for the History of Arabic-Islamic Science, series C, facsimile editions. Frankfurt am Main: Institute for the History of Arabic-Islamic Science at the Johann Wolfgang Goethe University.

Farhat, Hormoz. 1965. "The Dastgāh Concept in Persian Music." PhD diss., University of California.

Farmanfarmayan, Hafez. 1968. "The Forces of Modernization in Nineteenth-Century Iran." In The Beginnings of Modernization in the Middle East: The Nineteenth Century, edited by William Polk and Richard Chambers, 115-151. Chicago: Univeristy of Chicago Press.

Farmer, Henry George. 1926a. "The Old Persian Musical Modes." Journal of the Royal Asiatic Society of Great Britain and Ireland 1:93-95.

_. 1926b. "Some Musical MSS. Identified." Journal of the Royal Asiatic Society: 91-93. 
. 1928. "Ibn Khurdādhbih on Musical Instruments." Journal of the Royal Asiatic Society of Great Britain and Ireland 3:509-518.

1929. A History of Arabian Music to the XIIIth Century. London: Luzac.

. 1930. "Greek Theorists of Music in Arabic Translation." Isis 13 (2): 325-333.

. 1932a. "The Influence of Al-Farabi's 'Ihsa' al-'ulum' ('De scientiis') on the Writers on Music in Western Europe." Journal of the Royal Asiatic Society of Great Britain and Ireland 3:561-592.

—. 1932b. "An Old Moorish Lute Tutor." Journal of the Royal Asiatic Society of Great Britain and Ireland 4:379-389, 897-904.

—. 1933. "The 'Iḥsāa al-'Ulūm.”' Journal of the Royal Asiatic Society of Great Britain and Ireland 4:906-909.

- 1937a. "The Lute Scale of Avicenna." Journal of the Royal Asiatic Society of Great Britain and Ireland 2:245-257.

-1937b. "Was the Arabian and Persian Lute Fretted?" Journal of the Royal Asiatic Society of Great Britain and Ireland 3:453-460.

—. 1938. "The Instruments of Music on the Țāq-i Bustān Bas-Reliefs." Journal of the Royal Asiatic Society of Great Britain and Ireland 3:397-412.

—. 1939a. "An Outline of Music and Musical Theory." In A Survey of Persian Art from Prehistoric Times to the Present, edited by Arthur Upham Pope and Phyllis Ackerman, 2783-2804. London: Oxford Univeristy Press.

-1939b. "The Structure of the Arabian and Persian Lute in the Middle Ages." Journal of the Royal Asiatic Society of Great Britain and Ireland 1:41-51.

—.1939c. Studies in Oriental Musical Instruments, Second Series. Glasgow: Civic Press.

. 1941. "Music: The Priceless Jewel." Journal of the Royal Asiatic Society of Great Britain and Ireland 1:22-30.

—. 1942a. "Ta’tīr va nufūż-i İān dar tab 'ìyat alāt-i mūsīqī" Rūzgār-i naw 6:40-44.

—. 1942b. " 'Ulāmā' -i bozorg-i İrān dar fann-i mūsīqī.” Rēzgār-i naw 5:48-53.

-1943. Sa'adyah Gaon on the Influence of Music. London: A. Probsthain.

_. 1950. "Arabian Musical Instruments on a Thirteenth Century Bronze Bowl." Journal of the Royal Asiatic Society of Great Britain and Ireland 3/4:110-111.

-1955. The Song Captions in the Kitab al-Aghani al-Kabir. London: H. Baron.

1959. The Science of Music in the Mafatih al-Ulum. Glasgow.

1962. "Abdalqadir Ibn Gaibi on Instruments of Music." Oriens 15:242-248.

— 1964. "Iranian Musical Instruments in the Ninth/Fifteenth Century." Islamic Culture 38:175-181.

-1965. The Sources of Arabian Music: An Annotated Bibliography of Arabic Manuscripts Which Deal with the Theory, Practice, and History of Arabian Music from the Eighth to the Seventeenth Century. Leiden: E. J. Brill.

—. 1966. Islam, Musikgeschichte in Bildern. Leipzig: VEB Deutscher Verlag für Musik.

- 1970. Historical Facts for the Arabian Musical Influence. Hildesheim: Georg Olms.

-1976. Turkish Instruments of Music in the Seventeenth Century as Described in the Silyahat Nama of Ewliya Chelebi. Portland: Longwood.

—. 1977. "An Outline of Music and Musical Theory." In A Survey of Persian Art from Prehistoric Times to the Present, vol. 6, edited by Arthur Upham Pope Ackerman and Phyllis, 2783-2804. Tehran: Soroush Press. 
Farmer, Henry George, and E. Neubauer. 1997. Studies in Oriental Music. Frankfurt am Main: Institute for the History of Arabic-Islamic Science at the Johann Wolfgang Goethe University.

Fatemi, Sasan. 2001. "Moțrebhā: az șafavīeh tā mashrūṭiāt." Mahoor Music Quarterly 12:27-39.

Feldman, Walter. 1993. "Ottoman Sources on the Development of the Taksîm." Yearbook for Traditional Music 25:1-28.

-1996. Music of the Ottoman Court: Makam, Composition and the Early Ottoman Instrumental Repertoire, Intercultural Music Studies. Vol. 10. Berlin: VWB-Verlag für Wissenschaft und Bildung.

Ferydoun Barjesteh van Waalwijk van Doorn, L. A. 2007. "Introduction to Entertainment in Qajar Persia." Iranian Studies: Bulletin of the Society for Iranian Cultural and Social Studies 40 (4): 447-454.

Foran, John. 1988. "Social Structure and Social Change in Iran from 1500 to 1979." PhD diss., University of California, Berkeley.

— 1992. "The Long Fall of the Safavid Dynasty: Moving Beyond Standard Views." International Journal of Middle East Studies 24:281-304.

Foucault, Michel. 1970. The Order of Things: An Archaeology of the Human Sciences. New York: Vintage.

1972. The Archaeology of Knowledge. London: Tavistock.

Frye, Richard N. 2000. The Golden Age of Persia: The Arabs in the East. London and New York: Weidenfeld and Nicolson, Barnes \& Noble.

—. 1975a. "Preface." In Cambridge History of Iran, edited by R.N. Frye, xi-xiii. Cambridge: Cambridge University Press.

—. 1975b. "The Samanids." In Cambridge History of Iran, edited by R.N. Frye, 136-161. Cambridge: Cambridge University Press.

Geary, Patrick J. 2002. The Myth of Nations: The Medieval Origins of Europe. Princeton, NJ: Princeton University Press.

Gellner, Ernest. 1997. Nationalism. London: Weidenfeld and Nicolson.

Gelvin, James L. 2008. The Modern Middle East: A History. New York: Oxford University Press.

Ghaznavi, abd al-Rahman Sayf. 2003. "Resāleh-i mūsīqī”. In Seh resāleh-i mūsīqī-i qadìm-i Irān, edited by Mansourah Sabetzadeh, 105-144. Tehran: Society for the Appreciation of Cultural Works and Dignitaries.

Ghazzali, 'abd Hamad Muhammad ibn Muhammad. 1957. Ihyā 'ulūm al-dīn. Cairo: Dar Ihya al-Kutub al-Arabiya.

—. 1975. Kìmīyā-i sa' ādat. Tehran: Shirikat-i Sehami-i Ketab-ha-i Jibi.

-1980a. The Alchemy of Happiness. London: Octagon Press.

—. 1980b. Tarjameh-i ihyyā 'ulūm al-dīn. Tehran: Intisharat-i Bungah-i Tarjamah va Nashr-i Ketab.

Ghods, Reza M. 1991. "Iranian Nationalism and Reza Shah.” Middle Eastern Studies 27:35-45.

Gilani, Nazam al-Din Ahmad. 1577. [Untitled.] Staatsbibliothek Preussischer Kulturbesitz zu Berlin: Petermann I. 175, 58b-59a.

Gorgani, 'Ali Muhammad. c. 1700. Dar kīfìyat-i mūsīqī. Malek Library (Tehran): No. 805. 82-91. 
Gorji, Amir Khan. 2005. "Resāleh-i kamtarīn ghulāmān Amīr Khān.” In “The Musical Codex of Amir Khan Gorji," edited by Amir Hosein Pourjavady, 86-157. PhD diss., University of California, Los Angeles.

Grabar, O. 1975. “The Visual Arts, 1050-1350.” In Cambridge History of Iran, edited by R.N. Frye, 329-363. Cambridge: Cambridge University Press..

Gribetz, Arthur. 1991. "The Samā' Controversy: Sufi vs. Legalist.” Studia Islamica 74: 43-62.

Hajarian, Mohsen. 1999. "Ghazal as a Determining Factor of the Structure of the Iranian Dastgah.” PhD diss., University of Maryland, College Park.

Halliday, Fred. 1999. "The Nationalism Debate in the Middle East." Middle Eastern Lectures 3:23-48.

Hassanpour, Amir. 1994. "The Nationalist Movements in Azarbaijan and Kurdistan, 19411946." In A Century of Revolution: Social Movements in Iran, edited by John Foran, 78105. Minneapolis: University of Minnesota Press.

Hedayat, Mehdi Qoli. 1938. Majma al-advār. Tehran.

- 1950. Khätrāt va Khatrāt. Vol. 5. Tehran: Intisharat-i Zavar.

Helmholtz, Hermann von. 1895. On the Sensations of Tone as a Physiological Basis for the Theory of Music. New York: Longmans, Green.

Hodgson, Marshall G. S. 1974. The Venture of Islam: Conscience and History in a World Civilization. Chicago: University of Chicago Press.

-1993. Rethinking World History: Essays on Europe, Islam and World History. New York: Cambridge University Press.

Holt, P. M., Ann K. S. Lambton, and Bernard Lewis. 1977. The Cambridge History of Islam. Cambridge: Cambridge University Press.

Homerin, Emil. 2010. "Soul." In Encyclopedia of the Qur'ān, edited by Jane Dammen McAuliffe. Chicago: Brill Online.

Hourani, Albert. 1991. A History of the Arab Peoples. Cambridge, MA: Harvard University Press.

Huart, Clément, and M. R. Dobie. 1927. Ancient Persia and Iranian Civilization: The History of Civilization. London and New York: K. Paul, Trench, Trubner, Knopf.

Huart, Cl., and H. Massé. 2012. “Djāmī." In Encyclopedia of Islam, edited by Th. Bianquis, P. Bearman, C.E. Bosworth, E. van Donzel, and W. P. Heinrichs. Online Reference Works: Brill.

Hujviri, 'Ali ibn 'Usman. 1957. Kashf al-mahjūb. Tehran: Amir Kabir.

Husayni, Zayn al-Abiddin Mahmud. 1987. Qanūn-i 'ilmī va 'amalī-i mūsīqī. Dushanbe: Nashriyat-i Danish.

ibn Abi al-Dunya, Abu Bakr 'Abdullah ibn Muhammad ibn Ubayd. 1938. "Dhamm almalāhī." In Tracts on Listening to Music, edited by James Robson, 41-62. London: Royal Asiatic Society.

ibn al-Munajjim, Ala al-Din 'Ali Shah ibn Muhammad ibn Qasim al-Kharazmi al-Bukhari. 1273. Ashjār va as $m \bar{a} r$. Staatsbibliothek Preussischer Kulturbesitz zu Berlin: Petermann I. $712,154 a-156 a$.

ibn Butlan, abu al-Hasan al-Mukhtar ibn al-Hasan ibn 'Abdun ibn Sa'dun. 1971. Tarjameh-i taqvīm al-ṣihhah az mutarjimī nāma lìm. Tehran: Intisharat-i Bunyad-i Farhang-i Iran. 
ibn Fakhr al-Din Muhammad, Mirza Khan. 1975. Tohfat al-Hind. Tehran: Intisharat-i Bunyad-i Farhangi.

ibn Khaldun, 'abd al-Rahman. 1957. Muqaddimat Ibn Khaldūn. Cairo: Lajna al-Bayan al-Arabi.

ibn Mutahhar, abu al-Fath Muhammad. 1964. Hadīqat al haqiqaat. Tehran: Intisharat-i Bungah-i Tarjamah va Nashr-i Ketab.

ibn Sina, Abu Ali. 1981. Fann-i samāe tabī $\bar{\imath}^{\top}$ az ketāb-i shefā. Tehran: Chapkhaneh-i Bahman.

ibn Sina, Abu Ali, and Juzjani 'Ubaydallah. 1992. "Dānishnāmeh-i alā’̀”. In Seh resāleh-i Fārsī dar mūsīqī, edited by Taqi Binesh, 3-29. Tehran: Markaz-i Nashr Danishgahi.

ibn Voshmgir, 'abd al-Mo'men ibn Safi al-Din ibn Ezz al-Din Mohy al-Din ibn Na 'mat ibn Qabus. c. 160ob. Bahjat al-rūh. Bodliean Library (Oxford): Ouseley 117, 1b-23.

ـ1967. Bahjat al-rūh. Edited by H. L. Rabino de Borgomale. Tehran: Intisharat-i Bunyad-i Farhangi.

Isfahani, Sadiq bin Salij. 1646. Shāhed șādeq. British Library (London): Egerton, 1016.

Issawi, Charles. 1977. "Population and Resources in the Ottoman Empire and Iran." In Studies in Eighteenth Century Islamic History, edited by Thomas Naff and Roger Owen. Edwardsville: Southern Illinois University Press.

Jackson, Myles W. 2006. Harmonious Triads: Physicists, Musicians and Instrument Makers in Nineteenth-Century Germany. Cambridge, MA: MIT Press.

Jameson, Fredric. 1991. Postmodernism, or, The Cultural Logic of Late Capitalism. Durham: Duke University Press.

Jami, Nur al-Din abd al-Rahman. 1492. Resāleh-i mùsīqī. Bodleian Library (Oxford): Ouseley $288,572 \mathrm{a}-581 \mathrm{a}$.

Jung, Angelika. 1989. Quellen der traditionellen Kunstmusik der Usbeken und Tadshiken Mittelasiens: Untersuchungen zur Entstehung und Entwicklung des šašmaqãm. Vol. 23, Beiträge zur Ethnomusikologie. Hamburg: Verlag der Musikalienhandlung K. D. Wagner.

Kalhor, Kayhan. 1998. Scattering Stars Like Dust. New York: Traditional Crossroads.

Kalhor, Kayhan, and Erdal Erzincan. 2013. Kula kulluk yakışır mı. München: ECM Records.

Kashani, Hassan. 1992. "Kanz al-toḥaf." In Seh resāleh-i fārsī dar mūsīqī, edited by Taqi Binesh, 56-128. Tehran: Markaz-i Nashr Danishgahi.

Kashani, 'Izz al-Din. 1946. Miṣbāḥ al-hidāyah wa miftāh al-kifāyah. Tehran: Intisharat-i Ketabkhanah-i Sana'i.

Kashani-Sabet, Firoozeh. 1999. Frontier Fictions: Shaping the Iranian Nation, 1804-1946. London: I. B. Tauris.

Katirài, Mahmud. 1968. Ferāmāsonerī dar İrān az aghāz ta tashkīl-i luzh-i bìdarī İrān. Tehran: Iqbal.

Katouzian, Homa. 2000. State and Society in Iran: The Eclipse of the Qajars and the Emergence of the Pahlavis. Vol. 28, Library of Modern Middle East Studies. London and New York: I. B. Tauris; New York: St. Martin's.

2009. The Persians: Ancient, Mediaeval, and Modern Iran. New Haven: Yale University Press.

Kawkabi, Najm al-Din. 2003. "Resāleh-i mūsīqī”. In Seh resāleh-i mūsīqī-i qadīm-i İrān, edited by Mansourah Sabetzadeh, 15-103. Tehran: Society for the Appreciation of Cultural Works and Dignitaries. 
Kaykavus ibn Iskandar ibn Qabus. Unsur al-Ma'ali. 1993. Dars-i zendegī: guzīdeh-i Qābūsnāmeh. Vol. 7, Az mīrā̄s $-i$ adāb-i Fārsī. Tihrān: Intishārāt-i Sukhan.

—. 1967. Qabūsnāmeh. Tehran: Bungah.

Keddie, Nikki. 1981. Roots of Revolution: An Interpretive History of Modern Iran. Binghamton, NY: Vail-Ballou Press.

-1999. Qajar Iran and the Rise of Reza Khan. Costa Mesa: Mazda Press.

Kennedy, E.S. 1975. "The Exact Sciences in Iran under the Seljuqs and Mongols." In Cambridge History of Iran, edited by R.N. Frye, 378-395. Cambridge: Cambridge University Press.

Kennedy, Hugh. 2004. The Prophet and the Age of the Caliphates: The Islamic Near East from the Sixth to the Eleventh Century. New York: Pearson/Longman.

Keyvani, Mehdi. 1982. Artisans and Guild Life in the Later Safavid Period: Contributions to the Social-Economic History of Persia. Vol. 65, Islamkundliche Undersuchungen. Berlin: Klaus Schwarz.

Khaleqi, Ruhallah. 1954. Sargozasht-i mūsīqīi İrān. Tehran: Safi 'Ali Shah.

Khaleqi, Zahreh. 1994. Āvā-i mehrebānī: yādvareh-i Qamar al-Mulūk Väzīrī. Tehran: Danya-i Modar.

Khatschi, Khatschi. 1962. Der dastgāh: Studien zur neuen presischen Musik. Vol. 19, Koelner Beitraege zur Musikforschung. Regenburg, Germany: Gustav Bosse Verlag.

Khayyam, 'Umar. 1967. Khayamnāmeh. Tehran: Silsilah-i Intisharat-i Anjuman-i Asar-i Milli. Khoshzamir, Mojtaba. 1979. "Ali Naqi Vaziri and His Influence on Music and Music Education in Iran." PhD diss., University of Illinois at Urbana-Champaign.

Kiani, Majid. 199o. Haft dastgāh. Tehran: Moassese-i Saz-i Nawruz.

Kiesewetter, Raphael Georg. 1842. Die Musik der Araber. Leipzig: Breitkopf und Härtel.

Kinnear, Michael S. 200o. The Gramophone Company's Persian Recordings, 1899 to 1934: A Complete Numerical Catalogue, by Matrix Serials, of Persian Recordings Made from 1899 to 1934 by the Gramophone Company, Ltd., together with a Supplement of Recordings Made by Columbia Gramophone Company Ltd., from 1928 to 1934. Heidelberg Victoria, Australia: Bajakhana.

Klein, Yaron. 2009. "Musical Instruments as Objects of Meaning in Classical Arabic Poetry and Philosophy." PhD diss., Harvard University.

Kubra, Najm al-Din. 1984. Ādāb al-șūfìyeh. Edited by Masud Qasimi. Tehran: Ketabfurushii Zavvar.

Lambton, Ann. 1988. Qajar Persia: Eleven Studies. Austin: University of Texas Press.

Lawergren, Bahman, Hormoz Farhat, and Stephen Blum. 2016. "Iran." In Grove Music Online. New York: Oxford University Press.

Lazard, G. 1975. "Rise of the New Persian Language." In Cambridge History of Iran, edited by R.N. Frye, 595-632. Cambridge: Cambridge University Press.

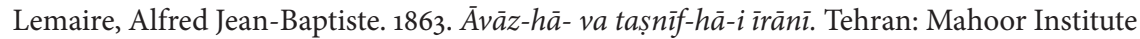
of Culture and Art.

— 1900. Avâz et Tèsnĭf Persans. Paris: H. Jacques Parès.

-2003. Āvāz-hā- va tașnīf-hā-i ìrānī. Edited by Manuchehr Sahba'i. Tehran: Mahoor Institute of Culture and Art.

Leoni, Stefano A.E. 1996. "Kanz al-Tuhaf (Al-Musiqi): The Casket of (Music) Rarities: Ars Musica and Musica Practica between Islam and Christianity." International Review of the Aesthetics and Sociology of Music 27 (2): 167-183. 
Lewisohn, Leonard. 1997. “The Sacred Music of Islam.” British Journal of Ethnomusicology 6:1-33.

—. 2010. "Tașawwuf (a.)." In Encyclopedia of Islam, edited by J. O. Hunwish, C. Ernst, and Th. Zarcone. Chicago: Brill Online.

Lockhart, Laurence. 1938. Nader Shah: A Critical Study Based Mainly Upon Contemporary Sources. London: Luzac.

-1958. The Fall of the Safavi Dynasty and the Afghan Occupation of Persia. Cambridge: Cambridge University Press.

—. 1986. "European Contacts with Persia, 1350-1736." In Cambridge History of Iran vol. 6, edited by Peter Jackson and Lawrence Lockhart, 373-409. Cambridge: Cambridge University Press.

Lucas, Ann E. 2012. "Caught between Heaven and Hell: The Morality of Music and Cosmologies of the Past in Persian Writings on Listening, c. 1040-c. 1800." Asian Music 43 (1): 91-130.

- 2013. "The Creation of Iranian Music in the Age of Steam and Print, c. 1880-1914." In Global Muslims in the Age of Steam and Print, edited by Nile Green and James L. Gelvin, 143-157. Berkeley: University of California Press.

- 2014. "Ancient Music, Modern Myth: Persian Music and the Pursuit of Methodology in Ethnomusicology." In Theory and Method in Historical Ethnomusicology, edited by Jonathan McCollum and David G. Hebert, 175-195. London: Lexington.

Ludi, Shir 'Ali ibn `Ali Amjad. 168o. Tazkirat mir'āt al-khīyāl. Bombay.

Malcolm, Sir John. 1815. The History of Persia from the Most Early Period to the Present Time: Containing an Account of the Religion, Government, Usages and Character of the Inhabitants of That Kingdom. London: John Murray.

Malkeyeva, Aygul. 1997. "Musical Instruments in the Text and Miniatures of the 'Bāburnāma."' RIdIM/RCMI Newsletter 22 (1): 12-22.

Manz, Beatrice Forbes. 2007. Power, Politics and Religion in Timurid Iran. Cambridge: Cambridge University Press.

Maraghi, 'abd al-Qader bin Ghaybi. 1966. Maqāșid al-alhān. Vol. 26, Majmū 'ah-’i mutūn-i Fārsī, 26. Tihrān: Bungāh-i Tarjumah va-Nashr-i Ketab.

—. 1987. Jāmi al-alhān. Tehran: Muassaseh-i Mutala at va Tahqiqat-i Farhangi.

Marashi, Afshin. 2003. "Nationalizing Iran: Culture, Power and the State, 1870-1941." PhD diss., University of California, Los Angeles.

- 2008. Nationalizing Iran. Seattle: University of Washington Press.

Marcus, George E., and Michael M. J. Fischer. 1986. Anthropology as Cultural Critique: An Experimental Moment in the Human Sciences. Chicago: University of Chicago Press.

Marcus, George E., and Fred R. Myers. 1995. The Traffic in Culture: Refiguring Art and Anthropology. Berkeley: University of California Press.

Ma rufi, Musa, and Barkechli Mehdi. 1963. La musique traditionelle de l'Iran. Tehran: Secretariat d'Ètat aux Beaux-Arts.

Marvi, Mohammad Kazim. 1991. 'Ālām ārāyē nādīrī. Tehran: Nashr-i Ilm.

Mashun, Hassan. 2001. Tārìkh-i mūsīqīi İrān. Tehran: Farhang-i Nashr-i Naw.

Massoudieh, Mohammad Taghi. 1988. Musik in Balūčestān, Beiträge zur Ethnomusikologie. Hamburg: Karl Dieter Wagner.

—. 1992. "Die Begriffe Maqām und Dastgāh in der turkmenischen Musik des Iran." In Collected Work: Regionale maqām-Traditionen in Geschichte und Gegenwart: Materialien 
der 2. Arbeitstagung der Study Group 'Maqām' des International Council for Traditional Music vom 23. bis 28. März in Gosen bei Berlin, 377-397. Berlin: Humboldt-Universität (Institut für Musikwissenschaft und Musikerziehung), 1992.

—1996. Manuscrits persans concernant la musique: catalogue. Munchen: G. Henle.

Matini, J., and M. Caton. 2011. "Āref Qazvīnī., In Encyclopcedia Iranica, II,/4, 391-392, available at http://www.iranicaonline.org/articles/aref-qazvini-poet

Maysami, Seyyed Hossein. 2002. "Tashkīlāt-i mūsīqī-i darbār-i Șafavī̄" Mahoor Music Quarterly 17:31-54.

Me'mar, 'Ali bin Muhammad. 1989. Resāleh dar mūsīqī. Tehran: Markaz-i Nashr-i Daneshgahi.

Miller, Lloyd Clifton. 1999. Music and Song in Persia. Salt Lake City: University of Utah Press.

- 2012. Music and Song in Persia. Kindle ed. Salt Lake City: University of Utah Press.

Miller, Paul Allen. 1999. “Toward a Post-Foucauldian History of Discursive Practices." Configurations 7 (2): 211-225.

Mohammadi, Mohsen. 2001. "ZZìl-i bar maqāleh-i az maqām tā dastgāh.” Mahoor Music Quarterly 12:41-60.

—. 2004. "Resāleh-i naw yāfteh dar mūsīqīi İrān." 'Āyaneh-i mīrās 24 (Spring): 73-80.

- 2015. Musical Souvenirs: European Transcriptions of Persian Music, 160o-1910. Tehran: Mahoor Institute of Culture and Art.

—. 2017. "Modal Modernities: Formations of Persian Classical Music and the Recording of a National Tradition." PhD diss., Utrecht University.

Moïnfar, Mohammad Djafar. 1970. Le vocabulaire arabe dans le Livre des rois de Firdausi: étude philologique et de statistique linguistique, Beiträge zur Iranistik. Wiesbaden: O. Harrassowitz.

Mosannef, Aqa Mo’men. 2005. "Resāleh va tașānīf-i marḥūm-i Āqā Mo’men Moșannef." In “The Musical Codex of Amir Khan Gorji," edited by Amir Hosein Pourjavady, 193-199. $\mathrm{PhD}$ diss., University of California, Los Angeles.

Motoyoshi, Akiko. 2001. "Sensibility and Synaesthesia: Ibn al-Rūmīs Singing Slave-Girl." Journal of Arabic Literature 32 (1): 1-29.

Movahed, Azin. 2003. "Anti-Imperialist Nationhood and Persian Musicology after the 1979 Revolution." Asian Music 35 (1): 85-113.

Mustamli Bukhari, abu Ibrahim Isma'il ibn Muhammad. 1912. Sharh-i ketāb al-ta'arruf limazhab ahl al-tașawwuf. Lahore, India.

Muzaffar, Mazhar. 1763. Khulāșat ayī'sh 'ālam shāhī. British Library (London): 261b-264a. Nettl, Bruno. 1970. "Examples of Popular and Folk Music from Khorasan." In Musik als Gestalt

und Erlebnis: Festschrift Walter Graf zum 65. Wien: H. Böhlau, 138-146.

-1972. Daramad of Chahargah: A Study in the Performance Practice of Persian Music, Detroit Monographs in Musicology. Detroit: Information Coordinators.

— 1974a. "Aspects of Form in the Instrumental Performance of the Persian Avaz." Ethnomusicology 18 (3): 405-414.

— 1974b. “Thoughts on Improvisation: A Comparative Approach.” Musical Quarterly $60(1): 1-19$.

— 1978. "Some Aspects of the History of World Music in the Twentieth Century: Questions, Problems, and Concepts.” Ethnomusicology 22 (1): 123-136. 
1983. The Study of Ethnomusicology: Twenty-Nine Issues and Concepts. Urbana: University of Illinois Press.

-1987. The Radif of Persian Music: Studies of Structure and Cultural Context in the Classical Music of Iran. Urbana-Champaign, IL: Elephant \& Cat.

- 1992. The Radif of Persian Music: Studies of Structure and Cultural Context in the Classical Music of Iran. Urbana-Champaign, IL: Elephant \& Cat.

2015. The Study of Ethnomusicology: Thirty-Three Discussions. Urbana: University of Illinois Press.

Neubauer, Eckhard. n.d. "Ziryāb." Grove Music Online.

. 1997. "Zur Bedeutung der Begriffe Komponist und Komposition in der Musikgeschichte der islamischen Welt." Zeitschrift für Geschichte der arabisch-islamischen Wissenschaften 11:307-363.

-2000. "Music in the Islamic Environment." In Collected Work: History of Civilizations of Central Asia, vol. 4, The Age of Achievement-A.D. 750 to the End of the Fifteenth Century, pt. 2, The Achievements, 594-603. Paris: UNESCO.

—. 2007. "Eine Persische Handschrift Aus Dem 19. Jahrhundert Mit Augaben Zum Musikalischen Vortrag Der Elegie Auf Den Tod Des Märtyrers Hosein B. 'Al' B. Ab' Tâleb von Mohtasam Kâsân'” Zeitschrift für Geschichte der Arabisch-Islamischen Wissenshaften 17:301-372.

Newman, Andrew. 1999. "Clerical Perceptions of Sufi Practices in Late Seventeenth-Century Persia: Arguments over the Permissibility of Singing (Ghinā')." In The Heritage of Sufism, vol. 3, Late Classical Persianate Sufism, edited by Leonard Lewisohn and David Morgan, 135-164. Oxford: Oneworld.

Nishaburi, Muhammad ibn Mahmud Mahmud ibn Muhammad. 1995. "Resāleh-i musīqīi-i Muhammad ibn Mahmūd ibn Muhammad Nishābūrī.” In Ma arif, edited by Amir Hosein Pourjavady, 12 (1/2): 32-70.

Nooshin, Laudan. 2003. "Improvisation as 'Other': Creativity, Knowledge and Power: The Case of Iranian Classical Music." Journal of the Royal Musical Association 128 (2): 242-296.

- 2009. Iranian Classical Music: The Discourses and Practice of Creativity. London: Ashgate.

Nurbakhsh, Javad. 1978. In the Tavern of Ruin: Seven Essays on Sufism. London: Khaniqahi Nimatullahi.

Perry, John. 2010. "Shāh-Nāma: Arabic Words." In Encyclopcedia Iranica, http://www.iranicaonline.org/articles/sah-nama-v-arabic-words.

Potts, Daniel T., ed. 2013. The Oxford Handbook of Ancient Iran. Oxford and New York: Oxford University Press.

Pourjavady, Amir Hosein. 2003. "Kār 'amal va sīr-i tuhūl-i ān az dūreh-i tīmūrī tā emrūz." Mahoor Music Quarterly 19:11-31.

—. 2005. "The Musical Codex of Amir Khān Gorji." PhD diss., University of California, Los Angeles.

—. 2006. "Nigāhī be hayāàt-i mūsīqāī dūrehī afshārī" Mahoor Music Quarterly 8: 29-58.

- 2007. "Indian and Afghan Influences on Persian Music Culture during the 18th and 19th Centuries." In Premier congrès des musiques dans le monde de l'islam. Assilah: Centre de rencontres internationales Hassan II.

Powers, Harold S. 1989. "International Segāh and Its Nominal Equivalents in Central Asia and Kashmir." In Collected Work: Maqam-Raga-Zeilenmelodik: Konzeptionen und 
Prinzipien der Musikproduktion, 40-85. Berlin: International Council for Traditional Music (Nationalkomitee DDR).

2000. "Mode V.: Middle East and Asia." In The New Grove Dictionary of Music and Musicians, edited by Stanley Sadie, 829-846. New York: Grove.

Qays, Muhammad Osman. 1899. Resāleh-i mūsīqū: șūt al-nāqūs. Lucknow.

Qazvini, Mirza Abolqasem Aref. 1924. Dīvān-i Mìrzā Abol-Qāsem 'Āref Qazvīnī. Berlin: Chapkhaneh-i Mashreqi.

- 2002. Dìvān-i 'Āref Qazvīnī. Tehran: Mu’assaeh-i Intishirat-i Negah.

Qazvini, Sadr al-Din Muhammad. 2003. "Resāleh-i 'ilm-i mūsīqī." Edited by Ario Rostami. In Mahoor Music Quarterly 18:81-96.

Qushayri, 'abd al-Karim ibn Hawazin. 1948. al-Risālah al-Qushayrīyah. Cairo: Muhammad 'Ali Subh wa-Awladuh.

—. 1982. Tarjamah-i Resāleh-i Qushayrīyyah. Edited by Badīe al-Zamān Furūzānfar. Tehran: Markaz-i Intisharat-i 'Ilmi va Farhangi.

Qutb al-Din, Mahmud ibn Mas'ud. 1991. Durrat al-tāj: Bakhsh-i hikmat-i 'amalì va aayr va sulūk bih kūshish va taṣhịhh-i Māhdukht Bānū Humāyī. Vol. 2. Tehran: Shirkat-i Intisharat-i 'Ilmi va Farhangi.

Racy, 'Ali Jihad. 2015. "Comparative Musicologists in the Field: Reflections on the Cairo Congress of Arab Music, 1932." In This Thing Called Music: Essays in Honor of Bruno Nettl, 137-150. London: Rowman \& Littlefield.

Ramsari, Mohammad Qasem Salah. 1914. "Pīshgoftār." In Buhūr al-alhān dar 'ilm-i mūsīqū va nisbat ān $b \bar{a}$ 'aruz, i-xxii. Tehran: Intisharat-i Furughi.

Rawlinson, George. 1876. The Seventh Great Oriental Monarchy; or The Geography, History, and Antiquities of the Sassanian or New Persian Empire. London: Longmans, Scribner, Welford and Armstrong.

-1878. The Origin of Nations: In Two Parts: On Early Civilisations, On Ethnic Affinities, etc. New York: Scribner.

Razavi, Muhammad bin Jalal. 1619. [Untitled.] British Library (London): Or. 2361, 3b-15a.

Razi, Fakhr al-Din Muhammad 'Umar. 1967. Jami' al- ulūm yā Hadāyeq al-anwār fì haqāyeq al-asrār: ma' rūf beh Ketāb-i sittīnī. Tehran: Ketabkhanah-i 'Asadi.

—. 1993. "Ilm-i mūsīqĩ: bar gerefteh az Jāmi` al-'ulūm” In Måārif, edited by Amir Hosein Pourjavady, 12 (1/2).

Riggio, Milla C. 1994. “Ta’ziyeh in Exile: Transformations in a Persian Tradition.” Comparative Drama 28 (1; Early and Traditional Drama): 115-140.

Roemer, H.R. 1986. “The Safavid Period.” In Cambridge History of Iran, edited by Peter Jackson and Lawrence Lockhart, 189-349. Cambridge: Cambridge University Press.

Rubin, Zeev. 2008. "Eastern Neighbours: Persia and the Sasanian Monarchy (224-651)." In The Cambridge History of the Byzantine Empire, c. 500-1492, edited by Jonathan Shepard. Cambridge: Cambridge University Press.

Sachs, Curt. 1938. "Towards a Prehistory of Occidental Music." Musical Quarterly 24 (2): 147.

Sadeghi, Manoochehr. 1971. "Improvisation in Nonrhythmic Solo Instrumental Contemporary Persian Art Music." MA thesis, California State College.

Saduqi, Manuchehr. 2005. Resāleh dar musīqīi qadīm va seh guftār dar falsafah-i hunar. Tehran: Farhangistān-i Hunar.

Safahi, Ibrahim. 1962. Rahbarān-i mashrūteh. Vol. 1. Tehran. 
Safvate, Dariouche, and Nelly Caton. 1966. Iran: Traditions Musicales. Paris: Buchet-Chastel. Sahlins, Marshall David. 1995. How "Natives" Think: About Captain Cook, for Example. Chicago: University of Chicago Press.

200o. Culture in Practice. New York: Zone.

Said, Edward W. 1978. Orientalism. New York: Pantheon.

Sakata, Hiromi Lorraine Sakata. 1983. Music in the Mind: The Concepts of Music and Musician in Afghanistan. Kent, OH: Kent State University Press.

Sawa, George. 1981. "The Survival of Some Aspects of Medieval Arabic Performance Practice." Ethnomusicology 25 (1): 73-86.

—. 1985. "The Status and Roles of the Secular Musicians in the Kitāb al-Aghānī (Book of Songs) of Abu al-Faraj al-Ișbahānī (D. 356 A.H./967 A.D.)." Asian Music 17 (1): 69-82.

1989. Music Performance Practice in the Early 'Abbāsid Era, 132-320 A.H./750-932 A.D. Toronto: Pontifical Institute of Mediaeval Studies.

- 2009. "Rhythmic Theories and Practices in Arabic Writings to 339 AH/950 CE: Annotated Translations and Commentaries." Musicological Studies 93.

Schaar, Stuart. 2000. "Orientalism at the Service of Imperialism." In Orientalism: A Reader, edited by Alexander Lyon Macfie, 181-193. New York: New York University Press.

Schneider, Albrecht. 2006. "Comparative and Systematic Musicology in Relation to Ethnomusicology: A Historical and Methodological Survey." Ethnomusicology 50 (2): 236-258.

Schofield, Katherine Butler. 2010. "Reviving the Golden Age Again: Classicization, Hindustani Music, and the Mughals." Ethnomusicology 54 (3): 484-517.

Schülting, Sabine, Sabine Lucia Müller, and Ralf Hertel. 2012. Early Modern Encounters with the Islamic East-Performing Cultures. Burlington, VT: Ashgate.

Seeger, Anthony. 1993. "When Music Makes History." In Ethnomusicology and Modern Music History, edited by Stephen Blum, Philip V. Bohlman, and Daniel M. Neuman, 23-34. Chicago: University of Illinois Press.

- 2004. Why Suyá Sing: A Musical Anthropology of an Amazonian People. Urbana: University of Illinois Press.

Seeger, Charles. 1971. "Reflections Upon a Given Topic: Music in Universal Perspective." Ethnomusicology 15 (3): 385-398.

Sepanta, Sassan. 1998. Tārīkh-i tahūul-i żabț-i mūsīqì dar İrān. Tehran: Mahoor Institute of Culture and Art.

Seydi. 2004. Seydī's Book on Music: A 15th Century Turkish Discourse. Vol. 6, Publications of the Institute for the History of Arabic-Islamic Science: The Science of Music in Islam. Frankfurt am Main: Institute for the History of Arabic-Islamic Science at the Johann Wolfgang Goethe University.

Shahnazi `Ali Akbar Khan and Hooman Asadi. 2003. Radīf-i Āqā Husayn Qolī beh ravāyat-i ejrā-i Ustād 'Alī Akbar Khān Shahnāzī, jeld-i avval. M.CD-108. Tehran: Mahoor Institute of Culture and Art.

Shaked, Shaul. 1995. From Zoroastrian Iran to Islam: Studies in Religious History and Intercultural Contacts. Brookfield, VT: Variorum.

Shannon, Jonathan H. 2007. "Performing al-Andalus, Remembering al-Andalus: Mediterranean Soundings from Mashriq to Maghrib." Journal of American Folklore 120: 308-334, 377. 
2015. Performing al-Andalus: Music and Nostalgia Across the Mediterranean. Bloomington: Indiana University Press.

Shawqi,Yusuf. 1976. "Kitāb al-nagham ibn al-Munajjim. "Risālah ibn al-Munajjim fī al-mūsīqà wa kashf rumūz Kitāb al-aghānī. Cairo: al-Hay’ah al-Misriyah al-'Ammah lil-Kitab.

Shayda. 2010. Mawj-i sabz: majmu'eh-i she r. Suid: Ketab-i Arzan.

Shehadi, Fadlou. 1995. Philosophies of Music in Medieval Islam. Brill's Studies in Intellectual History 67. Leiden and New York: E. J. Brill.

Shelemay, Kay Kaufman. 1980. “'Historical Ethnomusicology': Reconstructing Falasha Litugical History." Ethnomusicology 24 (2): 233-258.

Shiloah, Amnon. 1978. "Introduction." In The Epistle on Music of the Ikhwān i-Ṣâfā, 5-11. Tel-Aviv: Tel-Aviv University.

-1995. Music in the World of Islam: A Socio-Cultural Study. Detroit: Wayne State University Press.

—. 1997. "Music and Religion in Islam." Acta Musicologica 69 (2): 143-155.

-2007. Music and Its Virtues in Islamic and Judaic Writings. Variorum Collected Studies Series. Aldershot, UK, and Burlington, VT: Ashgate.

Shirazi, Forsat al-Dowleh. 1914. Buhūr al-alhān dar 'ilm-i mūsìqì va nisbat ān bā 'aruz. Bombay: Muzaffari Lithographic Steam Press.

—. 1988. Buhūr al-alhān dar 'ilm-i mūsìqì va nisbat àn bā 'aruz. Tehran: Intisharat-i Furughi.

Signell, Karl. 1976. "The Modernization Process in Two Oriental Music Cultures: Turkish and Japanese." Asian Music 7 (2): 72-102.

Smith, Anthony D. 1998. Nationalism and Modernism: A Critical Survey of Recent Theories of Nations and Nationalism. London and New York: Routledge.

Sofrachi, Dawreh. 1582. Resāleh-i kermānìyeh. Biruni Academy of Sciences in (Tashkent, Uzbekistan): Ms. 468/III.

—. 1971. "Resāleh dar bāb-i ma refat-i 'ilm-i mūsīqī (Resāleh-i kermānīyeh)." In Nāmah-i Mìnūvì, edited by Habib Yaghma i, 189-198. Tehran: Chapkhanah-i Kaviyan.

Sourdel, D. 1970. "The 'Abbasid Caliphate." In Cambridge History of Islam, edited by Ann K. S. Lambton, P. M. Holt, and Bernard Lewis. Cambridge: Cambridge University Press.

Stokes, Martin. 200o. "East, West Arabesk." In Western Music and Its Others: Difference, Representation, and Appropriation in Music, edited by Georgina Born and David Hesmondhalgh, 213-233. Berkeley: University of California Press.

Suhrawardi, 'Umar ibn Muhammad. 1985. Avāref al-ma'äref. Edited by Khasim Ansari. Tehran: Shirikat-i Intisharat-i ' Ilmi va Farhangi.

Sultanova, Razia, and Theodore Levin. 2001. "The Classical Music of Uzbeks and Tajiks." In Garland Encyclopedia of World Music, edited by Scott Marcus, Dwight Reynolds, and Virginia Danielson. London: Routledge.

Taba-Taba, Muhammad Reza bin 'abd Qasim. 1882. Naghmeh 'andilīb. British Library (London): Or. 1811, 201a-204b.

Tabrizi, abu Talib ibn Marhum Haji Muhammad Beg Khan. 1804. Resāleh-i mușțalehāt-i mūsīqī. In Khalāṣah-i afkār. British Library (London): IO Islamic 2692, 369b-37oa.

Taherzadeh, Husayn, and Sepanta Sasan. 1999. Avāz-hā-i Țāherzādeh. M.CD-44. Tehran: Mahoor Institute of Culture and Art. 
Tala'i, Dariush. 200o. Traditional Persian Art Music: The Radif of Mirza 'Abdullah. Costa Mesa, CA: Mazda.

Tavakoli-Targhi, Mohamad. 1990. "Refashioning Iran: Language and Culture during the Constitutional Revolution." Iranian Studies 23 (1/4): 77-101.

_ 1996. "Contested Memories: Narrative Structures and Allegorical Meanings of Iran's Pre-Islamic History.” Iranian Studies 29 (1/2): 149-175.

- 2001. Refashioning Iran: Orientalism, Occidentalism and Historiography. New York: Palgrave.

2002. "From Patriotism to Matriotism: A Tropological Study of Iranian Nationalism, 1870-1909." International Journal of Middle East Studies 34 (2): 217-238.

Taylor, Timothy D. 1997. Global Pop: World Music, World Markets. London: Routledge.

Thiesen, Finn. 1982. A Manual of Classical Persian Prosody. Wiesbaden, Germany: Harrassowitz.

Tsuge, Gen'ichi. 1970. "Rhythmic Aspects of the Avaz in Persian Music." Ethnomusicology 14 (2): 205-227.

—. 1974. "Avaz: A Study of the Rhythmic Aspects in Classical Iranian Music." PhD diss., Wesleyan University.

—. 2013. "Musical Instruments Described in a Fourteenth-Century Persian Treatise Kanz al-tuhaf." Galpin Society Journal 66:165-184, 255-259.

Turner, Victor Witter. 1977. The Ritual Process: Structure and Anti-Structure. Ithaca, NY: Cornell University Press.

UNESCO. 2009. "Radif of Iranian Music." www.unesco.org/culture/ich/en/RL/radif-ofiranian-music-0o279.

Urmawi, 'abd al-Mu’min ibn Yusuf. 1982. al-Risālah al-sharafìyah fī al-nasab al-ta'lïfyah. Baghdad: al-Jumhuriyah al-Iraqiyah, Wizarat al-Thaqafah wa-al-Ilam, Dar al-Rashid lil-Nashr.

—. 1986. Kitāb al-adwār fì al-mūsīqā. Cairo: al-Hay'ah al-Miṣrīyah al-“Āmmah lil-Kitāb.

—. 2001. Kitāb al-adwār fī mūsīqì (beh tarjameh-i farsì beh enzemām-i arabī-i ān). Tehran: Miras-i Maktub.

Vaglieri, Laura Veccia. 2008. “The Patriarchal and Umayyad Caliphates.” In Cambridge History of Islam, vol. 1, edited by Ann Lambton, M. Hold, and Bernard Lewis. Cambridge: Cambridge History of Islam.

Vaziri, ‘Ali Naqi. 1923. Dastūr-i tār. Berlin: Kaviyani.

—. 1925. Dar 'ālam-i mùsīqì va șon'at. Tehran.

—. 1934a. Mūsìqīi nazarīi. Tehran: Matbae Tolue .

—. 1934b. Sorūd-ha-i madāres. Tehran: Matbae Tolue .

—.1936a. Dastūr-i jadìd-i tār. Tehran.

— 1936b. Dastūr-i jadìd-i tār va sehtār. Tehran: Farang-sara.

—. 1936c. Dastūr-i vìyūlīn. Tehran.

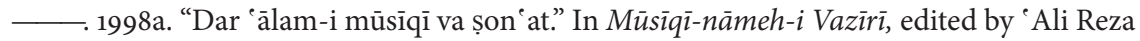
Mir 'Ali Naqi, 61-93. Tehran: Intisharat-i Mu’in.

—. 1998b. "Dar jashn-i sālāneh-i madreseh-i mūsīqīi dūlatî." In Mūsīqì-nāmeh-i Vazīrī, edited by 'Ali Reza Mir 'Ali Naqi, 179-19o. Tehran: Intisharat-i Mu’in.

—. 1998c. "Dard-i honarmand." In Mūsìqì-nāmeh-i Vazīrī, edited by 'Ali Reza Mir `Ali Naqi, 407-414. Tehran: Intisharat-i Mu'in. 
1998d. "Dastūr-i tar." In Mūsìqī-nāmeh-i Vazìrī, edited by 'Ali Reza Mir 'Ali Naqi, 19-39. Tehran: Intisharat-i Mu’in.

_. 1998e. "Madraseh-i mūsīqī az madāres-i 'ālīeh ast." In Mūsìqī-nāmeh-i Vazìrì, edited by 'Ali Reza Mir 'Ali Naqi, 133-144. Tehran: Intisharat-i Mu’in.

_. 1998f. "Mūsīqīi İrān dar 'Dastūr-i vīyūlīn.” In Mūsīqì-nāmeh-i Vazīrī, edited by 'Ali Reza Mir 'Ali Naqi, 151-164. Tehran: Intisharat-i Mu’in.

—. 1998g. "Mūsīqìi İrān: naqāàiṣ, mazāyā’ va rāh-i aṣlāḥ." In Mūsīqī-nāmeh-i Vazīrī, edited by 'Ali Reza Mir 'Ali Naqi, 240-260. Tehran: Intisharat-i Mu’in.

—. 1998h. "Mūsīqī, ham 'ilm ast ham șon ‘at." In Mūsìqì-nāmeh-i Vazīrī, edited by 'Ali Reza Mir 'Ali Naqi, 145-147. Tehran: Intisharat-i Mu’in.

—. 1998i. Șanāyì̄ zarīfeh.” In Mūsìqì-nāmeh-i Vazīrī, edited by 'Ali Reza Mir `Ali Naqi, 43-57. Tehran: Intisharat-i Mu’in.

. 1998j. "Tajassus va muțāla eh dar ārmūnī-i mūsīqīi İrān va mod-ha-ī keh bā ūsūl-i rob " pardeh tashkīl mīgardand.” In Mūsīqì-nāmeh-i Vazīrī, edited by Ali Reza Mir Ali Naqi, 293-310. Tehran: Intisharat-i Mu’in.

—. 1998k. "Mūsīqīi İrān.” In Mūsīqī-nāmeh-i Vazìrī, edited by 'Ali Reza Mir 'Ali Naqi, 274-276. Tehran: Intisharat-i Mu'in.

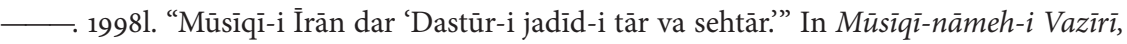
edited by 'Ali Reza Mir 'Ali Naqi, 167-176. Tehran: Intisharat-i Mu’in.

—. 1998m. "Mūsīqīi ìrānī va rādīyū." In Mūsīqì-nāmeh-i Vazìrī, edited by Ali Reza Mir Ali Naqi, 289-292. Tehran: Intisharat-i Ma’in.

Vaziri, 'Ali Naqi, and Naqi `Ali Reza Mir Ali. 1998. Mūsìqī-nāmeh-i Vazīrī. Tehran: Intisharat-i Mu'in.

Vizārat-i Farhang-i Iran, Idārah-i Mūsīqīi-i, Kishvar. 1939. Majallah-i mūsīqī. Tihrān: Gh. Mīn Bāshiyān.

Vohdani, Reza. 1997. Radīf-i sāzī-i mūsīqì-i irānī. Tehran: Sazman-i Farhangi va Intisharati Iran-i Jam.

Wachsmann, K. P. 1958. "Recent Trends in Ethnomusicology." Proceedings of the Royal Musical Association 85:65-80.

Wade, Bonnie C. 1998. Imaging Sound: An Ethnomusicological Study of Music, Art, and Culture in Mughal India, Chicago Studies in Ethnomusicology. Chicago: University of Chicago Press.

Walbridge, John. 1992. "A Sufi Scientist of the Thirteenth Century: The Mystical Ideas and Practices of Qutb al-Din Shirazi." In The Heritage of Sufism, vol. 1, The Legacy of Medieval Persian Sufism, edited by Leonard Lewisohn and David Morgan, 323-341. London: Khaniqahi Nimatullahi.

—. 1998. "Explaining Away the Greek Gods in Islam." Journal of the History of Ideas 59 (3): $389-403$.

Weil, G., and G. M. Meredith-Owens. 2007. "Aruḍ." In Encyclopedia of Islam, edited by Th. Bianquis, C.E. Bosworth, E. van Dozel, P. Bearman, and W.P.Heinrichs. University of California, Los Angeles, www.brillonline.nl/subscriber/entry?entry = islam_COM-oo66.

Weismann, Itzchak. 2001. "Between Sufi Reformism and Modernist Rationalism: A Reappraisal of the Origins of the Salafiyya from the Damascene Angle." Die Welt des Islams 41 (2): 206-237.

Wellesz, Egon. 1932. "Byzantine Music." Proceedings of the Musical Association 59:1-22. 
Widdess, Richard. 1992. "Historical Ethnomusicology." In Ethnomusicology: An Introduction, edited by Helen Meyers, 219-237. New York: Norton.

-1995. The Ragas of Early Indian Music: Modes, Melodies, and Musical Notations from the Gupta Period to c. 1250. Oxford: Oxford University Press.

Wilber, Donald Newton. 1975. Riza Shah Pahlavi: The Resurrection and Reconstruction of Iran. Hicksville, NY: Exposition Press.

Wright, Owen. 1966. "Ibn al-Munajjim and the Early Arabian Modes." Galpin Society Journal 19:27-48.

-1978. The Modal System of Arab and Persian Music, A.D. 1250-1300. Oxford: Oxford University Press.

—. 1992a. "Segah: An Historical Outline." In Geschichte und Gegenwart: Materialien der 2. Arbeitstagung der Study Group "Maqam" des International Council for Traditional Music vom 23. bis 28. März 1992 in Gosen bei Berlin, 480-509. Berlin: ICTM.

-1992b. Words Without Songs: A Musicological Study of an Early Ottoman Anthology and Its Precursors. SOAS Musicological Series 3. London: School of Oriental and African Studies, Univeristy of London.

—. 1994a. " "abd al-Qader al-Maraghi and 'Ali b. Muhammad Bina’i: Two Fifteenth Century Examples of Notation. Part One: Text." BSOAS 57:475-515.

—. 1994b. "'abd al-Qādir al-Marāghī and 'Alī B. Muhammad Bināì: Two Fifteenth-Century Examples of Notation Part 1: Text." Bulletin of the School of Oriental and African Studies, University of London 57 (3): 475-515.

_. 1995. "'abd al-Qādir al-Marāghī and 'Alī b. Muḥammad Bināìi: Two Fifteenth-Century Examples of Notation Part 2: Commentary." Bulletin of the School of Oriental and African Studies, University of London 58 (1): 17-39.

—. 1996a. "Middle Eastern Song-Text Collections." Early Music 24 (3; Early Music from Around the World): 454-458, 460, 462, 465-469.

—. 1996b. "On the Concept of Timurid Music." Oriente Moderno 15 (76): vol. 2, pp. 665-681.

2000. Demetrius Cantemir. Vol. 2. Aldershot, UK, and Burlington, VT: Ashgate.

—. 2001a. "'abd al-Qādir [ibn Ghaybī al-Marāghī]." In The New Grove Dictionary of Music and Musicians, edited by Stanley Sadie. London: Macmillian.

_. 2001b. "Quṭb al-Dīn [Maḥmūd ibn Mas'ū ald-Shīrāzī].” In The New Grove Dictionary of Music and Musicians, edited by Stanley Sadie. London: Macmillian.

—. 2001c. "Șafî al-Dīn [Urmawī]." In The New Grove Dictionary of Music and Musicians, edited by Stanley Sadie. London: Macmillian.

- 2006. "Al-Kindī's Braid." Bulletin of the School of Oriental and African Studies, University of London 69 (1): 1-32.

- 2010. On Music: An Arabic Critical Edition and English Translation of Epistle 5, Epistles of the Brethren of Purity. New York: Oxford University Press.

Youssefzadeh, Ameneh. 2000. "The Situation of Music in Iran since the Revolution: The Role of Official Organizations." British Journal of Ethnomusicology 9 (2): 35-61.

Yusif, Zia al-Din. 1797. Küllìyāt-i Yūsifì. Private Collection of Mehdi Sadri, Tehran.

Zahiri, Haji Hosein Isfahani. c. 160o. Resāleh-i Hājì Husayn Ișfahānī dar fann-i mùsīqū. University of Edinburgh Special Collections: Or. Ms. 585, 1-17.

Zayla, ibn. 1048. Kitāb al-kāfî̀ fì al-mūsīqì. British Library (London): Or. 2361. 
Zonis, Ella. 1966. "Persian Music: A Study of the History, Theory and Practice of Contemporary Art Music in Persia." PhD diss., University of California, Los Angeles.

- 1973. Classical Persian Music: An Introduction. Cambridge, MA: Harvard University Press.

Zubaida, Sami. 1989. Islam, the People and the State: Essays on Political Ideas and Movements in the Middle East. London: Routledge. 



\section{N D E X}

'Abbasid Caliphate, 6, 25, 35, 42, 98; ancient Iranian music and, 171; Graeco-Arabic writings on music, 29; patronage of musicians, 36 ; slow decline of, 36

'abd Allah Qutb Shah, 45

'Abdullah, Mirza, 113-14, 124, 126, 133, 143, 178; authentic Iranian tradition and, 180, 181; instrumental radifs and, 189; radif-dastgah tradition and, 179, 209; Saba as student of, 183 Abd al-shāmel melody, 149

Abu-'Ata ( $a b \bar{u}$ ' $\left.a t ̦ a \bar{a}^{\prime}\right)$ avaz-dastgah, 107, 136, 148; modal interpretations of, 107-8; tonic of, 109 Abu Bakr (companion of Muhammad), 68, 69 Abūl melody, 140

Achaemenid Empire, 1, 171, 203

acoustics, 143

adwar [adwār] (theory of scale creation), 27, 28, $30,44,143,146$

Afghan invasion (1722), 86, 88, 101, 116 Afshari (afshārī) avaz-dastgah, 107, 138, 141; as matin, 150 ; modal interpretations of, $107-8$; new music of Iran and, 161; Shur dastgah and, 148 ; tasnif and, 204

Afsharid Dynasty, 46, 116

agency, 11, 13, 14

ahang (ähang) melody, 135, 141

Ahmed, Shahab, 63, 64

'Aisha (wife of Prophet Muhammad), 68

'Ali (cousin of Muhammad), 68, 89, 96

'Ali (Shi'a Imam), 200

'Ali Akbar Shahnazi, 180
'Alizadeh, Hossein, 210-11

'amal ['amal] (practice), 34, 35, 50, 59, 63; musica practica and, 17; poetry and, 186

Amir Khan Gorgi, 32, 45, 88, 99, 187; Ramal rhythmic cycles according to, 33; song collection of, 95-98

Amuli, Muhammad ibn Mahmud Shams al-Din, 40,49

Anatolia, 25, 38

al-Andalus (Muslim Spain), medieval, 13

Anglo-Persian (later, Anglo-Iranian)

Oil Company, 117, 122

animal vocalizations, 56,85

anthropology, 13, 18, 219

Āqādeh melody, 148

Arabic language, 8, 11, 53, 59, 187; 'aruz ('aruż) poetic meter and, 31; decline of standing in Safavid Empire, 35; documentation of twelvemaqam system in, 26; ghazal genre and, 185; Islam and, 37,65 ; medieval writing on music, 10; on morality of instruments, 70 ; music treatises in, 7, 12; rise of Islam and, 19; rules of poetry and, 188; songs and singing in, 5 , 34; sources on music in, 9; Sufi texts in, 66

Arabic music, 1

archeology, Foucauldian, 18

architecture, 81, 83, 100, 147

'Aref Qazvini, Abolqassem, 20, 126, 206; critique of Vaziri, 169-71, 177-82, 184; tasnif compositions of, 177-78, 202-6, 207

Aristotle, 56 
'aruz ('aruż) poetic meter, 31

Aryan hypothesis, 121

Asadi, Hooman, 6

'Ashirān melody, 140, 150

Ashjār va asmār (Ibn al-Munajjim), 55

astronomy/astrology, 55, 62

Ataturk, Mustafa Kemal, 121

Aurangzeb Alamgir (Mughal ruler), 44

avaz (avāz) melodic complex, 4, 29, 31, 32, 150;

animal vocalizations and, 56; avaz-dastgah,

106, 107, 108, 109, 112, 164; in circular chart

representing twelve-maqam system, 30 ; cos-

mological alignments of, 135; dastgah scales

for, 159, 160; ghazal and, 141, 188; gusheh and, 115; improvisation and, 113; instruments and, 54; khaneh and, 33; Mahur dastgah and, 140; meanings of, 7-8; performance of, 206; types of people/geographies and, 53

avaz (awāzah) scale, 27, 28

avaz-dastgah, 106-9, 112, 165-66, 183, 188, 211, 212

Avāz seh qesm, 138

Aynur, 211

Azad Khan, territory of, 46

āzarbyjānī melody, 140, 149

Azerbaijan, 15, 203, 205-6

"Azerbaijan" ( Aref Qazvini), 205-6

Azeri music, 5, 15, 113, 116

Azeris, 5, 11; 'Aref Qazvini's appeal to, 205-6; as minority in Iran, 15,121

Baba Taher Orian, 187

Babayan, Kathryn, 99

Babism, 126

Baghdad, 25, 36, 116; as 'Abbasid capital, 26; in the Ilkhanate, 39; Mongol siege of, 37; in Safavid Empire, 43; in Timurid Empire, 41

Bahā' allah, 126

Baha'i religion, 126

Bahar, 201, 207

Bahram Shah, 26

Bakharzi, 'Abd al-Mafakhir Yahya, 69, 71, 74; on faking of sama', 76 ; on sama' and the soul, 77

Bakhtiari dastgah, 141, 190

Bāl-i Kabūtar melody, 150

Baluchis, as minority in Iran, 15

Bana'i, 42, 57

Bāq-i Nīshābūr melody, 148

Barbad, 59

bar-dasht (bar-dāsht) melodies, 148-50, 150

bar gasht [bar gasht] (recapitulations/reprises), $5,34,35$
Basij militia, 14

Bastami, Foroughi, 196

Baste-Negar gusheh, 192

Bayati (bayātī), 53

Bayat-i Isfahan (bayāt-i isfahān) avaz-dastgah, 107, 109, 136, 160; maqam scales and, 151, 152; as matin, 149; modal interpretations of, 107-8; tasnif and, 197, 198, 199, 201, 206, 212

Bayat-i Kord (bayāt-i kord) avaz-dastgah, 107, $138,141,148$; as matin, 150 ; modal interpretations of, $107-8$

Bayat-i rāje' melody, 140, 150

Bayat-i shīrāzī melody, 138

Bayat-i Tork (bayāt-i tork) avaz-dastgah, 107, 138, 141, 148; as matin, 150; modal interpretations of, 107-8; new music of Iran and, 161

Bidad ( $b \bar{i} d \bar{a} d$ ) gusheh, 161, 161

Bīd kānī melody, 138

Bizet, Georges, 175

Book of Songs [Kitāb al-aghānī] (al-Isfahani), 99

Borumand, Nur 'Ali, 106, 109

Bozorg bā do melody, 148

Bozorg gusheh, 109, 138, 150

Bozork (bozork) shadd, 27, 52, 53

Buhūr al-alhān (Forsat Shirazi), 131, 134-42; ghazal listed in, 189; Mahur (māhūr) dastgah in, 140; Shur (shür) dastgah in, 137, 138, 139

Bukhara, 25, 116; in the Afsharid Empire, 46; Emirate of, 46 ; in the Timurid Empire, 41

Bukhari, Mustamli, 74

Busalik (būsalìk) shadd, 27, 51, 52, 53

Būsalīk melody, 140, 150

Butler, Katherine, 13

Buyids, 36

Byzantine Empire, 36

capitalism, 219

Carmen (Bizet opera), 175

Caruso, Enrico, 175

Central Asia, 5, 17, 42, 120, 209; cosmopolitan Islamic empires in, 19; end of 'Abbasid rule in, 36; fall of Soviet Union and, 15; ghazal poetry in music performance, 185 ; musical instruments of, 3; music traditions of, 12; Persian-speaking people in, 15; political change across, 86; premodern empires in, 47; Turkic and Mongol rule in, 38, 215; twelvemaqam system in, 25

Chahargah (chahārgāh) dastgah, 52, 53, 107, 165, 179, 211; in Buhūr al-alhān (Forsat Shirazi), 136; ghazal and, 141, 192; maqam scales and, 151, 152; modal interpretations of, 107-8; 
poetic genres and, 190, 191, 192, 193, 194; tasnif and, 198

chahar mezrab [chahār meżrāb] (solo instrumental piece), 111, 112, 113, 138, 140, 148; gusheh and, 186; placement after the daramat, 206 chahar pāreh melody, 138

chakāvāk melody, 150

chanting, ritual (zikr), 66

Chekavak gusheh, 196

"Chinese Instrument of Bowls, The” ("Sāz-i qațāt-i chīnī”), 54

Chingiz Khan, 5, 38, 40, 90

Chobanids, 39

codas (zayl), 5, 34, 35

colonization, European, 5

composition, 4, 33-35, 61-62; composer (muṣannif), 62; creator of melody (mulahn), 62; improvisation contrasted with, 213; metered, 3

Congress of Arab Music (Egypt, 1932), 9

Conservatory of Music (Honaristān-i mūsīqī), 171

consonance, 85

"Crown of the Great King's Head" ( Aref

Qazvini), 204-5

cultural production, 18, 21

Cyrus the Great, 14

Dād melody, 140

daf (frame drum), 114

Danāseri melody, 140

Dar al-Fonun (Dār al-Fonūn) military school, $117,122,124$

daramad (darāmad) melodies, 110, 113, 135, 138, 140, 150, 160; chahar mezrab placed after, 206; darāmad-i aval, 140, 149; darāmad-i davvim, 140; darāmad-i seyyim, 140 ; poetry and, 191, 192, 193; Shur dastgah and, 148

D’Arcy Oil Concession (1901), 117

Dariush the Great, 203

Darvish Khan, 125, 126, 133, 183, 201

Dashti (dashtī) avaz-dastgah, 107, 138, 150, 159; Masnavi poetry and, 141, 190; as matin, 150; modal interpretations of, 107-8; new music of Iran and, 161; tasnif and, 203, 204, 206; tonic of, 109

Dastān-i 'arab melody, 138, 150

dastgah (dastgāh), 3, 6, 105, 155; ancient poetry and melodic structures of, 190-97; daramad [darāmad] (introduction), 110, 113, 135, 138, 140; maqam scales and, 151; modal interpretation by During, 107; modal interpretation by Miller, 108; pish-daramad, 112, 140; pitches in performance of, 4 ; poetic themes/symbolism in poetry of, 194-97; tasnif (tașnif) songs, 112. See also avaz-dastgah; radif-dastgah tradition; seven dastgah of Qajar court

Dastūr-i tār (Vaziri), 134, 159

Davami, Abdollah, 189, 190, 192, 199, 200, 212; on division of poetry in Chahargah, 193, 194; on earliest ghazal-based tasnif, 197; singing of tasnif, 206; vocal radif version of, 213

al-Dawlah, Sayf, 36

Delkash gusheh, 109, 179

Delkesh melody, 140

democracy, 120, 125

discourse, redundancy of, 17

discourse analysis, 18

dissonance, 85

dobaytī melody, 138

dobayti poetry, 141, 187, 188

documentation, historical, 18

Dogah (dogāh) maqam, 52, 53, 54

drums, 3, 114

al-Dunya, Ibn Abi, 70

During, Jean, 5, 106, 109

Durrani Empire, 46

Durrat al-tāj (Qutb al-Din Shirazi), 38, 40

Ebadi, Ahmad, 182

emotion, musical performance and, 50-51, 52, $173,174,176,178-80$

Enumeration of Knowledge (al-Farabi), 62-63

Erzincan, Erdal, 211

ethnolinguistic identities, 11, 217

ethnomusicology, 106, 110, 219

Euclid, 56, 57

European (Western) music, 127, 166, 178, 218; dominance of, 153, 173; fugue, 150; hegemony of, 5-6; influence on radif-dastgah tradition, 219; as international music, 173,177 ; intonation, 146, 157; military music in Western style, 9; scientific thought and, 144, 146, 147

fann [fann] (art), 48, 49, 50

al-Farabi, 8, 10, 11, 28, 57, 135; 'Abbasid patronage of, 36; Enumeration of Knowledge, 62-63; Kitāb al-mūsìqā al-kabìr, 36; legend about musical ability of, 50, 60; rules for intervallic structure, 172

Farahani, 114

Farānī melody, 150

Farmer, Henry George, 9, 26, 45. See also Systematic School 
Farsi, Khalif Shams al-Din Mohaqeq, 58, 59

fasil (Ottoman musical structure), 43

Faṣl-i mollā melody, 148

Ferdowsi, 70, 90-91, 95, 182, 195

fiddle, spiked. See kemancheh [kemäncheh]

filī melody, 140, 149

Forsat al-Dowleh Shirazi, 20, 130-32, 138, 141-42, 164, 165; on dastgah melodies as ancient and Persian, 213; on ghazal, 189-90; on instrumental sections and dastgah, 206. See also Buhūr al-alhān

forud (for $\bar{u}$ ) phrases, 110, 111, 135, 148, 149

foru-dasht (forū-dāsht) melodies, 150

foru dasht (furū dasht) song form, 34

forud seh qesm, 138

Foucault, Michel, 18

France, 174

"From the Blood of the Country"

('Aref Qazvini), 203

fugue, European, 150

Gabrī melody, 150

Gambarov, Salman, 211

Gardanieh (gārdāniyeh), 54, 140, 150

Gardaniya (kardāniya) scale, 27

Gavasht melody, 140, 150

Gavri, 136

Gawasht (kawāsht) scale, 27

Germany, 121, 174

Gham angiiz melody, 138, 148

ghazal (ghazal) song and poetry, 34, 141; dastgah and, 187, 194, 212; history of, 185; poetics of Iranian history and, $187-90$

Ghaznavi, 'abd al-Rahman Sayf, 51-52

Ghaznavid Empire, 26, 35, 36, 37

Ghazzali, 67, 70-71, 75, 78

ghīnā' (formal musical practice), 12, 69, 84

Gilakī melody, 138, 148, 150

Gilan, Nizam al-Din Ahmad, 45

Gilani (dastgah), 141

Go-Between, The (Hartley), 1

golriz melody, 138

Goshā melody, 148

Government School of Music (Madreseh-i mūsīīi), 17o, 171

Graeco-Arabic writings on music, 26-29, 48, 51, $57,65,85$

Grāylī melody, 138, 148

Grāylī shaștī melody, 138

Great Britain, 117, 120, 121, 204

"Great Sciences of Iran in the Art of Music, The" ["Ulamā'-i bozorg-i dar fann-i mūsīqī"] (journal article), 9
Greek music, ancient, 10, 171

Greek philosophy, 10, 26, 62, 63

Gūsheh melody, 149

"gunpowder empires," 42-46, 86

Gūrī melody, 138

gusheh (güsheh) melodies, 4, 5, 31, 85, 155, 192; chahar mezrab, 111, 112, 113; in circular chart representing twelve-maqam system, 30 ; cosmological alignments of, 135; dastgah in relation to, 106; forud (forūd) phrases and, 111; ghazal and, 188-89; modal parameters of, 109; modal variation and, 212; in Mughal-era texts, 45; Mughal ragini and, 55; new gusheh in the radif, 212, 213; poetry recitation and, 186, 206; reng, 111, 112, 113; scales and, 161-62; singing poetry and, 111; as source of sho beh, 29; subsets of, 106; systematic modality and, 160; tahrir and, 111; twelve-maqam system expanded to include, 60 gūsheh-i dūgāh melody, 138 gūsheh-i nayrīz melody, 140

Hafez, 182, 187, 190, 192, 194, 195, 197

hal [hăl] (sudden inspiration), 74

Hamdan family, 36

harmony, tonal, 134, 147, 153, 177

Hartley, L. P., 1

hava'i (hava' 'î) song, 33

Hedayat, Mehdi Qoli, 20, 124, 132-33, 134, 153, 218; on dastgahs in practice, $148,148-50,150$; on racial psychology and music, 144, 146-47; radif-dastgah tradition and, 166; Vaziri compared with, 156, 157, 158, 162, 163. See also Majma' al-advār

Helmholtz, Hermann, 143-44, 146

Herat, 40, 42; in the Afsharid Empire, 46; in Ghaznavid Empire, 37; in the Ilkhanate, 39; Maraghi in, 87; in Safavid Empire, 43; in the Timurid Empire, 41

al-Herawi, 'Inayattalah bin Mir Haj, 53

Hesar gusheh, 191, 192, 193, 194

Hezbollah, 14

ḥājiānī melody, 138

harbì (reng of Nava), 140

ḥazin do qesm, 138

haazin melody, 148, 149

hẹesār-i māhūr melody, 140, 149

ḥijāz melody, 138, 148, 150

Hijaz (hijäz) shadd, 27, 52, 53; Chinese segmented instrument and, 54; ghazal and, 141

Hindi language, 53

Hindustani music, 13, 211

hits (naqarāt), 34-35 
Hodi gusheh, 191, 192, 193, 194, 195

al-Hokma, Mirza Mehdi-Khan Montazam, 124,143

Homayun (homāyūn) dastgah, 52, 107; in Buhūr al-alhān (Forsat Shirazi), 136; ghazal and, 141, 196; maqam scales and, 151, 152; modal interpretations of, 107-8; scales and, 158; tasnif and, 206, 207; tonic of, 109

Hosein, Gholam, 113

Hoshang, 90, 97

Hujviri, 'Ali ibn 'Usman, 67, 71, 72, 73

Humayun (Mughal ruler), 81, 82

humeral theory, 51

Husayn, Sultan, 96, 97

Husayni (hūsaynī) melody, 27, 51, 52, 53, 54

Husayn I, Sultan, 40

Husayn melody, 140, 150

Husayn Qoli, Aqa, 149

Husayn Qoli, Mirza, 8, 124, 126, 131, 133, 143, 178; authentic Iranian tradition and, 180, 181; instrumental radifs and, 189; radif-dastgah tradition and, 209; as tar player, 113-14

Huzzan gusheh, 193, 194

Ibn al-Munajjim, 55

Ibn Khaldun, 53

Ibn Mutahhar, 71, 77

Ibn Qabus, 51

Ibn Sina, 10, 28, 36, 57, 156, 172

'ilm ['ilm, pl. 'ūlum] (science, knowledge), 49-50, 63, 74; knowledge of compiling melody ('ilm-i ta'aliff), 61; knowledge of rhythmic aspects ('ilm-i iqā'), 61; musica speculativa and, 17,48

'Iraq, Sa'di, 58, 59

Ilkhanate, $38,39,40,54,83$

"Impact and Influence of Iran on the Construction of Instruments, The" [“Ta' tīr va nufūz-i īrān dar țab 'atī alāt”] (journal article), 9

imperialism, Western, 219

improvisation, 4, 211; composition contrasted with, 213; gusheh and, 110, 111, 113; poetry and, 114; tahrir (tahrīr) vocal improvisation, 111; twelve-maqam system and, 32; unmetered, 3, 4

Injuids, 39, 40

"Instrument of Bars They Make from Metal" ("Sāz-i alvāh ke az pūlād sāzand"), 54

instruments, 3, 54, 80, 85, 182; daf (frame drum), 114; morality of, 70-71; nay [nāy] (reed flute), 114, 195; percussion, 31; wine and drunkenness associated with, 70; $\dot{z}$ arb (goblet-shaped drum), 114 instruments, stringed, 28, 49, 54; kemancheh [kemāncheh] (four-stringed spiked fiddle), 114; qanun (qanūn), 114; santur [santūr] (hammer dulcimer), 114; setar [setār] (longnecked lute), 3, 114; tar [tār] (long-necked, fretted lute), 105, 113-14, 134; 'ud [' $\bar{u} d]$ (short-necked lute), 114

interludes, musical, 186, 192, 206

intervals, $49,85,158$

intonation, 146, 157, 172

Iran, modern, 2, 20, 167; (re)constructed identity of, 209; concept of Iran in Safavid-era song texts, 97-98; Constitutional Period, 170, 172; cultural revival of, 151; distinct music history of, 10; dynastic governance and, 207; Islamic Republic, 14; Islamic Revolution (1978-1979), 13, 15, 210; musical and cultural diversity of, 15; musical/cultural renaissance of, 156, 163; music and modernity in, 123-28; music and revived greatness of, 170; national identity of, 19, 116, 121, 214; nationalization of music in, 120, 128, 129, 184, 186; pre-Islamic Iran as golden age and, 203, 205; Safavid imperial ambitions and, 101; tasnif and, 201

Iranian music, 2, 13, 131; authenticity and, 11, 109-10; emotional quality of, 178-79; ethnolinguistic identity and, 8; fusion collaborations with non-Iranian performers, 211; golden age narrative and, 38, 42, 185; as lost art, 156; morality and, 172-73; Orientalist musicology and, 10, 17; Persian language and, 1, 154; radif and, 15; radif-dastgah tradition and, 11; recordings of, 165 ; revival of past Persian practices, 150-51; Safavid Dynasty as low point of, 82; Timurid legacy outside Iran and, 86; twelve-maqam system and, 25; Vaziri and music education, 155; in world music market, 210-11. See also Persian music, traditional

Iraq ('irāq) melody, 27, 51, 52, 140, 179; maqam scales and, 151; in matin, 149; modal parameters of, 109; tasnif and, 206

Isfahan (ișfahān) shadd, 27, 53

Isfahan, city of, 40, 81; in the Afsharid Empire, 46; in Ghaznavid Empire, 37; in the Ilkhanate, 39; in Safavid Empire, 43; in the Timurid Empire, 41

al-Isfahani, 99

Islam, 47, 58, 62; adopted by nomadic invaders, 37; early Islamic leaders in song texts, 89; hadith, 68; halāl (lawful) status, 68; harām (forbidden) status, 68, 71, 77, 78; Islamic philosophy, 26, 62, 64; Mongol and Turkic kingdoms underpinned by, 25; mysticism 
and syncretism in, 38, 43, 65, 93; Persianate Islamic empires, 20, 26, 88; pre-Islamic Persian kings, 70, 90-91, 95, 97; prophets of, 64; relationship with dynasty, 100; rise of, 1 , 4, 156; shah and, 94; Sunni, 14; Turkic and Mongol adoption of, 38. See also Shi a Islam; Sufism

Isma 'il-Zadeh, Husayn Khan, 180, 182, 183

ist (ist) note, $158,159,160$

Jalayrids, 39, 40, 88

Jameh Daran, 136

Jami, Nur 'abd al-Rahman, 42

Jāmi al-alhân (Maraghi), 40, 54, 59, 87

Jāmi' al-'ulūm (Razi), 51

Jamshid, 90, 97, 203

Kabul: in the Afsharid Empire, 46; in Ghaznavid Empire, 37; in the Timurid Empire, 41

Kahn, Mirza Shafi, 105

Kalhor, Kayhan, 210-11

Kanz al-tuhaf (Kashani), 44

kar [kār] (general term for musical composition), 34-35, 186

karāghalī melody, 149

Kardi-Khaketi, Kingdom of, 46

Karimi, 189, 213

Kashani, Hassan, 44, 50

Kashani, 'Izz al-Din, 73, 75, 78

Kashfal-mahjūb (Hujviri), 67, 71

Kavadh II (Sassanian king), 58

kemancheh [kemāncheh] (four-stringed spiked fiddle), 3, 114, 180, 182, 183, 210

Kereshmeh (kereshmeh) gusheh, 110, 138, 194

Khaleqi, Ruhallah, 125, 200

Khan, Shujaat, 211

khaneh [khāneh] (melodic development within a composition), 33, 34-35

Khanom, Bibi, 170

Khārā melody, 148

Khāvarān melody, 140

Khavārazam Shāhī (Husayn Qoli), 149

Khiva, Khanate of, 46

Khojasteh melody, 140

Khosrovānī melody, 140

Khurasan, 38, 53

Kiesewetter, Raphael, 8, 10, 142

al-Kindi, 10

Kitāb al-mūsīqā al-kabìr (al-Farabi), 36

Klub Musical, 127, 170

Kohsrow Parviz (Sassanian king), 58, 59

koron [koron] (half-flat pitch), 157, 159 koshteh mordeh melody, 140

Kuchak (küchak) maqam, 52, 53

Kūcheh bāghī melody, 138

Kurds, as minority in Iran, 15, 121

Land, Jan Pieter Nicolaas, 8, 142

language, 7,11 ; minorities in Iran, 15; music in cosmopolitan spaces and, 12; shaky relationship with music, 8 ; twelve-maqam system and, 61-62

Lebanon, 14

Lemaire, Alfred Jean Baptiste, 124

listening. See sama

Maghlub (maghlüb) gusheh, 52, 192, 193

Maghmeh-ye Maghlub gusheh, 194

Mahammadi, Mohsen, 6

Mahur (māhūr) dastgah, 107, 135, 140, 179; in Buhūr al-alhān (Forsat Shirazi), 140; ghazal and, 141, 196; Hedayat's description, 148, 149, 164; maqam scales and, 151, 152; as matin, 149; modal interpretations of, 107-8; tasnif and, 206

Māhūr-i șaghīr melody, 140, 149

Majilisī melody, 140, 150

Majma' al-advār (Hedayat), 132, 142-43; dominance of European music and, 153-54; nodal lines illustrated in, 145; On the Sensations of Tone (Helmholtz) and, 143-44, 145, 146, 146; tuning fork experiment illustrated, 146

Malek husayni melody, 150

Mansuri gusheh, 191, 192, 193, 195, 197

Manuscrits persans concernant la musique (catalog, ed. Massoudieh), 16-17

maqam (maqām) melodic mode, 4, 7, 29, 31, 35; ambiguity of meaning in, 93; animal vocalizations and, 56 ; astronomy/zodiac and, 55-56; in circular chart representing twelvemaqam system, 30; cosmological alignments of, 135; evolution into the dastgah, 8 ; healing powers attributed to, 51-52; instruments and, 54; khaneh and, 33; in Mughal-era texts, 45; Mughal rag and, 55; scales in dastgah, 151; types of people/geographies and, 53; Uyghur maqam, 5

Maragha, city of: in the Afsharid Empire, 46; in the Ilkhanate, 39; in Safavid Empire, 43; in the Timurid Empire, 41

Maraghi, 'abd al-Qader, 8, 45, 59, 95, 99, 132, 187; on compositional forms, 33-34; dynastic courts served in, $87-88$; golden age narrative and, 185; on 'ilm and 'amal, 50; Jāmi' 
al-alhān, 40, 54, 59, 87; modern national conception of Iranian music and, 207; on music as practice, 59-60; music notation used by, 153; on the nawbat murattab, 34, 60, 148; Orientalists and, 10, 143; in pantheon of wise men, 57; poetry and, 186; rhythmic notation of, 31-32, 32; song collection of forty-five gatherings, 88-96; son in service of Ottoman Empire, 44; "Systematic School" and, 26; Timurid musical legacy and, 86; transnational legacy of, 11; twelvemaqam system and, $27,40,42,147,151$; on wise men, 59

Masnavi poetry, 141, 187, 188, 190, 195

mass media, musicians and, 128

Massoudieh, Mohammad Taghi, 16-17

Masters of Persian Music, 211

matin (matn) melodies, 148-50, 150

Maygoli dastgah, 141

mehdi żarrābī melody, 138

Mehmet II (Ottoman sultan), 44

Mehribāni melody, 138

melody, 3, 12, 67, 71; categories in dastgah, 150; creator of melody (mulahn), 62; Iranian scales and, 158; knowledge of compiling melody ('ilm-i ta'aliff), 61; melodic modes, 4-5; Persian melodies versus Iranian modes, 162-67; primary and secondary, 5, 34

Middle East, 1, 16, 217, 220; composers and music theorists of, 10; cultural change in, 218; cultural orders in, 18; integration into global economic and political system, 5; language groups of, 2; musical instruments of, 3 ; music jargon, 7; music traditions of, 12; premodern empires in, 47

Miller, Lloyd, 106, 109

Mirza 'Abdullah, 8

Mirza Khan ibn Fahr al-Din, 44

Miṣbāh al-hidāyah wa miftāḥ al-kifāyah (Kashani), 73

miyan khaneh [mīyān khāneh] (secondary melodic section), 34, 35

modality, abstract, 112, 211; radif-dastgah tradition and, 114; rhythmic cycles and, 115; seven Qajar dastgah and, 162-63

modality, systematic, 110, 154; changes in, 212; dastgah and, 164; gusheh and, 160; Iran's narrative of Persian music and, 153, 154; legacy of Persian music and, 131; poetry recitation and, 185; radif-dastgah tradition and, 210, 211; seven Qajar dastgah and, 155; tasnif and, 206, 213; Vaziri and, 154 modernization, 174, 218, 219; Pahlavi family and, 122, 128; of Qajar dynasty, 122, 133

Mohammadi, Mohsen, 165

Mohayyer maqam, 53, 54

Mokhalef gusheh, 191, 192, 193, 194

mollā nāzi melody, 138

Mongol empires and rulers, 25, 26, 81

Mongol invasion, 5, 19, 36, 38

moqademeh-i bozorg do qesm, 138

moqademeh-i golriz, 138

moqademeh melody, 148

Mosaddeq, Mohammad, 123

Mosannef, Aqa Mo'men, 6o, 88, 95-98, 99

Moses $(M \bar{u} s \bar{a})$, story about origin of music and, 58

motighayyer (motighayyer) note, 158, 159, 160

motreb [motreb] (lower-class performers), 127

Mozzafar al-Din Shah, 126

Mughal Empire, 42, 54, 101, 116; challenges to dynastic rule, 47; Timurid musicians in, 44; twelve-maqam system and, 55, 85-86

mugham, Azeri, 5, 15, 116

Muhammad, Prophet, 58, 68-70, 71, 89, 92, 96

Muhammad 'Ali, 126

music: adaptation to changing politics of empire, 20; approved or disapproved in sama texts, 69-71; as balance of science/art and theory/practice, 48-49, 156; changing politics of empire and, 98-102; cosmic reality (natural order) and, 56; cultural change and stability in relation to, 218; cultural order and, 17-19; depiction of dynastic authority and, 83; effect on the soul, 77; ethnolinguistic identity and, 217; evolutionary model and history of, 220; Graeco-Arabic writings on, 26-27; language and, 8, 12; morality or immorality of, $20,84,173$; national character and, 168; power of music and sound in sama', 71-75; purely theoretic ( $m \bar{u} s \bar{s} q \bar{q}), 12$; regulation of performance in Islamic Republic, 14; role in history, 21; royal patronage of, 35-46; urban music practices (ghīnà '), 12; written notation, 32. See also Iranian music; Persian music

musica practica (music in practice), 17

musica speculativa (music in theory), 17, 48

musicians, 7, 16, 83; end of dynastic patronage in modern Iran, 123-28; legends about progenitors of music, 59; modal identity, 166; morality and, 172, 184; nostalgia for medieval al-Andalus, 13; in Safavid courts, 45; world music market and, 210-11 
music notation (dastūr-abjad), 153, 155, 173 musicology, European Orientalist, 8-10, 17 musicology, Iranian, 6, 7, 16-17, 83, 133, 210, 219 music schools, in modern Iran, 124, 127, 170-71 music theory: Iranian, 106; racial psychology and, 144; Western, 143, 146, 151

Mūsìqì-i naẓarī (Vaziri), 134, 159, 160, 162, 165 Musli, Isaac, 71

al-Musta'sim, Caliph, 26

Muyeh gusheh, 150, 192

Muzaffar, Mazhar, 44

Muzaffarids, 39

Nader Mohamed Khan, 81

Nader Shah, 46

Nafā' is al-funūn (Amuli), 40, 49

naghmeh-i rāk melody, 140

Naghmeh-ye Maghlub gusheh, 193

nagmeh (nagmeh) scale, 135, 138, 140, 141, 149, 150, 161; ghazal and, 192; seven Qajar dastgah and, 162; systematic modality and, 164

nahịib melody, 140, 149

Nahoft (nahoft) sho'beh, 52, 54

$\mathrm{Na}$ 'ini, Baqiya, 55

Nasir al-Din Shah, 126, 130

Nastūrī (reng of Nava), 140

national identity, Iranian, 9, 13-14, 116, 121, 214

nationalism, 6, 13, 19, 155, 208, 218

nation-states, 5, 14, 15, 130; active construction of, 19; Qajar Dynasty and rise of Iranian nation-state, $26,116-17,120-21$

Nava (navā) dastgah, 107, 135, 212; in Buhūr alalhān (Forsat Shirazi), 140; ghazal and, 141; Hedayat's description, 148,150 ; instruments and, 51, 54; maqam scales and, 151, 152; modal interpretations of, 107-8

Nawa (nawā) shadd, 27, 53

nawbah (musical form of the Maghreb), 115

nawbat murattab (suite of songs with qawl and ghazal), 34, 60, 115, 148

Nawruz (nawrüz) scale, 27, 51

Nawruz-i 'Ajam (nawrūz-i 'ajam) sho'beh, 52 Nawruz-i Arab (nawrūz-i 'arab) sho'beh, 52 nay [nāy] (reed flute), 114, 195

Nayriz (nayrīz) maqam, 52, 53, 149, 150

Nayrīzī melody, 140

Nazami, 182

nāzī melody, 148

Nekisa, 138

Nettl, Bruno, 5-6, 19, 192, 206

Nikudar, Ahmad, 40
Nishaburak (nīshābūrak) maqam, 52, 140, 141 Nishaburi, Muhammad bin Muhammad bin Muhammad, 26, 28-29, 35, 38, 59

Nīshābūr mofașel melody, 150

Nishapur, city of: in the Afsharid Empire, 46; in Ghaznavid Empire, 37; in the Ilkhanate, 39; in Safavid Empire, 43; in the Timurid Empire, 41

Nohoft melody, 140, 150

Nooshirvan, 97

North Africa, 3

oil, discovered in Iran, 128

On the Sensations of Tone (Helmholtz), 143-44, $145,146,146$

'oqadeh goshā, 138

'Ozzal ('ozaāl) melody, 52, 53, 140

Orientalism, 8-10, 13, 132, 142, 218; Great Man Theory in musicology, 10; Safi al-Din Urmawi's adwar and, 28

Oshshaq ('oshshāq) shadd, 27, 51, 52, 54, 140, 150

Ottoman Empire, 35, 42, 45, 116; challenges to dynastic rule, 47; fasil musical structure, 43; musical instruments and, 114; Russian expansion into territory of, 101; Timurid musicians in, 44; twelve-maqam system and, 85

Pahlavi, Mohammad Reza, 121, 122-23, 128

Pahlavi, Reza Shah, 121-23, 127, 128, 170, 176

Pahlavi gusheh, 191, 192, 193, 194, 195

Pahlavi Ministries of Culture and Information, 13

Panjeh, 150

Panjreh Muyeh gusheh, 193, 194

pardeh (pardeh) melodic mode, 4, 28, 35, 40; ambiguity of meaning in, 93; geographical associations, 53

patronage, dynastic, 25, 35-36, 42, 45, 46, 215; Afghan invasion and gap in, 116; complete end of (1920s), 123; decline of dynastic governance and, 101-2, 130, 187; Qajar Dynasty and, 43; by Turkic and Mongol rulers, 98 pentachords (panjom), 27, 28, 160

performance practice, 3 , 19; of dastgah, 110; emotional tendencies and, 51; gusheh as frameworks for, 166; instruments and, 54; poetry and, 206; in Safavid Empire, 86; transregional dispersal of, 209

Persianate Islamic empires, 20, 26, 88

Persianate music, outside Iran, 15

Persian language, 1, 6, 7, 45, 53; 'aruz ('aruz) poetic meter and, 31; education under Reza Shah Pahlavi, 122, 123; French translations of 
texts in, 9; Iranian nation and, 163; as lingua franca of Islamic empire, $25,35,37,40,187$; music treatises in, 12, 17; prevalence among Iranians, 14-15; religious authority of Islam and, 37; rules of poetry and, 188; singing in, 34; sources on music in, 2; Sufi texts in, 74; twelve-maqam system and seven dastgah in relation to, 140; writings about music in, 20,85

Persian music, 5, 57, 85, 154; in historical perspective, 216-20; history of, 1-2, 132; nationalist narrative of golden age and, 169; new approach to historiography of, 16-21; performance practice, 3; pre-Islamic empires and, 156; systematic modality and legacy of, 131; writing and rewriting history of, 13-16

Persian music, traditional: antiquity of, 1 ; break with historic norms in Persian-language sources, 6; dastgah and authenticity of, 109-10; legacy of Oriental studies and, 10-11; modern nation of Iran as beginning of, 2. See also Iranian music

pish-daramad ( $p \bar{i}$ hhdarāmad) performance, 112, $140,148,149,150,182$

pishraw (pishraw) compositional form, 33, 34, 35 pitch, 4, 28-29, 115; avaz-dastgah and, 207; consonant pitch organization, 28, 29, 54; of gusheh, 110; intervallic relationships of, 85, 146; Iranian and European, 156-57; standardized, 182; systematic modality and, 164

Plato, 56

poetry, 31, 67, 73, 131, 142; approved or disapproved in sama' texts, 70; changes in, 212; dobayt genre, 141, 187, 188; genres of, 141; gusheh and, 112, 182; imagery of the shah, 89, 90-94; love poetry, 93-94, 95, 187, 196; melodic progression and, 115-16; musical interludes and, 186, 192, 206; music and structure of, 134; rhythm and, 33, 34; singing of, 114. See also ghazal; Masnavi poetry

Pope, Arthur Upham, 9

Powers, Harold, 12

Pythagoras, 56, 57-58, 59, 64

\section{Qābūsnāmeh (ibn Qabus), 51}

Qajar Dynasty, 5, 26, 43, 141, 163, 198; Babi millenarian movement and, 126; Constitutional Revolution (1905), 120, 124, 125, 126, 204; corruption of dynastic rule and, 178 , 207; Cossack Brigade in military of, 121, 133, 170; early small state, 46; long-form performance model and, 166; nation-state and rise of, 116-17, 120-21; Safavid territory reunited under, 105; ta 'zieh musical theater and, 123-24; territorial legacy of, 118-19, 203. See also seven dastgah of Qajar court

Qajar melody, 138, 148

Qandahar, 42, 97

qanun [qanūn] (stringed instrument), 114

Qara Qoyunlu (White Sheep) Turkmen, 41, 42

Qarātī melody, 148

qarcheh melody, 138

Qarjeh do qesm melody, 148

Qatāir melody, 138, 141, 148

qawl [qawl] (singing in Arabic), 34, 35

Qoçgirî, Cemîl, 211

Qorā'ī melody, 138

quarter tones (rob'pardeh), 157, 174, 177, 179

Quchani dastgah, 141, 190

Qur'an, 58, 63, 65; sama' (divine musical listening) and, 67, 69, 71, 75, 79; verses with effect of music and poetry, 72,73

Qushayri, 71, 75, 77, 78

Qutb al-Din Shirazi, 10, 44, 45, 57, 132; Durrat al-tāj, 38, 40; Maraghi's commentary on, 40; music as knowledge and, 49, 50; music notation used by, 153; Orientalists and, 143; "Systematic School" and, 26; twelve-maqam system and, 27, 147, 151

race/racial psychology, 147, 153, 163; Helmholtz and, 144; modernity and, 218; Orientalist musicology and, 9, 10

radif (radif $)$ melodic repertoire, 3, 6, 131, 155, 157, 211; changes in, 212-13; gusheh in relation to, 105-6; musical culture of, 7; as a musical whole, 110-16; poetry and, 212-13; range of melodic material, 4; traditionalists and, 183; UNESCO cultural heritage recognition of, 15 ; vocal, 189,213

radif-dastgah tradition, 4, 112, 129, 164, 177; ancient poetry and, 186, 192, 202; Babi movement and, 126; break with historic norms of Persian music, 5-6; compositional forms, 5; contrasts with twelve-maqam system, 12, 20, 21, 115, 163, 220; cultural history of Persian music and, 19; cultural order of, 20; diversity of practice in, 166; as dual system of pitch modalities, 131; emergence of, 105, 123, 128; emotional range of, 178; end of dynastic patronage and, 126; ethnographic research on, 9; evolution of, 6, 105-6; ghazal and, 185; influence of European music on, 219; instruments associated with, 114; interpretation of 
modality in, 109; Iranian national identity and, 208, 214; modernist versus traditionalist discourse surrounding, 169, 170, 179; modernity and, 209-10, 220; modern music performance and, 127; morality and, 168, 169, 181, 184; national ethnolinguistic identity and, 11 ; nationalism and, 20-21; notation and preservation of, 173; Orientalist scholars and, 8-9; poetry and, 116, 195, 197, 206; Qajar court and, 5, 187; as remnant of Persian music history, 171, 172; tasnif and, 201, 207 radio, $122,127,128,165$

Radio Iran, 122, 128 $\mathrm{rag} /$ ragini system, in South Asia, 44, 54, 85 Rahavi (rāhawi) shadd, 27, 52, 53, 140

Rahāwi melody, 138

Rajaz gusheh, 191, 192, 193, 194, 195

Rak (rāk) gusheh, 141, 149, 151, 152, 161; modal parameters of, 109; tasnif and, 206

rāk-i Abdullah melody, 140

rāk-i hindī melody, 140

Rast (rāst) shadd, 27, 51, 54

Rast-Panjgah (rāst-panjgāh) dastgah, 107, 141, 164-65, 166, 211-12; ghazal and, 196; modal interpretations of, $107-8$

Razavi, Muhammad Bin Jalal, 70

razavīi melody, 150

rażawī melody, 138

Razi, Fakhr al-Din Muhammad 'Umar, 51

Rażūmī melody, 148

recapitulations. See bar gasht [bar gasht]

reng [reng] (group instrumental piece), 111, 112, $113,136,182$; of Mahur dastgah, 140; of Nava dastgah, 140; of Shur dastgah, 138

rhythms, 3, 12, 31; knowledge of rhythmic aspects ('ilm-i iqā'), 61; "light-heavy" (khafîf śaqîl), 32; rhythmic cycles (advār-i ìqā'āt), 32, 115. See also usul ( $\bar{u}$ șùl) rhythmic cycle al-Riaḍi, Caliph, 36 Risāleh-i kermānīyeh (Sofrachi), 58 riyazi [riyāzīi] (math), 48, 49

Rokn al-Din, 182 ruba'i poetry, 141 rūh al-arwāḥ melody, 138

Rumi, Jalal al-Din, 141, 187, 188, 191, 195

Russia, Soviet, 15, 122

Russia, Tsarist Empire of, 46, 101, 117, 120, 204

Rüzgar-i Naw (journal), 9

Saba $(s a b \bar{a})$ maqam, 53

Saba, Abol Hassan, 183-84

Sa 'di, 182, 187, 190, 193, 196
Safa (gol-rīz) melody, 148

Safavid Empire, 20, 26, 42, 45, 187; Afghan invasion and end of, 86, 88, 101, 116; 'Ali Qapu Palace "music room," 81, 82; court musicians, 32; demise of, 46, 86; at largest extent, 43; music in service of dynastic authority, 98-102, 215; music treatises under, 34; Palace of Forty Columns murals, 81, 82, 83; Russian expansion into territory of, 101; seen as period of decline for Iranian music, 81, 82, 85; Shi'a Islam and, $43-44,65,84,86$, 100; song collections of Amir Khan and Mosannef, 95-98; Sufism and, 65-66; "theater of authority" of, 99,100

Safi al-Din Urmawi, 10, 11, 29, 35, 38, 132; consonant pitch conception of, 54; on emotional effects of music, 51-52; golden age narrative and, 185; 'ilm of music and, 49; Maraghi's commentary on, 40; music notation used by, 153; Orientalists and, 143; in pantheon of wise men, 57; rules for intonation, 172; "Systematic School" and, 26; theory of scale creation (adwār), 27, 28, 30, 44, 143, 146; twelve-maqam system and, 27-28, 55, 147, 151; Western music theory and, 146 Safvat, Dariush, 106, 109

Sahlins, Marshall, 18, 19, 219

Salmak (salmak) scale, 27

salmak do qesm, 138

salmak seh qesm, 148

al-Saltana, 'Ali Naqi Mirza A 'tizab, 198

al-Saltaneh, Hassam, 126

sama' (divine musical listening), 66-67, 79-80, $84,124,216$; approval and disapproval of music in sama texts, 68-71; experience of superhuman abilities and, 73, 74; fallibility and imperfection of human condition and, 75-79; forbidden [physical] (sama'-i tab $\left.{ }^{\prime} \bar{\imath}\right)$, 71 ; in song texts, 93, 95; tales of sudden death from words and melody, 72, 74; three categories of, 77

Samalì melody, 138, 150

Samanids, 36

Samarqand: in the Afsharid Empire, 46; in the

Timurid Empire, 41

santur [santūr] (hammer dulcimer), 114

Saqi-nameh gusheh, 196

sāqī nāmeh melody, 140, 149

sāranj melody, 138

sar khaneh [sar khāneh] (primary melodic section), 34-35

Sassanian Empire, 1, 36, 37, 58, 59, 138 
sayakhī melody, 138

scales, 4, 135, 143, 158, 160-62, 182; avaz-dastgah scales, 164; Iranian chromatic scale, 157, 158; notated, 30; primary and secondary dastgah scales, 158, 160, 161; Safi's theory of scale creation (adwār), 27, 28, 30, 44, 143, 146; systematic construction of, 85 ; twelvemaqam system and, 27-30, 151, 152, 153, 157; Vaziri's representation of dastgah scales, $157-58,159,160-61,171,174,178,181-82$; Western, 3

Scattering Stars Like Dust (Kalhor), 211

science, music theory and, 144, 146

secret civic groups (anjuman), 125

Seeger, Charles, 8

Segah (segāh) dastgah, 52, 53, 107, 151, 153, 179; ghazal and, 141; modal interpretations of, 107-8; pitch and, 165; tasnif and, 200; tonic of, 109

setar [setār] (long-necked lute), 3, 114, 210

seven dastgah of Qajar court, 105-7, 108, 113,

168; Forsat and, 131, 133, 135, 137-39, 142;

Hedayat and, 142-43, 147-48, 148-50, 150-51, 152, 153-54; melodically ambiguous context of, 162-63; modern renegotiation of culture and, 210; nawbat murattab and, 148, 150; presentation of poetry sections and, 206; radif-dastgah tradition and, 154, 156, 209; as remnants of ancient Persian music, 151, 174, 181; Vaziri and, 154-55, 157-58, 162, 174

shadd (shadd) melodic modes, 4, 27-28, 35, 51,105

Shafi, 78

Shafi' Khan, Mirza, 131

shah, in poetry and song texts, 89-92, 96-98, 200, 201, 203

Shah 'Abbas, 45

Shah 'Abbas I, 43, 81, 83, 100

Shah 'Abbas II, 81, 96, 97

Shah 'Alam II (Mughal emperor), 44

shahed (shähed) note, 158, 159, 160

Shah Isma' il I, 43, 84

Shahjarian, Homayun, 211

Shahjarian, Mohammad Reza, 211

Shāh Khanā' 'ì melody, 150

shāh khotā'ī melody, 138, 140

shahmaqom, Uzbek and Tajik, 5

Shāhnāmeh [Book of Kings] (Ferdowsi): legends of pre-Islamic Persian kings in, 70, 90-91, 95-96; poetry and, 187, 191, 192, 193, 195

shahnameh recitation, 45

Shahnaz (shahnāz) scale, 27
Shahnaz dastgah, 141, 206. See also Shur

shahnāz melody, 148

shahnāz qesm, 138

Shahr-āshūb (reng of Shur, Nava, and Mahur), $138,140,148$

Shah Safi, 45, 97

Shah Solomon Safavid, 70, 98

Shah Tahmasp I, 81, 82, 84

Shannon, Jonathan, 13

Shekasteh gusheh, 109, 149, 150

Sheyda, 198-202

Shi ' a Islam, 2, 42; Iranian identity and, 13-14; Safavid Empire and, 43-44, 45, 84, 86, 95, 100; ta 'zieh musical theater, 123-24

Shiraz, city of, 130; in the Afsharid Empire, 46; in the Ilkhanate, 39; in Safavid Empire, 43; in the Timurid Empire, 41

Shirazi, Sayyed 'Ali-Moḥammad, 126

sho'beh (sho'beh) pitch modality, 28, 29, 31; animal vocalizations and, 56 ; in circular chart representing twelve-maqam system, 30 ; cosmological alignments of, 135 ; healing powers attributed to, 51-52; instruments and, 54; khaneh and, 33; Mughal ragini and, 55; rhythm and, 32; types of people/geographies and, 53

shudragh $\bar{u}$ (stringed instrument), 54

Shur (shūr) dastgah, 107, 108, 153, 211; as avazdastgah, 212; in Buhūr al-alhān (Forsat Shirazi), 135, 136, 137-39; ghazal and, 141; Hedayat's description, 148 ; maqam scales and, 151, 152; modal interpretations of, 107-8; scales and, 158; sections converted to avazdastgah, 109, 164; tasnif and, 206; tonic of, 109. See also Shahnaz

Shushtari melody, 206, 207

Shuster, William Morgan, 204, 205

sina 'at [șinā'at] (skill), 48, 49, 50

Sistani, Farrukhi, 193, 194

Society of Brotherhood (anjuman-i ükhovat), $124-25,127,133,170,199,200$

Sofrachi, Dawreh, 58

song texts, 20, 87-88; Amir Khan and Mosannef collections, 95-98; Arabic, 99; Maraghi collection, 88-95

sori [ sorī] (half-sharp pitch), 157, 159

soul, human: spiritual aspect ( $r \bar{u} h), 77$; worldly aspect (nafs), 50, 51, 74, 77

sound production, $143-44,146$

South Asia, 12, 17, 42; British Empire in, 117, 120; ghazal poetry in music performance, 185 ; Hindustani music, 13; indigenous modal 
system of, 43; musical instruments of, 3 ; Persian-speaking people in, 15; political change across, 86; rag/ragini system, 44, 54, 85; Turkic and Mongol rule in, 215; twelvemaqam system in, 25

Soviet Union, fall of, 15

șafā melody, 138

șūfĩ nāmeh melody, 140, 149

starting note (shurū'), 160

Sufism, 38, 65-66, 67, 72, 78; poetry and, 187 ; Safi Order, 124; Shi'a orthodoxy of Safavids and, 84 , 95 ; in song texts, 94 ; sound, euphoria, and dance, 74 ; texts about sama', 68-71

Suhrawardi, 73

Sultan Khanom, 198

Sunni Islam, 14

Survey of Persian Art from Prehistoric Times to the Present, A (Pope, 1938), 9

Systematic School, 26-27, 45, 48, 57, 63. See also Farmer, Henry George

al-Tabari, Ibn Jarir, 69

Tabriz, 5, 42, 117; in the Afsharid Empire, 46; in the Ilkhanate, 39; in the Qara Qoyunlu Turkmen empire, 41; in Safavid Empire, 43; in the Timurid Empire, 41

tahrir (tahrīr) vocal improvisation, 111, 114, 194

Takht-i tāqdīs melody, 138, 140

$\operatorname{tar}[t \bar{a} r]$ (long-necked, fretted lute), 105, 113-14, $134,176,210$

Tarab-angiz melody, 151, 152

tarāneh (song-poem in quatrains), 34

tasnif (taṣnīf) metered songs, 21, 112, 126, 170; addressed to citizenry of Iran, 213; of 'Aref Qazvini, 177-78; equality and modernity celebrated, 198-206; ghazal and, 186, 197-98; systematic modality and, 206-7

ta' $z i e h$ (Shi' a musical theater), 123-24

Tehran, 117, 125, 127, 128

Tehran, University of, 170-71

tetrachords (dāng), 27, 28, 160

Timur, 40

Timurid Empire, 20, 26, 40, 54, 81, 87; fall of, 45, 86; as golden age of Persian music, 42; map showing geographic extent of, 41 ; musical renaissance under, 83 ; twelve-maqam system and legacy of, $85-86,87$

tonic note (tonì $k$ ), 160

traditions, true age of, 13

Transoxiana, 53

țarab angīz melody, 140, 149

țūsī melody, 140, 149
Tuhfat al-hind (Mirza Khan ibn Fahr al-Din), 44

Turkey, 121, 203

Turkic peoples, 2, 15, 45; empires and rulers, 26; migrations, 1,36

Turkish language, 53; Oghuz-Turkic speakers, 113; Ottoman Turkish, 44; song and poetry genres in, 35; songs in, 5, 45

Turkish music, 1

Turkmen, empire of, 40, 41, 81

twelve-maqam system, 4-5, 19, 62-64, 80, 132, 168 , 209; in age of gunpowder empires, 42-46; animal vocalizations and, 85 ; charts representing, 30, 31; consonance and derivation of, 27-31; contrasts with radif-dastgah tradition, 12, 20, 21, 115, 163, 220; cosmopoli$\tan$ music culture and, 38 ; cultural order of, 20; dastgah and, 106; decline of dynastic governance and, 47, 101-2, 130; dispersal across multiple empires, 85-86; emotion and, 50-53; empires and, 25-26; ethnolinguistic identities and, 11; geographical distribution of, 25,38 ; in historical perspective, 214-16, 217; Islam and, 65; legends about wise men and, 56-62; logic of cosmos and, 79; morality and, 215; in multiple music histories of Middle East, 12; music as balance of science/art and theory/ practice, 48-49; national (re)interpretation and, 129; natural world and, 94; pitch and, 157; poetic language structure and, 61-62; in rhythm and composition, $31-35$; rise of, 6 ; Safavid-era writings on, 84-85, 87, 100-102; seven Qajar dastgah and, 137, 139, 142, 151, 152, 153-54; song texts and, 87-88; Sufism and, 66, 67; technical discourse on, 20; temporal proximity to musical practice, 186 ; traditional Persian music and, 7; transregional dispersal of, 163; Turco-Mongol empires and rise of, 42 ; universality of, $53-56,220$

Tyson, Neil DeGrasse, 1

Umayyad Caliphate, 36,171

UNESCO cultural heritage list, 15

United States, 2, 121

Urdu language, 185

usul (ūṣül) rhythmic cycle, 4-5, 31; compositional forms and, 33; ramal, 32, 33, 33 'ud ['üd] (short-necked lute), 114 'Umar (companion of Muhammad), 68

'Uthman (early caliph), 89

Vali Muhammad Khan, 81, 83

Vaziri, 'Ali Naqi, 20, 126, 133-34, 154-62, 181, 
218; 'Aref Qazvini as critic and nemesis of, 169-71, 177-82, 184; Dastūr-i tār, 134, 159; on gusheh, 155-56; music and art education promoted by, 175-77, 202; on music and moral improvement of the nation, 174-76; Müsìqi-i nazarīi, 134, 159, 160, 162 , 165; on pitch, 156-58, 160, 166; radif-dastgah tradition and, 166, 171-72, 177; on reasons for loss of Iranian music, 172-73; on scales, $157-58,159,160-62$; on value of indigenous pre-Islamic Iranian music, 171-72; violin, tar, and setar teaching manuals of, 134, 159,176

violin, 114, 134, 176, 180, 182, 183

voice, human, 80,94

Wade, Bonnie, 13

wajd (wajd), 73-75, 76

wașla (musical form of the Mashreq), 115

West Asia, 1, 19, 42, 209; Chingiz Khan's invasion of, 38; political change across, 86 ; rise and fall of empires in, 215; Timurid Empire in, 40; Turkic and Mongol rule in, 215

Westernization, 3, 133, 167

Western music. See European (Western) music Western power and empires, 2, 19, 218, 219 wine: in ghazal genre, 188; musical instruments associated with drunkenness, 70 ; in Safavid murals of feasts, 81; in song texts, 91, 93, 94, 95, 96,98

world music market, Western, 210-11

World War I, 120, 121, 174

World War II, 121, 122

Wright, Owen, 27-28, 30

yātūghān (stringed instrument), 54

Zabol gusheh, 191, 192, 193, 194

Zabol-i Gavri, 136

Zahir el-Dowleh, Safi 'Ali, 124, 199

Zahiri, Haji Husayn Isfahani, 58, 59

Zand Dynasty, 46, 46, 116, 118

Zangulah, (Zanguleh zankülah) gusheh, 27, 51, 53, 149, 192

żarb (goblet-shaped drum), 114

żarb-i ușūl (reng of Shur), 138, 148

Zir-Afkand (zïräfkand) shadd, 27, 51, 149

Zirafkand melody, 140

zirkesh-i salmak chahār qesm, 138, 148

zither, 3

zodiac, 56, 85, 179

Zoroastrianism, 14, 205 
Founded in 1893 ,

UNIVERSITY OF CALIFORNIA PRESS

publishes bold, progressive books and journals

on topics in the arts, humanities, social sciences, and natural sciences-with a focus on social justice issues-that inspire thought and action among readers worldwide.

The UC PRESS FOUNDATION

raises funds to uphold the press's vital role as an independent, nonprofit publisher, and receives philanthropic support from a wide range of individuals and institutions-and from committed readers like you. To learn more, visit ucpress.edu/supportus. 
Iran's particular system of traditional Persian art music has been long treated as the product of an ever-evolving, ancient Persian culture. In Music of a Thousand Years, Ann E. Lucas argues that this music is a modern phenomenon indelibly tied to changing notions of Iran's national history. Rather than considering a single Persian music history, Lucas demonstrates cultural dissimilarity and discontinuity over time, bringing to light two different notions of music-making in relation to premodern and modern musical norms. An important corrective to the history of Persian music, Music of a Thousand Years is the first work to align understandings of Middle Eastern music history with current understandings of the region's political history.

"Ann E. Lucas very effectively combines historical analysis, ethnomusicology, and musicology to provide a broad, holistic explanation for complex, nuanced processes of change. Well written and highly original in its approach, this is a major contribution to the field." KAMRAN SCOT AGHAIE, Associate Professor of Iranian History, University of Texas

"Music of a Thousand Years presents an innovative narrative of Persian music history and also provides important new perspectives on how to analyze the meaning of music and culture in historical perspective." MOHSEN MOHAMMADI, Lecturer in Ethnomusicology, University of California, Los Angeles

"Lucas turns the standard history of Persian music on its head, proving it is not a story of the survival of an ancient tradition, but rather the story of the invention of tradition. Revisionist in the best sense of the word." JAMES L. GELVIN, author of The Modern Middle East: A History

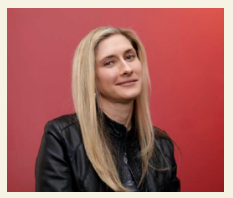

ANN E. LUCAS is Assistant Professor of ethnomusicology in the Department of Music at Boston College, where she also teaches in the Islamic Civilizations and Societies Program. She is recognized for her work on music historiography of the Middle East.

A Joan Palevsky Book in Classical Literature

\section{UNIVERSITY OF CALIFORNIA PRESS}

www.ucpress.edu | www.luminosoa.org

A free ebook version of this title is available through Luminos, University of California Press's Open Access publishing program for monographs.

Visit www.luminosoa.org to learn more.

Author photo credit: Nader el-Shaer.

Cover illustration: Solomon and the Queen of Sheba (folio from an illustrated manuscript, early nineteenth century). Metropolitan Museum of Art, New York, New York-bequest of Charles K. Wilkinson, 1986.

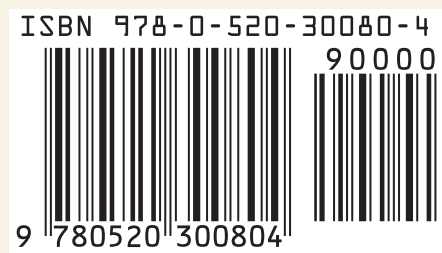

